





\section{Bibliography on Atomic Line Shapes and Shifts (1889 through March 1972)}

\begin{tabular}{r} 
U.S. \\
ARTMENT \\
OF \\
JMMERCE \\
\multicolumn{2}{c}{ A1-Linal } \\
QC u \\
00 if \\
1557 \\
.366 \\
972
\end{tabular}


The National Bureau of Standards ${ }^{1}$ was established by an act of Congress March 3, 1901. The Bureau's overall goal is to strengthen and advance the Nation's science and technology and facilitate their effective application for public benefit. To this end, the Bureau conducts research and provides: (1) a basis for the Nation's physical measurement system, (2) scientific and technological services for industry and government, (3) a technical basis for equity in trade, and (4) technical services to promote public safety. The Bureau consists of the Institute for Basic Standards, the Institute for Materials Research, the Institute for Applied Technology, the Center for Computer Sciences and Technology, and the Office for Information Programs.

THE INSTITUTE FOR BASIC STANDARDS provides the central basis within the United States of a complete and consistent system of physical measurement; coordinates that system with measurement systems of other nations; and furnishes essential services leading to accurate and uniform physical measurements throughout the Nation's scientific community, industry, and commerce. The Institute consists of a Center for Radiation Research, an Office of Measurement Services and the following divisions:

Applied Mathematics-Electricity-Heat-Mechanics-Optical Physics-Linac Radiation ${ }^{2}$ - Nuclear Radiation ${ }^{2}$ - Applied Radiation ${ }^{2}$ - Quantum Electronics ${ }^{3}$ Electromagnetics ${ }^{3}$ - Time and Frequency ${ }^{3}$ - Laboratory Astrophysics ${ }^{3}$ - Cryogenics ${ }^{3}$.

THE INSTITUTE FOR MATERIALS RESEARCH conducts materials research leading to improved methods of measurement, standards, and data on the properties of well-characterized materials needed by industry, commerce, educational institutions, and Government; provides advisory and research services to other Government agencies; and develops, produces, and distributes standard reference materials. The Institute consists of the Office of Standard Reference Materials and the following divisions:

Analytical Chemistry-Polymers-Metallurgy-Inorganic Materials-Reactor Radiation-Physical Chemistry.

THE INSTITUTE FOR APPLIED TECHNOLOGY provides technical services to promote the use of available technology and to facilitate technological innovation in industry and Government; cooperates with public and private organizations leading to the development of technological standards (including mandatory safety standards), codes and methods of test; and provides technical advice and services to Government agencies upon request. The Institute also monitors NBS engineering standards activities and provides liaison between NBS and national and international engineering standards bodies. The Institute consists of the following divisions and offices:

Engineering Standards Services-Weights and Measures-Invention and Innovation-Product Evaluation Technology-Building Research-Electronic Technology-Technical Analysis-Measurement Engineering-Office of Fire Programs.

THE CENTER FOR COMPUTER SCIENCES AND TECHNOLOGY conducts research and provides technical services designed to aid Government agencies in improving cost effectiveness in the conduct of their programs through the selection, acquisition, and effective utilization of automatic data processing equipment; and serves as the principal focus within the executive branch for the development of Federal standards for automatic data processing equipment, techniques, and computer languages. The Center consists of the following offices and divisions:

Information Processing Standards-Computer Information-Computer Services -Systems Development-Information Processing Tẹhnology.

THE OFFICE FOR INFORMATION PROGRAMS promotes optimum dissemination and accessibility of scientific information generated within NBS and other agencies of the Federal Government; promotes the development of the National Standard Reference Data System and a system of information analysis centers dealing with the broader aspects of the National Measurement System; provides appropriate services to ensure that the NBS staff has optimum accessibility to the scientific information of the world, and directs the public information activities of the Bureau. The Office consists of the following organizational units:

Office of Standard Reference Data-Office of Technical Information and Publications-Library-Office of International Relations. 


\section{Bibliography on}

\section{Atomic Line Shapes and Shifts}

\section{(1889 through March 1972)}

J. R. Fuhr, W. L. Wiese, and L. J. Roszman

Institute for Basic Standards

National Bureau of Standards

Washington, D.C. 20234

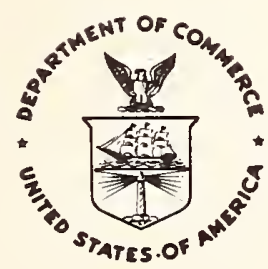

U.S. DEPARTMENT OF COMMERCE, Peter G. Peterson, Secrefary NATIONAL BUREAU OF STANDARDS, Lawrence M. Kushner, Acting Director 
Library of Congress Catalog Card Number: 72-600147

\section{National Bureau of Standards Special Publication 366}

Nat. Bur. Stand. (U.S.), Spec. Publ. 366, 165 pages (Sept. 1972)

CODEN: XNBSAV

For sale by the Superintendent of Documents, U.S. Govemment Printing Office, Washington, D.C. 20402 (Order by SD Catalog No. C13.10:366). Price 81.75 


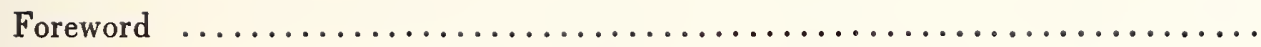

\section{A. INTRODUCTION}

1. OBJECTIVES AND BACKGROUND $\ldots \ldots \ldots \ldots \ldots \ldots \ldots \ldots \ldots \ldots \ldots \ldots$ viI

2. SCOPE OF THIS COLLECTION ........................... viII

3. ARRANGEMENT OF THE BIBLIOGRAPHY .................... vIII

4. FUTURE PLANS OF THE DATA CENTER ON ATOMIC LINE SHAPES AND SHIFTS, AND ACKNOWLEDGEMENTS $\ldots \ldots \ldots \ldots \ldots \ldots \ldots \ldots \ldots \ldots$ IX

5. TABLE OF CODE LETTERS AND ABBREVIATIONS ............... $\mathrm{x}$

\section{B. BIBLIOGRAPHICAL MATERIAL}

1. LITERATURE REFERENCES OF GENERAL INTEREST ............

1.0. General articles on line shapes and shifts (general theories and

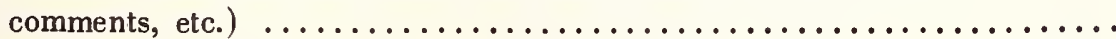

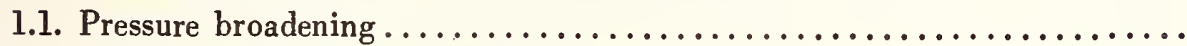

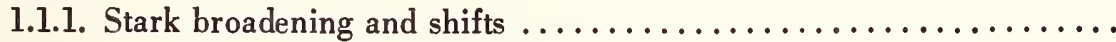

1.1.1.1. Hydrogen and hydrogen-like (overlapping) lines .......

1.1.1.2. Isolated lines of neutral spectra $\ldots \ldots \ldots \ldots \ldots \ldots \ldots \ldots$

1.1.1.3. Isolated lines of ionic spectra $\ldots \ldots \ldots \ldots \ldots \ldots \ldots \ldots$

1.1.1.4. Topics of particular interest: [Line wings; Effects of collective electric fields (plasma polarization shift, plasma oscillations with satellite bands); Asymmetries of H-lines; Microfield distributions; Magnetic fields] ..............

1.1.2. Broadening in foreign gases (Van der Waals broadening) .......

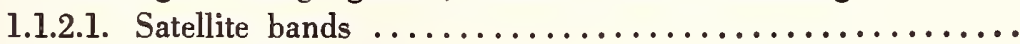

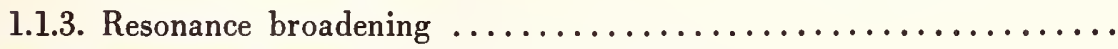

1.2. Basic articles on Doppler and natural line shapes $\ldots \ldots \ldots \ldots \ldots \ldots \ldots$

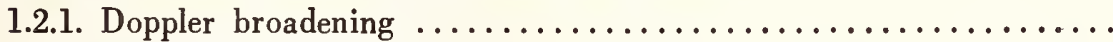

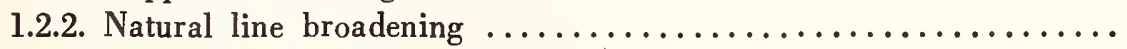

1.2.3. Radiation induced broadening ...................... 5

1.3. Basic papers on instrumental broadening, deconvolution, superposition of two or more simultaneously acting broadening mechanisms ..........

1.3.1. Determination of instrumental line profiles; experimental techniques for determining line shapes $\ldots \ldots \ldots \ldots \ldots \ldots \ldots \ldots \ldots \ldots$

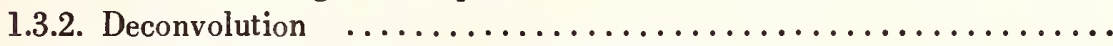

1.3.3. Superposition of broadening mechanisms ..............

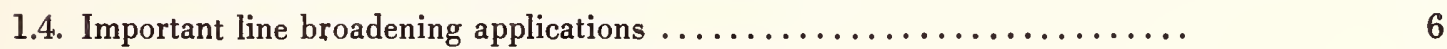

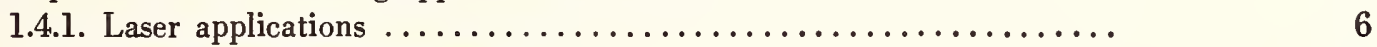

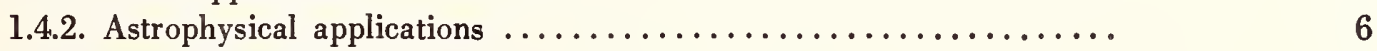

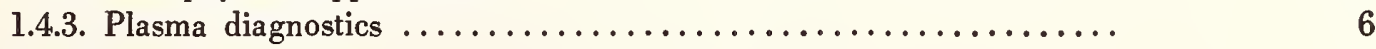

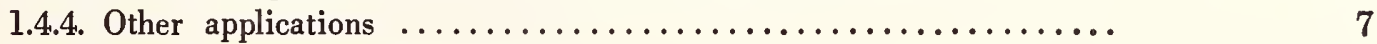


1.5. Other topics involving line shapes and shifts

1.5.1. The line shape in the presence of self-absorption; effects of

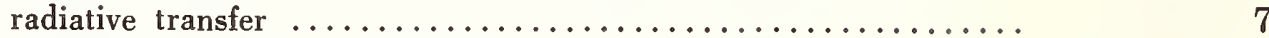

1.5.2. Broadening of scattered radiation ................... 7

1.5.3. Some important papers on molecular line broadening .......... 7

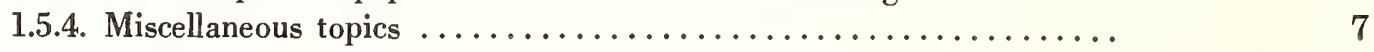

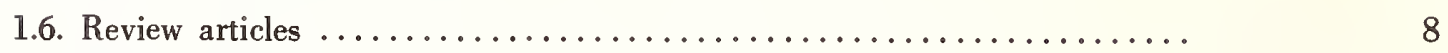

1.6.1. General line broadening reviews .................... 8

1.6.2. Reviews on pressure broadening $\ldots \ldots \ldots \ldots \ldots \ldots \ldots \ldots \ldots \ldots \ldots$

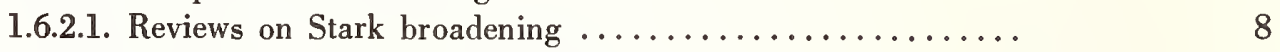

1.6.2.2. Reviews on foreign gas broadening .............. 8

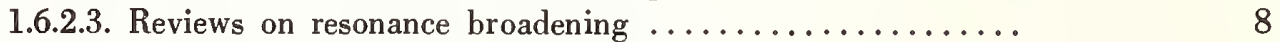

1.6.3. Reviews on Doppler and natural line broadening ........... 8

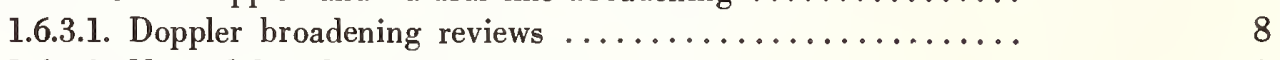

1.6.3.2. Natural line broadening reviews ............... 8

1.7. References on line broadening tables and bibliographies ........... 8

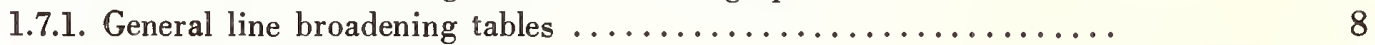

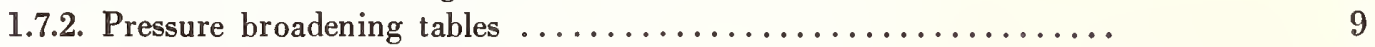

1.7.2.1. Special Stark broadening tables ................. 9

1.7.2.2. Special foreign gas broadening tables .............. 9

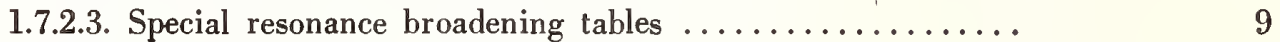

1.7.3. Doppler and natural line broadening tables ............... 9

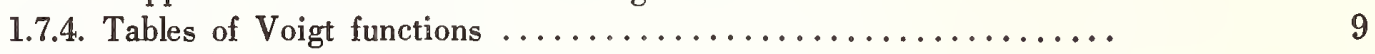

1.7.5. Line broadening bibliographies ................... 9

2. LITERATURE REFERENCES CONTAINING NUMERICAL DATA ........ 10

3. CHRONOLOGICAL LISTING OF ALL REFERENCES WITH FULL TITLES 28

4. LIST OF AUTHORS ............................. 128 


\title{
BIBLIOGRAPHY ON ATOMIC LINE SHAPES AND SHIFTS (1889 Through March 1972)*
}

\author{
J. R. Fuhr, W. L. Wiese, and L. J. Roszman
}

\begin{abstract}
This is the first general, annotated bibliography on atomic line shapes and shifts. It covers exhaustively the atomic spectral line broadening literature in about 1400 separate references extending from 1889 through March 1972. The bibliography contains four major parts: (1) All general interest papers are cataloged according to the broadening mechanisms (and, further, according to special topics under several of the mechanisms) and as to whether the work is a general theory, a general review, a table of profiles or parameters, a comment on existing work, a study of general experimental measurement techniques, or an experimental effort of general importance. Also included are selected papers on important applications of line broadening and on miscellaneous topics relating to atomic spectral line shapes and shifts. (2) In Part 2, all papers containing numerical data are ordered as to element, ionization stage, broadening mechanism (in the case of foreign gas broadening the perturbing species are listed), and it is indicated whether the data are experimentally or theoretically derived. (3) While in the two preceding parts of the bibliography the references are listed for brevity by identification numbers only, in Part 3 all references are listed completely by journal, authors, and title and are arranged chronologically and alphabetically within each year according to the principal author. (4) A final section contains a list of all authors and their papers.
\end{abstract}

Key words: Atomic; instrumental broadening; line shapes; line shifts; pressure broadening; resonance broadening; Stark broadening; Van der Waals broadening.

\section{A. INTRODUCTION}

\section{OBJECTIVES AND BACKGROUND}

A Data Center on Atomic Spectral Line Shapes and Shifts has been established recently in the Optical Physics Division of the National Bureau of Standards. The objectives of the Center are to collect and catalog the relevant literature and to prepare and publish bibliographies and critical reviews on various topics in atomic line broadening.

The collection of literature on line broadening was started some time ago parallel to a collection of the literature on atomic transition probabilities, which is an ongoing activity of this NBS group. Starting in 1970, all references in recent line broadening papers were scanned, and simultaneously, several title and abstracting journals were searched backward for several years. This latter search gradually overlapped completely with the independently found references. Reprints or copies of all articles were collected, cataloged, and filed according to a classification scheme which will be given in detail below. The literature collection is completely up-to-date through March 1972, and the current literature is constantly being monitored through several title and abstracting journals. However, we have been unable to secure a few older theses and technical reports, and we have several as yet untranslated Russian papers which could be potentially valuable for this collection. These papers are presently not included, but will be added in future bibliographies after we are able to make a definite classification.

- Research supported In part by the Advanced Research Projects Agency of the Department of Defense under the Strategic Technology Office. 


\section{SCOPE OF THIS COLLECTION}

A general bibliography on atomic line broadening seems to be long overdue, since the large number of articles we have collected indicates much continuing activity in this field. Nevertheless, no general annotated bibliography has been published.

In this first bibliography we have stressed the complete presentation of all relevant modern literature without regard to the quality of the paper. Therefore, all line broadening work back to the year 1930 and a number of important earlier papers have been included. In many instances the early work is superseded by more refined experimental or theoretical determinations, but there are still a number of cases where nothing but some older material is available. In such cases this older material should still be valuable for applications where a rough estimate will suffice.

In addition to the regular journal literature, we list books which are primarily devoted to the subject of line broadening or contain a special detailed chapter on line broadening. However, we do not list books which contain only a few pages of basic discussion on line broadening mechanisms.

Conference talks are quoted only if they are published in proceedings which can be generally obtained in libraries. However, if it appears that such a talk is superseded by a later paper of the same title in a journal, we quote only the more accessible journal publication. The above statement implies that we

\section{ARRANGEMENT OF THE BIBLIOGRAPHY}

The bibliography is arranged in four main parts. In the first part we list all papers which are of general interest, i.e., papers which describe a general theory, give a general review of line broadening mechanisms or have comments on refinements of existing work, refer to general experimental measurement techniques, etc. Specifically, these articles are arranged under seven major headings. A detailed listing of these headings is given in the Contents under Part 1 "LITERATURE REFERENCES OF GENERAL INTEREST." Under each of the individual headings the papers are given by an identification number only in order to keep the size of this compilation compact. This identification number is fully referenced by author, journal, and title of the paper in Part 3.

In Part 2 of the bibliography we list all papers which contain numerical data, either theoretical or do not quote conference talks which are only published in abstract form or which are distributed on some typewritten proceedings available essentially to conference participants only.

We also do not quote interim or final technical reports. Since many of these are written to fulfill either educational requirements at a university or serve to satisfy contract requirements, these reports are generally not available-except maybe for a short time-so that their listing in this bibliography does not represent any significant service to the scientific public. The large majority of these reports have become available later as publications in the open literature if they contained new and original results.

The situation on doctoral theses is quite similar, i.e., most theses are subsequently published in a shortened version which contains all the significant data. Again, we feel that we serve the scientific public most by listing only the journal publication which gives the shortened version of the thesis. If a full thesis is desired, the journal publication will usually list the author and his address.

While the bibliography is restricted to line shape and line shift data of atomic and ionic lines, we have included a representative cross section of recent papers on the broadening of molecular lines (Part 1.5.3). Also, we have included a cross section of representative recent papers on important applications of line broadening (Part 1.4) - usually about 20 to 25 papers for each major subject.

experimental. The papers are now ordered to element and within the elements to the successive stages of ionization. The elements are listed in alphabetical order of their symbols. One paper (No. 651) contains data for the whole isoelectronic sequence of hydrogen and is listed after the papers on hydrogen.

For each spectrum we have grouped together all papers dealing with the same line broadening mechanism and have subdivided them further into experimental (E) and theoretical (T) papers and comments (C). The explanatory code words and letters are given in the column "Description." The papers for each group are listed in the column "Reference No." according to the identification numbers assigned in Part 3. Since these numbers, as we shall see in Part 3, are in chronological order, this means that the most modern papers are at the end of each list, and one should preferably, in looking up the litera- 
ture, go from the high numbers back to the low ones.

For papers on Van der Waals broadening we also show the species which cause the broadening, if these are explicitly given by the authors. On natural line broadening we have presented only the directly determined numerical material. But since the natural line width or "damping constant" is given by the inverse sums of the lifetimes of upper and lower state of the line, one may use lifetime data for obtaining these widths. Available lifetime data are given in the recent NSRDS compilations on atomic transition probabilities $[1,2]^{1}$ or may be obtained from the NBS bibliography on atomic transition probabilities. [3].

In Part 3 of the bibliography the complete body of references is presented in chronological order, and the listings include the full titles. Within each year the references are arranged alphabetically according to the names of the principal author. For the current year 1972 this arrangement is, of course, preliminary since new papers will be added. If a paper is written in a foreign language, the title is translated, and the language in which the paper is written is added to the reference in parenthesis. The table at the end of this introduction contains a complete list of the applied abbreviations. Each reference in this part has been assigned a running number which serves as the identification number for the preceding parts of this bibliography.

The journal abbreviations were applied according to the "ACCESS" compilation of the American Chemical Society [4]. The authors' names were alphabetized according to the "Anglo-American Cataloging Rules" prepared by the American Library Association, The Library of Congress, The Library Association, and The Canadian Library Association [5].

Part 4 of the bibliography is an author list, where each reference is given by its identification number from Part 3.

To facilitate the sorting of the reference material according to each of the four parts of the bibliography, computer programs were developed and applied. Punched cards for each reference contain: the author(s) of paper, year of paper, language of paper, description (theoretical, experimental or comment), and the classification of paper.

\section{FUTURE PLANS OF THE DATA CENTER ON ATOMIC LINE SHAPES AND SHIFTS, AND ACKNOWLEDGEMENTS}

We intend to issue supplements to this bibliography from time to time depending on the volume of the new incoming literature. We also plan to undertake critical reviews on certain well-defined subjects of line broadening. A first review on the present status of our knowledge of hydrogen Stark broadening is in the planning stage.
We gratefully acknowledge the assistance of $\mathrm{Mrs}$. Georgia Martin in developing a computer program which allowed the easy cataloging and sorting of all articles for the various parts of this bibliography and Dean Pershing for assisting in the initial literature search. We also would like to thank Mrs. Roberta Jones for her competent assistance in typing and organizing this bibliography.

\section{References}

[1] Wiese, W. L. Smith, M. W., and Glennon, B. M., Atomic Transition Probabilities-Hydrogen through Neon (A Critical Data Compilation), Nat. Stand. Ref. Data Ser., Nat. Bur. Stand. (U.S.), 4, Vol. 1 (May 1966).

[2] Wiese, W. L., Smith, M. W., and Miles, B. M., Atomic Transition Probabilities-Sodium through Calcium (A Critical Data Compilation), Nat. Stand. Ref. Data Ser., Nat. Bur. Stand. (U.S.), 22, Vol. 2 (Oct. 1969). [3] Miles, B. M. and Wiese, W. L., Bibliography on Atomic
Transition Probabilities (January 1916 through June 1969), Nat. Bur. Stand. (U.S.), Spec. Publ. 320 (Feb. 1970), and Fuhr, J. R. and Wiese, W. L., Nat. Bur. stand. (U.S.), Spec. Publ. 320, Suppl. 1 (Sept. 1971).

[4] Access-Key to the Source Literature of the Chemical Sciences, (Chemical Abstracts Service, American Chemical Society, Columbus, Ohio, 1969).

[5] Anglo-American Cataloging Rules, Ed. C. Sumner (Spalding, American Library Assoc., Chicago, 1967).

1 Figures in brackets indicate the literature references on this page. 


\section{TABLE OF CODE LETTERS AND ABBREVIATIONS}

A. Description

1. T-theoretical method

2. E-experimental method

3. C-comment
B. Language

1. Dut.-Dutch

2. Fr.-French

3. Ger.-German

4. Ital.-Italian

5. Russ.-Russian 


\section{B. BIBLIOGRAPHICAL MATERIAL}

\section{LITERATURE REFERENCES OF GENERAL INTEREST}

\subsection{GENERAL ARTICLES ON LINE SHAPES AND SHIFTS (GENERAL THEORIES AND COMMENTS, ETC.)}

Theoretica 1 papers: $443,1559,1641,1820,1821$

1.1. PRESSURE BROADENING

Comments: $267,342,849,1293$

Experimenta 1 papers: 63,64

Theoretica 1 papers: $6,11,77,113,126,137,150,153,154$, $165,168,188,189,193,213,219,230$, $246,282,283,316,318,325,343,356$, $368,388,402,404,423,444,454,473$, $520,558,559,560,676,730,793,832$, $842,889,896,899,904,931,966,973$, $976,986,1042,1049,1050,1051,1057$, $1061,1078,1103,1145,1155,1159,1163$, $1187,1195,1202,1309,1342,1386,1391$, $1392,1396,1432,1433,1436,1437,1489$, $1497,1512,1584,1709,1723,1788,1797$, $1813,1814,1816,1825,1826,1830,1862$

1.1.1. Stark broadening and shifts

Comments: $604,657,848,1884$

Theoretica 1 papers: $47,48,69,152,370,432,480$, $482,498,506,532,537,544,558$, $570,571,572,574,620,652,662$, 
Theoretica 1 papers: $667,727,736,788,850,858$, (cont.)

$860,893,894,916,917,997$,
$1055,1056,1151,1161,1184$,
$1259,1275,1298,1338,1400$,
$1424,1425,1460,1461,1492$,
$1498,1502,1519,1520,1570$,
$1662,1666,1696,1711,1729$,
$1730,1735,1737,1748,1749$,
$1811,1819,1859,1871,1873$,
1885

Combined theoretica1-comments: 1782

1.1.1.1. Hydrogen and hydrogen-like (overiapping) lines

Theoretica 1 papers: 411, 535, 596, 711, 927, 1184, $1218,1345,1377,1508,1513$, $1594,1753,1874$

1.1.1.2. Isolated lines of neutra1 spectra

Theoretical papers: 770, 772, 1356, 1408, 1421, $1501,1569,1611,1728,1755$

1.1.1.3. Isolated lines of ionic spectra

Theoretical papers: 1069, 1213, 1214, 1265, 1283, $1385,1444,1501,1576,1610$, $1694,1754,1771,1772$

1.1.1.4. Topics of particular interest

A. Line wings

Theoretica 1 papers: $659,768,981,1222$

B. Effects of collective electric fields

Comments: 1720

Experimenta 1 papers: 965, 1043, 1276, 1301, $1382,1592,1599,1625$, $1651,1671,1751,1836$ 
Theoretica 1 papers: 698, 934, 1070, 1304, 1457,

$$
\begin{aligned}
& 1574,1577,1597,1661, \\
& 1705,1718,1818,1869
\end{aligned}
$$

Combined theoretical-experimenta 1: 1467

C. Asymmetries of H-lines

Experimenta 1 papers: 1833

Theoretical papers: 851, 852, 858, 1509

Combined theoreticalmexperimenta 1: 448

D. Microfield distributions

Comments: $521,657,774,841,1079,1186$

Theoretica 1 papers: $46,445,471,526,564$, $568,593,597,598,618$, $658,666,668,706,719$, $721,732,756,783,915$, $984,1015,1077,1289$, $1290,1291,1334,1352$, $1413,1414,1418,1426$, $1427,1438,1462,1578$, $1579,1711,1732,1740$, 1811,1876

E. Magnetic fields

Experimenta 1 papers: 1423

Theoretica 1 papers: 1073, 1267, 1418, 1869

Combined theoretical-experimenta 1: 1091, 1205, 1266

1.1.2. Broadening in foreign gases (Van der Waals broadening)

Comments: $319,1556,1761,1812$

Theoretica 1 papers: $94,108,114,167,170,171,182$, $204,207,214,238,250,275,290$, 
Theoretica 1 papers: $327,384,385,409,455,495,671$, (cont.)

$$
\begin{aligned}
& 672,794,863,1039,1182,1201, \\
& 1226,1299,1389,1404,1415, \\
& 1434,1455,1477,1494,1495, \\
& 1499,1507,1510,1564,1586, \\
& 1588,1602,1664,1715,1731, \\
& 1763,1766,1824,1880
\end{aligned}
$$

Combined experimenta1-comments: 1287

Combined theoretical-experimenta 1: 1443, 1716

\subsubsection{Satellite bands}

Comments: 1875

Theoretical papers: 1274, 1449, 1459, 1500, 1566, 1567,1872

Combined theoretica1-experimenta 1: 1443

1.1.3. Resonance broadening

Comments: 1092

Theoretica 1 papers: $41,124,245,264,270,664,839$,

$$
\begin{aligned}
& 961,1003,1011,1144,1221,1308, \\
& 1355,1389,1395,1410,1548,1565, \\
& 1626,1704,1710,1744,1747,1793
\end{aligned}
$$

Combined theoretica1-experimenta1-comments: 1466

1.2. BASIC ARTICLES ON DOPPLER AND NATURAL LINE SHAPES

1.2.1. Doppler broadening

Theoretical papers: $1,650,731,840,1260,1473$, 1624,1861

Combined experimenta1-comments: 1287

Combined theoretica1-experimenta 1: 1448 
1.2.2. Natura1 line broadening

Theoretical papers: $127,128,161,403,421,449$, $594,612,926,995,996,1470$, 1698,1779

1.2.3. Radiation induced broadening

Experimenta 1 papers: 1639

Theoretica 1 papers: 446, 595, 790, 1071, 1692, 1738, 1739,1770

1.3. BASIC PAPERS ON INSTRUMENTAL BROADENING, DECONVOLUTION, SUPERPOSITION OF TWO OR MORE SIMULTANEOUSLY ACTING BROADENI NG MECHANISMS

1.3.1. Determination of instrumental line profiles; experimental techniques for determining line shapes

Experimental papers: $483,722,824,900,1048$, $1216,1278,1585,1794,1810$

Theoretical papers: 123, 576, 1074, 1337, 1801, 1803 Combined theoretical-experimental: 93,825

1.3.2. Deconvolution

Theoretica 1 papers: $134,146,160,345,371,426$, $470,576,648,649,762,792$, $885,970,1005,1040,1101$, $1185,1254,1271,1317,1329$, $1582,1607,1726,1864$

Combined theoretical-experimenta1: 937, 1475, 1476

1.3.3. Superposition of broadening mechanisms

Comments: 990,1790

Theoretica 1 papers: $31,335,425,430,707,718,823$, $829,903,910,933,983,1008$, $1017,1018,1050,1053,1100$, 
Theoretical papers: 1138, 1203, 1210, 1211, 1269, (cont.)

1.4. IMPORTANT LINE BROADENING APPLICATIONS

1.4.1. Laser applications

Comments: 1148

Experimenta 1 papers: 1007, 1045, 1106, 1141, 1279, $1305,1409,1442,1481,1490$,

$1514,1786,1886$

Theoretical papers: 699, 1100, 1210, 1286, 1299, $1463, ' 1562,1598,1609,1652$, $1656,1707,1735,1770,1861$, 1868

Combined theoretica1-experimenta 1: 1046, 1108, 1448, 1887

\subsubsection{Astrophysical applications}

Comments: 1551,1796

Experimenta 1 papers: $617,1411,1480,1695,1727$, 1798,1833

Theoretica 1 papers: 891, 993, 1059, 1088, 1197,

$$
\begin{array}{lll}
1208,1340,1346,1347, & 1441, \\
1632,1637,1668,1713,1743, \\
1781,1792,1817, & 1822
\end{array}
$$

Combined theoretica1-experimenta1: 1600

1.4.3. Plasma diagnostics

Experimenta 1 papers: 575, 795, 906, 923, 929, 965, $1113,1524,1528,1549,1625$, $1671,1834,1836,1837$

Theoretica 1 papers: $266,366,698,835,859,1082$, $1302,1577,1882$. 
Combined theoretica1-experimenta1: 566, 1016

1.4.4. Other applications

Experimenta 1 papers: 969, 1076, 1194, 1757

Theoretical papers: 373, 1006, 1014, 1136

\subsection{OTHER TOPICS INVOLVING LINE SHAPES AND SHIFTS}

1.5.1. The line shape in the presence of self-absorption; effects of radiative transfer

Comments: 517,1172

Experimenta 1 papers: $107,800,801,1714$

Theoretica 1 papers: $148,334,351,352,386,422$,

$$
\begin{aligned}
& 452,613,621,759,859,911, \\
& 962,998,1001,1209,1260, \\
& 1693,1713,1744,1745
\end{aligned}
$$

Combined theoretica1-experimenta1: 735

\subsubsection{Broadening of scattered radiation}

Experimenta 1 papers: 1722

Theoretica 1 papers: 288, 421, 431, 1623, 1640, 1752

1.5.3. Some important papers on molecular line broadening

Experimenta 1 papers: 1268

Theoretica 1 papers: $350,474,760,765,963,1041$,

$$
\begin{aligned}
& 1044,1140,1152,1204,1256, \\
& 1344,1432,1437,1505,1526, \\
& 1527,1703,1823,1829,1888
\end{aligned}
$$

Combined theoretica 1-experimenta 1: 1147

1.5.4.. Misce1laneous topics

A. Broadening of $x$-ray lines

Theoretical papers: 192 
B. Light shifts

Theoretica 1 papers: 847, 1093, 1717, 1863

Combined theoretica1-experimenta 1: ' 1307

C. Zeeman broadening

Experimenta 1 papers: 890, 1216

D. Computer program calculation of line shapes,

Theoretica 1 papers: 1378

1.6. REVIEW ARTICLES

1.6.1. General line broadening reviews

$101,159,175,194,254,260,484,500,701,861$,

$895,908,1294,1653$

1.6.2. Reviews on pressure broadening

$217,303,519,545,579,645,663,729,797,1054$,

$1078,1343,1407$

1.6.2.1. Reviews on Stark broadening

$607,757,1004,1016,1504$

1.6.2.2. Reviews on foreign gas broadening 505,523

1.6.3. Reviews on Doppler and natura 1 line broadening

1.6.3.1. Doppler broadening reviews

656,977

1.6.3.2. Natura1 line broadening reviews

No papers in this category.

1.7. REFERENCES ON LINE BROADENING TABLES AND BI BLIOGRAPHIES

1.7.1. Genera1 line bröadening tables

$822,1010,1094$ 
1.7.2. Pressure broadening tables

369,903

1.7.2.1. Special Stark broadening tables

$619,843,907,908,999,1166,1603,1706$,

1769

1.7.2.2. Special foreign gas broadening tables

No papers in this category.

1.7.2.3. Special resonance broadening tables

No papers in this category.

1.7.3. Doppler and natural line broadening tables

No papers in this category.

1.7.4. Tables of Voigt functions

983

1.7.5. Line broadening bibliographies

1257 


\section{LITERATURE REFERENCES CONTAINING NUMERICAL DATA}

(References on individual elements and stages of ionization, classified according to broadening mechanism)

Description

Reference No.*

Description

Reference No.*

\section{Ag (Silver)}

$\mathrm{Ag} I$

$\begin{array}{ll}\text { Resonance, E } & 890 \\ \text { Stark, E } & 76 \\ \text { Van der Waals, E } & 405 \text { by Ar } \\ & 405 \text { by } \mathrm{He} \\ & 531 \text { by } \mathrm{N}_{2}\end{array}$

Ag II

Stark, E

469

\section{Al (Aluminum)}

\section{A1 I}

$\begin{array}{ll}\text { Pressure, E } & 220 \\ \text { Stark, E } & 1613 \\ \text { Stark, T } & 1706 \\ \text { Van der Waa1s, E } & 1451 \text { by Ar } \\ \text { Van der Waa1s, T } & 1750 \text { by } \frac{\text { Ar }}{\mathrm{H}} \\ & 1750 \text { by } \frac{\text { by }}{\mathrm{He}}\end{array}$

A 1 II

Stark, E
784,1310

A1 III

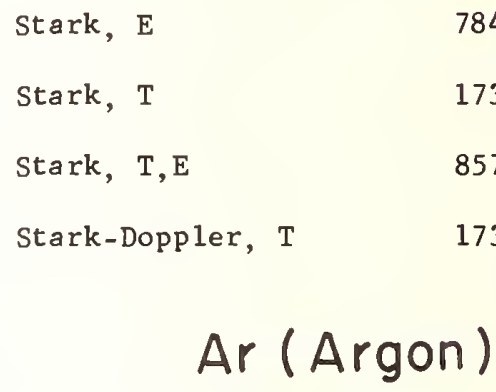

$536,600,715,930$ 938,1472

1196

$708,764,831,985$ $1000,1080,1090$, $1157,1167,1183$, $1248,1292,1310$, $1333,1394,1397$, $1491,1629,1633$, $1635,1644,1806$ $769,1249,1706$, 1775

938,1465 by Ar $1590,1604,1775$ by $\mathrm{Ar}$

*The numbers refer to paper identification numbers of Part 3. 


\section{Description}

Ar II

Naturàl, E

Pressure, E

Stark, E

Stark, T

Stark, T, E

\section{Reference No.*}

1886

1774

$139,580,603,605$, $608,708,784,785$, $965,1000,1081$, 1090, 1102, 1157, 1183, 1251, 1261, $1292,1326,1327$, 1405, 1454, 1464, 1491, 1615, 1629, 1806

1069, 1150, 1160, $1169,1213,1214$, $1247,1264,1282$, $1283,1324,1501$, 1646

$857,1212,1255$

\section{B (Boron)}

B I

Stark, T
Description

Van der Waals, T

Reference No **

1750 by Ar

1750 by $\mathrm{H}_{2}$

1750 by $\mathrm{He}$

Ba II

Stark, E

Stark, T

Van der Waals, E

Van der Waals, T

$543,557,614,1456$, 1802,1879

1160

773 by Ar

773 by $\mathrm{He}$

1750 by Ar

1750 by $\mathrm{H}_{2}$

1750 by $\mathrm{He}$

\section{Be (Beryllium)}

Be I

Stark, T

1706

Be II

Stark, E

1802,1879

Be III

Stark, E

1276

Be IV

\section{$\mathrm{Ba}$ (Barium)}

$\mathrm{Ba} I$
Resonance, E

Stark, E

Van der Waals, E
1487

557

1488 by Ar

$531,716,1605$ by $\mathrm{N}_{2}$

1488 by $\mathrm{Ne}$
1488 by $\mathrm{He}$

1488 by $\mathrm{Kr}$
1670

1276

\section{Bi (Bismuth)}

Bi I

Stark, E 1613

*The numbers refer to paper identification numbers of Part 3. 


\section{$\mathrm{Br}$ (Bromine)}

$\mathrm{Br} \mathrm{I}$

Pressure, E
Stark, E

1253

\section{C (Carbon)}

C I

\begin{abstract}
Stark, E
\end{abstract}
Stark, T

$1190,1253,1310$, 1484,1633

1225,1706

C II

Stark, E

$1190,1215,1341$, 1589

Stark, T

$1069,1150,1160$, $1330,1435,1501$, 1771,1815

Stark-Natura $1, T$

1878

C III
Stark, E
1341,1860
Stark, T
1815
C IV

Stark, E

1860

Stark, T

1815

Stark-Natura $1, \mathrm{~T}$

1878

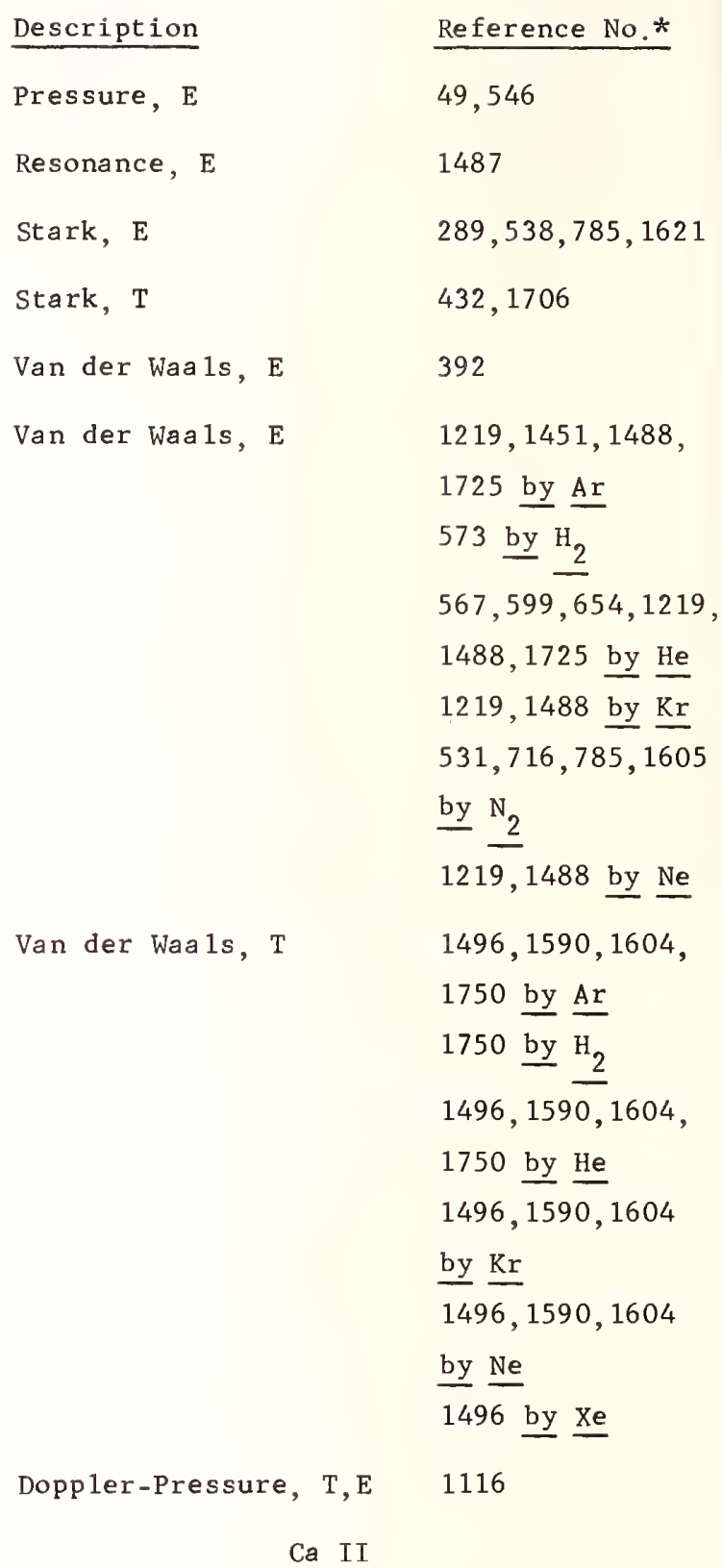

Stdrk, E

$1115,1215,1573$, $1621,1758,1805$, 1879

Stark, T
546

1714

\section{$\mathrm{Ca}$ (Calcium)}

\section{Ca I}

Doppler, E

Line, E

$1621,1758,1805$,
1879
Stark, T $432,828,893,894$,
$1058,1069,1149$,
$1150,1160,1169$,
$1283,1501,1554,1899$
$1699,1771,1889$

*The numbers refer to paper identification numbers of Part 3. 


$\begin{array}{ll}\text { Description } & \text { Reference } \\ \text { Stark, T, E } & 1871 \\ \text { Van der Waals, E } & 1451 \text { by Ar } \\ \text { Van der Waals, T } & 1750 \text { by } \frac{\text { Ar }}{\mathrm{H}_{2}} \\ & 1750 \text { by } \\ & 1750 \text { by } \frac{\mathrm{He}}{}\end{array}$

\section{Cd (Cadmium)}

Cd I

Resonance, E
Resonance, T
Stark, E
Van der Waals, E

Van der Waals, E

\begin{tabular}{|c|}
\hline 896 \\
\hline $709,758,1192$ \\
\hline $237,496,901,1139$, \\
\hline $1198,1273,1314$, \\
\hline 1430 by Ar \\
\hline 136,787 by Cd \\
\hline $237,1139,1273$, \\
\hline 1430 by $\mathrm{He}$ \\
\hline 21 by $\underline{\mathrm{Hg}}$ \\
\hline 1139 by $\mathrm{Kr}$ \\
\hline 1555 by $\mathrm{N}_{2}$ \\
\hline $1139,1314,1316$ \\
\hline by $\underline{\mathrm{Ne}}$ \\
\hline 1555 by $\mathrm{O}_{2}$ \\
\hline $1273,1314,1315$, \\
\hline $1316,1430,1634$ \\
\hline by $\underline{x e}$ \\
\hline 1496 by Ar \\
\hline 1496 by $\mathrm{He}$ \\
\hline 1496 by $\mathrm{Kr}$ \\
\hline 1496 by $\mathrm{Ne}$ \\
\hline 1496 by Xe \\
\hline
\end{tabular}

Cd II

Stark, E

\section{$\mathrm{Cl}$ (Chlorine)}

C1 I

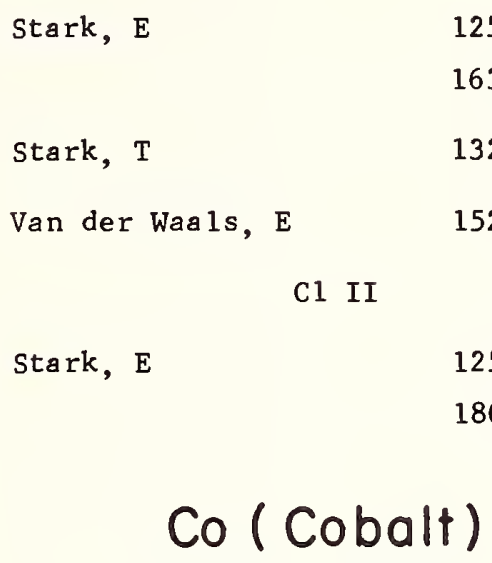

\section{$\mathrm{Cr}$ (Chromium)}

\section{Cr I}

Line, $T$

1743

Van der Waals, E

781,1452 by Ar 1452 by He 531 by $\mathrm{N}_{2}$

Van der Waals, T

$$
\begin{aligned}
& 1750 \text { by } \frac{\mathrm{Ar}}{\mathrm{H}} \\
& 1750 \text { by } 2 \\
& 1750 \text { by } \mathrm{He}
\end{aligned}
$$

\section{Cs (Cesium)}

Cs I

$$
\begin{array}{ll}
\text { Resonance, E } & 297,611,1086, \\
& 1262,1741,1785 \\
\text { Resonance, T } & 324,1003,1515, \\
& 1642,1663
\end{array}
$$




\section{Description}

Stark, E

stark, T

Stark, T,E

Van der Waals, C

Van der Waals, E

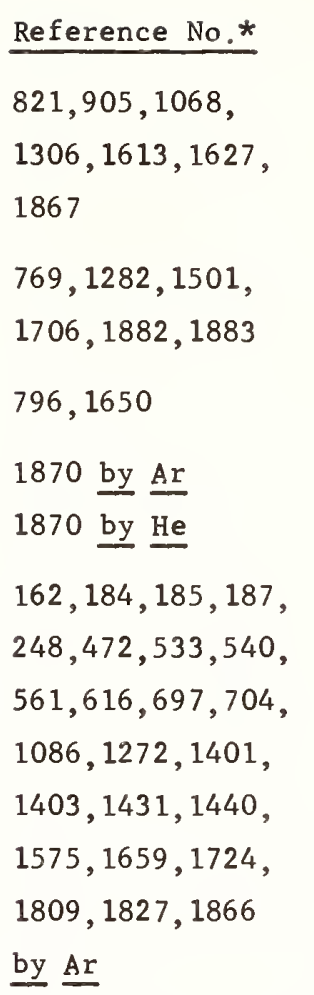

1724,1827 by Ar-He $206,1741,1875$

by $\mathrm{Cs}$

1402,1440 by $\mathrm{CF}_{4}$
1431 by $\mathrm{C}_{5} \mathrm{H}_{12}$

533 by $\mathrm{D}_{2}$

$247,248,533,791$

by $\mathrm{H}_{2}$

$162,184,185,187$,

$248,472,533,561$,

$697,704,1062,1272$,

$1431,1440,1659$,

1724, 1809, 1827 ,

by $\mathrm{He}$

1827 by $\mathrm{He}-\mathrm{Kr}$

1827 by $\mathrm{He}-\mathrm{Xe}$

183,200 by $\mathrm{Hg}$

533,845 by

Hydrocarbons
Description

Van der Waa $1 \mathrm{~s}, \mathrm{E}$ (cont.)
Van der Waa1s, T

Tan der Waa 1 s
Reference No.*

$201,533,697,704$, $1158,1285,1440$, 1659,1827 by $\mathrm{Kr}$ $36,162,163,185$, $187,247,248,533$, $616,697,716$ by $\mathrm{N}_{2}$

$162,163,184,185$, $187,248,533,561$, $704,1173,1431$, $1440,1659,1866$, by $\mathrm{Ne}$ $200,533,697,704$, $1272,1285,1402$, $1431,1440,1659$, 1827 by Xe

$166,556,602,606$, $670,713,844,1252$, $1412,1765,1766$, 1858 by Ar 1881 by $\mathrm{H}$ 556 by $\mathrm{H}_{2}$ $166,556,602,606$, $670,713,1647$, 1765,1766 by $\mathrm{He}$ $556,606,670,713$, $844,1297,1412$, 1872 by $\mathrm{Kr}$ $166,556,606,670$, 713 by $\mathrm{N}_{2}$ $166,556,606,670$, 713,1252 by $\mathrm{Ne}$ $556,602,606,713$, $844,1297,1658$, $1765,1766,1872$ by $\mathrm{Xe}$

Van der Waals, E, C 


\begin{tabular}{|c|c|}
\hline Description & Reference No.* \\
\hline $\begin{array}{l}\text { Van der Waals, E, C } \\
\text { (cont.) }\end{array}$ & $914 \underline{\text { by }} \underline{\mathrm{N}_{2}}$ \\
\hline Van der Waals, $T, E$ & 1443 by $\mathrm{Kr}$ \\
\hline & 1443 by $\mathrm{Ne}$ \\
\hline & 1443,1608 by $\mathrm{Xe}$ \\
\hline Stark-Zeeman, E & 1649 \\
\hline Stark-Zeeman, $T$ & 1882 \\
\hline & \\
\hline Van der Waals, T, E & 1443 by $\mathrm{Kr}$ \\
\hline & \\
\hline Pressure, E & 145 \\
\hline Stark, E & 76,135 \\
\hline Stark, T & 1764 \\
\hline Van der Waals, E & 781,1451 by Ar \\
\hline & 531 by $\mathrm{N}_{2}$ \\
\hline Van der Waals, $\mathrm{T}$ & 1764 by Ar \\
\hline
\end{tabular}

D I
Van der Waals, E

$$
\begin{aligned}
& 643,696,1742 \text { by Ar } \\
& 1669 \text { by } \mathrm{He} \\
& 643,696 \text { by } \mathrm{Ne}
\end{aligned}
$$

\section{Eu (Europium)}

\section{Eu II}
Van der Waals, T

Description

Reference No.*

\section{$F$ (Fluorine)}

F I

$\begin{array}{ll}\text { Stark, T } & 1706 \\ \text { Van der Waals, E } & 1831 \text { by } \frac{\mathrm{Ar}}{\mathrm{F}} \\ & 1831 \frac{\text { by }}{\mathrm{Fe}} \\ & 1831 \text { by }\end{array}$

F II

Stark, E

734

F III

Stark, E

734

\begin{tabular}{|c|c|}
\hline Line, $\mathrm{T}$ & 1743 \\
\hline Pressure, C & 281 \\
\hline Pressure, E & 106 \\
\hline Van der Waals, E & $\begin{array}{l}714,781,1450 \\
\frac{\mathrm{by}}{573,1411 \text { by } \mathrm{H}} \\
573 \text { by } \mathrm{H}_{2} \\
703,1450 \text { by } \mathrm{He} \\
531 \text { by } \mathrm{N}_{2}\end{array}$ \\
\hline Van der Waals, T & $\begin{array}{l}1750 \text { by } \frac{\mathrm{Ar}}{17} \\
1590,15 \text { by } \mathrm{H} \\
1750 \text { by } \mathrm{H}_{2} \\
1750 \text { by } \mathrm{He}\end{array}$ \\
\hline Zeeman, $\mathrm{T}$ & 1743 \\
\hline
\end{tabular}

\section{Fe (Iron)}

Fe I

*The numbers refer to paper identification numbers of Part 3. 


\section{Ga (Gallium)}

Ga I

$\begin{array}{ll}\text { Resonance, E } & 1207 \\ \text { Stark, E } & 1613 \\ \text { Van der Waals, E } & 1207 \text { by } \frac{\mathrm{Ar}}{\mathrm{He}} \\ & 1207 \text { by } \\ & 1207 \text { by }\end{array}$

\section{Ge (Germanium)}

Ge I

\section{Stark, C \\ 925 \\ Stark, E \\ 1612 \\ $H$ (Hydrogen)}

H I

$\begin{array}{ll}\text { Doppler, T, E } & 989 \\ \text { Pressure, E } & 26,55 \\ \text { Resonance, E } & 1655 \\ \text { Resonance, T } & 699,1474,1503 \\ \text { Stark, C } & 886,1099,1552, \\ & 1595,1596,1712 \\ & 62,97,135,261, \\ \text { Stark, E } & 332,383,407,450, \\ & 475,476,479,481, \\ & 499,507,518,529, \\ & 575,591,642,675, \\ & 700,705,720,761, \\ & 776,777,778,798, \\ & 799,830,833,865, \\ & 892,902,913,920, \\ & 940,964,992,1013, \\ & 1047,1063,1075,\end{array}$

Stark, E (cont.)

$1104,1105,1146$, $1181,1223,1310$, $1318,1319,1322$, $1331,1336,1388$, $1393,1446,1528$, $1560,1614,1660$, $1700,1798,1833$, 1835

Stark, T

$47,48,69,249,268$ $269,283,309,406$, $478,524,525,526$, $568,577,596,615$, $619,651,653,655$, $659,660,661,667$, $726,736,768,771$, $843,852,912,928$, $932,981,1060$, 1082, 1087, 1096, $1166,1170,1176$, $1177,1180,1189$, $1217,1218,1250$, $1282,1295,1296$, $1311,1312,1313$, $1338,1339,1377$, $1379,1380,1381$, $1509,1511,1518$, $1519,1557,1561$, $1603,1636,1665$, $1697,1711,1721$, $1748,1753,1799$, $1800,1819,1832$, 1877

Stark, T, C

1759

Stark, T, E

$429,448,566,712$, $1095,1205,1600$

Van der Waals, E $643,696,789$, 1258,1742 by Ar

* The numbers refer to paper identification numbers of Part 3. 


\section{Description}

Van der Waa 1s, E (cont.)

Reference No.*
1521 by $\mathrm{Ar}-\mathrm{H}_{2}$
$643,696,789,1521$
by $\mathrm{H}_{2}$
$643,696,789$ by $\mathrm{He}$
1270 by $\frac{\mathrm{Kr}}{6}$
$643,696,789$ by $\mathrm{Ne}$
1270 by $\mathrm{Xe}$
1415 by $\frac{\mathrm{Ar}}{\mathrm{H}}$
1474 by
$763,1415,1493$,
$1495,1510,1580$,
1586,1776 by $\mathrm{He}$
1415 by $\frac{\mathrm{Kr}}{1415,1586}$ by Ne
1415 by $\mathrm{Xe}$
717,1468
1165,1423
1073,1085
1091
1591
1303

Van der Waals, T

Stark-Doppler, T

Stark-Zeeman, E

Stark-Zeeman, T

Stark-Zeeman, T,E

Stark-Zeeman-Doppler, T

Stark-Doppler-Na tura 1-

Van der Waals, T

\section{$H$ (Hydrogen) Sequence}

Stark, T

651

\section{He (Helium)}

\section{He I}

$\begin{array}{ll}\text { Doppler, T,E } & 989 \\ \text { Resonance, E } & 140,918,930,1111, \\ & 1112,1162 \\ \text { Resonance, T } & 1196,1628 \\ \text { Resonance, T, E, C } & 1466\end{array}$

\section{Description}

Stark, C

Stark, E

Stark, T

Stark, T, C

Stark, T, E

Stark-Resonance, E

Stark-Zeeman, E

Stark-Zeeman, T

Stark-Zeeman, T, E

He II

Natura $1, E$

Stark, C

Stark, E
1807

1595,1756

Reference No.*

1795

$86,96,261,479$, $581,608,733,761$, $785,827,855,856$, $920,935,940,1280$, 1301, 1382, 1571, 1593, 1599, 1643, $1651,1672,1702$, $1708,1719,1767$, 1777,1791

$47,95,310,317$, $336,477,652,770$, $893,999,1097$, 1098, 1175, 1197, $1206,1281,1282$, $1383,1384,1408$, 1420, 1439, 1501, 1553, 1569, 1654, 1706,1711

1873

$601,857,1095$, 1600,1701

856

1651

1267, 1417, 1419, 1583,1736

1266,1869

$581,700,761,1043$, $1137,1179,1445$, $1563,1587,1592$, 1767,1768

*The numbers refer to paper identification numbers of Part 3. 


$\begin{array}{ll}\text { Description } & \text { Reference No.* } \\ \text { Stark, T } & 711,268,853,1620, \\ & 1661,1769 \\ \text { Stark, T,E } & 601,1600\end{array}$

\section{$\mathrm{Hg}$ (Mercury)}

$\mathrm{Hg} I$

Pressure, E

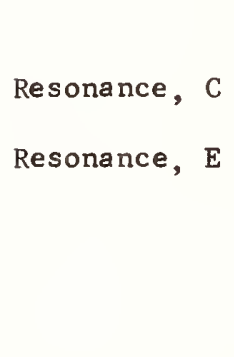

Resonance, $\mathrm{T}$

Stark, E

Van der Waa $1 \mathrm{~s}, \mathrm{C}$

Van der Waa 1s, E
$49,78,87,253,255$, 302,367

779

$61,98,136,203,225$, $226,227,232,251$, $252,291,355,447$, $527,578,723,991$, 1200,1422

$270,896,1321,1865$

758

919 by Ar

16 by Air

$61,125,129,138$, $231,237,252,389$, $410,504,528,539$, $541,542,578,616$, $673,909,1009,1012$, by Ar

129 by $\mathrm{CH}_{4}$

129 by $\mathrm{C}_{3} \mathrm{H}_{8}$

1227 by $\mathrm{C}_{6} \mathrm{H}_{14}$

129 by CO

$54,61,252$ by $\mathrm{CO}_{2}$

1357 by cd

$710,838,1067$,

1156 by $\mathrm{D}_{2}$

941,1838 by

Hydrocarbons
Description

Reference No.*

Van der Waals, E (cont.)

$16,54,61,125,129$ $389,410,453,528$, $541,578,616,710$, $728,838,967,1067$ 1156 by $\mathrm{H}_{2}$

61,344 by $\mathrm{H}_{2} \mathrm{O}$

$125,129,138,237$, $244,265,453,502$, $528,542,578,616$, $967,968,978,979$, $1009,1067,1168$ by $\mathrm{He}$

99 by $\mathrm{He}-\mathrm{Ne}$ $136,344,800,801$ by $\mathrm{Hg}$ 542,609, 909, 1009, 1447 by $\mathrm{Kr}$ 1357 by $\mathrm{Mg}$ $54,61,125,129$, $252,315,344,389$, $410,504,528,541$, 578,616 by $\mathrm{N}_{2}$ 129,941 by $\mathrm{NH}_{3}$ $138,539,542,967$, 1009,1168 by $\mathrm{Ne}$ $61,252,315$ by $\mathrm{O}_{2}$ $541,542,578,674$, 909,1009 by Xe 1357 by $\mathrm{Zn}$ Van der Waa1s, T $94,114,151,725$, 794, 896, 1109, 1516,1808 by Ar 114 by co 151 by $\mathrm{CO}_{2}$ 114,151 by $\mathrm{H}_{2}$ 114 by $\mathrm{H}_{2} \mathrm{O}$

*The numbers refer to paper identification numbers of Part 3. 


\section{Description}

Van der Waals, T (cont.)

Van der Waals, T,E
Reference No.*

$94,114,794,896$,

1220,1516,1517,

1657 by He

896,1808 by $\mathrm{Kr}$

$94,114,151,794$

by $\mathrm{N}_{2}$

896,1808 by $\mathrm{Ne}$

151,794 by $\mathrm{O}_{2}$

896,1808 by Xe

503,610 by $\mathrm{Ar}$

1443 by $\mathrm{D}_{2}$

1443 by $\mathrm{H}_{2}$

503,1443 by $\mathrm{He}$

610 by $\mathrm{Kr}$

503 by $\mathrm{N}_{2}$

$\mathrm{Hg}$ II

Pressure, E

147

Stark, E
Description

Van der Waals, E

(cont.)

647,1207 by $\mathrm{He}$

1207 by Ne

702 by Xe

\section{K (Potassium)}

K I

$228,458,1471$,

1784,1785

$324,1003,1515$,

1642,1663

1466

1613

1706

$180,183,184,186$, $200,215,390,410$, $504,540,616,644$, $704,781,988,1083$, 1084 by Ar $180,308,410,644$, 791 by $\mathrm{H}_{2}$

$180,183,184,186$, $263,644,704,988$

by $\mathrm{He}$

191 by $\mathrm{Hg}$

988 by Hydro-

carbons

$644,704,988$,

1479 by $\mathrm{Kr}$

$174,215,229,308$, $410,531,716,988$

by $\mathrm{N}_{2}$

$180,183,184,186$, $644,704,988$ by

Ne

341 by $\mathrm{Rb}$

*The numbers refer to paper identification numbers of Part 3. 


\section{Description}

Van der Waa 1s, E (cont.)

Van der Waals, T

Reference No.*
704,988 by Xe
602,794 by Ar
1881 by $\frac{\mathrm{H}}{602 \text { by } \mathrm{He}}$
1297,1872 by $\mathrm{Kr}$
794 by $\mathrm{N}_{2}$
$602,1297,1872$ by Xe

K IX

$\begin{array}{lr}\text { Stark, E } & 1154 \\ \text { Stark, T } & 1265 \\ & \\ & \text { Kr (Krypton) }\end{array}$

$\mathrm{Kr} I$ $\underline{\text { Description }}$

Reference No **

$\mathrm{Kr}$ II

$\begin{array}{lc}\text { Stark, E } & 784,786 \\ \text { Stark, T,E } & 857 \\ \text { Li(Lithium) }\end{array}$

Li I

Pressure, E

Resonance, $\mathrm{T}$

Van der Wasls, E

233 by $\mathrm{Kr}$

1349,1399 by Ar

1399 by $\mathrm{H}_{2}$

1349,1399 by $\mathrm{He}$

$216,826,1349$ by $\mathrm{Kr}$

1349,1399 by $\mathrm{Ne}$

1399 by Xe

1808 by Ar

1880 by He

1604 by $\mathrm{Kr}$

1808 by Ne

1466 by Ar

1466 by $\mathrm{Kr}$
Doppler, E

Resonance, E

Stark, E

Stark, T

Van der Waals, E

Van der Waa $1 \mathrm{~s}, \mathrm{~T}$

546

49,546

1114,1523

1515

$76,333,724,1288$, 1353, 1354, 1523,

$1524,1525,1613$

$767,980,1648$, 1706,1882

392

$704,780,781,1522$

by $\mathrm{Ar}$

$704,780,781,1522$

by $\mathrm{He}$

704 by $\mathrm{Kr}$

353 by Li

531,716 by $\mathrm{N}_{2}$

1522 by Ne

704 by Xe

602,1506 by Ar

1881 by $\underline{\mathrm{H}}$

602,1645 by He

1297,1872 by $\mathrm{Kr}$

$602,1297,1872$

by $\mathrm{Xe}$

Stark-Zeeman, T 


\section{Mg (Magnesium)}

\section{$\mathrm{N}$ (Nitrogen)}

Mg I

$\begin{array}{ll}\text { Resunance, E } & 136 \\ \text { Stark, E } & 557,758 \\ \text { Stark, T } & 218,1350,1706 \\ \text { Van der Waals, E } & 136 \text { by } \frac{\mathrm{Mg}}{2} \\ \text { Van der Waals, T } & 1750 \text { by } \frac{\mathrm{Ar}}{\mathrm{H}} \\ & 1750 \text { by } \\ & 1750 \text { by } \frac{\mathrm{He}}{\mathrm{Mg}}\end{array}$

Mg II

\section{Stark, E}

Stark, T

Stark, T, E

Van der Waals, T
$557,1573,1879$

1058, 1330, 1501, 1558,1699

1871

1750 by Ar

1750 by $\mathrm{H}_{2}$

1750 by He

Mn (Manganese)

Mn I

$\begin{array}{ll}\text { Van der Waals, E } & 646,1451 \text { by Ar } \\ & 646 \text { by } \mathrm{He} \\ & 531 \text { by } \underline{\mathrm{N}_{2}}\end{array}$

\section{Mo (Molybdenum)}

Mo I

Van der Waals, E

1451 by Ar

N I

\begin{tabular}{|c|c|}
\hline Resonance, E & 1622 \\
\hline Stark, E & $\begin{array}{l}862,1319,1482, \\
1485\end{array}$ \\
\hline Stark, $\mathrm{T}$ & 1225,1706 \\
\hline Van der Waals, E & $\begin{array}{l}834,854,1622 \\
\frac{\text { by }}{834} \frac{\mathrm{Ar}}{854}, 1622, \\
1667 \text { by } \frac{\mathrm{He}}{834,854,} \\
592,775,83,85 \\
1667 \text { by } \mathrm{N}_{2} \\
834,854,1667 \\
\text { by } \mathrm{Ne}\end{array}$ \\
\hline Van der Waals, T & $\begin{array}{l}1477,1493,1494 \\
\text { by He }\end{array}$ \\
\hline
\end{tabular}

N II

Stark, E $116,122,971,972$, $1102,1142,1143$, $1589,1606,1616$

Stark, T $1069,1150,1160$, $1265,1435,1501$, $1646,1771,1815$

Stark-Natura 1, T 1878

N III
Stark, E 122,1341
Stark, T
1771,1815

N V

$\begin{array}{ll}\text { Doppler, E } & 975 \\ \text { Stark, E } & 1072 \\ \text { Stark, T } & 1581,1815\end{array}$

*The numbers refer to paper identification numbers of Part 3. 


\section{$\mathrm{Na}$ (Sodium)}$$
\mathrm{Na} \mathrm{I}
$$

$$
\begin{aligned}
& \text { Doppler, E } \\
& \text { Natura 1, E } \\
& \text { Pressure, E } \\
& \text { Pressure, T, E } \\
& \text { Resonance, E }
\end{aligned}
$$

Resonance, T

Resonance, T, E

Stark, E

Stark, T

Van der Waals, C

Van der Waals, E

Van der Waa1s, E

\section{6}

100

$164,546,766$

74

$79,149,292,427$, 433,456

$75,324,1003,1515$, 1663

1052

$485,501,507,530$, $906,1486,1613$

$218,432,767,828$, $893,894,980,1706$, 1734,1760

468 by Ar

392

$84,100,115,172$, $180,183,184,186$, $202,205,326,391$, $410,704,781,887$, $888,1002,1451$ by Ar $887,888^{\circ}$ by $\mathrm{CO}_{2}$ 243 by Cs $84,100,115,149$, $172,180,181,202$, $247,308,410,791$, 1002 by $\mathrm{H}_{2}$ $100,115,149,180$, $183,184,186,202$, $704,887,888,1002$, $1107,1453,1572$ by $\mathrm{He}$

$$
\begin{aligned}
& \text { Van der Waals, E } \\
& \text { (cont.) }
\end{aligned}
$$

191 by $\mathrm{Hg}$

115 by Hydrocarbons

704,1002 by $\mathrm{Kr}$

$56,100,115,172$

$181,202,247,30$;

$391,410,451,50$ :

$531,716,887,88$ \&

$100,115,180,18:$

$184,186,202,70$

$1002,1107,1453$

by $\mathrm{Ne}$

704 by Xe

Van der Waals, $\mathrm{T}$.

$563,602,794,10$ :

$1507,1590,1750$

by Ar

$1760,1783,1881$

by $\underline{\mathrm{H}}$

1750 by $\mathrm{H}_{2}$

$354,602, \overline{794}$,

$1590,1645,1647$,

1750 by Hé

1297,1872 by $\mathrm{Kr}$

794 by $\mathrm{N}_{2}$

$602,1297,1872$

by $\mathrm{Xe}$

Van der Waals, T, E

503 by Ar

Natura 1-Resonance, E 85

Resonance-Zeeman, T

1332

Stark-Doppler-Resonance-

Van der Waals, E

906 by $\mathrm{N}$
1002 by $\mathrm{N}_{2}$

\section{$\mathrm{Ne}$ (Neon)}

$\mathrm{Ne} I$

Line, E 408

*The numbers refer to paper identification numbers of Part 3 . 


\begin{tabular}{|c|c|}
\hline Description & Reference No.* \\
\hline Natura 1, E & 190,1828 \\
\hline Pressure, E & $428,1284,1789$ \\
\hline Pressure, $\mathrm{T}$ & 1458 \\
\hline Resonance, E & $\begin{array}{l}387,1141,1188, \\
1398,1828\end{array}$ \\
\hline Resonance, $T$ & 1196,1628 \\
\hline Resonance, $T, E, C$ & 1466 \\
\hline Stark, E & $\begin{array}{l}538,1310,1633 \\
1635,1638\end{array}$ \\
\hline Stark, $\mathrm{T}$ & 1706,1775 \\
\hline Van der Waals, E & $\begin{array}{l}1106,1141,1300, \\
1335,1398,1478 \text { by He } \\
1481 \text { by } \mathrm{He}-\mathrm{Ne} \\
1224,1465,1631, \\
1787 \text { by Ne}\end{array}$ \\
\hline Van der Waals, T & 1775 by Ne \\
\hline Stark-Resonance, E & 1787 \\
\hline $\begin{array}{r}\text { Doppler-Van der Waals, E } \\
\text { Ne I }\end{array}$ & 1287,1448 by $\mathrm{He}$ \\
\hline Pressure, E & 1774 \\
\hline Stark, E & $139,603,784,786$ \\
\hline Stark, T,E & 857 \\
\hline
\end{tabular}

\section{$\mathrm{Ni}$ (Nickel)}

Ni I

$\begin{array}{ll}\text { Resonance, E } & 1469 \\ \text { Stark, E } & 76 \\ \text { Van der Waa1s, E } & 1452,1469,1778 \text { by Ar } \\ & 1452,1469 \text { by He } \\ & 531 \text { by } \mathrm{N}_{2}\end{array}$

\section{Description \\ O (Oxygen)}

Reference No.*

O I

$\begin{array}{ll}\text { Doppler, E } & 975 \\ \text { Stark, E } & 1154 \\ \text { Stark, T } & 1265,1815\end{array}$

\section{P (Phosphorus)}

\begin{tabular}{|c|c|}
\hline Stark, E & 1310,1633 \\
\hline Stark, $\mathrm{T}$ & 1706 \\
\hline \multirow[t]{3}{*}{ Van der Waals, } & 782 by $\mathrm{He}$ \\
\hline & 782 by $\mathrm{Ne}$ \\
\hline & \\
\hline Stark, E & 1310 \\
\hline
\end{tabular}

*The numbers refer to paper identification numbers of Part 3. 
Description

Van der Waals, E (cont.)

$\mathrm{Pb} \mathrm{I}$

$\begin{array}{lr}\text { Resonance, E } & 1178 \\ \text { Stark, E } & 1612\end{array}$

\section{Rb (Rubidium)}

$\mathrm{Rb} I$

Line, $\mathrm{T}, \mathrm{E}$

1307

Resonance, E

$277,341,457$

Resonance, $\mathrm{T}$

Stark, E

Van der Waals, C

Van der Waals, E

Van der Waals, T
$324,1003,1515$,

1663

1613

939 by Xe

$235,236,248,276$, $390,424,497,540$, $562,616,697,704$, $781,837,1066,1067$, $1387,1390,1428$, 1429 by Ar 1387 by $\mathrm{CH}_{4}$ $562,836, \overline{1067}$ by $\mathrm{D}_{2}$ $247,248,276,278$, $497,562,791,836$, 1067 by $\mathrm{H}_{2}$ $235,236,248,276$, $390,424,497,562$, $616,704,781,1387$, 1390 by $\mathrm{He}$ $522,562,569$ by Hydrocarbons $497,534,562,704$, $1065,1067,1390$, 1601 by Kr
Reference No.*

$247,248,278,390$, $497,562,616,716$,

1387 by $\mathrm{N}_{2}$

$235,236,248,262$, $279,280,497,562$, 704, 1064, 1067 , 1387,1390 by Ne 206,277 by Rb $497,534,704,898$, 1390 by Xe

$602,606,670,713$, 987 by Ar $602,606,670,713$

by $\mathrm{He}$

$606,670,713,987$, 1297,1872 by $\mathrm{Kr}$ $606,670,713$ by $\mathrm{N}_{2}$

$606,670,713$ by $\mathrm{N \epsilon}$ $602,606,713,987$, 1297,1872 by Xe

Van der Waals, T, E 503,1443 by Ar 1443 by $\mathrm{D}_{2}$ 1443 by $\mathrm{H}_{2}$ 503,1716 by $\mathrm{He}$ 1443 by $\mathrm{Kr}$ 503 by $\mathrm{N}_{2}$ 1443 by $\mathrm{Ne}$ Rb II

Van der Waals, T, E 1443 by Kr

\section{S (Sulfur)}

S I 
Description

stark, E

Stark, T

1706

S II

Stark, E
Stark, T

1153,1310

$1069,1160,1164$, $1328,1330,1501$

S III

Stark, T

$1330,1501,1815$

S IV

Stark, T

\section{5}

S VI

stark, T 1815

\section{$\mathrm{Sb}$ (Antimony)}

Sb I

Pressure, E
Stark, E

195

1613

Sb II

Pressure, E

195

Sb III

Pressure, E

195
Description
Si (Silicon)

Si I

$\begin{array}{ll}\text { Line, T } & 1743 \\ \text { Stark, E } & 734,1310,1612, \\ & 1630,1633 \\ \text { Stark, T } & 1350,1706,1889 \\ \text { Van der Waals, E } & 1171,1416,1866 \\ & \frac{\text { by }}{1630} \frac{\mathrm{Ar}}{\underline{\mathrm{b}}} \\ \text { Van der Waa 1s, T } & 1750 \frac{\mathrm{by}}{\mathrm{Ar}} \\ & 1750 \frac{\mathrm{by}}{\mathrm{H}} \\ & 1750 \frac{\mathrm{by}}{\mathrm{He}} \\ & 1350 \frac{\mathrm{by}}{\mathrm{Si}}\end{array}$

Si II

Stark, $\mathrm{E}$
Stark, T
Stark-Natural, T $734,1310,1618$ $1283,1330,1501$, 1815,1889

1878

Si III

$\begin{array}{lc}\text { Stark, E } & 734,784, \\ \text { Stark, T } & 1330,150 \\ & 1889 \\ \text { Stark, T,E } & 857 \\ \text { Stark-Natura 1, T } & 1878 \\ & \\ \text { Stark, E } & \\ \text { Stark, T } & 734,922 \\ \text { Stark, T, E } & 1815 \\ \text { Stark-Natura 1, T } & 857\end{array}$




\section{$\operatorname{Sn}(\operatorname{Tin})$}

Sn I

$\begin{array}{ll}\text { Pressure, E } & 208 \\ \text { Stark, E } & 1612\end{array}$

Sn II

Pressure, E

208

Sn III

Pressure, E

208

Sn IV

Stark, E 784,922

\section{Sr (Strontium)}

Sr I

Resonance, E

Van der Waals, E

$$
1487
$$

$888,1488,1746$

by $\mathrm{Ar}$

888 by $\mathrm{CO}_{2}$

$888,1488,1746$

by $\mathrm{He}$

1488 by $\mathrm{Kr}$

$531,716,888,1605$

by $\mathrm{N}_{2}$

1488 by Ne

Sr II

Stark, E

$543,614,1805,1879$

Van der Waa 1s, T

1750 by Ar

1750 by $\mathrm{H}_{2}$

1750 by He

Sr IV

Stark, T, E

\section{T (Tritium)}

T I

Van der Waa 1s, E $643,696,789$, 1742 by Ar $643,696,789$ by $\mathrm{Ne}$

\section{Te (Tellurium)}

Te I

Stark, E

1613

\section{Ti (Titanium)}

Ti I

Stark, E

924

Van der Waa 1s, E

1191,1263 by Ar

924 by $\mathrm{H}$

Van der Waals, T

1750 by Ar

1750 by $\mathrm{H}_{2}$

1750 by He

Ti II

Van der Waals, E

1191 by Ar

924 by $\mathrm{H}$

TI (Thallium)

T1 I

Doppler, E 546

Pressure, E 546

Resonance, E 136

Stark, E 1613

Van der Waals, C 1172 by $\mathrm{Hg}$

*The numbers refer to paper identification numbers of Part 3. 
Description

Van der Waals, E

Van der Waals, E
Reference No.*

392

$237,616,622,702$

by Ar

622,974 by $\mathrm{H}_{2}$

237,702 by $\mathrm{He}$

21 by $\mathrm{Hg}$

702 by $\mathrm{Kr}$

531 by $\mathrm{N}_{2}$

702 by $\mathrm{Ne}$

136 by $\mathrm{T} 1$

702 by $\mathrm{Xe}$

\section{Xe (Xenon)}

\section{Xe I}

Resonance, E

Resonance, $\mathrm{T}$

Van der Waals, E

an der Waals, T
$173,936,982,1568$

1196

$372,410,936,1174$, 1399 by Ar

$410,1174,1399$ by

$\underline{\mathrm{H}_{2}}$

$936,1174,1399$,

1568 by He

936,1399 by $\mathrm{Kr}$

410 by $\mathrm{N}_{2}$

$936,1174,1399$,

1568 by $\mathrm{Ne}$

1808 by Ar

1808 by $\mathrm{Kr}$

1808 by Ne

1443 by $\mathrm{Ne}$
Description

\section{Zn (Zinc)}

Zn I

\begin{tabular}{|c|c|}
\hline Pressure, E & 49 \\
\hline Resonance, E & 136 \\
\hline Resonance, $\mathrm{T}$ & 896 \\
\hline Stark, E & $669,758,1193$ \\
\hline Van der Waals, E & 1199,1406 by Ar \\
\hline & 1199,1406 by $\mathrm{He}$ \\
\hline & 1483 by $\mathrm{Hg}$ \\
\hline & 1199,1406 by $\mathrm{Kr}$ \\
\hline & 1199,1406 by $\mathrm{Ne}$ \\
\hline & 1199,1406 by Xe \\
\hline & 136 by $\mathrm{Zn}$ \\
\hline
\end{tabular}

$\mathrm{Zn} \mathrm{II}$

Stark, E

1193

*The numbers refer to paper identification numbers of Part 3. 


\section{CHRONOLOGICAL LISTING OF ALL REFERENCES WITH FULL TITLES}

1. Lord Rayleigh, On the Limit to Interference when Light is Radiated from Moving Molecules, Ph1l. Mag. 27, 298.

6. A. A. Michelson, On the Broadening of Spectral Lines, Astrophys. J. 2, 251.

1906

11. H. A. Lorentz, The Absorption and Emission Lines of Gaseous Bodies, Kon. Acad. Wetensch. Amsterdam, Proc. $\underline{8}, 591$.

1907

16. R. W. Wood, Modification in the Appearance and Position of an Absorption Band Resulting from the Presence of a Forelgn fas, Astrophys. J. 26, 41.

1909

21. R. W. Wood \& D. V. Guthrle, The Ultra-V1olet Absorption Spectra of Certain Metallic Vapors and Their Mixtures, Astrophys. J. 29, 211.

26. R. Rossi, The Widening of the Hydrogen Lines by High Pressures, Astrophys. J. 34, 299. 
31. W. Volgt, On the Intensity Distribution Within Lines of a Gaseous Spectrum, Sitzungsber. Math.-Phys. K. Bayer. Akad. W1ss. München, 603. (Ger.)

1914

36. C. Füchtbauer \& W. Hofmann, On Maximum Intensity, Damping and True Intensity Distribution of Spectral Lines in Absorption, Ann. Phys. (Le1pzig) 43, 96. (Ger.)

1915

41. Lord Rayleigh, On the Widening of Spectrum Lines, Ph1l. Mag. 29, 274.

46. P. Debye, The Molecular Electric Fleld in Gases, Physik. Z. 20, 160. (Ger.)

47. J. Holtsmark, On the Broadening of Spectral Lines, Ann. Phys. (Le1pz1g) $\underline{58}, 577$. (Ger.)

48. J. Holtsmark, On the Broadening of Spectral Lines, Physik. Z. 20, 162. (Ger.)

49. M. Ritter, Observations on the Effect of the Electric Field, the Pressure Shift and the Broadening of Spectral Serles, Ann. Phys. 59, 170. (Ger.)

1922

54. C. Füchtbauer \& G. Joos, On the Intensity and Broadening of Spectral Lines, Physik. Z. 23,73 . (Ger.)

55. E. O. Hulburt, The Broadening, of the Balmer Lines of Hydrogen with Pressure, Astrophys. J. 25 , 399 .

55. R. Minkowsk1, On the Dependence of the Sodium D-Lines on Forelgn Gases, Physik. Z. 23,69 . (Ger.)

1923

61. C. Füchtbauer, G. Joos, \& 0. Dinkelacker, Concerning the Intensity, Broadening and Pressure Shift of Spectral Lines, Particularly the Absorption Line 2537 of Mercury, Ann. Phys. (Le1pzig) 71, 204. (Ger.) 
62. E. O. Hulburt, The Distribution of Intensity in the Broadened Balmer Lines of Hydrogen, Phys. Rev. 22, 24.

63. M. Kimura \& G. Nakamura, Self-Reversal of the Lines $H_{\alpha}$ and $H_{\beta}$ of Hydrogen, Jap. J. Phys. $2,53$.

64. M. Kimura \& G. Nakamura, The Broadening of Spectral Lines Caused by Increased Current Density and Their Stark Effects, Jap. J. Phys. 2, 61.

1924

69. J. Holtsmark, On the Broadening of Spectral Lines. II., Physik. Z. 25, 73. (Ger.) 1925

74. G. R. Harrison \& J. C. Slater, Line Breadths and Absorption Probabilities in Sodium Vapor, Phys. Rev. 26, 176.

75. J. Holtsmark, On the Absorption in Na Vapor, Z. Phys. 34, 722. (Ger.)

76. J. Holtsmark \& B. Trumpy, On the Broadening of Spectral Lines, Z. Phys. $31,803$. (Ger.)

77. L. Mensing, Contribution to the Theory of Spectral Line Broadening, Z. Phys. 34 , 611. (Ger.)

78. W. Orthmann, On the Impact Broadening of the Hg I Resonance Line, Ann. Phys. (Leipzig) 78, 601. (Ger.)

79. B. Trumpy, Peak Intensity and Width of the Lines of the Principal Series of Na I, Z. Phys. 34, 715. (Ger.)

1926

84. C. Füchtbauer \& H. Meier, On the Intensity Ratio of the Principal Series Doublets of Alkali Metals, Physik. Z. 27, 853. (Ger.)

85. R. Minkowski, Natural Width and Pressure Broadening of Spectral Lines, Z. Phys. 36, 839. (Ger.)

86. T. Takamine, Spectroscopic Study on the Discharge in Helium, Sci. Pap. Inst. Phys. Chem. Res., Tokyo $\underline{5}, 55$. 
87. B. Trumpy, On the Intensity and Width of Spectral Lines, Z. Phys. $40,594$. (Ger.)

92. K. Asagoe, Large Displacements and Broadening of the Spectral Lines of Bromine and Iodine, Jap. J. Phys. $\underline{4}, 85$.

93. H. C. Burger \& P. H. van Cittert, True and Apparent Widths of Spectral Lines, Z. Phys. 44, 58. (Ger.)

94. P. D. Foote, The Quenching of Mercury Resonance Radiation by Forelgn Gases, Phys. Rev. 30, 288 .

95. J. S. Foster, Application of Quantum Mechanics to the Stark Effect in Helium, Proc. Roy. Soc,, Ser. A $117,137$.

96. J. S. Foster, Stark Patterns Observed in Helium, Proc. Roy. Soc., Ser. A $114,47$.

97. M. Hanot, Broadening of the Balmer Lines by the Intermolecular Electric Field, C. R. H. Acad. Sc1. 184, 281. (Fr.)

98. W. Orthmann \& P. Pringsheim, The Broadening and Weakening of the Hg Resonance Line due to Increasing the Hg-Vapor Pressure, Z. Phys. 46, 160. (Ger.)

99. W. Orthmann \& P. Pringsheim, On the Broadening of the Hg Resonance Line by Foreign Gases, Z. Phys. $\underline{43}$, 9. (Ger.)

100. W. Schütz, On the Natural Width and Broadening of the D-Lines in Absorbing Na-Vapor, Caused by the Vapor Density and Pressure of Foreign Gases, Z. Phys. 45, 30. (Ger.)

101. B. Trumpy, on the Intensity and Width of Spectral Lines, Kgl. Nor. Vidensk. Selsk. Skr. No. 1. (Ger.)

106. H. D. Babcock, The Effect of Pressure on the Spectrum of the Iron Arc, Astrophys. J. 67,240 .

107. H. C. Burger \& P. H. van Cittert, Broadening of Spectral Lines by Self-Absorption, Z. Phys. 51, 638. (Ger.)

108. M. W. Zemansky, The Quenching of Mercury Resonance Radiation by Foreign Gases, Phys. Rev. 31, 812 . 
113. J. Frenkel, On the Quantum Mechanical Energy Transfer Between Atomic Systems, Z. Phys. 58, 794. (Ger.)

114. E. Gaviola, The Efficiency of Quenching Collisions and the Radius of the Exc1ted Mercury Atom, Phys. Rev. 33, 309.

115. R. Minkowski, Dependence of the Shape of Pressure Broadened Spectral Lines on the Foreign Gas, Z. Phys. 55, 16. (Ger.)

116. W. E. Pretty, Pressure Shifts in the Spectrum of Ionized Nitrogen, Proc. Phys. Soc., London 41, 442.

117. F. Walbel, Absorption Measurements in the Principal Series of Cs; Pressure Broadening by Its Own Vapor Pressure, Z. Phys. 53, 459. (Ger.)

122. K. Asagoe, Large Displacements in the Spectra of Ionlzed Nitrogen, Sc1. Rept. Phys. Inst. Univ. Tokyo $1,47$.

123. P. H. van Cittert, The Influence of the Slit Width on the Intensity Distribution in Spectral Lines, Z. Phys. 65, 547. (Ger.)

124. J. Frenkel, The Theory of Resonance Broadening of Spectral Lines, Z. Phys. $59,198$. (Ger.)

125. E. A. Neumann, On the Absorption of the Hg-Resonance Line Under the Influence of Foreign Gases, Z. Phys. 62, 368. (Ger.)

126. L. Schütz-Mensing, On the Theory of Correlation-Broadening of Spectral Lines, z. Phys. 61, 655. (Ger.)

127. V. Weisskopf \& E. Wigner, Calculation of the Natural Line width on the Basis of Dirac's Radiation Theory, Z. Phys. 63, 54. (Ger.)

128. V. Weisskopf \& E. Wigner, Concerning the Natural Linewidth in the Radiation of Harmonic Oscillators, Z. Phys. 65, 18. (Ger.)

129. M. W. Zemansky, Absorption and Collision Broadening of the Mercury Resonance Line, Phys, Rev. 36, 219. 
134. P. H. van Cittert, On the Influence of the Slitwidth on the Intensity Distribution in Spectral Lines, Z. Phys. 69, 298. (Ger.)

135. W. Finkelnburg, The Emission Spectrum of Compressed Hydrogen and Some Characteristics of Metallic Vapor Spectra at High Pressures, Z. Phys. $70,375$. (Ger.)

136. H. Hamada, On the Molecular Spectra of Mercury, Zinc, Cadmium, Magnesium, and Thallium, Phil. Mag. 12, 50 .

137. A. Jablonski, On the Impact Broadening of Spectral Lines and the Energy Transfer at Collisions, Z. Phys. 70, 723. (Ger.)

138. P. Kunze, Intensity, Broadening, Quenching and Satellites of the Hg-Resonance Line in the Presence of Noble Gases, Ann. Phys. (Leipzig) 8 , 500. (Ger.)

139. W. E. Pretty, Displacements of Certain Lines in the Spectra of Ionized Oxygen (O II, O III), Neon (Ne II) and Argon (A II), Proc. Phys. Soc., London 43, 279.

140. W. Weizel, The Broadening of the Resonance Atomic Line of Helium, Phys. Rev. 38 , 642 .

145. C. W. Allen, Broad Lines in the Arc Spectrum of Copper, Phys. Rev. 39, 42.

146. H. C. Burger \& P. H. van Cittert, True and Apparent Intensity Distributions in Spectral Lines, Z. Phys. $\underline{79}, 722$. (Ger.)

147. A. Imazato, Wave-Length Shifts of Certain Spectral Lines of Hg II, Sc1. Rep. Tokyo Bunrika Daigaku, Sect. A 1 , 179.

148. C. Kenty, On Radiation Diffusion and the Rapidity of Escape of Resonance Radiation from a Gas, Phys. Rev. 42, 823.

149. S. A. Korff, Width of the D Lines of Sodium in Absorption, Astrophys. J. 76, 124.

150. M. Kulp, Pressure Broadening and Pressure Shift of Spectral Lines, Z. Phys. $\underline{79}$, 495. (Ger.)

151. H. Margenau, Pressure Shift and Broadening of Spectral Lines, Phys. Rev. 40, 387.

152. B. Mrowka, on the Theory of Spectral Line Broadening Applying Quantum Mechanics, Ann. Phys. (Leipzig) 12, 753. (Ger.) 
153. V. Weisskopf, On the Theory of the Correlation-Width, Z. Phys. 77, 398. (Ger.)

154. V. Weisskopf, The Theory of Correlation Width and Collisional Damping, Z. Phys. 75, 287. (Ger.)

1933

159. M. Born, Emission, Absorption, Dispersion, "Optik," 421-455 (Springer-Verlag, Berlin). (Ger.)

160. H. C. Burger \& P. H. van Cittert, True and Apparent Intensity Distributions in Spectral Lines. II., Z. Phys, 81, 428. (Ger.)

161. H. Casimir, On the Line Width, Using the Theory of the Correspondence Principle, z. Phys. $\underline{81}, 496$. (Ger.)

162. C. Füchtbauer \& F. Gössler, Shift and Asymmetrical Broadening of Absorption Lines by Foreign Gases, Naturwissenschaften 21, 675. (Ger.)

163. C. Füchtbauer \& F. Gössler, Counteracting Asymmetries in the Broadening of Different Lines of a Series, Naturwissenschaften 21, 315. (Ger.)

164. H. Hamada, On the Continuous Spectrum of Sodium, Sci. Rep. Tokoku Imp. Univ., Ser. $1 \underline{22}, 31$.

165. H. Jensen, On Some Integrals, Which are Important for the Theory of Pressure Broadening of Spectral Lines, 2 . Phys. 80 , 448. (Ger.)

166. M. Kulp, Interpretation of Broadening Effects on Spectral Lines by Foreign Gases, z. Phys. 87,245 . (Ger.)

167. W. Lenz, On the Application of the Franck-Condon Rule for Line Broadening, $Z$. Phys. 83, 139. (Ger.)

168. W. Lenz, General Theory of Spectral Line Broadening, Z. Phys. 10 , 423. (Ger.)

169. H. Margenau, On the Theory of Broadening of Spectral Lines, Z. Phys. 66 , 523. (Ger.)

170. H. Margenau, Pressure Broadening of Spectral Lines, Phys. Rev. 43, 129.

171. H. Margenau, Asymmetries of Pressure Broadened Spectral Lines, Phys. Rev. $44,931$.

172. H. Margenau \& W. W. Watson, Pressure Effects of Foreign Gases on the Sodium DLines, Phys. Rev. $44,92$. 
173. J. C. McLennan \& R. Turnbull, The Broadening of the Ultraviolet Absorption Bands of Xenon under Pressure, Proc. Roy. Soc., Ser. A 139, 683.

174. W. W. Watson \& H. Margenau, Pressure Effects of Nitrogen on Potassium Absorption Lines, Phys. Rev. $44,748$.

175. V. We1sskopf, The Width of Spectral Lines in Gases, Physik. Z. 34, 1. (Ger.)

1934

180. E. Amaldi \& E. Segre, Effect of Pressure on the High-Lying Levels of the Alkal1s, Nuovo Cimento 11, 145. (Ital.)

181. E. Amald1 \& E. Segre, Effect of Pressure on H1gh Terms of Alkaline Spectra, Nature (London) $133,141$.

182. E. Fermi, On the Pressure Shift of High-Lying Terms of Spectral Series, Nuovo Cimento 11, 157. (Ital.)

183. Chr. Füchtbauer, On the Broadening and Shift of Absorption Lines, Phys1k. Z. 35 , 975. (Ger.)

184. C. Füchtbauer, On the Broadening and Shift of Absorption Lines, Z. Tech. Phys. 15, 551. (Ger.)

185. C. Füchtbauer \& F. Gössler, Sh1ft and Asymmetrical Broadening of Absorption Lines by Foreign Gases, Z. Phys. 87, 89. (Ger.)

186. C. Füchtbauer, P. Schulz, \& A. F. Brandt, Shift of High Series Lines of Sodium and Potassium by Foreign Gases. Calculation of the Cross Sections of Noble Gases Interacting with Slow Electrons, Z. Phys. 90, 403. (Ger.)

187. F. Gössler \& H. E. Kundt, Pressure Broadening and Pressure Shift for the Fourth Member of the Principal Series of Cesium, Z, Phys. 89, 63. (Ger.)

188. H. Kuhn, Pressure Shift and Broadening of Spectral Lines, Phil. Mag. 18, 987.

189. H. Kuhn \& F. London, Limitation of the Potential Theory of the Broadening of Spectral Lines, Phil. Mag. 18, 983.

190. E. Lau \& J. Johannesson, The Widths of Neon Lines, Physik. Z. 35, 457. (Ger.)

191. B. Pontecorvo, Effect of Hg Vapor on the High-Lying Terms of the Alkalis, Atti. Accad. Naz. Lincei, Cl. Sc1. Fis., Mat. Natur., Rend. 20, 105. (Ital.) 
192. F. K. Richtmyer, S. W. Barnes, \& E. Ramberg, The Widths of the L-Series Lines and of the Energy Levels of Au(79), Phys. Rev. 46, 843.

193. A. Vlasov, Observation of the Theory of the Broadening of Spectral Lines, Zh. Eksp. Teor. Fiz. 4,24 . (Russ.)

194. H. E. White, The Breadth of Spectrum Lines, "Introduction to Atomic Spectra," 418 (McGraw-Hill Book Company, Inc., New York).

195. T. Yuasa, Wave-Length Shifts of the Spectral Lines of Sb due to the Change of Pressure, Sc1. Rep. Tokyo Bunrika Daigaku, Sect. A 2, 57.

1935

200. C. Füchtbauer \& F. Gössler, Shift and Broadening of High Serles States of Cesium by Mercury and Xenon. Broadening of Potassium by Argon, Z. Phys. 93, 648. (Ger.)

201. C. Füchtbauer \& H. J. Reimers, Broadening and Shift of Cesium Lines by Krypton, Z. Phys. 95, 1. (Ger.)

202. C. Füchtbauer \& P. Schulz, The Influence of Foreign Gases on, the High Principal Series Members of Sodium, 2. Phys. 97, 699. (Ger.)

203. W. De Groot, Hot Emission and Absorption Spectrum of Hg-Vapor at Very High Pressures, Ingenieur (The Hague) 50, 92. (Dut.)

204. H. Margenau, Theory of Pressure Effects of Foreign Gases on Spectral Lines, Phys. Rev. 48,755 .

205. Ro Minkowsk1, Intensity Distribution in Pressure Broadened Spectral Lines, Z. Phys. 93, 731. (Ger.)

206. T. Z. Ny \& S. P. Choong, On the Nelghboring Absorption Bands of the Lines of the Principal Series of Rubidium and Cesium, J. Phys. Radium 6, 203. (Fr.)

207. C. Reinsberg, On the Theory of Pressure Shifts of Spectral Lines Near the Series Limit, Z. Phys. 93, 416. (Ger.)

208. T. Yuasa, Wave-Length Shifts of the Spectral Lines of Sn due to the Change of Pressure, Sc1. Rep. Tokyo Bunrika Daigaku, Sect. A $2,267$. 
213. V. S. Fursov \& A. A. Vlasov, The Theory of Broadening of Spectral Lines in a Homogeneous Gas, Phys. Z. Sowjetunion 10, 378. (Ger.)

214. E. Gora, On the Theory of Pressure Broadening of Spectral Lines, Proc. Indian Acad. Sci., Sect. A $\underline{3}, 272$.

215. G. F. Hull, Jr. Pressure Broadening of the Potassium Resonance Lines by Argon and N1trogen, Phys. Rev. 50, 1148.

216. C. V. Jackson, Wave-Length Standards in the First Spectrum of Krypton, Phil. Trans. Roy. Soc. London 236A, 1.

217. H. Margenau \& W. W. Watson, Pressure Effects on Spectral Lines, Rev. Mod. Phys. 8, pp. $22-53,398$.

218. A. UnsöId, Collisional Damping in the Solar Atmosphere, Z. Astrophys. $12,56$. (Ger.)

219. A. A. Vlasov \& V. S. Fursov, Theory of the Width of Spectral Lines in a Homogeneous Gas, Zh. Eksp. Teor. Flz. 6, 75l. (Russ.)

220. W. W. Watson \& G. F. Hull, Jr., Spectroscopic Investigation of Discharges at High Gas Pressure, Phys. Rev. $49,592$.

225. G. P. Balin, Broadening of the Hg-Resonance Line $2536.7 \AA$ by Increasing the Density of the $\mathrm{Hg}$-Vapor, Phys. Z. Sowjetunion 12, 701. (Ger.)

226. G. P. Balin, Broadening of the Resonance Line of Mercury $\lambda 2536.7 \AA$ by Increasing the Density of the Mercury Vapor, Zh. Eksp. Teor. Fiz. I, 1382. (Russ.)

227. L. Grillet, Broadening of the Green Line (5461 § Hg) in Vapor Arcs of Mercury Under High Pressure, C. R. H. Acad. Sc1. 204, 426. (Fr.)

228. D. S. Hughes \& P. E. Lloyd, Pressure Effects of Homogeneous K Vapor in Absorption, Phys. Rev. 52, 1215 .

229. G. F. Hull, Jr. Temperature Shift of the Potassium Resonance Lines, Phys. Rev. 51, 572 .

230. A. Jablonski, On the Quantum Mechanical Treatment of Line Broadening, Acta Phys. Pol. 6, 371. (Ger.) 
231. H. Kuhn, Pressure Broadening of Spectral Lines and van der Waals Forces I--Influence of Argon on the Mercury Resonance Line, Proc. Roy. Soc., Ser. A $158,212$.

232. H. Kuhn, Pressure Broadening of Spectral Lines and van der Waals Forces II--Continuous Broadening and Discrete Bands in Pure Mercury Vapour, Proc. Roy. Soc., Ser. A 158,230 .

233. H. Kuhn, Pressure Shift of Spectral Lines, Phys. Rev. 52, 133.

234. H. Margenau \& W. W. Watson, Pressure Shifts of Krypton Lines, Phys. Rev. $\underline{52}, 384$.

235. T. Z. Ny \& S. Y. Ch'en, The Displacement of Principal Series Lines of Rubidium by the Addition of Rare Gases, Phys. Rev. 51, 567.

236. T. Z. Ny \& S. Y. Ch'en, Pressure Effects of Rare Gases on the Second Doublet of Rubidium Principal Series, Phys. Rev. 52, 1158.

237. W. M. Preston, The Modification of Spectral Lines by Very Close Collisions, Phys. Rev. 51, 298.

238. C. Reinsberg, On the Theory of the Broadening of Lines of a Spectral Serles by Fore1gn Gases, Z. Phys. 105, 460. (Ger.)

1938

243. C. Füchthauer \& G. Heimann, On the Broadening and Shift of Higher Serles Lines of Sodium Caused by Cesium Vanor, Z. Phys. 110, 8. (Ger.)

244. H. Horodniczy \& A. Jablonski, Temperature Influence on the Pressure Broadening of Spectral Lines, Nature (London) 142, 1122.

245. W. V. Houston, Resonance Broadening of Spectral Lines, Phys. Rev. $54,884$.

246. A. Jablonsk1, On the Quantum Mechanical Treatment of Spectral Line Broadening, Acta Phys. Pol. , $^{196 .(G e r .)}$

247. T. Z. Ny \& S. Y. Ch'en, Pressure Shifts of the High Terms of the Absorption Series of $\mathrm{Na}, \mathrm{Rb}$, and $\mathrm{Cs}$ Produced by Hydrogen and N1trogen, Phys. Rev. 54, 1045.

248. T. Z. Ny \& S. Y. Ch'en, Absorption Bands of Rubidium and Cesium in the Presence of Foreign Gases, J. Phys. (Paris) 9, 169. (Fr.)

249. A. Pannekoek, The Hydrogen Lines Near the Balmer Limit, Mon. Not1c. Roy. Astron. Soc. $\underline{98}, 694$. 
250. C. Reinsberg, Quantum Mechanical Calculation of the Pressure Effects Encountered by Spectral Lines, 2. Phys. 111, 95. (Ger.)

251. R. Rompe \& P. Schulz, The Widths of Spectral Lines in Hg High Pressure Discharge, Z. Phys. 108, 654. (Ger.)

252. H. A. Rühmkorf, On the Resonance- and Foreign Gas Broadening in the Wings of the Hg-Resonance Line at 2537 凡, Ann. Phys. 33, 21. (Ger.)

253. P. Schulz, Widths and Shifts of Spectral Lines in the Hg-High Pressure Discharge, 2. Tech. Phys. 19, 585. (Ger.)

254. P. Schulz, Dependence of Width and Position of Spectral Lines on Presence of Gases, Physik. Z. 39, 412. (Ger.)

255. P. Schulz, Widths and Shifts of Spectral Lines in a Hg High Pressure Discharge, Physik. Z. 39, 899. (Ger.)

260. P. Budini, On the Broadening and Displacement of Spectral Lines, Nuovo Cimento 16, 86. (Ital.)

261. J. S. Foster \& A. V. Douglas, Stark Effect in B Stars, Mon. Notic. Roy. Astron. Soc. 99, 150 .

262. Chr. Füchtbauer \& G. Häusler, Density Dependence of the Shift of High Series Members in Alkalis, When Broadened by Foreign Gases, Naturwissenschaften 27, 658. (Ger.)

263. C. Füchtbauer \& W. von Heesen, Broadening and Shift of Median and Higher Series Members of Potassium Caused by Helium at High Pressure, 2. Phys. 113, 323. (Ger.)

264. V. Fursov \& A. Vlassov, The Breadth of Spectral Lines at Large Densities of a Homogeneous Gas, J. Phys. (USSR) 1, 335.

265. H. Horodniczy \& A. Jablonsk1, Influence of Temperature on the Pressure Broadening of Spectral Lines, Nature (London) 144, 594.

266. D. R. Inglis \& E. Teller, Ionic Depression of Series Limits in One-Electron Spectra, Astrophys. J. 90, 439 .

267. A. Jablonsk1, Comments to My Paper: On the Quantum Mechanical Treatment of Line Broadening II, Acta Phys. Pol. 8 , 71. (Ger.) 
268. L. Spitzer, Jr., Stark-Effect Broadening of Hydrogen Lines II. Observable Profiles, Phys. Rev. $\underline{56}, 39$.

269. L. Spitzer, Jr., Stark-Effect Broadening of Hydrogen Lines I. Single Encounters, Phys. Rev. 55, 699.

270. A. A. Vlasov \& V. S. Fursov, The Width of Spectral Lines of a Homogeneous Gas at High Densities, Zh. Eksp. Teor. Fiz. , 783. (Russ.)

\section{0}

275. G. Burkhardt, On the Impact Broadening and Statistical Broadening of Spectral Lines, Z. Phys. 115, 592. (Ger.)

276. S. Y. Ch'en, Broadening, Asymmetry and Shift of Rubidium Resonance Lines under Different Pressures of Helium and Argon up to 100 Atmospheres, Phys. Rev. 58, 1051.

277. S. Y. Ch'en, Pressure Effects of Homogeneous Rubidium Vapor on Its Resonance Lines, Phys. Rev. $\underline{58}, 884$.

278. S. Y. Ch'en \& C. S. Pao, Pressure Effects of Hydrogen and Nitrogen on the Second Doublet of Rb Principal Series, Phys. Rev. 58, 1058.

279. Chr. Füchtbauer \& G. Häusler, Density Dependence of the Shift of High Series Members of Alkalis, Broadened by Forelgn Gases, Z. Tech. Phys. 2l, 307. (Ger.)

280. C. Füchtbauer \& G. Häusler, Density Dependence of the Shift of Higher Alkali Series Lines Caused by Foreign Gases, Physik. Z. 41, 555. (Ger.)

281. C. J. Humphreys, Note on the Effect of Pressure on the Wavelengths of the International Secondary Standards in the First Spectrum of Iron, J. Res. Nat. Bur. Stand., Sect. A $24,389$.

282. A. Jablonski, Pressure Broadening of Spectral Lines, Physica (Utrecht) $\mathbf{7}, 541$.

283. L. Spitzer, Jr., Impact Broadening of Spectral Lines, Phys. Rev. 58, 348.

$$
1941
$$

288. V. L. Ginsburg, On the Broadening of Rayleigh Scattering Lines Depending Upon Pressure, C. R. (Dokl.) Acad. Sci. URSS $\underline{30}, 399$.

289. L. Jenckel \& H. Kopfermann, A Method to Observe Very Small Stark-Effects, Z. Phys. 117, 145. (Ger。) 
290. E. Lindholm, The Theory of Broadening of Spectral Lines, Ark. Mat., Astron. Fys. 28B, 1. (Ger.)

291. R. Rompe \& P. Schulz, On the Resonance Broadening of Hg-Lines, Z. Phys. $118,269$. (Ger.)

292. K. Watanabe, Resonance Broadening of the Sodium D Lines, Phys. Rev. 59, 151.

297. C. Gregory, Resonance Broadening of Caesium, Phys. Rev. 61; 465.

302. P. Schulz, On the Widths of Spectral Lines in Gaseous Discharges, Especially in Hg-High Pressure Discharge, Tech.-W1ss. Abh. Osram-Ges. $\underline{5}, 88$. (Ger.)

303. A. Unsöld, On the Theory of Pressure Broadening and Shifts of Spectral Lines, Vierteljahrsschr. Astron. Ges. 78,213 . (Ger.)

1944

308. S. Y. Ch'en, New Absorption Band of Alkalis in the Presence of Foreign Gases, Phys. Rev. 65, 338.

309. M. K. Krogdahl, The Interaction of a Proton and a Hydrogen Atom in its Excited States, Astrophys. J. 100,311 .

310. M. K. Krogdahl, The Interaction of a Proton and a Helium Atom in 1ts Excited States, Astrophys. J. $\underline{100}, 333$.

315. D. K. Bhattacharyya \& J. Murari, Study of the Absorption Spectra of Mercury Vapour with Varying Temperature and Pressure, Indian J. Phys. 19, 20.

316. A. Jablonski, General Theory of Pressure Broadening of Spectral Lines, Phys. Rev. $\underline{68}, 78$.

317. M. K. Krogdahl, The Interaction of a Proton and a Helium Atom in 1ts Exclted States. II, Astrophys. J. 102, 64. 
318. J. H. Van Vleck \& V. F. Welsskopr, On the Shape of Collision-Broadened Lines, Rev. Mod. Phys. 17, 227.

319. T. Y. Wu, Absorption Bands of Alkal1 Atoms in the Presence of Forelgn Gases: Remarks on Chen's Paper, Chinese J. Phys. (Peking) $6,17$.

324. H. M. Foley, The Pressure Broadening of Spectral Lines, Phys. Rev. 69, 616.

325. H. Fröhlich, Shape of Collision-Broadened Spectral Lines, Nature (London) 157, 478.

326. B. Kleman \& E. Lindholm, The Broadening of Na Lines by Argon, Ark. Mat., Astron. Fys. B 32, No. 10, 1 .

327. E. Lindholm, Pressure Broadening of Spectral Lines, Ark. Mat., Astron. Fys. A 22 , No. 17,1 .

1947

332. J. D. Craggs \& W. Hopwood, Ion Concentrations in Spark Channels in Hydrogen, Proc. Phys. Soc., London, Sect. A $\underline{59}, 755$.

333. V. I. Danilova, The Width of the Lithium Line at $4132 \AA$ and the Electron Concentration in the Arc Discharge, Izv. Akad. Nauk SSSR, Ser. F1z. 11, 252. (Russ.)

334. T. Holstein, Imprisonment of Resonance Radiation in Gases, Phys. Rev. 72, 1212.

335. H. C. van de Hulst \& J. J. M. Reesinck, Line Breadths and Volgt Profiles, Astrophys. J. 106, 121 .

336. M. K. Krogdahl, on the Broadening of Neutral Helium Lines in Stellar Spectra, Astrophys. J. 105, 327.

1948

341. S. Y. Ch'en, Violet Asymmetry of Potassium Resonance Lines Under High Rubidium Vapor Pressure, Phys. Rev. 13, 1470.

342. H. M. Foley, The Theory of the Pressure Broadening of Spectral Lines: A Reply, Phys. Rev. $\underline{73}, 259$. 
343. A. Jablonski, On the Phase Shift Approximation in the Theory of Pressure Broadening of Spectral Lines, Phys. Rev. 13, 258.

344. Yu. A. Kushnikov, Broadening of the 2536.5 \& Line and Quas1-Molecular Development in Systems of Mercury-Molecular Gases, Izv. Akad. Nauk SSSR, Ser. Fiz. 12, 366. (Russ.)

345. A. R. Stokes, A Numerical Fourier-analysis Method for the Correction of Widths and Shapes of Lines on X-ray Powder Photographs, Proc. Phys. Soc., London 61, 382.

350. P. W. Anderson, Pressure Broadening in the Microwave and Infra-Red Regions, Phys. Rev. 16,647 .

351. H. Bartels, Line Emission in Inhomogeneous Layers, Z. Phys. 126, 108. (Ger.)

352. H. Bartels, Line Emission in Inhomogeneous Layers, Z. Phys. 125, 597. (Ger.)

353. S. Y. Ch'en \& C. S. Chang, The Absorption Spectrum of Dense Lithium Vapor, Phys. Rev. 15,81 .

354. O. B. Firsov, Width of Atomic Energy Levels at High Principal Quantum Numbers, Dokl. Akad. Nauk SSSR 69,357 . (Russ.)

355. G. S. Kastha, On the Structure of the Resonance Line of $\mathrm{Hg}$ Filtered Through $\mathrm{Hg}$ Vapour, Indian J. Phys. 23, 247.

356. J. H. Van Vleck \& H. Margenau, Collision Theories of Pressure Broadening of Spectral Lines, Phys. Rev. $16,1211$.

366. H. Bartels, A New Method of Temperature Measurement in High Temperature Arc Columns, Z. Phys. 128, 546. (Ger.)

367. L. M. Biberman \& I. M. Gurevich, Absorption of Resonance Radiation and the Production of Metastable Atoms in Mercury Vapor, Zh. Eksp. Teor. Fiz. 20, 108. (Russ.)

368. T. Holstein, Pressure Broadening of Spectral Lines, Phys. Rev. 79, 744.

369. G. Joos \& A. Saur, Pressure Broadening, and Pressure Shifts of Spectral Lines, "Zahlenwerte und Funktionen," $\underline{1}, 256$, (Ed. Landolt-Boernstein, Springer-Verlag, Berlin). (Ger.) 
370. S. L. Mandel'shtam \& N. N. Sobolev, Broadening of Spectral Lines Under the Action of Ions and Electrons, Zh. Eksp. Teor. Fiz. 20, 323. (Russ.)

371. M. S. Paterson, Calculation of the Correction for Instrumental Broadening in X-ray Diffraction Lines, Proc. Phys. Soc., London, Sect. A 63, 477.

372. St. Robin \& J. Romand, Study of the Perturbation of the $1469 \AA$ Line of Xenon by Argon of Pressures up to $650 \mathrm{~kg} / \mathrm{cm}^{2}$, C. R. H. Acad. Sc1. 231, 1455. (Fr.)

373. M. M. Sushchinski1, The Shape and Width of Lines and Their Influence on the Measurement of Intensity, Tr. Fiz. Inst., Akad. Nauk SSSR 5, 210. (Russ.)

1951

383. H. Edels \& J. D. Craggs, Balmer Line Widths in Hydrogen Arcs, Proc. Phys. Soc., London, Sect. A 64 , 574 .

384. O. B. Firsov, The Influence of a Foreign Gas on the Absorption Spectrum Near the Series Limit, Zh. Eksp. Teor. Fiz. 2l, 634. (Russ.)

385. O. B. Firsov, The Influence of a Foreign Gas on the Absorption Spectrum Near the Series Limit, Zh. Eksp. Teor. Fiz. 21, 627. (Russ.)

386. T. Holstein, Imprisonment of Resonance Radiation in Gases. II, Phys. Rev. 13 , 1159.

387. K. Lang, Resonance Broadening of Neon Spectral Lines, Acta Phys. Austr. 5 , 376.

388. H. Margenau, Statistical Theory of Pressure Broadening, Phys. Rev. 82, 156.

389. J. Robin \& St. Robin, Study of the Perturbation of the 2537 \& Line of Mercury by Argon, Nitrogen, and Compressed Hydrogen, C. R. H. Acad. Sc1. 233, 928.

$(\mathrm{Fr}$.

390. J. Robin \& St. Robin, Displacement of Absorption Lines of Rubidium and Potassium Perturbed by Argon, Helium and Nitrogen Under Approximately 1000 Atm. of Pressure, C. R. H. Acad. Sci. 233, 1019. (Fr.)

391. St. Robin, J. Robin, \& B. Vodar, Experimental Study of the Perturbation of the D Lines of Sodium by Nitrogen and Arpon up to $1000 \mathrm{~kg} / \mathrm{cm}^{2}$ Pressure, C. R. H. Acad. Sci. 232, 1754. (Fr.)

392. N. N. Sobolev, E. M. Mezhericher, \& G. M. Rodin, Dependence of the Intensity of Spectral Lines on the Concentration of the Element in the Flame, Zh. Eksp. Teor. Fiz. 21, 350. (Russ.) 
402. P. W. Anderson, A Method of Synthesis of the Statistical and Impact Theories of Pressure Broadening, Phys. Rev. 86 , 809.

403. E. Arnous, General Theory of Damping Phenomena for Non-Stationary Processes. III. $\mathrm{e}^{4}$ Correction of Line Widths, Helv. Phys. Acta 25, 631. (Ger.)

404. R. Bergeon, St. Robin, \& B. Vodar, Statistical Theory of the Effect of Pressure on Spectral Lines, C. R. H. Acad. Sci. 235, 360. (Fr.)

405. E. D. Clayton \& S. Y. Ch'en, Pressure Effects of Argon and Helium on the Resonance Lines of Silver, Phys. Rev. 85, 68.

406. C. de Jager \& L. Neven, The Interpretation of the Observed Hydrogen Lines in the Infrared Solar Spectrum, Kon. Acad. Wetensch. Amsterdam, Proc. 55B, 153.

407. G. Jürgens, Temperature and Electron Density in a Water-Stabilized Arc, Z. Phys. 134, 21 . (Ger.)

408. K. Lang, The Spectral Intensity Distribution of a Ne I Line at Different Discharge Conditions, Sitzungsber. Akad. Wiss. Wien, Math.-Naturwiss. K1., Abt. $2 \mathrm{~A} 161,65$. (Ger.)

409. G. N. Plass \& D. Warner, Pressure Broadening of Absorption Lines, Phys. Rev. 86, 138 .

410. St. Robin, Study of the Perturbation of Spectral Lines Under a Pressure of Approximately $1200 \mathrm{Kg} / \mathrm{cm}^{2}$, J. Chim. Phys. Physicochim. Biol. 49, 1. (Fr.)

411. C. Weniger \& L. Herman, The Effect of the Electric Field on the Shape of the Lines of $\mathrm{H} \mathrm{I}\left(2^{2} \mathrm{P}^{0}-\mathrm{n}^{2} \mathrm{D}\right)$ Emitted in Radiative Recombination, C. R. H. Acad. Sci. 235, 1020. (Fr.)

421. E. Arnous \& W. Heitler, Theory of Line-Breadth Phenomena, Proc. Roy. Soc., Ser. A $220,290$.

422. H. Bartels, The Influence of Induced Transitions and Strong Continuous Emission on the Line Profile with Inhomogeneous Layers, Z. Phys. 136, 411. (Ger.)

423. S. Bloom \& H. Margenau, Quantum Theory of Spectral Line Broadening, Phys. Rev. 90, 791 . 
424. S. Y. Ch'en \& D. A. Kohler, Broadening and Shift of the Second Doublet of the Rubidium Absorption Series Under Different Pressures of Argon and Helium, Phys. Rev. 90, 1019 .

425. R. H. Dicke, The Effect of Collisions Upon the Doppler Width of Spectral Lines, Phys. Rev. $199,472$.

426. G. Elste, Unfolding of Spectral Lines by Volgt Functions, Z. Astrophys. 33 , 39. (Ger.)

427. G. S. Kastha, Change of Frequency of Resonance Lines of Sodium During Transmission Through Sodium Vápour, Ind1an J. Phys. 27, 67.

428. K. Lang, Line Profiles in Gaseous Discharges, Spectrochim. Acta 5, 491. (Ger.)

429. J. K. McDonald, Hydrogen Absorption Lines in the Spectra of B-Type Stars, Publ. Dominion Astrophys. Observ., Victoria, B. C. 9, 269.

430. S. S. Penner \& R. W. Kavanagh, Radiation from Isolated Spectral Lines with Combined Doppler and Lorentz Broadening, J. Opt. Soc. Amer. 43, 385.

431. I. I. Sobel'man, The Width of Lines of Raylelgh Scattering in a Gas, Dokl. Akad. Nauk SSSR 18 , 653. (Russ.)

432. I. I. Sobel'man \& L. A. Vainshtein, Broadening of Spectral Lines by the Quadrupole Stark Effect, Dokl. Akad. Nauk SSSR 90, 757. (Russ.)

433. J. Tomiser, Resonance Broadening of the Na-Resonance Lines, Acta Phys. Austr. $\underline{8}$, 198. (Ger.)

1954

443. P. W. Anderson, A Mathematical Model for the Narrowing of Spectral Lines by Exchange or Motion, J. Phys. Soc. Jap. 9, 316.

444. R. Bergeon, Statistical Theory of the Effect of Pressure on Spectral Lines, C.R. H. Acad. Sc1. 238, 2507. (Fr.)

445. R. Cayrel, Theory of the Stark Effect in a Nonuniform Field. Case for Atoms Other than Hydrogen, C. R. H. Acad. Sc1. 239, 1601. (Fr.)

446. R. H. Dicke, Coherence in Spontaneous Radiation Processes, Phys. Rev. $93,99$.

447. P. Gerthsen, Experimental Investigations on the Broadening of Resonance Terms, $Z$. Phys. 138, 515. (Ger.) 
448. H. R. Griem, Stark Effect Broadening of Balmer Lines by a Large Electron Density, Z. Phys. 137,280 . (Ger.)

449. W. Heitler, Theory of the Natural Line Breadth, "The Quantum Theory of Radiation," 3rd Ed., 181-189 (Clarendon Press, Oxford).

450. W. D. Henkel, On the Stark Effect Broadening of H1gh Balmer Lines, Z. Phys. 137, 295. (Ger.)

451. L. Huldt \& E. Knall, Pressure Broadening of the Yellow Na I Lines In an Acetylene Flame, Z. Naturforsch. A $\underline{9}, 663$. (Ger.)

452. R. Kubo, Note on the Stochast1c Theory of Resonance Absorption, J. Phys. Soc. Jap. $\underline{9}, 935$.

453. J. Robin, Experimental Study of the Perturbation of the 2537 \& Line of Mercury by Hydrogen and Helium Up to $1450 \mathrm{~kg} / \mathrm{cm}^{2}$ Pressure, C. R. H. Acad. Sc1. 238, 1491. (Fr.)

454. I. I. Sobel'man, On Statistical Relations and the Theory of Spectral Line Impact Widths, Dokl. Akad. Nauk SSSR $\underline{98}$, 43. (Russ.)

455. M. Takeo \& S. Y. Ch'en, Theory of Fine Structure Pressure Broadening of Spectral Lines, Phys. Rev. 93, 420.

456. J. Tomiser, Resonance Broadening of the Inverse Zeeman Components of the Na-DLines, Acta Phys. Austr. 8 , 276. (Ger.)

457. J. Tomiser, Resonance Broadening of the Rb Lines $\lambda=7800.23 \AA$ and $\lambda=7947.60 \AA$ and Their Zeeman Components in Absorption, Acta Phys. Austr. $\underline{9}$ 18. (Ger.)

458. J. Tomiser, Resonance Broadening of the Potassium Lines at 7664.91 \& and 7698.98 \& and Their Zeeman Components in Absorption, Acta Phys. Austr. $\mathbb{8}^{3} 323$. (Ger.)

1955

468. R. Bergeon \& B. Vodar, Statistical Theory of the Effect of Pressure on Spectral Lines, C. R. H. Acad. Sc1. 240, 172. (Fr.)

469. L. Blitzer, Shifts and Asymmetries in Condensed Spark Spectra of Electroplated Electrodes, J. Opt. Soc. Amer. $\underline{45}, 564$.

470. R. N. Bracewell, A Method of Correcting the Broadening of X-ray Line Profiles, Aust. J. Phys. $\underline{8}, 61$. 
471. A. A. Broyles, Stark Fields from Ions in a Plasma, Phys. Rev. 100, 1181.

472. S. Y. Ch'en \& W. J. Parker, Pressure Broadening of the Blue Cesium Doublet Produced by Argon and Helium, J. Opt. Soc. Amer. 45, 22.

473. F. N. Edmonds, Jr., Noncoherent Scattering due to Collisions. I. Zanstra's Ratio of Coherent to Uncorrelated Noncoherent Scattering, Astrophys. J. $121,418$.

474. E. P. Gross, Shape of Collision-Broadened Spectral Lines, Phys. Rev. 97 , 395.

475. G. Hepner, Contours of Paschen Lines of Atomic Hydrogen, C. R. H. Acad. Sci. 241, 380. (Fr.)

476. M. Johnson, Problems of Stark Broadening for Experimental and Astronomical Spectra Liable to Self-Absorption, Mon. Not1c. Roy. Astron. Soc. 115, 15.

477. B. Kivel, Electron Broadening and Shift of Spectral Lines of Helium, Phys. Rev. 98, 1055 .

478. B. Kivel, S. Bloom, \& H. Margenau, Electron Impact Broadening of Spectral Lines, Phys. Rev. 98, 495 .

479. W. Lochte-Holtgreven, I'he Thermally Excited Plasma in the Column of an Electric Arc, Appl. Sci. Res., Sect. B 5, 182.

480. H. Margenau \& B. Kivel, Effects of Electron Collisions on the Width of Spectral Lines, Phys. Rev. $\underline{98}, 1822$.

481. H. Margenau \& R. Meyerott, Quantum Theorv of Line Broadening by an Ionic Plasma, Astrophys. J. 121, 194.

482. R. E. Meyerott \& H. Margenau, Line Broadening by Electrons: Validity of Simple Theories, Phys. Rev. 99, 1851.

483. H. Moser, The Instrumental Line Profile in Prism Spectrographs, Z. Phys. 140, 36. (Ger.)

484. A. Unsöld, "Physik der Sternatmosphären," 2nd Ed. (Springer-Verlag, Berlin). (Ger.)

485. S. Weniger \& R. Herman, Broadening of $\mathrm{Na} I$ Lines Under the Influence of the Intermolecular Stark Effect, C. R. H. Acad. Sc1. 240, 1876. (Fr.)

\section{6}

495. P. W. Anderson \& J. D. Talman, Pressure Broadening of Spectral Lines at General Pressures, Bell Telephone System, Technical Publication No. 3117. 
496. N. R. Batarchukova \& G. B. Dubrovski1, The Effect of the Change in Pressure of Argon in an Electrodeless Discharge on the Reproducibility of the Wave Length of the Red Line of Call4, Opt. Spektrosk. I, 330. (Russ.)

497. S. Y. Ch'en, R. B. Bennett, \& O. Jefimenko, Absorption Bands of Rubidium Due to the Presence of Foreign Gases, J. Opt. Soc. Amer. 46, 182.

498. F. N. Edmonds, The Debye-Huckel Effect and Statistical Theories for Collision Broadening, Astrophys. J. 123, 95.

499. G. Elste, J. Jugaku, \& L. H. Aller, Theoretical Line Intensities and the Spectrum of Tau Scorpi1, Publ. Astron. Soc. Pac. 68, 23.

500. R. G. Fowler, Broadening of Spectral Lines, "Handbuch der Physik," Vol. 22, $211-$ 216 (Ed. S. Fluegge, Springer-Verlag, Berlin).

501. V. F. Kitaeva \& N. N. Sobolev, The Shape and Width of Spectral Lines in a Constant Current Electric Arc, Opt. Spektrosk. I, 302.

502. A. Michels \& H. De Kluiver, The Influence of Helium on the 2536.52 \& Line of Mercury, Physica (Utrecht) 22, 919.

503. J. Robin, R. Bergeon, L. Galatry, \& B. Vodar, Perturbation of Electronic Resonance Spectra by Foreign Gases Under High Pressure, Discuss. Faraday Soc. No. 22, 30.

504. J. Robin \& B. Vodar, Observation of Two "Satellite Bands" Near the Resonance Lines of Potassium Under a Pressure of Argon of $1200 \mathrm{Atm}$. and of Mercury Under a Pressure of Argon and Nitrogen uo to 6000 Atm., C. R. H. Acad. Sci. 242, 2330. (Fr.)

505. St. Robin \& Si. Robin, Atomic Spectral Lines for Electrically Neutral Particles Perturbed by Pressure, J. Phys. Radium 17, 143. (Fr.)

506. I. I. Sobel'man, Broadening of Spectral Lines due to Collisions with Electrons, Opt. Spektrosk. I, 617. (Russ.)

507. S. Weniger \& R. Herman, Contour of the Lines of a Sodium Arc Broadened by the Intermolecular Stark Effect, J. Phys. Radium 17, 37. (Fr.)

517. H. Bartels \& R. Beuchelt, On the Typical Appearance of the Spectrum of Dense Plasmas, Z. Phys. 149, 608. (Ger.)

518. P. Bogen, Experimental Verification of the Holtsmark Theory of Line Broadening, z. Phys. 149, 62. (Ger.) 
519. R. G. Breene, Jr., Line Shape, Rev. Mod. Phys. 29, 94.

520. R. Brout, Width and Shift of Spectral Lines Due to Dissipative Interaction, Phys. Rev, 107, 664.

521. A. A. Broyles, Fields on Plasma Ions by Collective Coordinates, Phys. Rev. 105, 347.

522. S. Y. Ch'en \& O. Jefimenko, Absorption Bands of Rubidium in the Presence of Hydrocarbons, J. Chem. Phys. 26, 256.

523. S. Y. Ch'en \& M. Takeo, Broadening and Shift of Spectral Lines Due to the Presence of Foreign Gases, Rev. Mod. Phys. 29, 20.

524. G. Ecker, Balmer Line Profiles Influenced by Electron and Ion Impacts, Z. Naturforsch. A 12 , 517. (Ger.)

525. G. Ecker, Departures of the Balmer Lines from the Holtsmark Profile in a Plasma, Z. Phys. 149, 254. (Ger.)

526. G. Ecker, Line Broadening in High Density Plasma, Z. Naturforsch. A $12,346$. $($ Ger.)

527. J. A. Galt \& H. L. Welsh, Selective Reflection from Mercury Vapor at High Pressures, Can. J. Phys. 35, 98.

528. J. A. Galt \& H. L. Welsh, Influence of Foreign Gases at High Pressures on the Selective Reflection from Mercury Vapor, Can. J. Phys. 35, 114.

529. G. Hepner, Experimental Study of the Profile of the Lines of the Paschen Serles of the Hydrogen Atom, Emitted in a Condensed Discharge, Spectrochim. Acta $11,356$. (Fr.)

530. L. Herman, S. Weniger, \& R. Herman, Broadening of the Lines of a Sodium Arc Under the Influence of the Intermolecular Stark Effect, Spectrochim. Acta 11,333 . (Fr.)

531. E. Hinnov \& H. Kohn, Optical Cross Sections from Intensity-Density Measurements, J. Opt. Soc. Amer. $47,156$.

532. H. Hoffman \& O. Theimer, Shielding, Correction to Holtsmark's Theory of Line Broadening, Astrophys. J. 126, 595.

533. O. Jefimenko \& S. Y. Ch'en, Modifications of the Cs Absorption Spectrum Due to Interatomic Interactions, J. Chem. Phys. 26, 913. 
534. O. Jefimenko \& W. Curtis, Modifications of the Rb Emission Spectrum due to Atomic Interactions, J. Chem. Phys. 27, 953.

535. A. C. Kolb, Theory of Hydrogen Line Broadening in High-Temperature Partially Ionized Gases, AFOSR-TN-57-8, ASTIA Document No. AD 115 040, Engineering Research Institute, The University of Michigan.

536. K. Lang, Pressure Broadening in the Ar I Spectrum, Acta Phys. Austr. $11,76$. (Ger.)

537. H. Margenau \& M. B. Lewis, Stark Effects in Line Broadening, Phys. Rev. $106,244$.

538. M. A. Mazing \& S. L. Mandel'shtam, Broadening and Shift of spectral Lines in Gas-Discharge Plasma, Opt. Spektrosk. $2,276$. (Russ.)

539. A. Michels, H. De Kluiver, \& B. Castle, The Influences of Argon and Neon on the $2536.52 \AA$ Line of Mercury, Physica (Utrecht) $23,1131$.

540. J. Robin, Study Under High Argon Pressure of the Resonance Lines of the Potassium Spectrum and Satellite Bands Appearing Near the Resonance Lines of $\mathrm{K}$, $\mathrm{Rb}$, and Cs, J. Phys. Radium 18, 639. (Fr.)

541. S1. Robin \& St. Robin, Perturbation of the Resonance Line $1850 \AA$ of Mercury by $\mathrm{H}_{2}, \mathrm{~N}_{2}$, Ar and Xe Under Pressure, C. R. H. Acad. Sc1. 245, 1056. (Fr.)

542. Si. Robin \& St. Robin, Bands Induced by Pressure Near the Resonance Lines of Mercury, in Fmission, in the Presence of Rare Gases, J. Phys. Radium 18, 411. (Fr.)

543. Yu. A. Sherstkov \& M. M. Noskov, Absorption of Light in an Arc of Constant Current, Izv. Vyssh. Ucheb. Zaved., Fiz. No. 1, 192. (Russ.)

544. I. I. Sobel'man, Electron Broadening of Spectral Lines, Sov. Phys. - JETP 4 , 453.

545. I. I. Sobel'man, On the Theory of the Linewidth of Atoms, Fortschr. Phys. $5,175$. (Ger.)

546. N. N. Sobolev, The Shape and Width of Spectral Lines Emitted by a Flame and by a Direct-Current Arc, Spectrochim. Acta $11,310$. 
556. M. Ardit1 \& T. R. Carver, Frequency Shift of the Zero-Fleld Hyperfine Splitting of $\mathrm{Cs}^{133}$ Produced by Various Buffer Gases, Phys. Rev. 112, 449.

557. E. Aulehla \& L. Herman, Stark Effect Constants Deduced from Metallic Lines Broadened by an Intermolecular F1eld, C. R. II. Acad. Sc1. 2ㄴ6, 1676. (Fr.)

558. M. Baranger, Problem of Overlapping Lines in the Theory of Pressure Broadening, Phys. Rev. 111, 4.94 .

559. M. Baranger, Simplified Quantum-Mechanical Theory of Pressure Broadening, Phys. Rev. 111, 481 .

560. M. Baranger, General Impact Theory of Pressure Broadening, Phys. Rev. $112,855$.

561. E. C. Beaty, P. L. Bender, \& A. R. Chi, Narrow Hyperfine Absorption Lines of $\mathrm{Cs}^{133}$ In Various Buffer Gases, Phys. Rev. 112, 450.

562. P. L. Bender, E. C. Beaty, \& A. R. Chi, Optical Detection of Narrow Rb 87 Hyperfine Absorption Lines, Phys. Rev. Lett. 1 , 311.

563. R. Bergeon, Perturbation of Atomic Spectral Lines by Forelgn Gas Pressure, J. Rech. Cent. Nat. Rech. Sci., No. 44, 198. (Fr.)

564. A. A. Broyles, Calculation of Fields on Plasma Ions by Collective Coordinates, Z. Phys. 151, 187 .

565. C. D. Cooper \& M. Lichtenstein, Spectra of Argon, Oxygen, and Nitrogen Mixtures, Phys. Rev. 109, 2026.

566. P. J. Dickerman, The Determination of the Equilibrium Temperature of a Plasma, "Conference on Extremely High Temperatures," 77 (Ed. H. Fischer \& L. C. Mansur, John Wlley \& Sons, Inc., New York).

567. W. R. Hindmarsh, Pressure Shift and Broadening in the Resonance Line of Calcium, Proc. Phys. Soc., London $72,279$.

568. H. Hoffman \& O. Theimer, Shieldinf Correction to the Electrical Microfield in a Plasma and to Holtsmark's Theory of Line Broadening, Astrophys. J. 127, 477.

569. O. Jefimenko \& J. A. Gwinn, Absorption Spectrum of Rubidium in the Presence of Isomeric Hydrocarbons, J. Chem. Phys. 29, 148.

570. V. I. Kogan, On the Theory of the Broadening of Spectral Lines in a Plasma, Sov. Phys. - Dokl. $\underline{3}, 130$. 
571. V. I. Kogan, The Theory of the Broadening, of Spectral Lines in a Plasma, Izv. Akad. Nauk SSSR, Ser. Fiz. 22, 714. (Russ.)

572. A. C. Kolb \& H. R. Griem, Theory of Line Broadening in Multiplet Spectra, Phys. Rev. 111, 514 .

573. H. J. Kusch, Experimental Investigation of the Pressure Broadening of Fe I Lines by Hydrogen Atoms and Hydrogen Molecules, Z Astrophys. $45,1$. (Ger.)

574. M. Lewis \& H. Margenau, Statistical Broadening of Spectral Lines Emitted by Ions in a Plasma, Phys. Rev. 109, 842 .

575. S. Yu. Luk'yanov \& V. I. Sinitsyn, Spectroscopic Investigation of Intense Pulsed Discharges in Hydrogen, Sov. Phys. - JETP I, 587.

576. S. G. Rautian, Real Spectral Apparatus, Sov. Phys. - Usp. 1, 245.

577. H. Van Regemorter, On the Broadening of Hydrogen Lines by Electron Fields, C. R. H. Acad. Sc1. 246, 2737. (Fr.)

578. Si. Robin \& St. Robin, A Grating Spectropraph Study of the Pressure Perturbations of the Resonance Lines of Mercury in the Far Ultraviolet, Rev. Opt., Theor. Instrum. 37, 161. (Fr.)

579. I. I. Sobel'man, Some Problems in the Theory of the Widths of Spectral Lines, Tr. Fiz. Inst., Akad. Nauk SSSR 9, 313. (Russ.)

580. L. A. Vainshtein, V. K. Koloshnikov, M. A. Mazing, S. L. Mandel'shtam, \& I. I. Sobel'man, Broadening and Shift of Spectral Lines in Highly Ionized Plasma, Bull. Acad. Sc1. USSR, Phys. Ser. 22, 714.

581. H. Wulff, The Line Profile of Thermally Excited Helium Lines, Z. Phys. 150, 614. (Ger.)

591. V. N. Alyamovski1 \& V. F. Kitaeva, The Contour of the H Hydrogen Line Behind a Shock Wave in Argon, Opt. Spectrosc. (USSR) 6, 80.

592. L. W. Anderson, F. M. Pipkin, \& J. C. Baird, Jr., $N^{14}-N^{15}$ Hyperfine Anomaly, Phys. Rev. 116, 87 .

593. M. Baranger \& B. Mozer, Electric Field Distributions in an Ionized Gas, Phys. Rev. 115, 521. 
594. G. Breit \& M. H. Hull, Jr., Natural Line width for Transient Excitations, Astrophys. J. 129, 456.

595. V. M. Fain, On the Theory of the Coherent Spontaneous Emission, Sov. Phys. - JETP $\underline{9}, 562$.

596. H. R. Griem, A. C. Kolb, \& K. Y. Shen, Stark Broadening of Hydrogen Lines in a Plasma, Phys. Rev. 116, 4.

597. G. Hettner \& H. Wagner, Fourier Analysis of Electric Microfields in a Plasma, Ann. Phys. (Leipzig) 5, 405. (Ger.)

598. G. Hettner \& H. Wagner, Fourier Analysis of Electric Microfields in a Plasma, Ann. Phys. (Leipzig) 4, 89. (Ger.)

599. W. R. Hindmarsh, Collision Broadening, and Shift in the Resonance Line of Calcium, Mon. Not1c. Roy. Astron. Soc. 119, 11 .

600. W. R. Hindmarsh \& K. A. Thomas, Collision Shifts in the Argon Spectrum, Mon. Notic. Roy. Astron. Soc. $119,21$.

601. J. Jugaku, On the Abundance Ratio of Helium to Hydrogen in the Atmosphere of Tau Scorpli, Publ. Astron. Soc. Jap. 11, 161.

602. L. Klein \& H. Margenau, Theory of Pressure Effects on Alkali Doublet Lines, J. Chem. Phys. 30, 1556.

603. L. I. Maissel, Selective Pressure Broadening and the Stark Effect, Proc. Phys. Soc., London $74,97$.

604. S. L. Mandel'shtam \& M. A. Mazing, On Spectral Line Broadening in the Plasma, "Proceedings of the Eighth International Conference on Spectroscopy, Lucerne," 184-187 (H. R. Sauerländer \& Co., Aarau, Switzerland).

605. S. L. Mandel'shtam \& M. A. Mazing, Broadening and Shift of Spectral Lines in Gas Discharge Plasma, Bull. Acad. Sc1. USSR, Phys. Ser. 23, 1005.

606. H. Margenau, P. Fontana, \& L. Klein, Frequency Shifts in Hyperfine Splitting of Alkalis Caused by Foreign Gases, Phys. Rev. 115, 87.

607. H. Margenau \& M. Lewis, Structure of Spectral Lines from Plasmas, Rev. Mod. Phys. 31, 569 .

608. M. A. Mazing \& S. L. Mandel'shtam, Broadening of Spectral Lines in Strongly Ionized Plasma, Sov. Phys. - JETP $\underline{9}, 942$. 
609. A. Michels, H. De Klulver, \& D. Middelkoop, The Influence of Krypton on the $2536.52 \AA$ Line of Mercury, Physica (Utrecht) 25, 163.

610. A. Michels, H. De Kluiver, \& C. A. Ten Seldam, The Formation of Weakly Bound Molecules Mercury-Inert Gas and Their Contribution to the Satellite Bands of the Mercury $2537 \AA\left({ }^{1} \mathrm{~S}_{0}-{ }^{3} \mathrm{P}_{1}\right)$ Resonance Line Perturbed by Inert Gases at Low Densities, Physica (Utrecht) 25, 1321.

611. H. Moser \& H. Schulz, The Resonance Broadening of the Cs I 4555 \& Line, Ann. Phys. (Leipzig) 4 , 243. (Ger.)

612. E. A. Power \& S. Zienau, Coulomb Gauge in Non-Relativistic Quantum Electrodynamics and the Shape of Spectral Lines, Ph1l. Trans. Roy. Soc. London, Ser. A 251, 427.

613. N. G. Preobrazhenskil, The Functional Description of Spectrum Line Profiles in the Cowan-Dieke and Bartels Theories, Opt. Spectrosc. (USSR) I, 173.

614. N. G. Preobrazhenski1, on the Problem of the Degree of Heterogeneity of an Arc Discharge, Izv. Vyssh. Ucheb. Zaved., Fiz. No. 6, 31. (Russ.)

615. H. Van Regemorter, Research on Theoretical Problems in Stellar Classifications. III. Broadening of Hydrogen Lines, Ann. Astrophys. 22, 363. (Fr.)

616. J. Robin, An Experimental Study, Under Very Hiph Pressure, of the Perturbation of the Visible and Ultraviolet Absorption Spectrum of Oxygen, Nitric Oxide, and of the Resonance Lines of Certain Metals, J. Rech. Cent. Nat. Rech. Sc1. 10, 89. (Fr.)

617. Z. Suemoto \& E. Hiei, Balmer Series Lines of the Flare and Its Structure, Publ. Astron. Soc. Jap. 11, 185 .

618. 0. Theimer \& R. Gentry, Scattering Potential in Fully Ionized Gases, Phys. Rev. $\underline{116}, 787$.

619. A. B. Underhill \& J. H. Waddell, Stark Broadening Functions for the Hydrogen Lines, Nat. Bur. Stand. (U.S.), Circ. 603.

620. L. A. Vainshtein \& I. I. Sobel'man, Non-Stationary Theory of the Stark Broadening; of Spectral Lines in Plasmas, Opt. Spectrosc. (USSR) $\underline{6}, 279$.

621. P. J. Walsh, Effect of Simultaneous Doppler and Collision Broadening and of Hyperfine Structure on the Imprisonment of Resonance Radiation, Phys. Rev. 116, 511.

622. C. Weltkamp \& J. Robin, Perturbation of the Thallium Snectrum by Compressed Argon and Hydrogen, C. R. H. Acad. Sc1. 249, 1205. (Fr.) 
642. V. N. Alyamovski1 \& V. F. Kitaeva, The Contour of the $H_{B}$ Hydrogen Line Behind a Shock wave in Argon, Opt. Spectrosc. (USSR) $\underline{8}, 80$.

643. L. W. Anderson, F. M. Pipkin, \& J. C. Baird, Jr., Precision Determination of the Hyperfine structure of the Ground State of Atomic Hydrogen, Deuterium, and Tritium, Phys. Rev. Lett. $\underline{4}, 69$.

644. A. L. Bloom \& J. B. Carr, Pressure Shifts in the Hyperfine Structure Constant of Potassium, Phys. Rev. 119, 1946.

645. K. H. Böhm, Pressure Broadening of Spectral Lines, "Stellar Atmospheres," 120 (Ed. J. L. Greenstein, University of Chicapo Press, Chicago).

646. S. Y. Ch'en \& R. B. Bennett, Pressure Broadening of the Violet Triplet of Manganese in the Presence of Argon and Helium, Phys. Rev. 119, 1029.

647. S. Y. Ch'en, A. Smith, \& M. Takeo, Pressure Effects of Helium and Argon on the First Sharp Series Doublet of Indium, Phys. Rev. 117, 1010.

648. P. M. Duffieux, The Snectrum Analysis: Tynes of Integrations and Convolutions, Rev. Opt., Theor. Instrum. 39, 491。 (Fr.)

649. C. P. Flynn \& E. F. W. Seymour, The Correction of Spectral Line Shapes for Instrumental and Other Broadening, Proc. Phys. Soc., London $\underline{75}, 337$.

650. L. Gold, Doppler Phenomenon in Radiant Gaseous Atmospheres with Velocity and Density Flelds, "Proceedings of the Fourth International Conference on Ionization Phenomena in Gases," Vol. II, 813 (Ed. N. R. Nilsson, North-Holland Publishing Co., Amsterdam).

651. H. R. Griem, Stark Broadening, of Higher Hydrogen and Hydrogen-Like Lines by Electrons and Ions, Astrophys. J. 132, 883.

652. H. R. Griem \& A. C. Kolb, Advances in the Theory of Stark Broadening of Spectral Lines, "Proceedings of the Fourth International Conference on Ionization Phenomena in Gases," 808 (Ed. N. R. Nilsson, North-Holland Publishing Co., Amsterdam).

653. H. R. Griem, A. C. Kolb, \& K. Y. Shen, Stark Broadening of Hydropen Lines in Plasma, Naval Research Laboratory Renort 5455.

654. W. R. Hindmarsh, Collision Broadening and Shift in the $\lambda 6_{573}$ Line of Calcium, Mon. Not1c. Roy. Astron. Soc. 121, 48.

655. L. Houzlaux, The Stark Effect for the Elevated Lines of Hydrogen, Ann. Astrophys. 23, 940 . (Fr.) 
656. S. Huang \& 0. Struve, Turbulence as Understood in Stellar Spectroscopy, "Stellar Atmospheres," 350 (Ed. J. L. Greenstein, University of Chicago Press, Chicago).

657. K. Hunger \& R. W. Larenz, Critical Remarks on the Theory of Pressure Broadening of Spectral Lines, Ann. Astrophys. 23, 853.

658. J. L. Jackson, Electric Field Distribution in a Dense Plasma, Phys. Fluids $\underline{3}, 927$.

659. C. de Jager, Asymptotic Widening Parameters for the Hydrogen Lines, Ann. Astrophys. $\underline{23}, 889$.

660. J. T. Jefferies, Thermally Broadened Stark Profiles of Some High Balmer Lines, Astrophys. J. 131, 690 .

661. V. I. Kogan, Broadening of Spectral Lines in a Hiph Temperature Plasma, "Plasma Physics and the Problem of Controlled Thermonuclear Reactions," Vol. 4, pp. 305-362 (Ed. M. A. Leontovich, Pergamon Press, New York).

662. H. Marpenau, Formulas for Estimating Widths of Spectral Lines Emitted from Plasmas and Their Limits of Validity, "Proceedings of the Fourth International Conference on Ionization Phenomena in Gases," Vol. II, 799 (Ed. N. R. Nilsson, North-Holland Publishing Co., Amsterdam).

663. H. Margenau, The Structure of Spectral Lines from Plasmas, "Proceedings of the Fourth International Conference on Ionization Phenomena in Gases," Vol. II, 791 (Ed. N. R. Nilsson, North-Holland Publishing Co., Amsterdam).

664. C. A. Mead, Resonance Broadening of Spectral Lines, Phys. Rev. 120, 860 .

665. A. Misyunas, Temperature Influence on the Self-Broadening of Spectral Lines, Byull. Vil'nyuss. Astron. Observ. No. 2, 6. (Russ.)

666. T. Morita, Virial Expansion Formulae for the Microfield and Micropotential Distribution Functions and Their Application to a High Temperature Plasma, Progr. Theor. Phys. 23, 1211 .

667. B. Mozer, Atomic Line Shapes from a Plasma, Carnegie Institute of Technology, Pittsburgh, Pa., Technical Report No. 3, Contract Nonr-760(15) Office of Naval Research.

668. B. Mozer \& M. Baranger, Elentric Field Distributions in an Ionized Gas. II, Phys. Rev. 118,626 .

669. H. Muntenbruch, Schueler's Hollow Cathode as a Source for Stark Effect Investigations, Spectrochim. Acta 16, 1031. (Ger.) 
670. L. B. Robinson, Frequency Shifts in the Hyperfine Spectra of Alkalis Caused by Forelgn Gases, Phys. Rev. 117, 1275.

671. F. Schuller \& B. Vodar, On a Rigid Sphere Model in the Theory of Shift and Broadening of Spectral Lines by Collisions. Attractive Rigid Spheres, C. R. H. Acad. Sc1. 251, 1877. (Fr.)

672. F. Schuller \& B. Vodar, On a Rigid Sphere Model in the Theory of Shift and Broadening; of Spectral Lines by Collisions. Attractive and Repulsive Rigid Spheres, C. R. H. Acad. Sc1. 251, 1997. (Fr.)

673. T. Skalinski, Influence of Temperature on the Pressure Broadening of the Mercury Resonance Line, Bull. Acad. Pol. Sc1., Ser. Sc1., Math,. Astron., Phys. 8 , 119.

674. T. Skalinski, J. Rogaczewski, \& M. I. Kapuscinska, Influence of Temperature on the Broadening of the Mercury Resonance Line by Xenon, Bull. Acad. Pol. Sc1., Ser. Sc1., Math., Astron., Phys. $\underline{8}, 265$.

675. N. N. Sobolev, V. N. Kolesnikov, \& V. F. Kitaeva, Spectroscopic Study of Carbon Arc Burning in Inert Gases, "Proceedings of the Fourth International Conference on Ionization Phenomena in Gases," 370 (Ed. N. R. Nilsson, North-Holland Publishing Co., Amsterdam).

676. G. Traving, "On the Theory of Pressure Broadening of Spectral Lines," (Verlag G. Braun, Karlsruhe, Germany). (Ger.)

696. L. W. Anderson; F. M. Pipkin, \& J. C. Baird, Jr., Hyperfine Structure of Hydrogen, Deuterium, and Tritium, Phys. Rev. 120, 1279; Phys. Rev. 121, 1864; Phys. Rev. 122,1962 .

697. M. Arditi \& T. R. Carver, Pressure, Light, and Temperature Shifts in Optical Detection of 0-0 Hyperfine Resonance of Alkali Metals, Phys. Rev. 124, 800 .

698. M. Baranger \& B. Mozer, Light as a Plasma Probe, Phys. Rev. 123, 25.

699. P. L. Bender, Effect of Hydrogen-Hydrogen Exchange Collisions, Phys. Rev. 132, 2154.

700. K. Bergstedt, E. Ferguson, H. Schlüter, \& H. Wulff, Experimental Contribution to the Theory of Spectral Line Broadening, "Proceedinfs of the Fifth International Conference on Ionization Phenomena in Gases," (North-Holland Publishing Co., Amsterdam). (Ger.) 
701. R. G. Breene, Jr., "The Shift and Shape of Spectral Lines," 1-323 (Pergamon Press, Oxford).

702. S. Y. Ch'en, M. R. Atwood, \& T. H. Warnock, Collision Induced Satellite Bands of In and Tl Lines in the Presence of Rare Gases, Physica (Utrecht) 27, 1170.

703. S. Y. Ch'en \& V. Chandrasekharan, The Shift of the Absorption Lines of Fe I Due to the Presence of Hellum, Astrophys. J. 133, 1067.

704. S. Y. Ch'en \& R. A. Wilson, Jr., The Position Dependence of Collision Induced Satellites of Alkali Lines on the Nature of the Alkali, Physica (Utrecht) 27, 497 .

705. A. P. Dronov, A. G. Sviridov, \& N. N. Sobolev, Study of the State of Krypton Behind a Shock Wave, Opt. Spectrosc. (USSR) 10, 157.

706. I. Fidone, Correlation of an Electric Fleld in a Plasma, Nuovo Cimento 20, 1219. $(\mathrm{Fr}$.

707. L. Galatry, Simultaneous Effect of Doppler and Foreign Gas Broadening on Spectral Lines, Phys. Rev. 122, 1218.

708. W. E. Gerlcke, Measurement of the Transition Probability from the Half-Width and Shift of Al Lines in a Thermally Radiating Plasma, Z. Astrophys. 53, 68. (Ger.)

709. M. G. Gorodnichyute \& G. A. Gorodnichyus, Pressure Effects in the UnderwaterSpark for the Spectral Lines of $\mathrm{Cd} I$ and their Dependence on the Concentration of $\mathrm{Cd}$ and $\mathrm{Zn}$ in the Electrodes, Litov. Fiz. Sb. 1, 163. (Russ.)

710. R. Granier, F. Schuller, \& B. Vodar, Displacement of the Mercury Line $2537 \AA$ by Hydrogen and Deuterium, C. R. H. Acad. Sc1. 252, 3216. (Fr.)

711. H. R. Griem \& K. Y. Shen, Stark Broadening of Hydrogenic Ion Lines in a Plasma, Phys. Rev. 122, 1490.

712. G. Hepner, Contribution to the Study of Infrared Emission of Atomic and Molecular Spectra in the Region 1-3 . Application to the Broadening of the Paschen Series Lines of the Hydrogen Atom, Ann. Phys. (Paris) 6 , 735. (Fr.)

713. R. Herman \& H. Margenau, Frequency Shifts in Hyperfine Splitting of Alkalis: A Correction, Phys. Rev. 122, 1204.

714. P. Hey, Pressure Broadening and Shift of Fe I Lines by Argon Atoms, Z. Astrophys. 52, 254. (Ger.)

715. W. R. Hindmarsh \& K. A. Thomas, Collision Broadening in the Argon Spectrum, Proc. Phys. Soc, London, Sect. A $77,1193$. 
716. F. W. Hofmann \& H. Kohn, Optical Cross Section of Resonance Lines Emitted by Flames under Conditions of Partial Thermal Ionization, J. Opt. Soc. Amer. 51, 512.

717. L. Houzlaux, Stark and Doppler Broadening for H1gh Balmer and Paschen Lines I. The Absorption Coefficient., Ann. Astrophys. 24, 541.

718. D. G. Hughes \& D. K. C. MacDonald, Some Properties of Resonance Line-Shape Functions, Proc. Phys. Soc., London $\underline{78}, 75$.

719. K. Hunger \& R. W. Larenz, The Microfield in a Plasma, Z. Phys. 163, 245. (Ger.)

720. V. F. Kitaeva \& N. N. Sobolev, Broadening of the Hydrogen Lines from Arc Plasma and Shock Tubes, Sov. Phys. - Dokl. 6, 328.

721. V. I. Kogan, The Fluctuating Microfield and Multiple Collisions in a Gas of Charged (or. Gravitating) Particles, Sov. Phys. - Dokl. , 1316.

722. V. G. Koloshnikov, M. A. Mazing, S. L. Mandel'shtam, \& Yu. P. Marasanov, Use of a Fabry-Perot Etalon for Studying Spectral Line Widths in Pulsed Discharges, Opt. Spectrosc. (USSR) 11, 302 .

723. D. Lagarde \& R. Lennuier, Observation of the Asymmetrical Broadening of the Absorption Line $\lambda 2537 \AA$ of Mercury Vapor at Low Pressures, C. R. H. Acad. Sci. 253, 832. (Fr.)

724. K. C. Lapworth, Stark Broadening of the Spectrum Line $4603 \AA$ of Lithium, Nature (London) 192, 252.

725. S. Legowski, Calculation of the Shape of the Proflle of the Resonance Line of Mercury Broadened by Argon, Based on the Theory of Jablonski, J. Phys. Radium 22, 154. (Fr.)

726. M. Lewis, Stark Broadening of Spectral Lines by High-Velocity Charged Particles, Phys. Rev. 121, 501.

727. S. Matsuo \& H. Narumi, On the Validity of the Adiabatic Approximation in the Theory of Electron Broadening in a Plasma, Progr. Theor. Phys. 26, 424.

728. A. A. Misyunas \& V. I. Gaidelis, Temperature Influence on the Pressure Broadening of the Resonance Line of Mercury $2537 \AA$, Litov. Fiz. Sb. 1, 153. (Russ.)

729. A. C. G. Mitchell \& M. W. Zemansky, Collision Processes Involving Excited Atoms, "Resonance Radiation and Excited Atoms," 158-195 (Cambridge University Press, London).

730. A. Ohno, Cluster Expansion of Relaxation Function and Its Application to the Theory of Pressure Broadening, J. Phys. Soc. Jap. 16, 2402. 
731. M. I. Podgoretski1 \& A. V. Stepanov, The Doppler Width of Emission and Absorption Lines, Sov. Phys. - JETP 13 , 393.

732. A. Ron \& G. Kalman, Velocity-Dependent Correlations in the Statistical Distribution of the Electric Microfield in a Plasma, Phys. Rev. 123, 1100.

733. H. Sadjian, H. K. Wimmel, \& H. Margenau, Forbidden Helium Line in a Plasma Spectrum, J. Quant. Spectrosc. Radiat. Transfer $1,46$.

734. M. B. K. Sarma, Selective Pressure Broadening of Si and F Spectral Lines, Proc. Phys. Soc., London 77, 665.

735. T. Tako, Self-Absorption of Spectral Line, J. Phys. Soc. Jap. 16, 2016.

736. H. K. Wimmel, Statistical Line Broadening in Plasmas, J. Quant. Spectrosc. Radiat. Transfer 1,1 .

756. V. N. Alyamovski1, Electric Microfield Distributions in an Ionized Gas, Sov. Phys. - JETP $\underline{15}, 1067$.

757. M. Baranger, Spectral Line Broadening in Plasmas, "Atomic and Molecular Processes," 493-548 (Ed. D. R. Bates, Academic Press, Inc., New York).

758. A. Bardocz, T. Vörös, \& U. M. Vanyek, The Time Denendence of the Broadening of Spectral Lines and of the Ion Concentration in Spark Discharges, Z. Angew. Phys. 14, 581. (Ger.)

759. H. Bartels \& H. Zwicker, The Determination of the Line Profile from the Observed Shape When Self-Absorption is Present I. Theory of the Technique, Z. Phys. $\underline{166}, 148$. (Ger.)

760. W. S. Benedict, R. Herman, G. E. Moore, \& S. Silverman, The Strengths, Widths, and Shanes of Lines in the Vibration-Rotation Bands of CO, Astrophys. J. 135, 277.

761. H. F. Berg, A. W. Al1, R. Lincke, \& H. R. Grjem, Measurement of Stark Profiles of Neutral and Ionized Helium and Hydrogen Lines from Shock-Heated Plasmas in Electromapnetic T Tubes, Phys. Rev. 125, 199.

762. A. F. Bondarev, The Determination of the True Contour of a Spectral Line from the observed Contour, Opt. Spectrosc. (USSR) 12, 282.

763. G. A. Clarke, Effects of Helium Buffer Gas Atoms on the Atomic Hydrogen Hyperfine Frequency, J. Chem. Phys. 36, 2211. 
764. P. J. Dickerman \& B. P. Alpiner, Spectral Line Shapes and Transition Probabilities for Argon, J. Quant. Spectrosc. Radiat. Transfer $2,305$.

765. J. Fiutak \& J. Van Kranendonk, Impact Theory of Raman Line Broadeninf, Can. J. Phys. 40, 1085 .

766. L. I. Grechikhin, Broadering of the $4982.8 \AA$ Sodium Line in the Direct Current Arc Jet, Opt. Spectrosc. (USSR) 13, 325.

767. L. I. Grechikhin \& M. A. El'yashevich, Broadening of Sodium and Lithium Lines in Nonhomopeneous Flelds, Vesti Akad. Navuk Belarusk. SSR, Ser. Fiz. - Tekhn. Navuk No. 4, 37. (Russ.)

768. H. R. Griem, Wing Formulae for Stark-Broadened Hydrogen and Hydrogenic Lines, Astrophys. J. 136, 422 .

769. H. R. Griem, Stark Broadening of Isolated Spectral Lines from Heavy Elements in a Plasma, Phys. Rev. 128, 515.

770. H. R. Griem, M. Baranger, A. C. Kolb, \& G. Oertel, Stark Broadening of Neutral Helium Isines in a Plasma, Phys. Rev. $125,177$.

771. H. R. Griem, A. C. Kolb, \& K. Y. Shen, Stark Profile Calculations for the $H_{\beta}$ Line of Hydrogen, Astrophys. J. 135, 272.

772. H. R. Griem \& C. S. Shen, Application of a Disnersion Relation to the Electron Impact Widths and Shifts of Isolated Spectral Lines from Neutral Atoms, Phys. Rev. 125, 196.

773. G. L. Hammond, The Shift and Broadening of the Resonance Doublet of Ba II Caused by He and Ar Collisions, Astrophys. J. 136, 431.

774. E. Hantzsche \& G. Vojta, On the Theory of the Plasma Microfield According to Hunger and Jarenz, Bettr. Plasmaphys. $\underline{2}, 205$. (Ger.)

775. W. W. Holloway, Jr., E. Lüscher, \& R. Novick, Hyperfine Structure of Atomic Nitropen, Phys. Rev. 126, 2109.

776. V. F. Kitaeva, V. V. Obukhov-Denisov, \& N. N. Sobolev, Concentration of Charged Particles in the Plasma of an Arc Burning in an Atmosnhere of Argon and Helium, Opt. Spectrosc. (USSR) $12,94$.

777. V. F. Kitaeva \& N. N. Sobolev, On the Broadening of Hydrogen Lines in the Plasma of Arc and Shock Tube, "Proceedinfs of the Fifth International Conference on Ionization Phenomena in Gases," 18.97 (North-Holland Publishing Co., Amsterdam). 
778. Yu. N. Konovalov \& V. V. Magidson, Electron Density and Temperature in a WaterStabilized Plasmatron Jet, Sov. Phys. - Tech. Phys. I, 328.

779. D. Lagarde, Observation of the Asymmetrical Broadening of the Absorption Line $\lambda 2537 \AA$ of Mercury Vapor at Low Pressure, J. Phys. Radium 23, 266. (Fr.)

780. G. T. Lalos, Laboratory Production of Hot Dense Gases, Rev. Sci. Instrum. $33,214$.

781. G. T. Lalos \& G. L. Hammond, Emission Spectra of Hot Dense Gases, Astrophys. J. 135,616 .

782. R. H. Lambert \& F. M. Pipkin, Hyperfine Structure of Atomic Phosphorus, Phys. Rev. 128, 198; Phys. Rev. 129, 2836.

783. R. W. Larenz, Nyquist Formula, Debye-Length and Microfield in a Plasma, "Proceedings of the Fifth International Conference on Ionization Phenomena in Gases," Vol. II, 1650 (Ed. H. Maecker, North-Holland Publishing Co., Amsterdam). (Ger.)

784. S. L. Mandel'shtam, On the Broadening, and Shift of Spectral Lines in a Highly Ionized Plasma, "Optik und Spektroskopie Aller Wellenlärgen," 372-378 (AkademieVerlag, Berlin). (Russ.)

785. M. A. Mazing, On the Broadening and Shift of Spectra Lines in the Plasma of a Gaseous Discharge, Trans. P. N. Lebedev Phys. Inst. 15, Part 2, 1.

786. M. A. Mazing \& N. A. Vrublevskaya, The Broadening of Spectral Lines in a Strongly Ionized Plasma, Opt. Spectrosc. (USSR) 13, 172.

787. A. Misyunas, The Influence of Temperature on the Imnact Broadening, of Spectral Lines at Normal Pressure, Fiz. Probl. Spektrosk, Mater. Soveshch., 13th 1, 94. (Russ.)

788. L. E. Pargamanik, Shift of Atomic Energy Levels in a Plasma, Sov. Phys. - JETP 14, 794 .

789. F. M. Pipkin \& R. H. Lambert, Hynerfine Splittings of Hydrogen and Tritium, Phys. Rev. 127,787 .

790. S. G. Rautian \& I. I. Sobel'man, Line Shape and Disnersion in the Vicinity of an Absorntion Band, as Affected by Induced Transitions, Sov. Phys. - JETP $14,328$.

791. J. Robin \& S. Robin-Kandare, Perturbation of the Absorption Spectrum of the Alkali Metals by Compressed Hydrofen, C. R. H. Acad. Sci. 255, 1715. (Fr.)

792. J. S. Rollett \& L. A. Hipgs, Correction of Snectroscopic Line Profiles for Instrumental Broadening by a Fourier Analysis Method, Proc. Phys. Soc., London 79, 87. 
793. O. Von Roos, General Theory of Collision Broadening of Spectral Lines, "Proceedings of the Fifth International Conference on Ionization Phenomena in Gases," 913 (North-Holland Publishing Co., Amsterdam).

794. F. Schuller, Contribution to the Theory of Spectral Perturbations in Compressed Gas, J. Rech. Cent. Nat. Rech. Sc1. 13, 281. (Fr.)

795. J. B. Shumaker, Jr. \& W. L. Wiese, Measurement of Electron Density and Temperature in Dense Plasmas by Application of Line Broadening Theory, "Temperature - Its Measurement and Control in Science and Industry," Vol. 3, Part 1 (Reinhold Publishing Corp.; New York).

796. P. M. Stone \& L. Agnew, Plasma-Broadened Cesium Lines, Phys. Rev. 127, 1157.

797. C. J. Tsao \& B. Curnutte, Line-Widths of Pressure-Broadened Spectral Lines, J. Quant. Spectrosc. Radiat. Transfer 2, 41.

798. V. Vujnovic, J. A. Harrison, \& J. D. Craggs, Balmer Line Profiles in a Capillary Arc Discharge, Proc. Phys. Soc., London $\underline{80}, 516$.

799. W. L. Wiese, D. R. Paquette, \& J. E. Solarski, Experimental Study of the Stark Broadening of the Balmer Line $\mathrm{H} \gamma$, "Proceedings of the Fifth International Conference on Ionization Phenomena in Gases," 907 (North-Holland Publishing Co., Amsterdam).

800. H. Zwicker, The Determination of the Line Profile from the Observed Shape When Self-Absorption is Present II. Application to Lines of a $\mathrm{Hg} \mathrm{High} \mathrm{Pressure} \mathrm{Arc,}$ Z. Phys. 166, 163. (Ger.)

801. H. Zwicker, The Determination of the Line Shape in Optically Thick Plasmas, "Proceedings of the Fifth International Conference on Ionization Phenomena in Gases," 1906 (North-Holland Publishing, Co., Amsterdam). (Ger.)

821. L. Agnew \& C. Summers, Experimental Cesium Line Shapes, Advan. Energy Convers. $\underline{3}$, 79.

822. C. W. Allen, Line Broadening, "Astrophysical Quantities," 2nd Ed., 81 (Athlone Press, London).

823. F. Bayer-Helms, An Analysis of Line Profiles: Half-Widths of Voigt Functions, Z. Angew. Phys. 15, 532. (Ger.)

824. F. Bayer-Helms, Analysis of Line Profiles. I. Fundamentals and Apparatus (FabryPerot), Z. Angew. Phys. 15, 330. (Ger.) 
825. F. Bayer-Helms, Analysis of Line Profiles. II. Evaluation of Intensity Distributions of a Fabry-Perot, Z. Angew. Phys. 15, 416. (Ger.)

826. F. Bayer-Helms, Analysis of Line Profiles, Z. Angew. Phys. 16, 44. (Ger.)

827. W. Bötticher, O. Roder, \& K. H. Wobif, Measurement of Transition Probabilities, Half-Widths, and Shifts of He I Lines, Z. Phys. 175, 480. (Ger.)

828. S. Brechot \& H. Van Regemorter, A New Method of Calculating the Absorption Factors by Electron Collisions, C. R. H. Acad. Sc1. 256, 609. (Fr.)

829. J. T. Davies \& J. M. Vaughan, A New Tabulation of the Volgt Profile, Astrophys. J. 137,1302 .

830. R. C. Elton, Stark Profile Measurement of the Lyman- $\alpha$ and Lyman- $\beta$ Lines of Hydrogen, Naval Research Laboratory Report 5967.

831. E. Fabre, J. Seguier, \& L. Herman, Broadening of Argon Infrared Lines in a Plasma Jet, J. Phys. (Paris) 24, 737. (Fr.)

832. U. Fano, Pressure Broadening as a Prototype of Relaxation, Phys. Rev. 131, 259.

833. E. Ferguson \& H. Schlüter, Stark Broadening of Balmer Lines at Low Electron Densities, Ann. Phys. (New York) 22, 351.

834. F. A. Franz, E. Lüscher, \& D. W. Smith, Pressure-Shift of the Atomic Nitrogen Hyperfine Structure, Nuovo Cimento 28, 1093.

835. N. S. Gorbacheva \& N. G. Preobrazhenski1, Asymmetric Self-Reversible Spectral Line Profile as a Source of Information on Plasma Properties, Opt. Spectrosc. (USSR) $15,244$.

836. R. Granier \& J. Granier, Shift of the 7800 and 7948 A Lines of Rubidium, by Hydrogen and Deuterium. Influence of Temperature, C. R. H. Acad. Sci. 257, 2627. $(\mathrm{Fr}$.

837. R. Granier, J. Granier, \& E. De Croutte, Shift and Broadening of the Resonance Lines of Rubidium by Argon Under Pressure, J. Phys. (Paris) 24, 349. (Fr.)

838. R. Granier, J. Granier, \& E. DeCroutte, Influence of the Mass of the Perturber on the Shift and Broadening of the 2537 \& Line of Mercury, C. R. H. Acad. Sci. 256, 3622. (Fr.)

839. L. I. Grechikhin, Resonance Broadening of Spectral Lines and Its Application to the Determination of the Concentration of Neutral Atoms in the Plasma of the Arc Discharge, Dokl. Akad. Nauk Belorussk. SSR I, 313. (Russ.) 
840. A. G. Hearn, Radlative Transfer of Doppler Broadened Resonance LInes, Proc. Phys. Soc., London 81, 648 .

841. K. Hunger \& R. W. Larenz, A Short Contribution to the Plasma-Microfield (Comments on a Note of E. Hantzsche and G. Vojta), Beltr. Plasmaphys. , 161. (Ger.)

842. A. Jablonsk1, Pressure Effects on Spectral Lines, Acta Phys. Pol. 23, 493.

843. C. de Jager \& L. Neven, Tables and Graphs Enabling the Computation of the Profiles of $\mathrm{H}_{\gamma}$ and $\mathrm{H}_{\delta}$ in Stellar Spectra, Ann. Obs. Roy. Belg. 9 , No. 2, 47.

844. 0. Jefimenko, Satellite Bands in the Spectra of Gaseous Mixtures and the Shape of Potential Curves for Neutral Atoms and Molecules in the State of Collision, J. Chem. Phys. 39, 2457.

845. O. Jefimenko \& R. J. Exton, Absorption Spectrum of Cs in the Presence of Isomeric Hydrocarbons, J. Chem. Phys. 39, 229.

846. M. Jung, Broadening of Spectral Lines of Neutral Oxygen by Microfields, Z. Astrophys. 58, 93. (Ger.)

847. A. Kastler, Displacement of Energy Levels of Atoms by Light, J. Opt. Soc. Amer. 53. 902 .

848. V. I. Kogan, On the Generalization of the Holtsmark Theory Taking Account of the Thermal Motion of the "Broadening" Ions, "Proceedings of the Sixth International Conference on Ionization Phenomena in Gases," Vol. III, 415 (S.E.R.M.A., Paris).

849. A. Kossakowsk1, S. Kw1atkowsk1, \& S. Prusk1, Some Notes on the Theory of Pressure Effects on Spectral Lines, Acta Phys. Pol. 244, 327.

850. L. P. Kudrin, On the Width of Spectral Atoms Line in Plasma, "Proceedings of the Sixth International Conference on Ionization Phenomena in Gases," Vol. III, 429 (S.E.R.M.A., Paris).

851. L. P. Kudrin \& G. V. Sholin, The New Methods of Plasma Diapnostics by the Use of Spectroscopic Data, "Proceedings of the Sixth International Conference on Ionization Phenomena in Gases," Vol. III, 433 (S.E.R.M.A., Paris).

852. L. P. Kudrin \& G. V. Sholin, Asymmetry of Spectral Lines of Hydrogen in Plasma, Sov. Phys. - Dokl. I, 1015.

853. L. P. Kudrin \& G. V. Sholin, The Displacement of the Spectral Lines of He II in a Dense Plasma, Opt. Spectrosc. (USSR) 14, 322.

854. R. H. Lambert \& F. M. Plpkin, Pressure Shifts of the Hyperfine Structure of Atomic N1trogen, Phys. Rev. 129, 1233. 
855. Y. Leycuras, Broadening of Helium Lines by the Stark Effect in an Arc Under Variable Pressures, C. R. H. Acad. Sc1. 256, 5094. (Fr.)

856. Y. Leycuras, Electrical and Spectroscopic Study of DC Discharge in Helium Under Pressure, Ann. Phys. (Paris) $\underline{8}, 577$. (Fr.)

857. S. L. Mandel'shtam, M. A. Mazing, I. I. Sobel'man, \& L. A. Vainshtein, Stark Broadening of Nonhydrogen Lines in Plasma, "Proceedings of the Sixth International Conference on Ionization Phenomena in Gases," Vol. III, 331 (S.E.R.M.A., Paris).

858. L. E. Pargamanik \& G. M. Pyatigorski1, Shifts and Broadening of Energy Levels of Single-Electron Atoms and Ions in a High-Temperature Plasma, Sov. Phys. - JETP $\underline{17}, 1365$.

859. N. G. Preobrazhensk11, An Extension of the Limits of Applicability of the SelfAbsorption Method, Opt. Spectrosc. (USSR) 14, 183.

860. H. Van Regemorter, On the Diffusion of Low Energy Electrons, C. R. H. Acad. Sci. 257, 63. (Fr.)

861. I. I. Sobel'man, The Broadening of Spectral Lines, "Introduction to the Theory of Atomic Spectra," 452-557 (State Publishing House Phys1co-Mathematical Literature). (Russ.)

862. A. Stampa, Broadening of Spectral Lines of Neutral N1trogen by Microfields, Z. Astrophys. 58 , 82. (Ger.)

863. T. Tletz, Pressure Shift of the High Series of the Alkali Metals, Nuovo Cimento 28, 1509 .

864. W. L. Wiese \& P. W. Murphy, Shifts and Widths of Some Stark-Broadened Oxygen Lines in an Arc Plasma, Phys. Rev. 131, 2108.

865. W. L. Wiese, D. R. Paquette, \& J. E. Solarski, Profiles of Stark-Broadened Balmer Lines in a Hydrogen Plasma, Phys. Rev. 129, 1225.

\section{4}

885. L. C. Allen, H. M. Gladney, \& S. H. Glarum, Resolution Enhancement for Spectra of Chemical and Physical Interest, J. Chem. Phys. 40, 3135.

886. B. H. Armstrong, Broadening of Balmer Lines for High Quantum Number, J. Quant. Spectrosc. Rad1at. Transfer $\underline{4}, 491$.

887. W. Behmenburg, Broadening and Shift of the Sodium $\mathrm{D}_{2}$ Line by Various Perturbing Gases Under Flame Conditions, J. Quant. Spectrosc. Radiat. Transfer 4 , 177. 
888. W. Behmenburg \& H. Kohn, Broadening of Resonance Lines by Various Perturbing Gases Under Flame Conditions, J. Quant. Spectrosc. Radiat. Transfer 4 , 163.

889. P. L. Bender, Interpretation of Frequency Shifts due to Electron Exchange Collisions, Phys. Rev. 134, Al174.

890. T. M. Bieniewski, Collision Broadening of Spectral Lines by Identical Atoms, "Atomic Collision Processes," 1055 (Ed. M. R. C. McDowell, North-Holland Publishing Co., Amsterdam).

891. D. E. Billings, The Shape of Coronal-Line Profiles, Astrophys. J. 139, 710.

892. G. Boldt \& W. S. Cooper, Measurement of the Line Wing Profiles of the Hydrogen Lyman a Line, Z. Naturforsch. A 19 , 968. (Ger.)

893. S. Brechot \& H. Van Repemorter, Collision Broadening of Spectral Lines, Ann. Astrophys. 27, 739. (Fr.)

894. S. Brechot \& H. Van Regemorter, Collision Broadening of Spectral Lines, Ann. Astrophys. 27, 432. (Fr.)

895. R. G. Breene, Jr., Line Width, "Handbuch der Physik," Vol. 27, 1-79 (Ed. S. Flügge, Springer-Verlag, Berlin).

896. F. W. Byron \& H. M. Foley, Theory of Collision Broadening in the Sudden Approximation, Phys. Rev. 134, A625.

897. F. W. Byron, M. N. McDermott, \& R. Novick, Self-Broadening of Optical Double Resonance Lines in Cadmium, Phys. Rev. 134, A615.

898. S. Y. Ch'en \& C. W. Fountain, The Effect of Xenon Pressure on the Red RubidiumXenon Satellite Bands, J. Quant. Spectrosc. Radiat. Transfer $\underline{4}, 323$.

899. A. Di Giacomo, Imnact Approximation for Line Shane in the Microwave Region, Nuovo Cimento 34, 473.

900. E. M. Drobyshevsk11, Photoelectric Method of Scanning the Dopnler Shift of Spectral Iines, Instrum. Fxp. Tech. (USSR) No. 6, 1149.

901. Yu. P. Efremov \& S. N. Ivashevski1, Line Shift in the Visible Spectrum of Cd ${ }^{14}$ Due to (Varlation of) the Arpon Pressure in a Lamn with Heated Electrodes, Opt. Snectrosc. (USSR) 17, 334 .

902. R. C. Elton \& H. R. Grjem, Measurement of Stark Profiles of the Lyman- $\alpha$ and Lyman- $\beta$ Lines of Hydrofien in an Electromagnetic Shock Tube, Phys. Rev. 135, A1550. 
903. G. D. Finn \& D. Mugfilestone, Tables of the Line Broadening Function $H(a, v)$, Mon. Notic. Roy. Astron. Soc. 129, 221.

904. J. Flutak, On Pressure Broadening of Spectral Lines, Acta Phys. Pol. 26, 919.

905. V. M. Goldfarb \& F. V. Ilyina, The Broadening, of Cesium Lines in the Plasma of a Direct-Current Arc, Opt. Spectrosc. (USSR) 17, 159.

906. L. I. Grechikhin \& E. S. Tyunina, Effect of the Surrounding Gas Pressure on the Physical State of Arc Discharge Plasma, Hifh Temp. (USSR) 2, 622.

907. H. R. Griem, Stark Broadening of Isolated Spectral Lines in a Plasma, Naval Research Laboratory Report 6084.

908. H. R. Griem, Line Broadening Calculations, "Plasma Spectroscopy," Chs. 4, 15-3, pp. 444-527, 538-539 (McGraw-Hill Book Company, Inc., New York).

909. T. Grycuk, M. Kublak, \& J. Prochorow, Temperature Effect on Pressure Broadening of the Mercury Resonance Line, Bull. Acad. Pol. Sc1., Ser. Sc1., Math., Astron., Phys. 12, 517 .

910. C. F. Hansen, Combined Stark and Doppler Line Broadeninf, J. Opt. Soc. Amer. 54, 1198 .

911. A. G. Hearn, Radiative Transfer of Doppler Broadened Resonance Lines: II, Proc. Phys. Soc., London 84, 11 .

912. R. A. H11l, Tables of Electron Density As a Function of the Halfwidth of StarkBroadened Hydrogen Lines, J. Quant. Spectrosc. Radiat. Transfer $\underline{4}, 857$.

913. R. A. Hill \& E. H. Beckner, A Rapid Scan Spectrograph for Plasma Spectroscopy, Appl. Opt. $\underline{3}, 929$.

914. O. Jefimenko, Suppression of the Doublet Fine Structure in the Spectra of Gaseous Mixtures, J. Opt. Soc. Amer. 54, 129.

915. G. Kelbg, On the Theory of Microfields in a Plasma, Ann. Phys. (Leipzig) $13,385$. (Ger.)

916. V. I. Kogan, A Single Generalization of the Statistical Theory of Broadening of Spectral Lines in a Plasma, J. Quant. Spectrosc. Radiat. Transfer 4, 243. (Russ.)

917. L. P. Kudrin \& Yu. A. Tarasov, The Width of Spectral Lines of Atoms and Ions in a Plasma, Opt. Spectrosc. (USSR) 17, 265.

918. H. G. Kuhn \& J. M. Vaughan, Radiation Width and Resonance Broadening in Helium, Proc. Roy. Soc., Ser. A 277, 297. 
919. S. Kwlatkowsk1, Shape and Shift of Atomic Spectral Lines Broadened by Higher Pressures of Perturbing Atoms, Bull. Acad. Pol. Sci., Ser. Sci., Math., Astron., Phys. 12, 125.

920. R. Lincke, Measurement of the Oscillator Strength of the Neutral Helium Resonance Line, Thesis, University of Maryland.

921. M. A. Mazing, M. D. Marinkovic, \& N. A. Vrublevskaya, Broadening and Shift of the Al III Spectral Lines in Strongly Ionized Plasma, Bull. Boris Kidric Inst. Nucl. Sc1. 15, 15 .

922. M. A. Mazing \& N. A. Vrublevskaya, The Broadening of Spectral Lines in a Strongly Ionized Plasma III. Wavelengths of the Lines of Multiply Charged Ions, Opt. Spectrosc. (USSR) 16, 6 .

923. R. Mewe \& R. F. de Vries, Method of Measuring Time-Resolved Electron Density and Ion Temperature of Plasmas with a Fabry-Perot Etalon, Plasma Phys. 6 , 591.

924. J. Meyer, Pressure Broadening of TI I and II Lines by Neutral Hydrogen Atoms and Electrons, Z. Astrophys. 60, 94. (Ger.)

925. L. Minnhagen, Correlation between Observed Wavelength Shifts Produced in Electrodeless Discharge Tubes and Predicted Stark-Effect Shifts in the Spectrum of Neutral Germanium (Ge I), J. Opt. Soc. Amer. 54, 320.

926. M. Mizushima, Theory of Resonance Frequency Shift due to Radiation Field, Phys. Rev. 133, A 414.

927. T. Nakayama \& H. DeW1tt, A Quantum Statistical Apnroach to Level Shift and Level Width in a Hydrogenic Plasma, J. Quant. Spectrosc. Radiat. Transfer 4 , 623.

928. Nguyen-Hoe, H. W. Drawin, \& L. Herman, Asymmetry of the Profile of the Ly- $\alpha$ Line of Atomic Hydrogen, J. Quant. Spectrosc. Radiat. Transfer 4, 847.

929. N. J. Peacock, J. Cooper, \& J. R. Grelg, Emission-Line Profile Measurements in Transient Plasmas, Using a Scanninp, Fabry-Perot Interferometer, Proc. Phys. Soc., London 83 , 803 .

930. U. Plttack, Measurement of Resonance Broadening of Some He I and A I Lines, Z. Astrophys, 60, 190. (Ger.)

931. H. Van Regemorter, On a Supplementary Factor of Broadening of Spectral Lines, C. R. H. Acad. Sc1. 258, 1741. (Fr.)

932. H. Van Regemorter, On the Broadening of Hydrogen Lines, C. R. H. Acad. Sc1. 259, 3979. (Fr.) 
933. A. Reichel, Voigt Profile Functions in the Complex Domain, J. Aust. Math. Soc. 4. 476 .

934. J. Reinheimer, Stark Coupling of Radiation and Plasma Oscillations, J. Quant. Spectrosc. Radiat. Transfer $\underline{4}, 671$.

935. O. Roder \& A. Stampa, Photoelectric Detection of the Line Profile of Thermally Excited He I Lines, Z. Phys. 178,348 . (Ger.)

936. J. M. Rupin \& St. Robin, An Emission Study of the Resonance Line $1469.6 \AA$ of Xenon and of the Satelifte Bands Induced in Its Vicinity by Foreign Gas Pressure, C. R. H. Acad. Sc1. 258, 3255. (Fr.)

937. V. N. Snopko, The Effect of the Spectrograph Slit on the Measurement of the Intensity of Spectral Lines, Dokl. Akad. Nauk Beloruss. SSR 8 , 788. (Russ.)

938. D. N. Stacey \& J. M. Vaughan, Pressure Broadening and Oscillator Strengths in Argon, Phys. Lett. 11, 105.

939. M. Takeo \& S. Y. Ch'en, Intensity Analysis of the Nature of Rb/Xe Red Satellite Bands, J. Quant. Spectrosc. Radiat. Transfer $4,471$.

940. C. R. Vidal, The Pressure Broadening of the Balmer Lines and the Diffuse Lines of Helium, Z. Naturforsch. A 19 , 947. (Ger.)

941. A. Yu. Zav'yalova, G. I. Zav'yalov, \& N. A. Prilezhaeva, Broadening of the Resonance Lines of Mercury $\lambda 2537 \AA$ in the Presence of Some Complex Molecules, Izv. Vyssh. Ucheb. Zaved., Fiz. No. 5, 3. (Russ.)

961. A. W. Ali \& H. R. Griem, Theory of Resonance Broadening of Spectral Lines by Atom-Atom Impacts, Phys. Rev. 140, A1044; Phys. Rev. A 144, 366.

962. E. H. Avrett \& D. G. Hummer, Non-Coherent Scattering II: Line Formation with a Frequency Independent Source Function, Mon. Notic. Roy. Astron. Soc. 130, 295.

963. A. Ben-Reuven, Transition from Resonant to Nonresonant Line Shape in Microwave Absorption, Phys. Rev. Lett. 14, 349.

964. G. Boldt, Measurements of Absorption Oscillator Strengths and Line Broadening in the Wavelength Region from 1000 to $2000 \AA$, J. Quant. Spectrosc. Radiat. Transfer $\underline{5}, 91$.

965. D. D. Burgess \& J. Cooper, A New Method of Measuring Electron Temperatures in Plasmas in the Absence of Local Thermodynamic Equilibrium, Proc. Phys. Soc., Lond on 86, 1333. 
966. A. I. Burshtein \& Yu. I. Naberukhin, Applicability of a Perturbation Method to Phase Relaxation and Line Shape Problems in Gases, J. Appl. Spectrosc. (USSR) $\underline{3}, 342$.

967. J. Butaux \& R. Lennuier, The Fffect of Forelgn Gases on the Position and Shape of the $\lambda 2537$ R Line of $\mathrm{Hg}^{198}$, C. R. H. Acad. Sc1. 261, 671. (Fr.)

968. S. Chudzynski \& T. Grycuk, Studies on the Shape of the Mercury Resonance Lirie Broadened by He and Temperature Effect on this Line, Bull. Acad. Pol. Sc1., Ser. Sc1., Math., Astron., Phys. 13, 693.

969. T. R. Connor \& M. A. Biondi, Dissociative Recombination in Neon: Spectral LineShape Studies, Phys. Rev. 140, A778.

970. M. L. Dalton, Jr., Determination of Line-Widths by Slit-Width Alterations, Appl. opt. 4,603 .

971. R. A. Day, Measurement of the Stark Widths and Shifts of Nitrogen Ion Lines, Thesis, University of Maryland.

972. R. A. Day \& H. R. Griem, Measurement of Stark Profiles of Singly Ionized Nitrogen Lines from a T-Tube Plásma, Phys. Rev. 140, All29.

973. A. DI Glacomo, On the Shape of Zeeman and Stark Components of Spectral Lines in the Microwave Region at Low Pressure and High Temperature, Nuovo Cimento $\underline{36}, 916$.

974. V. A. Dudkin, T. L. Andreeva, V. I. Malyshev, \& V. N. Sorokin, Broadening of Emission Lines of Thallium by Molecular Hydrogen, Opt. Spectrosc. (USSR) $19,99$.

975. A. Eberhagen, M. J. Bernstein, \& H. Hermansdorfer, T1me-Resolved Profile Measurements of Impurity Lines in a Theta Pinch Discharge, Z. Naturforsch. A 20, 1375.

976. J. Flutak, Overlapping and Splitting of Spectral Lines, Acta Phys. Pol. 27, 753.

977. T. P. Gill, The Doppler Broadening of Spectral Lines, "The Doppler Effect," 47 (Logos Press, Ltd., Plainfleld, New Jersey).

978. R. Cranier \& J. Granier, The Influence of Density and Temperature on the Shift and Intensity of the "Blue Satellite" of the 2537 \& Line of Mercury, Perturbed by Helium Under Pressure, C. R. H. Acad. Sc1. 260, 3025. (Fr.)

979. R. Granier \& J. Granier, Influence of the Temperature on the Displacement of the Mercury Line 2537 \& Under the Effect of Helium at Low and High Densities, C. R. H. Acad. Sc1. 260, 92 . (Fr.)

980. L. I. Grechikhin \& M. A. El'yashevich, Use of the Quadratic Stark Effect to Determine the Concentration of Charged Particles in a Plasma from the Broadening of L1thium and Sodium Lines, J. Appl. Spectrosc. (USSR) $\underline{3}, 145$. 
981. H. R. Griem, Theory of Wing Broadening of the Hydrogen Lyman- $\alpha$ Line by Electrons and Ions in a Plasma, Phys. Rev. 140, Al140; Phys. Rev. A 144, 366.

982. L. Herman \& K. C. Clark, Emission and Continuous Absorption of Xenon in the Vacuum Ultraviolet, J. Quant. Spectrosc. Radiat. Transfer $\underline{5}, 765$. (Fr.)

983. D. G. Hummer, The Voigt Function. An Eight-Significant-Figure Table and Generating Procedure, Mem. Roy. Astron. Soc. 70 , 1.

984. K. Hunger, R. W. Larenz, \& K. Wilke, On the Plasma Microfield, Z. Naturforsch. A $20,158$. (Ger.)

985. I. Iova \& M. Prodan, The Behavior of the Profile of an Argon Spectral Line in an Electric Snark Plasma, Rev. Roum. Phys. 10, 747. (Fr.)

986. A. Jablonski, Inclusion of the Lorentz Effect into Theorles of Pressure Broadening of Spectral Lines Based on the Franck-Condon Principle, Acta Phys. Pol. 27, 49.

987. O. Jefimenko, Potential Curves for Neutral Atoms and Molecules in the State of Collision, J. Chem. Phys. 42, 205.

988. O. Jefimenko \& G. M. Williams, Satellite Bands in the Spectra of Potassium-ForeignGas Mixtures, J. Chem. Phys. 42, 207.

989. F. A. Korolyov \& V. I. Odintsov, Investigation of the Width of Helium Spectral Lines with Electron Excitation in an Atomic Beam, Opt. Spectrosc. (USSR) 18, 547.

990. H. G. Kuhn, E. L. Lewis, \& J. M. Vaughan, Enhancement of Radiation Damping by Resonance Coupling, Phys. Rev. Lett. 15, 687.

991. D. Lagarde \& R. Lennuier, Effect of Pressure on the Spectral Profile on the Resonance Line $\lambda 25.37$ \& of the Mercury Isotope 198, C. R. H. Acad. Sc1. 261, 919. (Fr.)

992. E. A. McLean \& S. A. Ramsden, Optical Interferometric and Spectroscopic Measurements of Electron Density in a Plasma, Phys. Rev. 140, All22.

993. D. Mihalas, Model Atmosnheres and Line Profiles for Early-Type Stars, Astrophys. J., Suppl. Ser. $\underline{9}, 321$.

994. A. A. Misyunas \& A. D. Valuzhis, Temperature Influence on the Pressure SelfBroadening, of the Resonance Line of $\mathrm{Cd}^{113} 3261$ \& and Its Hyperfine Structure Components, Litov. Fiz. Sb. 5, 259. (Russ.)

995. M. Mizushima, D. Robert, \& L. Galatry, Natural Width of Spectral Lines and Irreversibility, J. Phys. (Paris) 26, 194. (Fr.) 
996. V. A. Morozov \& P. P. Shorygin, On the Theory of the Radiative Width of Spectral Lines, Opt. Spectrosc. (USSR) 19, 164.

997. K. G. Müller, Influence of Field Inhomogeneity on Ionic Line Broadening, J. Quant. Spectrosc. Radiat. Transfer 5, 403.

998. J. Oxenius, Emission and Absorption Profiles in a Scattering Atmosphere, J. Quant. Spectrosc. Radiat. Transfer $\underline{5}, 771$.

999. H. Pfennig \& E. Trefftz, Tables of the Stark Effect of Helium, Max-Planck-Institut für Physik und Astrophysik, 18/65, München.

1000. C. H. Popenoe \& J. B. Shumaker, Jr., Arc Measurement of Some Argon Transition Probabilities, J. Res. Nat. Bur. Stand., Sect. A $\underline{69}, 495$.

1001. N. G. Preobrazhenski1, O. V. Ravodina, \& N. S. Terpugova, Formation of a Spectral Line Contour with Asymmetric Self-Reversal, J. Appl. Spectrosc. (USSR) $\underline{3}, 151$.

1002. A. T. Ramsey \& L. W. Anderson, Pressure Shifts in the ${ }^{23}$ Na Hyperfine Frequency, J. Chem. Phys. 43, 191 .

1003. G. P. Reck, H. Takebe, \& C. A. Mead, Theory of Resonance Absorption Line Shapes in Monatomic Gases, Phys. Rev. 137, A683.

1004. H. Van Regemorter, Spectral Line Broadening, Annu. Rev. Astron. Astrophys. 3,71 .

1005. W. Ruland, The Interral Width of the Convolution of a Gaussian and a Cauchy Distribution, Acta Crystallogr. 18, 581.

1006. I. I. Sobel'man, Excltation of Atoms by Electrons and Broadening of Spectral Lines, Sov. Phys. - JETP 21, 642.

1007. E. Spiller, Experimental Investigations on Gain and Maximum Output of the He-Ne Laser, Z. Phys. 182, 487.

1008. W. J. Surtees, Calculation of Combined Donpler and Collision Broadening, J. Opt. Soc. Amer. 55, 893.

1009. K. Tittel, Measurement of the Cross Sections for the Line Broadening of HighFrequency Transitions in the $6{ }^{3} \mathrm{P}_{2}$ Term of $\mathrm{Hg}$ by Collisions with Noble Gas Atoms, Z. Phys. 187, 421. (Ger.)

1010. G. Traving, Line Absorption (Line Broadening), "Zahlenwerte und Funktionen aus Naturwissenschaften und Technik," Vol. 6, No. 1, 445-451 (Ed. Landolt-Boernstein, Springer-Verlaf, Berlin). (Ger.) 
1011. C. H. van Trigt, Ty. Hollander, \& C. T. J. Alkemade, Determination of the a'Parameter of Resonance Lines in Flames, J. Quant. Spectrosc. Radiat. Transfer 5, 813 .

1012. F. A. Uvarov \& V. A. Fabrikant, Experimental Determination of the Effective Probability of Photon Emission by Plasma Atoms, Opt. Spectrosc. (USSR) 18, 323.

1013. C. R. Vidal, Stark Broadening; of the Paschen Lines, "Proceedings of the Seventh International Conference on Ionization Phenomena in Gases," (Gradevinska Knjiga Publishing House, Belgrade).

1014. V. Vujnovic, Behaviour of the First Balmer Lines in a High Density Plasma, Int. J. Electron. 18, 411 .

1015. K. Weise, The Distributions of the Electric Microfields and Micropotentials in a Plasma, Z. Phys. 183, 36. (Ger.)

1016. W. L. Wiese, Line Broadening, "Plasma Diagnostic Techniques," Ch. 6 (Ed. R. H. Huddlestone \& S. L. Leonard, Academic Press, Inc., New York).

1017. C. Young, Tables for Calculating the Volgt Profile, University of Michigan, College of Engineering Report 05863.

1018. C. Young, Calculation of the Absorption Coefficient for Lines with Combined Doppler and Lorentz Broadening, J. Quant. Spectrosc. Radiat. Transfer 5 , 549.

1038. L. Agnew \& C. Summers, Quantitative Snectroscopy of Cesium Plasmas, "ProceedIngs of the Seventh International Conference on Ionization Phenomena in Gases," Vol. II, 574 (Cradevinska Knjlga Publishinr House, Belfrade).

1039. V. A. Alekseev \& I. I. Sobel'man, $\Lambda$ Spectrosconic Method for the Investigation of Flastic Scatterinf, of Slow Electrons, Sov. Phys. - JETP 22, 882.

1040. E. A. Ball1k, The Response of Scanninr Fabry-Perot Interferometers to Atomic Transition Profiles, Apnl. Opt. 5, 170.

1041. A. Ben-Reuven, Impact Broadening of Microwave Spectra, Phys. Rev. $145,7$.

1042. A. Ben-Reuven, Symmetry Considerations in Pressure-Broadenine Theory, Phys. Rev. 141, 34 .

1043. H. F. Berf, Plasma Effects on an Ionized Helium Line, 7. Phys. 191, 503. (Ger.) 
1044. G. Birnbaum, Theory of Microwave Nonresonant Absorption and Relaxation in Gases, Phys. Rev. 150, 101.

1045. A. L. Bloom \& D. L. Wright, Pressure Shifts in a Stabilized Single Wavelength Helium-Neon Laser, Proc. IEEE 54, 1290.

1046. A. L. Bloom \& D. L. Wright, Pressure Shifts in a Stabilized Single Wavelength Helium-Neon Laser, Appl. Opt. $\underline{5}, 1528$.

1047. J. M. Bridges \& W. L. Wiese, Comparison of the Stark Widths of the Balmer Lines $\mathrm{H}_{\beta}$ and $\mathrm{H}_{\alpha}$, "Proceedings of the Seventh International Conference on Ionization Phenomena in Gases," Vol. III, 165 (Gradevinska Knfiga Publishing House, Belgrade).

1048. H. G. van Bueren \& H. Nieuwenhu1jzen, Determination of the Instrumental Profile of the Utrecht Solar Spectrograph by Use of a Laser, Bull. Astron. Inst. Neth. $\underline{18}, 170$.

1049. A. I. Burshtein, Relaxation in Line Spectra in an Instantaneous-Collision Approximation, Sov. Phys. - Dokl. 11, 65.

1050. A. I. Burshtein, Kinetics of the Relaxation Induced by a Sudden Potential Change, Sov. Phys. - JETP 22, 939.

1051. A. I. Burshtein \& Yu. I. Naberukhin, Adiabatic Theory of the Shape of Spectral Lines in Gases in Terms of the Hard Sphere Model, Opt. Spectrosc. (USSR) 20, 521.

1052. M. A. Cayless, Resonance Radiation from High Pressure Alkal1-Metal Vapour Discharges, "Proceedings of the Seventh International Conference on Ionization Phenomena in Gases," Vol. I, 651 (Gradevinsḳa Knj1ga Publishing House, Belgrade).

1053. C. Chiarella \& A. Reichel, On the Evaluation of Volgt Spectral Line Functions, Mon. Notic. Roy. Astron. Soc. $134,83$.

1054. J. Cooper, Plasma Spectroscopy, Rep. Progr. Phys. 29, 65.

1055. J. Cooper, Line Profile in the One-Electron Approximation, Phys. Rev. Lett. 17, 991.

1056. G. J. Dalenoort, Collision Broadening, and Correlation Functions in Plasmas, Association EURATOM-FOM, FOM-Inst,1tuut voor Plasma-Fysica Rijnhuizen, Jutphaas, Nederland, p. $11-37$.

1057. A. Di Giacomo, On the Validity of the Semi-Classical Treatment of Collisions, in Problems of Pressure Shift and Broadening, of Spectral Lines, Nuovo Cimento $44,140$. 
1058. S. Dumont, Theoretical Profiles of the Resonance Lines of $\mathrm{Ca}$ II and $\mathrm{Mg}$ II Ions, C. R. H. Acad. Sci., Ser. B 263,85 . (Fr.)

1059. F. N. Edmonds, Jr., The Determination of the Ultraviolet Continuum of Procyon from Balmer Line Profiles, "Abundance Determinations in Stellar Spectra," Proc. 26th I.A.U. Symposium, 159-167 (Ed. H. Hubenet, Academic Press, New York).

1060. L. D. de Feiter, The Broadening of the Balmer Lines Produced in Flares, Rech. Astron. Observ. Utrecht $18,18$.

1061. J. Fiutak, Classical Path Approximation in Pressure Broadening Theory, Bull. Acad. Pol. Sci., Ser. Sci., Math., Astron., Phys. 14, 647.

1062. R. O. Garrett \& S. Y. Ch'en, Pressure Effects of Foreign Gases on the Absorption Lines of Cesium. II. The Effects of Helium on the First Two Members of the Principal Series, Phys. Rev. 144, 66; Phys. Rev. A $1,975$.

1063. J. B. Gerardo \& R. A. Hill, Test of the Theory of Stark Broadening of $H_{\beta}$, Phys. Rev. Lett. $17,623$.

1064. R. Granier \& J. Granier, An Attempt to Determine the Potential Energy Curves of the $\mathrm{Rb}-\mathrm{Ne}$ Pair. Relation with an Interpretation of the Blue Satellites, C. R. H. Acad. Sci., Ser. B 262, 1502. (Fr.)

1065. R. Granier \& J. Granier, Influence of Density and Temperature on the "Red Satellite" of the Second Doublet of Rubidium Perturbed by Kryoton, C. R. H. Acad. Sci., Ser. B 262, 605. (Fr.)

1066. R. Granier \& J. Granier, Influence of the Temperature on the Displacement and Broadening of the Resonance Lines of Rubidium Perturbed by Argon, C. R. H. Acad. Sci., Ser. B 262, 761. (Fr.)

1067. R. Granier, J. Granier, \& B. Vodar, Influence of the Mass and Temperature on the Displacement of Several Resonance Lines Perturbed by Foreign Gas Under Pressure, J. Quant. Spectrosc. Radiat. Transfer $\underline{6}, 741$. (Fr.)

1068. S. M. Gridneva \& G. A. Kasabov, Oscillator Strengths and Cesium Spectral Line Profiles in a Plasma, "Proceedings of the Seventh International Conference on Ionization Phenomena in Gases," Vol. II, 581 (Gradevinska Knjiga Publishing: House, Belgrade). (Russ.)

1069. H. R. Griem, Electron-Impact Broadening of Isolated Ion Lines, Phys. Rev. Lett. 17, 509 .

1070. H. R. Griem, Plasma Polarization Shifts of Ion Lines, "Proceedings of the Seventh International Conference on Ionization Phenomena in Gases," Vol. II, 551 (Gradevinska Knjiga Publishing House, Belgrade). 
1071. H. Haken, Theory of Intensity and Phase Fluctuations of a Homogeneously Broadened Laser, Z. Phys. 190, 327.

1072. R. Hallin, The Spectrum of $\mathrm{N}$, Ark. Fys. $\underline{31}, 511$.

1073. L. Herman, Nguyen-Hoe, H. W. Drawin, B. Petropoulos, \& C. Deutsch, Shift and Intensity of the Components of the Lines of Atomic Hydrogen Subjected to Uniform Exterior Electric and Magnetic Fields, "Proceedings of the Seventh International Conference on Ionization Phenomena in Gases," Vol. II, 562 (Ed. B. Perovic \& D. Tosic, Gradevinska Knjiga Publishing, House, Belgrade). (Fr.)

1074. G. Hernandez, Analytical Description of a Fabry-Perot Photoelectric Spectrometer, Appl. Opt. $\underline{5}, 1745$.

1075. R. A. Hill \& R. D. Fellerhoff, A Dual Recording, Varlable Range, Rapid-Scan Spectrometer; Comparison of Simultaneously Recorded Stark-Broadened $\mathrm{H}_{\alpha}$ and $\mathrm{H}_{\beta}$ Line Profiles, Appl. Opt. $\underline{5}, 1105$.

1076. R. L. Hilliard \& G. G. Shepherd, Wide-Angle Michelson Interferometer for Measuring Doppler Line Widths, J. Opt. Soc. Amer. $\underline{56}, 362$.

1077. C. F. Hooper, Electric Microfield Distributions in Plasmas, Phys. Rev. $149,77$.

1078. D. L. Huber \& J. H. Van Vleck, The Role of Boltzmann Factors in Line Shape, Rev. Mod. Phys. 38, 187.

1079. K. Hunger, R. W. Larenz, \& K. H. Wilke, On the Sipnificance of the Far Field Portion of the Plasma Microfield, "Proceedings of the Seventh International Conference on Ionization Phenomena in Gases," Vol. II, 29 (Ed. B. Perovic \& D. Tosic, Gradevinska Knjlga Publishing House, Belgrade).

1080. I. Iova, The Shift of Ar I Spectral Lines in the Plasma of a Low-Power Spark Discharge, Opt. Spectrosc. (USSR) 20, 13.

1081. N. W. Jalufka, G. K. Oertel, \& G. S. Ofelt, Measurements of Stark Broadening of Some Singly Ionized Argon Lines, Phys. Rev. Lett. 16, 1073.

1082. V. O. Jensen, On the Possibility of Detecting Microinstabilities by Their Polarizing Effect on Spectral Lines, "Proceedings of the Seventh International Conference on Ionization Phenomena in Gases," Vol. II, 553 (Gradevinska Knjiga Publishing, House, Belgrade).

1083. Y. Leycuras, Red Shifts of Resonance Lines and Beams of Atoms of High Density, J. Quant. Spectrosc. Radiat. Transfer $\underline{6}, 137$. (Fr.) 
1084. Y. Leycuras, On the Appearance of Violet Satellites and Their Position as a Function of the Density of the Perturbinf, Atoms, J. Quant. Spectrosc. Radiat. Transfer $\underline{6}$, 131. (Fr.)

1085. E. K. Maschke \& D. Voslamber, Stark Broadening of Hydrogen Lines in Strong Magnetic Fields, "Proceedings of the Seventh International Conference on Ionization Phenomena in Gases," Vol. II, 568 (Gradevinska Knflga Publishing House, Belgrade).

1086. M. A. Mazing \& N. A. Vrublevskaya, Spectroscopic Investipation of the Elastic Scattering of Slow Electrons by Cesium and Argon Atoms, Sov. Phys. - JETP 23, 228.

1087. L. A. Minaeva \& I. I. Sobel'man, On the Stark Broadening of Atomic Hydrogen Spectral Lines in Radio Region, Astron. Tsirk., No. 383. (Russ.)

1088. D. Mugglestone \& B. J. O'Mara, The Influence of Stark Broadening on Abundance Determinations, Mon. Notic. Roy. Astron. Soc. 132, 87.

1089. K. Murakawa, Stark Broadening of an Ionized-Mercury Line, Phys. Rev. $146,135$.

1090. K. Murakawa, M. Yamamoto, \& S. Hashimoto, Snectroscopic Investigation of an Argon Plasma Jet, "Proceedings of the Seventh International Conference on Ionization Phenomena in Gases," Vol. II, 594 (Gradevinska Knfiga Publishing House, Belgrade).

1091. Nguyen-Hoe, H. W. Drawin, \& L. Herman, Influence of a Magnetic Field on the Broadening of Hydropen Lines, Z. Naturforsch. A 2l, 1515. (Ger.)

1092. A. Omont, Remarks on the Theory of Holtsmark Broadening of Optical Resonance Lines, C. R. H. Acad. Sc1., Ser. B 262 , 190. (Fr.)

1093. S. Pancharatnam, Lipht Shifts in Semiclassical Dispersion Theory, J. Opt. Soc. Amer. 56, 1636.

1094. M. L. Parsons, W. J. McCarthy, \& J. D. Winefordner, Apnroximate Half-Intensity Widths of a Number of Atomic Spectral Lines Used in Atomic-Emission and AtomicAbsorntion Flame Spectrometry, Appl. Spectrosc. 20, 223.

1095. H. Pfennig, Comparison of Quasistatic Line Profiles with Measurements on Balmer and Paschen Hydrogen Lines and Lines of the Diffuse Series of Neutral Helium, J. Quant. Spectrosc. Radiat. Transfer $\underline{6}, 549$.

1096. H. Pfennig, The Wings of the Balmer and Paschen Lines of Atomic Hydrogen: A Comparison between Theory and Experiment, Z. Naturforsch. A 2l, 1648. (Ger.) 
1097. H. Pfennif \& E. Trefftz, Pressure Broadening of the Diffuse Helium Lines; Comparison between Measurement and Theory in the Quasistatic Regime, Z. Naturforsch. A 21,697 . (Ger.)

1098. H. Pfennif \& E. Trefftz, The Quasistatic Pressure Broadening of Diffuse Helium Lines, Z. Phys. 190, 253. (Ger.)

1099. H. Pfennig, E. Trefftz, \& C. R. Vidal, A Critical Note on the Up to Now Available Stark Broadening, Theories of Hydrogen, J. Quant. Spectrosc. Radiat. Transfer 6 , 557 .

1100. S. Rautian \& I. I. Sobel'man, The Theory of Dopnler and Impact Broadening of Snectral Lines and Pressure Effects on the Power Outnut of a Gas Laser, IEEE J. Quantum Electron. QE-2, 446.

1101. R. H. Ritchie \& V. E. Anderson, The Use of Fourier Transforms in the Unfolding of Experimental Data, Nucl. Instrum. Methods 4 5, 277.

1102. D. E. Roberts, The Stark Widths of Singly Ionized Argon Lines Emitted by a Plasma, Phys. Lett. 22, 417 .

1103. D. W. Ross, Pressure Broadening, as a Many-Body Problem, Ann. Phys. (New York) 36, 458.

1104. H. Schlüter \& C. Avila, Observations on Collisional Stark Broadening in Radio Frequency Discharges, Astrophys. J. 144, 785.

1105. H. Schlüter, C. Avila, \& J. Durham, Studies in the Quasi-Static Regime of Stark Broadening, of Electrons, "Proceedings of the Seventh International Conference on Ionization Phenomena in Gases," Vol. III, 160 (Gradevinska Knjiga Publishing House, Belgrade).

1106. P. W. Smith, Jinewidth and Saturation Parameters for the 6328-R Transition in a He-Ne Laser, J. Appl. Phvs. 37, 2089.

1107. F. Strumia, Magnetic Rotatory Power of Opticallv Pumped Na Vapour and Its Anplication to the Study of Lonpitudinal Relaxation Time and of Buffer-Gas-Pressure Broadening of optical Lines, Nuovo Cimento B $44,387$.

1108. A. Szöke \& A. Javan, Effects of Collisions on Saturation Behavior of the 1.15-u Transition of Ne Studied with He-Ne Laser, Phys. Rev. 145, 137.

1109. J. Szudy, The Mercury Resonance Line Broadened by Argon, Acta Phys. Pol. 29, 605.

1110. J. Szudy, The Interaction Potentjal Between Mercury and Helium Atoms, Acta Phys. Pol. $30,721$. 
1111. J. M. Vaughan, An Experimental Determination of the Resonance Broadening Constant, Phys. Lett. 21, 153.

1112. J. M. Vaughan, Self Broadening and Radiation Width in the Singlet Spectrum of Helium, Proc. Roy. Soc., Ser. A 295, 164.

1113. R. F. de Vries, Unfolding Stark and Doppler Profiles to Obtain Electron Densities and Ion Temperatures, "Proceedings of the Seventh International Conference on Ionization Phenomena in Gases," Vol. III, 173 (Gradevinska Knjlga Publishing House, Belgrade).

1114. B. Ya'akobi, The Self-Broadening of the Resonance Lines of Lithium, J. Quant. Spectrosc. Radiat. Transfer $\underline{6}, 909$.

1115. M. Yamamoto, Profile of Ionized-Calcium Lines in an Arc-Plasma Jet, Phys. Rev. $146,137$.

1116. K. Yasuda, Relationship Between Resonance Line Profile and Absorbance in Atomic Absorption Spectrometry, Anal. Chem. 38, 592.

1136. V. A. Alekseev, M. A. Mazing, P. D. Serapinas, I. I. Sobel'man, \& L. A. Vainshtein, The Evaluation of Effective Scattering Cross Sections From Spectral Line Broadeninf, "Fifth International Conference on the Physics of Electronic and Atomic Collisions," 528 (Lening,rad, USSR).

1137. K. Ando, Stark Broadeninf of He II 3203 \&, J. Phys. Soc. Jap. 23, 1183.

1138. B. H. Armstrong, Spectrum Line Profiles: The Voift Function, J. Quant. Snectrosc. Radiat. Transfer $7,61$.

1139. R. L. Barper, Rare-Gas Collision Broadenint in the Lowest ${ }^{3} \mathrm{P}_{1}$ Level of $\mathrm{Cd}$, Phys. Rev. 154, 74.

1140. A. Ben-Reuven \& A. Lifhtman, Impact Broadening of the Oxygen Microwave Spectrum, J. Chem. Phys. $46,2429$.

1141. W. R. Bennett, Jr., V. P. Chebotaev, \& J. W. Knutson, Jr., Direct Observation of Collision Broadeninf, and Effect of Resonant Interactions on Gas-Laser Transitions, Phys. Rev. Lett. 18, 688.

1142. H. F. Berf, W. Frvens \& B. Furch, Exnerimental Stark-Widths of iv II-Lines, "Proceedings of the Eifhth International Conference on Ionization Phenomena in Gases," 439 (Springer-Verlar, Berlin). 
1143. H. F. Berp, W. Ervens, \& B. Furch, Stark Effect on Lines of Sinply Ionized Nitrogen, Z. Phys. 206, 309. (Ger.)

1144. B. Bezzerides, Resonance Broadeninf of Absorption Lines, Phys. Rev. 159, 3.

1145. B. Bezzerides, Radiation Absorotion Phenomena in Gases--I General Theory of Line Broadening, J. Quant. Spectrosc. Radiat. Transfer 7, 353.

1146. J. W. Birkeland, J. P. Oss, \& W. G. Braun, A Comparison of Stark Broadened H and $\mathrm{H}_{B}$ Half-Widths, "Proceedings of the Eighth International Conference on Ionization Phenomena in Gases," (Springer-Verlaf, Berlin).

1147. G. Birnbaum, Microwave Pressure Broadening, and Its Anplication to Intermolecular Forces, Advan. Chem. Phys. 12, 487.

1148. P. T. Bolwifn \& C. T. J. Alkemade, Power Broadening and Collision Broadening of Gas Laser Trans1tions, Phys. Lett. A 2ㄷ, 632.

1149. S. Brechot, On Flectron Impact Broadening of Positive Ion Lines, Phys. Lett. A 24, 476 .

1150: S. Brechot \& N. Feautrier, Semi-Classical Calculation of the Broadening of Positive Ion Lines by Electronic Collisions, C. R. H. Acad. Sc1., Ser. B 265, 39. (Fr.)

1151. S. Brechot, N. Feautrier, \& H. Van Regemorter, Broadening of Spectral Lines by Electron Impact, "Excitation Electronique D'Une Vapeur Atomique-Application a la Spectroscopie," no. 162, 51-59 (Centre National de la Recherche Scientifique, Par1s).

1152. R. G. Breene, Jr., Spectral Line Broadening in Air Molecule Systems, Appl. Opt. 6. 141 .

1153. J. M. Bridges \& W. L. Wiese, Experimental Determination of Transition Probabilities and Stark Widths of S I and S II Lines, Phys. Rev. 159, 31.

1154. D. D. Burgess, B. C. Fawcett, \& N. J. Peacock, Vacuum Ultra-Violet Emission Spectra from Laser-Produced Plasmas, Proc. Phys. Soc., London 92, 805.

1155. A. I. Burshtein \& Yu. I. Naberukhin, Phase-Memory Effects in the Theory of Spectral Line Broadening in Gases, Sov. Phys. - JETP 25, 799.

1156. J. Butaux \& R. Lennuier, Comparative Effects of Hydrogen and Deuterium on the Position and Spectral Profile of the Line $\lambda=2537 \AA$ of Mercury 198, C. R. H. Acad. Sc1., Ser. B 265, 43. (Fr.) 
1157. J. Chapelle, A. Sy, F. Cabannes, \& J. Blandin, Study of Widths and Transition Probabilities of Argon Lines by Means of a Plasma Jet, J. Quant. Spectrosc. Radiat. Transfer 8 , 1201; C. R. H. Acad. Sc1., Ser. B, 264, 853. (Fr.)

1158. S. Y. Ch'en, E. C. Loo1, \& R. O. Garrett, Pressure Effects of Forelgn Gases on the Absorption Lines of Cesium. III. The Effects of Krypton, Phys. Rev. 155, 38; Phys. Rev. A $1,975$.

1159. J. Cooper, Broadening of Isolated Lines in the Impact Approximation Using a Density Matrix Formulation, Rev. Mod. Phys. 39, 167.

1160. J. Cooper \& G. K. Oertel, Stark Broadening of Isolated Ion Lines In a Plasma, Phys. Rev. Lett. 18, 985.

1161. G. J. Dalenoort, On Stark-Broadening of Spectral Lines from Plasmas, Physica (Utrecht) 36,161 .

1162. R. Damaschini \& J. Brochard, On the Profile of Two Lines of Helium at Low Temperature, C. R. H. Acad. Sci., Ser. B $264,1350$.

1163. J. Davis, A Density Matrix Approach to Impact Broadening of Spectral Lines, Proc. Phys. Soc., London 90, 283.

1164. J. Davis \& D. E. Roberts, The Influence of Elastic Collisions on the Broadening of Ion Lines, Proc. Phys. Soc., London $\underline{92}, 889$.

1165. H. W. Drawin, H. Henning, L. Herman, \& Nguyen-Hoe, Stark-Broadening of Hydrogen Balmer Lines $\mathrm{H}_{\alpha}, \mathrm{H}_{\beta}$ and $\mathrm{H}_{\gamma}$ in the Presence of Strong, Magnetic Fields in Plasmas, "Proceedings of the Eighth International Conference on Ionization Phenomena in Gases," 437 (Springer-Verlag, Berlin).

1166. F. N. Edmonds, Jr., H. Schlüter, \& D. C. Wells, III, Hydrogen-Line Stark BroadenIng Functions, Mem. Roy. Astron. Soc. $71,271$.

1167. D. Evans \& R. S. Tankin, Measurement of Emission and Absorption of Radiation by an Argon Plasma, Phys. Fluids 10, 1137.

1168. J. P. Faroux, Broadening of Level-Crossing Curves of the $6{ }^{3} \mathrm{P}_{1}$ State of ${ }^{199} \mathrm{Hg}$ by Collisions with Rare Gas Atoms, C. R. H. Acad. Sci., Ser. B 264, 1573. (Fr.)

1169. N. Feautrier, S. Brechot, \& H. Van Regemorter, On Electron Impact Broadening of Ionized Calcium and Argon Lines, "Fifth International Conference on the Physics of Electronic and Atomic Collisions," 525 (Leningrad, USSR).

1170. N. Feautrier, F. Praderie, \& H. Van Regemorter, On the Lines of Hydrogen II: The Respective Importance of the "Impact" and Quasistatic Domains for Electrons, Ann. Astrophys. 30, 45 . (Fr.) 
1171. H. Feldhausen \& H. J. Kusch, Van der Waals Broadening of Si I Lines by Argon, Z. Astrophys. 67, 123. (Ger.)

1172. C. F. Gallo, Role of Self-Absorption in $\mathrm{Hg}+\mathrm{Tl}$ Sensitized Fluorescence ExperIments, Phys. Rev. $158,1$.

1173. R. O. Garrett, S. Y. Ch'en, \& E. C. Loo1, Pressure Effects of Foreign Gases on the Ahsorption Lines of Cesium. IV. The Effects of Neon, Phys. Rev. 156, 48; Phys. Rev. A I, 975 .

1174. R. Granier, M. C. Castex, J. Granier, \& J. Romand, Study of the Perturbation of the Resonance Line 1469 \& of Xenon by Various Rare Gases and by Hydrogen, C. R. H. Acad. Sc1., Ser. B 264,778 . (Fr.)

1175. H. R. Griem, Semi-Empirical Formulas for the Electron Impact Broadening of Isolated Spectral Lines in Plasmas, "Proceedings of the Eighth International Conference on Ionization Phenomena in Gases," 433 (Springer-Verlag, Berlin).

1176. H. R. Griem, Stark Broadening by Electron and Ion Impacts of na Hydrogen Lines of Large Principal Quantum Number, Astrophys. J. 148, 547.

1177. H. R. Griem, Corrections to the Asymptotic Holtsmark Formula for Hydrogen Lines Broadened by Electrons and Ions in a Plasma, Astrophys. J. 147, 1092.

1178. W. Happer \& E. B. Saloman, Resonant Collision Broadening of the $\left(6 s^{2} 6 p 7 s\right)^{3} \mathrm{P}_{1}{ }^{\circ}$ State in Lead, Phys. Rev. 160, 23.

1179. H. Hessberg \& W. Bötticher, Measurement of the Pressure Broadening, of Lines of the 2. Lyman-Series of the Helium Ions, Z. Naturforsch. A 22, 316. (Ger.)

1180. R. A. Hill, Fractional-Intensity Widths and Stark-Broadening Formulas for the Hydrogen Balmer Lines, J. Quant. Spectrosc. Radiat. Transfer $\underline{7},-401$.

1181. R. A. Hill \& J. B. Gerardo, Stark Broadening of $\mathrm{H}_{B}, \mathrm{H}_{\gamma}$, and $\mathrm{H}_{\delta}$ : An Experimental Study, Phys. Rev. 162, 45.

1182. W. R. Hindmarsh, A. D. Petford, \& G. Smith, Interpretation of Collision Broadening and Shift in Atomic Spectra, Proc. Roy. Soc., Ser. A $297,296$.

1183. I. Iova, Broadening and Shift of Spectral Lines of Ar I and Ar II in Electric Spark Plasma Under Pressures Higher than $1 \mathrm{Atm}$. , "Proceedings of the Eighth International Conference on Ionization Phenomena in Gases," 440 (SpringerVerlag, Berlin).

1184. T. Ishimura, Stark Effect of the Lyman Alpha Line by a Rotating Electric Field, J. Phys. Soc. Jap. 23, 42.2 . 
1185. A. F. Jones \& D. L. Misell, A Practical Method for the Deconvolution of Experimental Curves, Brit. J. Appl. Phys. 18, 1479.

1186. V. I. Kogan, V. S. Lisitza, \& A. D. Selidovkin, On the Plasma Microfield and Some Related Effects, "Proceedings of the Elghth International Conference on Ionization Phenomena in Gases," 273 (Springer-Verlag, Berlin).

1187. M. A. Kozhushner, On the Width and Density of Hirhly Excited Atomic Levels in Gases, Sov. Phys. - JETP 24, 982 .

1188. H. G. Kuhn \& E. L. Lewis, Self Broadening and f-Values in the Spectrum of Neon, Proc. Roy. Soc., Ser. A 299, 423.

1189. L. N. Kurochka, Stark Broadening of Hydrogen Lines, Sov. Astron. - AJ 11, 290.

1190. H. J. Kusch, Broadening of Carbon Lines by Microfields, Z. Astrophys. 67, 64. (Ger.)

1191. H. J. Kusch \& G. Meinhold, Pressure Broadening of Titanium Lines by Central Argon Atoms, Z. Astrophys. 66, 364. (Ger.)

1192. H. J. Kusch \& E. Oberscheln, Broadening of Cadmium Lines by Microfields, Z. Astrophys. 67,85 . (Ger.)

1193. H. J. Kusch \& E. Oberscheln, Broadening of Zinc-Lines by Microflelds, Z. Astrophys. 67, 77 . (Ger.)

1194. D. Lagarde, J. Butaux, R. Lennu1er, \& J. Y. Prevot, Determination of Spectral Profiles by the Method of Magnetic Scanning, J. Phys. (Paris) C-2, 243. (Fr.)

1195. P. Lambropoulos, Spectral Line Shape in the Presence of Weak Collisions and Intense Fields, Phys. Rev. 164, 84.

1196. E. L. Lewis, Self-Broadening and Oscillator Strengths in the Rare Gases, Proc. Phys. Soc., London $\underline{92}, 817$.

1197. D. Messerschmidt, M. Scholz, \& G. Traving, On the Internretation of Strong He I Lines in Early Type Spectra, Z. Astrophys. 66, 246.

1198. A. A. Misyunas \& A. D. Valuzhis, Temperature Influence on the Collison Broadening of the Resonance Line of Cadmium $\lambda 3261$ \& by the Arron Pressure, Litov. Fiz. Sb. I, 491. (Russ.)

1199. A. A. Misyunas \& V. K. Norkunas, The W1dth, Shift, and Asummetry of the Resonance Line of $\mathrm{Zn} 3075.9$ \& by the Perturbation of Rare Gases, Litov. Fiz. Sb. $1,221$. (Russ.) 
1200. A. A. Misyunas \& A. D. Valuzhis, Temperature Influence on the Resonance Broadening of a Spectral Line, Litov. Fiz. Sb. I, 849. (Russ.)

1201. M. H. Mittleman, Pressure Shifts of Highly Excited States of Atoms, Phys. Rev. 162,81 .

1202. M. Mizushima, Contribution to Theory of Pressure Broadening, Progr. Theor. Phys. Suppl. No. 40, 207.

1203. M. Mizushima, Velocity Distribution in Spectral Line Shape, J. Quant. Spectrosc. Radiat. Transfer $\underline{7}, 505$.

1204. J.S. Murphy \& J. E. Bopgs, Collision Broadening of Rotational Absorption Lines. I - IV., J. Chem. Phys. 47, 691; 47, 4152; 49, 3333; 50, 3320.

1205. Nguyen-Hoe, H. W. Drawin, \& L. Herman, Effect of a Uniform Magnetic Field on Hydrogen Line Profiles, J. Quant. Spectrosc. Rad1at. Transfer 7, 429. (Fr.)

1206. G. K. Oertel, Debye Shieldinf in Stark Broadening of Isolated Helium I Lines, "Proceedings of the Eighth International Conference on Ionization Phenomena in Gases," 279 (Springer-Verlag, Berlin).

1207. N. P. Penkin \& L. N. Shabanova, Oscillator Strengths and Effective Cross Sections of the Resonance Lines of Gallium and Indium Atoms for Line-Broadening Collisions, Opt. Spectrosc. (USSR) 23, 11 .

1208. F. Praderie, on Hydrogen Lines I. Quasi-Static Profiles in Stellar Atmospheres, Ann. Astrophys. 30, 3l. (Fr.)

1209. N. G. Preobrazhenski1, The Snectral Line Shape in an Opt1cally Dense Plasma, Opt. Spectrosc. (USSR) 22, 95.

1210. S. G. Rautian, The Effect of Collisions on Spectral Characteristics of Gas Lasers, Sov. Phys. - JETP 24,788 .

1211. S. G. Rautian \& I. I. Sobel'man, The Effect of Collisions on the Doppler. Broadening of Snectral Lines, Sov. Phys. - Usn. 9, 701.

1212. D. E. Roberts, Investigations of Spectral Lines from High Temperature Plasmas Usinf, Fabry-Perot Interferometrv, Thesis, University of London.

1213. D. E. Roberts, The Stark Widths of Isolated Ion Lines, Phys. Lett. A $24,694$.

1214. D. E. Roberts \& J. Dav1s, The Shjft and Width of Isolated Ion Lines in the Adiabat1c Limit, Phvs. Lett. A 25, 175. 
1215. J. R. Roberts \& K. L. Eckerle, Measurements of Stark Proflles of C II and Ca II Lines, Phys. Rev. 159, 104.

1216. G. Schulz \& W. Stopp, Magneto-optical Determination of Line Profiles, Z. Phys. 207, 470 . (Ger.)

1217. E. W. Smith, Influence of Flectron Correlations on a Plasma-Broadened Lyman-Aloha Line, Phys. Rev. Lett. 18, 990.

1218. E. W. Smith \& C. F. Hooper, Jr., Relaxation Theory of Spectral Line Broadeninf In Plasmas, Phys. Rev. 157, 126.

1219. G. Smith, Collision Broadening and Shift in the $\lambda 6573$ Line of Calcium, Proc. Roy. Soc., Ser. A 297,288 .

1220. J. Szudy, The Pressure Broadening of the Mercury Resonance Line by Helium, Acta Phys. Pol. 32, 359.

1221. Yu. A. Vdovin \& V. M. Galitsk11, Dielectric Constant of a Gas of Resonant Atoms, Sov. Phys. - JETP 25, 894.

1222. D. Voslamber, Stark Broadening, Theory in the Transition Region Between the Quasistatic and the Collision Dominated Part of the Line Wing, "Proceedings of the Fiphth International Conference on Ionization Phenomena in Gases," 434 (springer-Verlag, Berlin).

1223. B. Wende, Asymmetrical Broadening of the Balmer Line H in a Plasma, Z. Angew. Phys. 2.2, 181. (Ger.)

1224. A. D. White, Pressure- and Current-Denendent Shifts in the Center Freauency of the Doppler-Broadened $\left(2 \mathrm{n}_{4} \rightarrow 3 \mathrm{~s}_{2}\right) 6328-\AA 20 \mathrm{Ne}$ Transition, Apnl. Phys. Lett. 10,24 .

1225. K. H. Wilson \& W. E. INicolet, Spectral Absorntion Coefficients of Carbon, Nitrogen and Oxygen Atoms, J. Quant. Spectrosc. Radiat. Transfer $7,891$.

1226. V. V. Yakimets, Theory of Broadening of Spectral Lines, Sov. Phys. - JETP 24 , 990.

1227. G. I. Zav'yalov, N. A. Prilezhaeva, \& A. Yu. Zav'valova, Conditions for Appearance of Continuum in Absorption Spectrum of Hg + M Vanor at the Ho, Line 2537 A, Sov. Phys. J. 10, 84 . 
1247. V. A. Alekseev \& E. A. Yukov, The Broadening of the Spectral Lines of Non-HydrogenLike Ions, Opt. Spectrosc. (USSR) 25, 363.

1248. R. Assous, Stark Effect of Infrared Lines of Ar I in a Plasma Jet Maintained at High Frequency, J. Phys. (Par1s) 29, 877. (Fr.)

1249. R. Assous, Correction to the Calculation of the Electronic Contribution to the Broadening of Lines by the Stark Effect, C. R. H. Acad. Sc1., Ser. B 267, 325 . (Fr.)

1250. M. E. Bacon \& D. F. Edwards, Effect of Stronf, Collisions on the $H_{\alpha}$ Profile, Phys. Rev. 170,125 .

1251. A. J. Barnard, H. G. James, \& C. R. Neufeld, Widths and Shifts of Argon-II Lines in a Pulsed Arc, Can. J. Phys. $46,1083$.

1252. W. Behmenburg, On the Interpretation of Spectral Line Broadening by Foreign Gases, Z. Astrophys. 69 , 368. (Ger.)

1253. R. D. Benftson, The Measurement of Transition Probabilities and Stark Widths for C I, F I, Ne I, Cl I, Cl II, Br I, and Br II, University of Maryland Technical Note $\mathrm{BN}-559$.

1254. D. W. Berreman, Unfolding Spectrometer Slit Broadening, Effects from Broad Spectra, Appl. Opt. . 1447.

1255. J. Blandin, S. Sahal-Brechot, J. Chapelle, \& A. Sy, Stark Shifts of A II Lines, Phys. Lett. A $26,487$.

1256. R. G. Breene, Jr., Relaxation Treatment of Molecular Stark Broadening, J. Mol. Spectrosc. 26,465 .

1257. R. G. Breene, Jr., Broadening of Molecular Spectral Lines, Vol. III, Line Broadening Bibliopraphy, Technical Renort No. AFWL-TR-67-77, Vol. III, Air Force Weapons Laboratory, Kirkland Air Force Base, New Mexico.

1258. R. A. Brown \& F. M. Plpkin, Pressure Shifts of Hyperfine Splitting of Hydrogen and Tritium in Argon, Phys. Rev. 174, 48.

1259. D. D. Burgess, Contribution of Perturber Radiation to the Shapes of Spectral Lines Broadened by Electron Impacts, Phys. Rev. 176, 150; Harvard College Observatory, Scientific Report No. 29.

1260. A. I. Burshtein, Saturation of the Doppler Spectrum, Sov. Phys. - JETP $27,600$. 
1261. J. Chapelle, A. Sy, F. Cabannes, \& J. Blandin, Profiles of Ar II Lines Observed in an Argon Plasma Jet, C. R. H. Acad. Sc1., Ser. B 266, 1513. (Fr.)

1262. C. L. Chen \& A. V. Phelps, Self-Broadening of Cesium Resonance Lines at 8521 and 8944 R, Phys. Rev. $173,62$.

1263. M. Dahmen \& H. J. Kusch, Pressure Broadening and Shift of T1 I Lines by Argon, Z. Astrophys. $\underline{68}, 445$. (Ger.)

1264. J. Davis \& D. E. Roberts, Temperature Dependence of Stark Broadening Parameters of Two Ionized Argon Multiplets, J. Phys. B $1,317$.

1265. J. Davis \& D. E. Roberts, Simple Formulae for Predicting Ion Linew1dths Including Debye Shielding, J. Phys. B $1,245$.

1266. C. Deutsch, H. W. Draw1n, L. Herman, \& Nguyen-Hoe, Combined Stark and Zeeman Effects on Hydrogenic Transitions of Neutral Hellum, J. Quant. Spectrosc. Radiat. Transfer $\underline{8}, 1027$.

1267. C. Deutsch, H. W. Drawin, L. Herman, \& Nguyen-Hoe, Dipolar Transitions of Atomic Hellum Subjected to Unfform External Fields, J. Phys. (Par1s), Colloq. 29, C3-56; "Proceedings of the Eighth International Conference on Ionization Phenomena in Gases," 436 (Springer-Verlag, Berlin). (Fr.)

1268. D. A. Draegert \& D. Williams, Collisional Broadening of CO Absorption Lines by Forelgn Gases, J. Opt. Soc. Amer. 58, 1399.

1269. F. N. Edmonds, Jr., Line Absorption Coefficient Profiles for Velocity-Dependent Broaden1ng, J. Quant. Spectrosc. Radiat. Transfer 8 , 1447.

1270. E. S. Ensberg \& C. L. Morgan, Pressure Shift of the Hydrogen Hyperfine Frequency by Krypton and Xenon, Phys. Lett. A $\underline{28}, 106$.

1271. S. Ergun, Direct Method for Unfolding Convolution Products--Its Application to X-ray Scattering, Intensities, J. Appl. Crystallopr. 1, 19.

1272. Yu. V. Evdokimov, Broadening of the Second Caesium Doublet by Inert Gases, Opt. Spectrosc. (USSR) 24, 448 .

1273. Yu. V. Evdokimov, N. I. Kaliteyevski1, \& M. P. Cha1ka, Measurement of Broadening and Displacement of Spectral Lines Using the Magnetic Scanning Method, Opt. Spectrosc. (USSR) 27, 98 .

1274. J. M. Farr \& W. R. Hindmarsh, An Interpretation of Red Satellite Bands in Atomic Spectra, Phys. Lett. A 27, 512. 
1275. N. Feautrier, Semi-Classical Calculation of Excitation Cross Sections by Electron Impact for Ions, Ann. Astrophys. 31, 305. (Fr.)

1276. B. S. Fraenkel, S. Goldsmith, \& U. Feldman, High Energy Satellites in the Vacuum U. V. Spectrum of Be III and Be IV, Phys. Lett. A 27, 111.

1277. J. I. Gersten \& H. M. Foley, Combined Doppler and Collision Broadening, J. Opt. Soc. Amer. $\underline{58}, 933$.

1278. R. Göhring, Determination of the Instrumental Profile of a Grating Spectrograph by Use of a Laser, Z. Astrophys. 69, 403. (Ger.)

1279. S. A. Gonchukov, G. A. Mikhnenko, \& E. D. Protsenko, Effect of Collisions on Certain Characteristics of the He-Ne Laser, Opt. Spectrosc. (USSR) 25, 305.

1280. J. R. Greig; C. P. Lim, G. A. Moo-Young, G. Palumbo, \& H. R. Griem, Measurements of the Stark Broadening of Two Neutral Hellum Lines in a Plasma, Phys. Rev. 172, 148.

1281. H. R. Griem, Calculated Electron and Ion Stark Broadening of the Allowed and Forbidden $2{ }^{3} \mathrm{P}-4{ }^{3} \mathrm{P},{ }^{3} \mathrm{D}, 3_{\mathrm{F}}$ Transitions in Neutral Helium, Astrophys. J. $154,1111$.

1282. H. R. Griem, Pressure Effects on Spectral Lines In Plasmas, "Optical Pumping and Atomic Line Shape," 331 (Ed. T. Skalinsk1, Panstwowe Wydawnictwo Naukowe, Warsaw).

1283. H. R. Griem, Semiempirical Formulas for the Electron-Impact Widths and Shifts of Isolated Ion Lines in Plasmas, Phys. Rev. 165, 258.

1284. M. A. Gubin, A. I. Popov; \& E. D. Protsenko, Pressure Dependence of the Line Width of the $3 s_{2}-3 p_{4}$ Transition of Neon, Opt. Spectrosc. (USSR) 25, 421.

1285. J. A. Gwinn, P. M. Thomas, \& J.F. Kielkopf, Satellite Bands in the Emission Spectrum of Cesium, J. Chem. Phys. $\underline{48}, 568$.

1286. B. L. Gyorffy, M. Borenstein, \& W. E. Lamb, Jr., Pressure Broadening Effects on the Output of a Gas Laser, Phys. Rev. 169, 340 .

1287. T. Hänsch \& P. Toschek, Power Broadening in a He-Ne Laser, IEEE J. Quantum Electron. QE-4, 530 .

1288. R. von der Heyde \& H. J. Kusch, Broadening of Li I Lines by Microfields, Z. Astrophys. 68, 1. (Ger.)

1289. C. F. Hooper, Jr., Low-Frequency Comnonent Electric Microfield Distributions in Plasmas, Phys. Rev. 165, 215. 
1290. C. F. Hooper, Jr., Asymptotic Electric Microfield Distributions in Low-Frequency Component Plasmas, Phys. Rev. 169, 193.

1291. K. Hunger \& R. W. Larenz, On the Collective Effect of Plasma Microfields, Z. Naturforsch. A 23, 1488. (Ger.)

1292. I. Iova, New Data Concerning the Broadening, and Shift of Ar I and Ar II Spectral Lines in a Spark Plasma, Rev. Roum. Phys. 13 , 267.

1293. A. Jablonski, A Remark to the Paner: Inclusion of the Lorentz Effect into Theories of Pressure Broadening of Spectral Lines Based on the Frank-Condon Principle, Acta Phys. Pol. 34 , 561 .

1294. J. T. Jefferies, The Line Absorption Coefficient, "Spectral Line Formation," 57-9l (Blaisdell Publishing Co., Waltham, Massachusetts).

1295. P. C. Kepple, Improved Stark Profile Calculations for the First Four Members of the Hydrogen Lyman and Balmer Series, Center for Theoretical Physics of the Department of Physics and Astronomy, University of Maryland, Report \#831.

1296. P. Kepple \& H. R. Griem, Improved Stark Profile Calculations for the Hydrogen Lines $\mathrm{H}_{\alpha}, \mathrm{H}_{\beta}, \mathrm{H}_{\gamma}$, and $\mathrm{H}_{\delta}$, Phys. Rev. 173,317 .

1297. J. F. Kielkopf \& J. A. Gwinn, Semiclassical Theory of Satellite Bands Produced in the Spectra of Alkali Metals by Interaction with Foreign Gases, J. Chem. Phys. $\underline{48}, 5570$.

1298. V. I. Kogan, Radiation Processes in an Incompletely Ionized Plasma, "A Survey of Phenomena in Ionized Gases," 583 (International Atomic Energy Agency, Vienna). (Russ.)

1299. S. P. Koutsoyannis \& K. Karamchet1, The Role of Repulsive Forces in the Shape of Collision-Broadened Spectral Lines and in the Output of Gas Lasers, IEEE J. Quantum Electron. QE-4, 912.

1300. S. I. Krylova, L. A. Luizova, \& A. D. Khakhaev, The Broadening of Excited Neon Levels due to Interaction with Normal Atoms, Opt. Spectrosc. (USSR) 25, 87.

1301. H. J. Kunze \& H. R. Griem, Laboratory Observations of Plasma Satellites on the $2^{1} \mathrm{P}-4^{1} \mathrm{D}$ and $2^{3} \mathrm{P}-4^{3} \mathrm{D}$ Lines of Helium, Phys. Rev. Lett. $21,1048$.

1302. L. N. Kurochka, The Last Resolved Line in the Balmer Series, Astrophysics (USSR) 岁, 240 .

1303. L. N. Kurochka, Line Profiles of Balmer Series, Caused by a Combined Action of Broadening Factors, Izv. Krym. Astrofiz. Observ. $\underline{38}, 96$. (Russ.) 
1304. E. V. Lifshitz, Stark Effect in High Freauency Stochastic Fields in a Plasma, Sov. Phys. - JETP 26, 570 .

1305. V. N. Lisitsyn \& V. P. Chebotaev, Absorption Saturation Effects in a Gas Laser, Sov. Phys. - JETP $27,227$.

1306. R. F. Majkowski \& R. J. Donohue, Measured Shifts of Cesium Atomic Lines Correlation with Electron Density Derived from Widths, Phys. Rev. 173, 177.

1307. B. S. Mathur, H. Tang, \& W. Happer, Light Shifts in the Alkali Atoms, Phys. Rev. 171,11 .

1308. C. A. Mead, Theory of Resonance Pressure Broadening: Resolvent Operator Formalism and Classical Path Approximation, Int. J. Theor. Phys. 1, 317.

1309. F. H. Mies, Quantum Oscillations in the Shape of Pressure-Broadened Atomic Lines, J. Chem. Phys. $48,482$.

1310. M. H. Miller, Thermally Insensitive Determinations of Transition Probabilities for C I, O I, Ne I, AI II, Si I, Si II, P I, P II, S I, S II, and CI I, University of Maryland Technical Note BN-550.

1311. A. A. Minaeva, Broadening of Hydropen Spectral Lines by Plasma Electrons, Sov. Astron. - AJ $12,459$.

1312. L. A. Minaeva \& I. I. Sobel'man, On the Spectral Line Broadening of Highly Excited Hydrogen Atoms in a Plasma, J. Quant. Spectrosc. Radiat. Transfer $8,783$. (Russ.)

1313. L. A. Minaeva, I. I. Sobel'man, \& R. L. Sorochenko, The Discrete Radio-Frequency Spectrum of Atomic Hydropen, Sov. Astron. - AJ 11, 800 .

1314. A. A. Misyunas \& A. D. Valuzhis, The Influence of Temperature on Impact Effects of the Resonance Line of $\mathrm{Cd}^{113} \lambda 3261$ A due to the Pressure of Inert Gases, Litov. Fiz. Sb. $\underline{8}, 285$. (Russ.)

1315. A. A. Misyunas \& A. D. Valuzhis, The Investipation of Pressure Effects on the Resonance Line $\lambda 3261 \AA$ of $\mathrm{Cd}$, Litov. Fiz. Sb. , 673. (Russ.)

1316. A. A. Misyunas \& A. D. Valuzhis, Temnerature Influence on the Collision Broadening, of the Resonance Line of $\mathrm{Cd}^{114}$ 入 3261 \& Broadened by the Pressure of Inert Gases, Litov. Fiz. Sb. 8 , 461 . (Russ.)

1317. L. Moore, Deconvolution of Physical Data, J. Phys. D 1, 237.

1318. J. C. Morris \& R. U. Krey, Experimental Test of $\mathrm{H}_{\beta}$ Stark-Broadening Theory at High Electron Densities, Phys. Rev, Lett. 21, 1043. 
1319. J. C. Morris, R. U. Krey, \& R. L. Garrison, Radiation Studies of Arc Heated Nitrogen, Oxygen, and Argon Plasmas, AVCO Corporation, Space Systems Division, Report AVSSD-0049-68-RR.

1320. E. A. Müller, B. Baschek, \& H. Holweger, Center-to-Limb Analysis of the Solar Oxygen Lines, Solar Phys. $\underline{3}, 125$.

1321. A. Omont \& J. Meunier, Resonant Broadening of Double-Resonance and Level-Crossing Signals: Application to the $6^{3} \mathrm{P}_{1}$ State in Mercury, Phys. Rev. 169, 92.

1322. M. Pavlov \& A. N. Prasad, Experimental Studies of the Wing Broadening of the $D_{B}$ Line, Z. Phys. 209, 244.

1323. N. G. Preobrazhensk11 \& S. B. Galaktionova, The Spectral Line Profile Formed by the Combined Effect of Resonance Broadening and Reabsorption, Opt. Spectrosc. (USSR) 24,472 .

1324. D. E. Roberts, An Investigation of the G.B.K.O. Theory of Electron Collision Broadening of Spectral Lines, J. Quant. Spectrosc. Radiat. Transfer $\underline{8}, 1241$.

1325. D. E. Roberts, On the Stark Broadening of Neutral Chlorine Lines, Phys. Lett. A $\underline{27}, 716$.

1326. D. E. Roberts, Measurement of the Stark Broadening Parameters of Several Ar II Lines, J. Phys. B 1,53 .

1327. D. E. Roberts \& F. L. Curzon, Measurement of the Shift-to-Width Ratio and Shift of an Ar II Line as Functions of Electron Temperature and Density, J. Phys. B 1 , 973.

1328. D. E. Roberts \& J. Dav1s, Inelast1c Electron Collision Contributions to Ion Linewidths, J. Phys. B 1,48 .

1329. W. Ruland, The Separation of Line Broadening Effects by Means of Line-Width Relations, J. Appl. Crystallogr. 1 , 90 .

1330. S. Sahal-Brechot, Flectron Impact Broadening of Some Lines of SI II/III, S II/III, C II and Mg II, Z. Astrophys. 69, 74. (Ger.)

1331. H. Schlüter, Studies on the Transition from Quasi-Static to Impact Electron Contributions of Linear Stark Broadening, J. Quant. Spectrosc. Radiat. Transfer 8, 1217 .

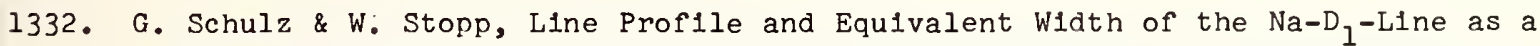
Function of Temperature and Magnetic Induction, Z. Phys. 210, 223. (Ger.) 
1333. P. Schulz \& B. Wende, Stark Broadening of Argon I Spectral Lines in an Arc Plasma, Z. Phys. 208, 116. (Ger.)

1334. A. D. Selidovkin, Theory of Microfield in a Plasma, High Temp. (USSR) $\underline{6}, 8$.

1335. C. V. Shank \& S. E. Schwarz, A Nonlinear Traveling-Wave Interaction Technique for Measuring Homogeneous Linewidths, Appl. Phys. Lett. 13, 113.

1336. J. B. Shumaker, Jr. \& C. H. Popenoe, Experimental Test of $\mathrm{H}_{\beta}$ Stark-Broadening Theory at H1gh Electron Densities, Phys. Rev. Lett. 21, 1046.

1337. K. Singh \& V. P. Nayyar, A Graphic Technique for the Determination of Line-Shape Parameters Using a Reflection Echelon, J. Phys. D 1, 1353.

1338. E. W. Smith, Electron Correlations in Plasma Line Broadening, Phys, Rev, 166, 102.

1339. E. W. Smith \& C. F. Hooper, Jr., Comments on Ion Microfield Distributions as Used in Plasma Line Broadening Theorles, J. Quant. Spectrosc. Radiat. Transfer $\underline{8}$, 1617 .

1340. S. E. Strom \& D. M. Peterson, Surface-Gravity Determinations for Main-Sequence B Stars, Astrophys. J. 152, 859.

1341. P. Subrahmaniam, Broaden1ng of Lines from Ionized Nitrogen, Carbon and Oxygen, Mon. Not1c. Roy. Astron. Soc. 140, 1.

1342. J. Szudy, On the Pressure Shift of the Spectral Lines, Acta Phys. Pol. $34,761$.

1343. G. Traving, Interpretation of Line Broadening and Line Shift, "Plasma Diagnostics," 66 (Ed. W. Lochte-Holtgreven, North-Holland Publishing Co., Amsterdam).

1344. C. O. Trindle \& K. H. Illinger, Scattering Theory of Pressure Broadening of Rotational and Vibration-Rotation Transitions, J. Chem. Phys. $48,4415$.

1345. A. Tsuj1, Y. Urabe, \& H. Narum1, Quantum Theory of Pressure Broadening in Plasma, Prog. Theor. Phys. 39, 1079.

1346. A. B. Underhil1, Numerical Experiments Concerning the Rotational Broadening of Spectral Lines, Bull. Astron. Inst. Neth. 19, 526.

1347. A. B. Underhill, An Investigation of the Meaning of Type O Spectra, Bull. Astron. Inst. Neth. 19, 500 .

1348. J. M. Vaughan, Self-Broadening and the Resonance Oscillator Strengths in Krypton, Phys. Rev. 166, 13 . 
1349. J. M. Vaughan \& G. Smith, Interpretation of Foreign-Gas Broadening and Shift in Krypton, Phys. Rev. 166, 17.

1350. B. Warner, Level-Broadening Constants for $\mathrm{Mg}$ I and Si I, Z. Astrophys. $69,161$.

1351. E. E. Whiting, An Empirical Approximation to the Voigt Profile, J. Quant. Spectrosc. Radiat. Transfer 8 , 1379.

1352. K. Wilke, Numerical Investigations of the Characteristic Parameters of a Plasma Model, Z. Naturforsch. A $\underline{23}, 761$.

1353. B. Ya'akobi, Spectroscopic Investigation of the High-Density Plasma from Exploded Lithium Wires, "Exploding Wires," 4,87 (Ed. W. G. Chace \& H. K. Moore, Plenum Press, New York).

1354. B. Ya'akobi, Linear Stark Broadening in High-Density Lithium Plasma, Phys. Rev. $\underline{176}, 227$.

1355. H. R. Zaidi, Calculation of Resonance Broadening, Phys. Rev. 173, 123.

1356. H. R. Zaidi, Electron Broadening of Isolated Spectral Lines, Phys. Rev. $173,132$.

1357. G. I. Zav'yalov, A. Yu. Zav'yalova, N. A. Prilezhaeva, M. P. Belyaev, M. V. Gileva, \& V. S. Grudanov, Broadening of the 2537 \& Mercury Line due to Vapors of Some Metals, Izv. Vyssh. Ucheb. Zaved., Fiz. No. 3, 156. (Russ.)

\section{9}

1377. M. H. Alexander, Exact Treatment of the Stark Effect in Atomic Hydrogen, Phys. Rev. 178,34 .

1378. J. O. Arnold, E. E. Whiting, \& G. C. Lyle, Line by Line Calculation of Spectra from Diatomic Molecules and Atoms Assuming a Volgt Line Profile, J. Quant. Spectrosc. Radiat. Transfer 9 , 775 .

1379. M. E. Bacon \& D. F. Edwards, Effects of Strong Collisions and Lower-State Broadening on the $\mathrm{H}_{\gamma}$ Profile, J. Quant, Spectrosc. Radiat. Transfer 9 , 951.

1380. M. E. Bacon \& D. F. Edwards, Stark Broadened Profiles of the Hydrogen Lines $H_{\alpha}$ and $\mathrm{H}_{\gamma}$ as a Function of Temperature and Density, Aerospace Research Laboratories Report ARL 69-0109, Profect No. 7073, Office of Aerospace Research, USAF.

1381. M. E. Bacon, K. Y. Shen, \& J. Cooper, Classical-Path Calculation of the S Matrices for Stark Broadening of the Lyman- $\alpha$ Line, Phys. Rev, $188,50$. 
1382. G. Baravian, R. Benattar, J. Bretagne, J. L. Godart, \& G. Sultan, Experimental Study of Satellite Lines of a Forbidden Transition in a Helium Plasma Produced by Laser, Phys. Lett. A $\underline{30}$, 198. (Fr.)

1383. A. J. Barnard, J. Cooper, \& L. J. Shamey, Calculated Profiles of He I 4471 and $4922 \AA$ and Their Forbidden Components, Astron. Astrophys. $1,28$.

1384. A. J. Barnard, J. Cooper, \& L. J. Shamey, The Broadening of He I 4471 \& and Its Forbidden Components, Mem. Soc. Roy. Sc1. Liege, Ser. 5, 17, 89.

1385. O. Bely, Line-Broadening Theory for Positive Ions, Phys. Rev. 185, 79.

1386. A. Ben-Reuven, The Meaning of Collision Broadening of Spectral Lines: The Classical-Oscillator Analog, Advan. At. Mol. Phys. 5, 201.

1387. P. L. Bender \& V. W. Cohen, Coll1sional Broadening of the Rb ${ }^{87}$ Hyperfine Transition, "Proceedings of the Sixth International Conference on the Physics of Electronic and Atomic Collisions, Cambridge, Mass.," 720 (W. Benfamin, New York).

1388. R. D. Bengtson, M. H. Miller, W. D. Davis, \& J. R. Greig, Measurements of the Stark Broadening of $\mathrm{H}_{\gamma}$, Astrophys. J. 157, 957.

1389. P. R. Berman \& W. E. Lamb, Jr., Influence of Resonant and Foreign Gas Collisions on Line Shapes, Phys. Rev. 187, 221.

1390. F. Besombes, J. Granter, \& R. Granier, Satellite Bands Observed in Absorption Near the Forbidden Lines of Rubidium: 5S-4D 5/2, 3/2, Opt. Commun. 1, 161. (Fr.)

1391. B. Bezzerides, Transition between the Quasistatic and Impact Limits in Spectral Line Broadening, Phys. Rev. 186, 239.

1392. B. Bezzerides, Theory of Line Shapes, Phys. Rev. 181, 379.

1393. J. W. Birkeland, J. P. Oss, \& W. G. Braun, Experimental Investigation of Stark Broadening in $\mathrm{H}_{\alpha}$, Phys. Rev. $\underline{178}, 368$.

1394. L. Bober \& R. S. Tankin, Emission and Absorption Measurements on a Strongly SelfAbsorbed Argon Atom Line, J. Quant. Spectrosc. Radiat. Transfer 9, 855.

1395. C. Bottcher, Resonance Widths in Electron-Heavy Atom Scattering, "Proceedings of the S1xth International Conference on the Physics of Electronic and Atomic Collisions, Cambridge, Mass.," 899 (W. Benjamin, New York).

1396. H. A. Buckmaster, Relationships Between Fourler Coefficients Describing the Absorption Components $a_{n}$ and the Dispersion Components $d_{n}$ of a Lorentzian Line Shape, "Optical Pumping and Atomlc Line Shape," 117-121 (Ed. T. Skalinski, Panstwowe Wydawnictwo Naukowe, Warsaw). 
1397. I. Bues, T. Haag \& J. Richter, Spectroscopic Investigation of an Argon Arc Plasma, Astron. Astrophys. 2 , 249 .

1398. C. G. Carrington \& A. Corney, Lifetimes and Pressure Broadening of Excited Levels of Neon by the Hanle Effect, "Premiere Reunion de l'Association Europeene de Spectroscopie Atomique," No. 76 (Faculte des Sclences, Paris-Orsay).

1399. M. C. Castex, R. Granier, \& J. Romand, Study of the Perturbation of the Resonance Line $\lambda 1236 \AA$ of Krypton and of the Line $\lambda 1295 \AA$ of Xenon by Various Rare Gases, C. R. H. Acad. Sc1., Ser. B 268, 552.

1400. W. R. Chappell, J. Cooper, \& E. W. Smith, Electron Correlations in Stark BroadenIng, J. Quant. Spectrosc. Radiat. Transfer $\underline{9}, 149$.

1401. S. Y. Ch'en, Pressure Effects of Rare Gases on the Absorption Lines of Cesium, "Optical Pumping and Atomic Line Shape," 403 (Ed. T. Skalinski, Panstwowe Wydawnictwo Naukowe, Warsaw).

1402. S. Y. Ch'en, D. E. Gilbert, \& D. K. L. Tan, Pressure Effects of Forelgn Gases on the Absorption Lines of Cesium. V. The Effects of Xenon and $\mathrm{CF}_{4}$, Phys. Rev. 184,51 .

1403. S. Y. Ch'en, E. L. Lew1s, \& D. N. Stacey, Broadening of the Hyperfine Components of Cs I 4555 \& Line by Argon, J. Phys. B $\underline{2}, 274$.

1404. M. H. Choudhury, Pressure Shifts of High-Series Spectral Lines and Cross Sections for Scattering of Very Slow Electrons from Rare-Gas Atoms, Phys. Rev. 186, 66.

1405. S.S. Chowdhury, Measurement of the Shift-to-Width Ratio of Ar II $4806 \AA$, J. Phys. B 2 , 1090 .

1406. D. W. Cook, R. S. Timsit, \& A. D. May, Collision Broadening in the ${ }^{3} P_{1}$ State of $\mathrm{Zn}^{1}$, Can. J. Phys. 47, 747 .

1407. J. Cooper, Line Broadening, "Lectures in Theoretical Physics, Atomic Collision Processes," Vol. XI-C, 241 (Gordon \& Breach, New York).

1408. J. Cooper \& G. K. Oertel, Electron-Impact Broadening of Isolated Lines of Neutral Atoms in a Plasma, Phys. Rev. 180, 286; JILA Report No. 99.

1409. R. H. Cordover \& P. A. Bonczyk, Effects of Collisions on the Saturation Behavior of the 6328 \& Transition of Ne Studied with a He-Ne Laser, Phys. Rev. 188, 696.

1410. A. Corney, Resonance Coupling and the Profile of Atomic Line Radiation, "Optical Pumping and Atomic Line Shape," 87-99 (Ed. T. Skalinsk1, Panstwowe Wydawnictwo Naukowe, Warsaw). 
1411. C. R. Cowley, G. H. Elste, \& R. H. Allen, Astrophysical Damping Constants for Neutral Iron, Astrophys. J. 158, 1177.

1412. E. Czuchaj \& J. Flutak, Inert Gas Broadening of Cesium Lines, "Optical Pumping and Atomic Line Shape," 527 (Ed. T. Skalinsk1, Panstwowe Wydawnlctwo Naukowe, Warsaw).

1413. G. J. Dalenoort, Jo1nt Probab1lity Distributions of the Electric Microfield in Hot Plasmas with Neglect of Interactions Between Particles, Physica (Utrecht) 42, 93.

1414. G. J. Dalenoort, Short-Range Corrections to the Probability Distributions of the Electric Microfield in a Plasma, Physica (Utrecht) $45,283$.

1415. W. D. Davison, Long-Range Interactions and the Hyperfine Pressure Shift: Hydrogen in an Inert Gas, J. Phys. B $2,1110$.

1416. R. A. Day, Shock-Tube Measurements of van der Waals Broadened S1licon Lines, Shock Tube Symposium - Phys. Fluids Suppl. I, I-47.

1417. C. Deutsch, Forbidden Lines of the Hellum Atom Emitted in the Presence of a Magnetic Fleld, Mem. Soc. Roy. Sc1. Llege, Ser. 5 17, 83. (Fr.)

1418. C. Deutsch, Electric Microfield Distributions in Plasmas in Presence of a Magnetic Fleld, Phys. Lett. A $30,381$.

1419. C. Deutsch, H. W. Drawin, L. Herman, \& H. Tittel, Stark-Broadening of Hydrogenic He I Lines in the Presence of Strong Magnetic Flelds in Plasmas, "Proceedings of the Ninth International Conference on Ionization Phenomena in Gases," 587 (Editura Academiel Republicil Socialiste Romania, Bucharest).

1420. C. Deutsch, L. Herman, \& H. W. Drawin, Electron-Impact Broadening of Overlapplng He I Lines Plasmas, Phys. Rev. 178, 261.

1421. C. Deutsch, L. Herman, \& H. W. Drawin, Asymptotic Behavior of the Generalized Width and Shift Functions in the Electron-Impact Broadening Theory of Neutral Spectral Lines in Plasmas, Phys. Rev. 186, 204.

1422. B. M. Dodsworth \& A. Omont, Self-Broadening of Level Crossing Curves in the ${ }^{3} \mathrm{P}_{1}$ State of Mercury, "Optical Pumping and Atomic Line Shape," 517 (Ed. T. Skalinsk Panstwowe Wydawnictwo Naukowe, Warsaw).

1423. H. W. Drawin, H. Henning, L. Herman, \& Nguyen-Hoe, Stark-Broadening of Hydrogen Balmer Lines in the Presence of Strong Magnetic Flelds in Plasmas, J. Quant. Spectrosc. Radiat. Transfer 2, 317. 
1424. J. W. Dufty, Charge-Density Fluctuations in Spectral Line Broadening, Phys. Rev. 187, 305 .

1425. R. J. Dyne, Stark Broadening in the Two-Level Approximation, Proc. Astron. Soc. Australla 1,242 .

1426. G. Ecker \& K. G. Fischer, Collective Aspects of the Microfield Distribution, "Proceedings of the Ninth International Conference on Ionization Phenomena in Gases," 378 (Editura Academiel Republicil Socialiste Romania, Bucharest).

1427. G. Ecker \& W. Kröll, On the Decomposition of the Microfield in a Low- and a High Frequency Component, "Proceedings of the Ninth International Conference on Ionization Phenomena in Gases," 377 (Edftura Academiei Republicil Socialiste Romania, Bucharest).

1428. E. S. Ensberg \& G. zu Putlitz, Nonlinear Hyperfine Pressure Shift by Optical Pumping with White Light, Phys. Rev. Lett. 22, 1349.

1429. E. S. Ensberg \& G. zu Putlitz, Non-Linear Hyperfine Pressure Shift by Optical Pumping with White Light at High Buffer Gas Pressures, "Premiere Reunion de l'Assoclation Europeene de Spectroscopie Atomique," No. 37 (Faculte des Sciences, ParisOrsay).

1430. Yu. V. Evdokimov, Measurement of the Broadening and Shift of Spectral Lines by a Magnetic Scanning Method, Vestn. Leningrad Univ. Ser. Fiz. Rhim. No. 10, 20. (Russ.)

1431. R. J. Exton, Doublet Suppression in the Principal Series of Cesium, Phys. Rev. 177, 114.

1432. V. J. Falcone, Jr., A Persistent Error in Collision-Broadened Line Shape Factors, Appl. Opt. $\underline{8}, 2362$.

1433. J. Fiutak, Heisenberg Picture in the Pressure Broadening Theory, "Optical Pumping and Atomic Line Shape," 101 (Ed. T. Skalinski, Panstwowe Wydawnictwo Naukowe, Warsaw).

1434. J. Fiutak, Atomic Lines Broadening, by Inert Gases, "Optical Pumping and Atomic Line Shape," 109 (Ed. T. Skalinski, Panstwowe Wydawnictwo Naukowe, Warsaw).

1435. J. D. E. Fortna, Measurement of Nitrogen II. and Carbon II Resonance Multiplet Line Shapes from a Plasma, Naval Research Laboratory Report 6950.

1436. R. L. Fox \& H. C. Jacobson, Calculation of Spectral Line Shapes for General Pressures, Phys. Rev. 188, 232. 
1437. J. I. Gersten \& H. M. Foley, Theory of Pressure Broadening of Microwave Spectral Lines, Phys. Rev. 182, 24.

1438. A. Gervat \& D. Rossignol-Guzzi, Monte-Carlo Study of Stark Fields in Dense Plasmas Astron. Astrophys. $\underline{3}, 5$.

1439. H. A. Gieske \& H. R. Griem, Calculated Electron and Ion Stark Broadening of the Allowed and Forbidden $2 \mathrm{P}-\mathrm{nL}(\mathrm{n} \geq 5, \mathrm{~L}=1,2, \ldots, \mathrm{n}-1)$ Triplet and Singlet Transitions in Neutral Helium, Astrophys. J. 157, 963.

1440. D. E. Gilbert \&, S. Y. Ch'en, Pressure Effects of Foreign Gases on the Absorption Lines of Cesium. VI. Intensity Measurements of the Cesium Resonance Lines and Their Associated Satellites in the Presence of Varlous Forelgn Gases, Phys. Rev. 188,40 .

1441. G. Gompertz \& W. R. Hindmarsh, The Interpretation of the Wing of the Solar Line $\mathrm{H}_{\alpha}$, Mon. Notic. Roy. Astron. Soc. 142,97 .

1442. S. A. Gonchukov, G. A. Mikhnenko, E. D. Protsenko, \& A. I. Troinikov, Line Shape and Dip Width in the Gain Curve of a He-Ne Laser at Wavelength of $0.63 \mu$, Sov. Phys. - Tech. Phys. 14, 391.

1443. R. Granier, Contribution to the Study of the Influence of Atomic Interactions on the Profile of Spectral Lines, Ann. Phys. (Paris) 4 , 383.'(Fr.)

1444. H. R. Griem, On Semiclassical Approximations to the Electron Impact Broadening of Isolated Ion Lines, Comments At. Mol. Phys. $1,27$.

1445. H. R. Griem \& H. J. Kunze, Stark Broadening of Two Ionized-Helium Lines by Collective Electric Fields in a Laboratory Plasma, Phys. Rev. Lett. 23, 1279.

1446. R. Grifrith, L. Bober, \& R. S. Tankin, Measurement of Emission and Absorption Coefficients of the Balmer Line $H_{\alpha}$, Plasma Phys. $11,529$.

1447. T. Grycuk, Pressure Effects of Foreign Gas on the Resonance Line of Mercury 2537 凡, "Optical Pumping and Atomic Line Shape," 353 (Ed. T. Skalinsk1, Panstwowe Wydawnictwo Naukowe, Warsaw).

1448. T. W. Hänsch \& P. Toschek, On Pressure Broadening in a He-Ne Laser, IEEE J. Quantum Electron. QE-5, 61.

1449. W. R. Hindmarsh \& J. M. Farr, Pressure-Induced Satellites in the Red Wings of Spectral Lines, J. Phys. B 2, 1388.

1450. Q. A. Holmes, S. Y. Ch'en, \&. Takeo, The Shift of Iron Emission Lines Produced by Argon and Helium, J. Quant. Spectrosc. Radiat. Transfer 9, 749. 
1451. Q. A. Holmes, M. Takeo, \& S. Y. Ch'en, The Shift of Some Strong Lines of Al, Ca, $\mathrm{Cu}, \mathrm{Mn}$, Mo, and $\mathrm{Na}$ In Emission, Produced by Argon, J. Quant. Spectrosc. Radiat. Transfer $\underline{9}, 769$.

1452. Q. A. Holmes, M. Takeo, \& S. Y. Ch'en, The Shift of the Emission Lines of $\mathrm{Cr}$ and N1 Produced by Argon and Helium, J. Quant. Spectrosc. Radiat. Transfer $9,761$.

1453. N. Iol1 \& F. Strumia, Detection of the Absorption and Dispersion $D_{1}$ Line of Optically Pumped Sodium Vapour, "Optical Pumping and Atomic Line Shape," 253 (Ed. T. Skalinsk1, Panstwowe Wydawnictwo Naukowe, Warsaw).

1454. I. Iova, An Ar $+\mathrm{H}_{2}$ Plasma Diagnosis Using Ar II Spectral Lines, "Proceedings of the Ninth International Conference on Ionization Phenomena in Gases," 627 (Editura Academiel Republicil Socialiste Romania, Bucharest).

1455. A. Jablonsk1, On the Quas1-Molecular Treatment of Pressure Effects on Spectral Lines, "Optical Pumping and Atomic Line Shape," 323 (Ed. T. Skalinski, Panstwowe Wydawnictwo Naukowe, Warsaw).

1456. H. Jäger, Stark Width of Ba II Lines Emitted by a Discharge Along the Surface of a Liquid Jet, Z. Phys. 223, 19. (Ger.)

1457. S. A. Kaplan \& V. N. Tsytovich, Scattering of Radiation Within a Spectral Line Emitted by Turbulent Plasma, Astrophysics (USSR) $\underline{5}, 8$.

1458. N. N. Khristov, Broadening of Neon Spectral Lines in Discharges at Medium Pressures, Vestn. Leningrad. Univ., Ser. Fiz. Khim. No. 10, 26. (Russ.)

1459. J. Kieffer, Satellites Induced by Foreign-Gas Perturbation of the Lennard-Jones Type, J. Chem. Phys. $\underline{\text { I, }} 1852$.

1460. L. Klein, Green's Function Theory of Atomic Line Broadening in Plasmas, J. Quant. Spectrosc. Radiat. Transfer $\underline{9}, 199$.

1461. V. I. Kogan \& V. S. Lisitza, On the Theory of Stark Line Broadening in Plasmas, "Proceedings of the Ninth International Conference on Ionization Phenomena in Gases," 594 (Editura Academiel Republicil Soclaliste Romania, Bucharest).

1462. V. I. Kogan \& A. D. Selidovkin, On the Fluctuating Microfield in a System of Charged Particles, Beltr. Plasmaphys. , $^{199 .}$ (Russ.)

1463. A. P. Kol'chenko, S. G. Rautian, \& R. I. Sokolovski1, Interaction of an Atom with a Strong Electromagnetic Fleld with the Recoll Effect Taken into Consideration, Sov. Phys. - JETP 28, 986. 
1464. N. Konjevic, J. Labat, Lj. Cirkovic, J. Purfic, Measurements of the Stark Broadening of Several Ar II Lines, "Proceedings of the Ninth International Conference on Ionization Phenomena in Gases," 593 (Editura Academiel Republicil Socialiste Romania, Bucharest).

1465. S. I. Krylova, L. A. Luizova, V. A. Solyanikova, \& A. D. Khakhaev, Broadening and Shifts of Neon and Argon Lines in the Positive Column of a DC Discharge, Opt. Spectrosc. (USSR) 27, 210 .

1466. H. G. Kuhn, Pressure Broadening at Low Densities, "Optical Pumping and Atomic Line Shape," 43-54 (Ed. T. Skalinski, Panstwowe Wydawnictwo Naukowe, Warsaw).

1467. H. J. Kunze, H. R. Griem, A. W. DeSilva, G. C. Goldenbaum, \& I. J. Spalding, Spectroscopic Investigation of Enhanced Plasma Oscillations in a High-Voltage Theta P1nch, Phys. Fluids 12, 2669.

1468. L. N. Kurochka, An Analysis of Hydrogen-Line Profiles Broadened by the Stark and Doppler Effects, Sov. Astron. - AJ 13, 64.

1469. J. Laurent \& S. Weniger, Spectroscopic Investigation of Nickel Thermic Plasma in the Near Ultra-Violet Region, "Proceedings of the Ninth International Conference on Ionization Phenomena in Gases," 588 (Editura Academiei Republicil Socialiste Romania, Bucharest).

1470. Y. C. Lee \& D. L. Lin, Coherent Enhancement of the Natural Linewidth, Phys. Rev. $\underline{183}, 147$.

1471. E. L. Lewis, M. M. Rebbeck, \& J. M. Vaughan, Resonance Broadening of Spectral Lines in Potassium, Phys. Lett. A $\underline{30}, 50$.

1472. E. L. Lewis \& D. N. Stacey, Self-Broadening in Argon, "Optical Pumping and Atomic LIne Shape," 123 (Ed. T. Skalinski, Panstwowe Wydawnictwo Naukowe, Warsaw).

1473. E. V. Lifshitz, Doppler Broadening of Spectral Lines of Ions in Stochastic Varying Fields in a Plasma, Sov. Phys. - JETP 29, 1015.

1474. M. C. Lortet \& E. Roueff, Broadening of Hydrogen Lines in a Neutral Medium, Astron. Astrophys. 3 , 462 .

1475. D. Louër \& D. Weigel, Direct Method of Correction of the Line Profiles of X-ray Diffraction. II. Influence of the Receiving Slit on the Recording of an X-ray Diffraction Line Profile, Acta Crystallogr., Sect. A 25, 338. (Fr.)

1476. D. Louër, D. Weigel, \& R. Louboutin, Direct Method of Correction of the X-ray Diffraction Lines. I. Numerical Method of Deconvolution, Acta Crystallogr., Sect. A 25,335 . (Fr.) 
1477. J. D. Lyons, S. Ray, \& T. P. Das, Hyperfine Pressure Shift and van der Waals Interaction. II. Nitrogen-Helium System, Phys. Rev. 174, 112; Phys. Rev. 181, 465.

1478. A. P. Makarov, Variation in the Broadening of the Absorption Spectral Lines of Neon Caused by Helium, Opt. Spectrosc. (USSR) 26, 189.

1479. D. G. McCartan \& W. R. Hindmarsh, Collision Broadening and Satellite Bands in the Potassium Line $4047 \AA$ Perturbed by Krypton, J. Phys. B 2, 1396.

1480. T. K. Menon \& J. Payne, Observations of 28 Hydrogen na Lines from the Orion Nebula, Astrophys. Lett. $\underline{3}, 25$.

1481. G. A. Mikhnenko \& E. D. Protsenko, The Contribution of $\mathrm{Ne}^{*}-\mathrm{Ne}$ and $\mathrm{Ne}^{*}-\mathrm{He}$ Collisions to the Lorentz Broadening of the $3 \mathrm{~S}_{2}-2 \mathrm{p}_{4}$ Transition in Neon, Opt. Spectrosc. (USSR) 26, 367 .

1482. J. C. Morris \& R. L. Garrison, Measurement of the Radiation Emitted $\mathrm{f}$ Values and Stark Half-Widths for the Strong Vacuum Ultraviolet Lines of $0 I$ and $N$, Phys. Rev. 188,112 .

1483. V. Norkunas, A. Misyunas, \& R. Machekute, Influence of $\mathrm{Hg}$ on the Pressure Broadening of the Resonance Line of $\mathrm{zn}^{64} \lambda 3075.9$ \&, Litov. Fiz. Sb. 9, 187. (Russ.)

1484. H. Nubbemeyer \& B. Wende, Stark Broadening of Carbon I Spectral Lines in an Arc Plasma, Z. Phys. 225, 69. (Ger.)

1485. H. Nubbemeyer \& B. Wende, Stark Broadening of Nitrogen I Spectral Lines in an Arc Plasma, Z. Angew. Phys. 27, 214. (Ger.)

1486. P. E. Oettinger \& J. Cooper, Stark Broadening of the Na I 5682-88 \& and 4978-82 \& Lines, J. Quant. Spectrosc. Radiat. Transfer $\underline{9}, 591$.

1487. N. P. Penkin \& L. N. Shabanova, Broadening of the Resonance Lines of Ca I, Sr I, and $\mathrm{Ba} I$ due to Collisions with Atoms of the Same Gas, Opt. Spectrosc. (USSR) $\underline{26}, 191$.

1488. N. P. Penkin \& L. N. Shabanova, Broadening of the Resonance Lines of Ca I, Sr I, and $\mathrm{Ba} I$ by Inert Gases, Opt. Spectrosc. (USSR) 25, 446.

1489. E. G. Pestov \& S. G. Rautian, Kinetic Equation for the Density Matrix, Sov. Phys. JETP $\underline{29}, 488$.

1490. P. Platz, Shift of a Mercury Line by a High Power Laser Pulse, Appl. Phys, Lett. 14, 168 . 
1491. W. R. Powell, Stark Broadening of A I and A II Lines at H1gh Electron Concentrations, Diss. Abstr. B 29, 3030.

1492. S. Rand, Effects of Dynam1c Ion Shielding on the Stark Broadening of Spectral Lines, J. Quant. Spectrosc. Radiat. Transfer 9 , 921.

1493. B. K. Rao \& T. P. Das, Hyperfine Pressure Sh1ft and Van der Waals Interaction. III. Temperature Dependence, Phys. Rev. 185, 95.

1494. S. Ray \& T. P. Das, Short-Range Effects on the Pressure Shift for a N1trogen Atom In a Rare-Gas Atmosphere, Phys. Rev. 174, 32.

1495. S. Ray, J. D. Lyons, \& T. P. Das, Hyperfine Pressure Shift and van der Waals Interactions. I. Hydrogen-Helium System, Phys. Rev. 174, 104; Phys. Rev. 181, 465.

1496. V. N. Rebane, Relation Between the Optical Broadening, Sh1ft, and Depolarizat1on of a Spectral Line Caused by Collisions, Opt. Spectrosc. (USSR) 26, 371.

1497. G. P. Reck, Binary Collision Broadening Theory, J. Quant. Spectrosc. Radiat. Transfer 9, 1419.

1498. H. Van Regemorter, Beyond the Impact Approximation, Phys. Lett. A $30,365$.

1499. E. Roueff \& H. Van Regemorter, Spectral Line Broadening Due to Atomic Collisions, Astron. Astrophys。 1, 69.

1500. A. Royer, Stat1stical Theory of Satell1te Bands, J. Chem. Phys. 50, 1906.

1501. S. Sahal-Brechot, Impact Theory of the Broadening and Shift of Spectral Lines Due to Electrons and Ions in a Plasma (Continued), Astron. Astrophys. 2, 322. (Fr.)

1502. S. Sahal-Brechot, Impact Theory of the Broadening and Shift of Spectral Lines due to Electrons and Ions in a Plasma, Astron. Astrophys. $\underline{1}, 91$.

1503. K. Sando, R. O. Doyle, \& A. Dalgarno, Resonance-Broadening Absorption in the Wings of Lyman Alpha, Astrophys. J. 157, L143.

1504. H. Schlüter, Line Broaden1ng, "Physics of the One- and Two-Electron Atoms," 824 (North-Holland Publishing Co., Amsterdam).

1505. F. Schuller \& B. Oksengorn, General Expansion for the Elast1c Cross-Sect1on in the Theory of Pressure-Induced Shifts of Infrared Molecular Lines, J. Quant. Spectrosc. Radiat. Transfer 2, 185. 
1506. F. Schuller \& B. Oksengorn, Influence of Transitions Induced by Non-Adiabatic Collisions in the Theory of Broadening and Shift of Atomic Spectral Lines, J. Phys. (Par1s) 30, 919. (Fr.)

1507. F. Schuller \& B. Oksengorn, Theoretical Study of the Broadening and Shift by Impact of the Fine Structure Components of Atomic Spectral Lines, J. Phys. (Paris) 30, 531. (Fr.)

1508. K. Y. Shen \& J. Cooper, On Strong Collisions in Hydrogenic Line Broadening, Astrophys. J. 155, 37 .

1509. G. V. Sholin, on the Nature of the Asymmetry of the Spectral Line Prof 1les of Hydrogen in a Dense Plasma, Opt. Spectrosc. (USSR) 26, 275; "Proceedings of the Elghth International Conference on Ionization Phenomena in Gases," 435 (SpringerVerlag, Berlin).

1510. A. L. Smith \& K.-W. Chow, Structure in the Low Energy Wings of Vacuum - Ultraviolet Emission Lines, "Optical Pumping and Atomic Line Shape," 533-543 (Ed. T. Skalinski, Panstwowe Wydawnictwo Naukowe, Warsaw).

1511. E. W. Smith, J. Cooper, \& C. R. Vidal, Unifled Classical-Path Treatment of Stark Broadening in Plasmas, Phys. Rev. 185, 140.

1512. E. W. Smith, C. R. Vidal, \& J. Cooper, Classical Path Methods in Line Broadening. I. The Classical Path Approximation, J. Res. Nat. Bur. Stand., Sect. A $73,389$.

1513. E. W. Smith, C. R. Vidal, \& J. Cooper, Classical Path Methods in Line Broadening. II. Application to the Lyman Series of Hydrogen, J. Res. Nat. Bur. Stand., Sect. A $73,405$.

1514. T. P. Sosnowski \& W. B. Johnson, Frequency Shifts of the Lamb Dip Minimum in the Helium-Neon Laser, IEEE J. Quantum Electron. QE-5, 151.

1515. D. N. Stacey \& J. Cooper, Impact Theory of Resonance Broadening in Spectral Lines of the Alkall Metals, Phys. Lett. A $\underline{30}, 49$.

1516. J. Szudy, The Intensity Distribution and Shift of the Mercury Resonance Line Broadened by Noble Gases, "Optical Pumping and Atomic Line Shape," 347 (Ed. T. Skalinsk1, Panstwowe Wydawnictwo Naukowe, Warsaw).

1517. J. Szudy, On the Origin of the Satellite Band Apnearing Near the Hg-Resonance Line Broadened by Hellum, Bull. Acad. Pol. Sc1., Ser. Sc1., Math., Astron., Phys. 17, 315 . 
1518. C. R. Vidal, J. Cooper, \& E. W. Smith, New Classical Path Calculations of the Stark Broadening of Hydrogen, "Proceedings of the Ninth International Conference on Ionfzation Phenomena in Gases," 592 (Editura Academiel Republicil Socialiste Romania, Bucharest).

1519. D. Voslamber, Unified Model for Stark Broadening, Z. Naturforsch. A $24,1458$.

1520. D. Voslamber, A Non-Markovian Impact Theory, "Proceedings of the Ninth International Conference on Ionization Phenomena in Gases," 590 (Editura Academiel Republic11 Socialiste Romania, Bucharest).

1521. A. A. Westenberg \& N. deHaas, Observations on ESR Linewidths and Concentration Measurements of Gas-Phase Radicals, J. Chem. Phys. $51,5215$.

1522. J. J. Wright, L. C. Balling, \& R. H. Lambert, Hyperfine Splittings and Pressure Shifts of $\mathrm{Li}^{6}$ and $\mathrm{LI}^{7}$, Phys. Rev. 183,180 .

1523. B. Ya'akob1, The Self-Broadening of the Resonance Line of Lichium at High Densities, J. Quant. Spectrosc. Radiat. Transfer 9, 309.

1524. B. Ya'akob1, Self-Reversed Profiles of Lines Broadened by the Stark Effect, J. Quant. Spectrosc. Radiat. Transfer 9, 1097.

1525. B. Ya'akobi \& G. Bekef1, Excitation of an Optical Satellite by Thermal Electron Oscillations of a Lithium Plasma, Phys. Lett. A $30,539$.

1526. G. Yamamoto, M. Tanaka, \& T. Aoki, Estimation of Rotational Line Widths of Carbon Dioxide Bands, J. Quant. Spectrosc. Radiat. Transfer $\underline{9}, 371$.

1527. R. Yaris \& A. L. Shain, A General Method for the Calculation of Lineshapes of Molecular Spectra, Chem. Phys. Lett. $\underline{3}, 597$.

1528. S. P. Zagorodnikov, G. E. Smolkin, \& G. V. Sholin, Charged Particle Density Measurement in Nonstationary Plasma Through Stark Broadening of the $\mathrm{H}_{B}$ Balmer Line, High Temp. (USSR) $\underline{6}, 220$.

1970

1548. V. A. Alekseev, A. V. Vinogradov, \& I. I. Sobel'man, On the Problem Concerning the Broadening of Spectral Lines of a Homogeneous Gas at Low Pressure, J. Quant. Spectrosc. Radiat. Transfer 10, 55. (Russ.)

1549. A. S. Antonov, O. A. Zinov'ev, V. D. Rusanuv, \& A. V. Titov, Broadening of Hydrogen Spectral Lines During Turbulent Heating of a Plasma, Sov. Phys. - JETP $31,838$. 
1550. R. Assous, Stark Broadening and Shift of Neutral Atomic Oxygen Lines, J. Quant. Spectrosc. Rad1at. Transfer 10, 975. (Fr.)

1551. A. M. Aurela, On Line Shifts in the Solar Spectrum, Ann. Acad. Sci. Fenn., Ser. A6 \#347, 3 .

1552. M. E. Bacon \& D. F. Edwards, Comments on Recent Stark-Broadening Calculations for the $\mathrm{H}_{\alpha}$ and $\mathrm{H}_{\gamma}$ Lines of Hydrogen, J. Quant. Spectrosc. Radiat. Transfer 10, 563.

1553. A. J. Barnard \& J. Cooper, Computed Proflles of He I 5016 \& at High Electron Densities, J. Quant. Spectrosc. Radiat. Transfer 10, 695.

1554. K. S. Barnes \& G. Peach, The Shape and Shift of the Resonance Lines of Cat Perturbed by Electron Collisions, J. Phys. B 3 , 350; Nature 225, 374 .

1555. A. S. Bazhov \& A. V. Zherebenko, Determination of the Width of the Resonance Line of Cadmium Absorption in a Flame, 2h. Prikl. Spektrosk. 12, 403. (Russ.)

1556. B. Bederson, Line Shifts and Elastic Scattering by Slow Electrons, Comments At. Mol. Phys. 2, 114.

1557. J. D. Bekenstein \& J. B. Krleger, Stark Effect in Hydrogen Atoms for Nonuniform Flelds, J. Math. Phys. (NY) $11,2721$.

1558. 0. Bely \& H. R. Griem, Quantum-Mechanical Calculation for the Electron-Impact Broadening of the Resonance Lines of Singly Ionized Magnesium, Phys. Rev. A 1, 97.

1559. A. Ben-Reuven, On the Yaris and Shain Method for Calculating Lineshapes, Chem. Phys. Lett. $\underline{5}, 273$.

1560. R. D. Bengtson, M. H. Miller, D. W. Koopman, \& T. D. Wilkerson, Comparison of Measured and Predicted Conditions Behind a Reflected Shock, Phys. Flu1ds 13, 372.

1561. R. D. Bengtson, J. D. Tannich, \& P. Kepple, Comparison Between Measured and Theoretical Stark-Broadened Profiles of $\mathrm{H}_{6}-\mathrm{H}_{12}$ Emitted from a Low-Density Plasma, Phys. Rev. A 1 , 532 .

1562. P. R. Berman \& W. E. Lamb, Jr., Theory of Collision Effects on Line Shapes Using a Quantum-Mechanical Description of the Atomlc Center-of-Mass Motion -- Application to Lasers, Phys. Rev. A 2, 2435.

1563. P. Bogen, Broadening of the He II Line $\lambda=4686$ \& in a Plasma, Z. Naturforsch. A 25, 1151 . 
1564. C. C. Bouchiat \& M. A. Bouchiat, Alkali-Rare-Gas van der Waals Molecules and Ground-State Relaxation Processes in Optical Pumping, Phys. Rev. A $2,1274$.

1565. R. G. Breene, Jr. Density Dependence in Resonance Broadening, Phys. Lett. A $\underline{32}$, 466.

1566. R. G. Breene, Jr., Satellites of Spectral Lines, Acta Phys. Pol. A $37,477$.

1567. R. G. Breene, Jr., Origin of Spectral-Line Satellites, Phys. Rev. A $2,1164$.

1568. J. Brochard \& R. Vetter, Study of the Shift of the Infrared Laser Lines of Xenon under the Influence of Pressure, Phys. Lett. A $\underline{33}, 398$. (Fr.)

1569. D. D. Burgess, Some Comments on Present Theoretical Calculations of the Profiles of Forbidden Components in the Wings of Stark-Broadened Spectral Lines, J. Phys. B $\underline{3}$, L70.

1570. D. D. Burgess, The Treatment of Correlations in the Theory of Electron Impact Broadening, J. Quant. Spectrosc. Radiat. Transfer 10, 365.

1571. D. D. Burgess \& C. J. Cairns, Experimental Observations of the Profiles and Relative Intensities of He. I $2^{3} \mathrm{P}-4^{3} \mathrm{D}$ ( $\lambda 4471$ ) and $2^{3} \mathrm{P}-4^{3} \mathrm{~F}$ ( $\lambda 4470$ ) at Low Electron Densities, J. Phys. B $\underline{3}$, L67.

1572. D. D. Burgess \& J. E. Grindlay, The Pressure Broadening of Na I $\lambda 5889$ by HighTemperature Neutral Hellum, Astrophys. J. 161, 343.

1573. J. Chapelle \& S. Sahal-Brechot, Experimental and Theoretical Electron Impact Broadening of Some Mg II. and Ca II Lines of Astrophysical Interest, Astron. Astrophys. $6,415$.

1574. W. R. Chappell, J. Cooper, \& E. W. Smith, Non-Thermal Effects in Stark Broadening, J. Quant. Spectrosc. Radiat. Transfer 10, 1195.

1575. S. Y. Ch'en \& R. O. Garrett, Pressure Effects of Forelgn Gases on the Absorpt1on Lines of Cesium. I. The Effects of Argon on the First Two Members of the Principal Series, Phys. Rev. 144, 59; Phys. Rev. A 1, 975.

1576. J. Cooper, U. Palmer, \& G. K. Dertel, Classical Path A and B Functions for Line Broadening of Positive Ions, JILA Report No. 105, University of Colorado.

1577. W. S. Cooper \& W. W. Hicks, Use of the High Frequency Stark Effect in Plasma Diagnostics, Phys. Lett. A $\underline{33}, 188$.

1578. G. J. Dalenoort, The Holtsmark-Continuum Model for the Stat1st1cal Descript1on of a Plasma, FOM-Instituut voor Plasma-Fysica Rijnhulzen, Jutphaas, Nederland, Report I.R. 70/015. 
1579. G. J. Dalenoort, The Holtsmark-Continuum Model for an Ionized Gas, Phys. Lett. A $\underline{31}, 285$.

1580. G. Das \& S. Ray, Theoretical Study of the Interaction Potent1al and the Hyperfine Pressure Shifts in $\mathrm{HeH}$, Phys. Rev. Lett. 24, 1391.

1581. J. Dav1s \& S. Morin, Cross Sections, Osc1llator Strengths and Inelast1c W1dths for Some NV Lines, J. Quant. Spectrosc. Rad1at. Transfer 10, 357.

1582. R. A. Day, Deconvolution of Fabry-Perot Profiles, Appl. Opt. 9 , 1213.

1583. C. Deutsch, Influence of a Strong Magnet1c F1eld on Plasma-Broadened 2P-4Q ( $Q=P, D, F)$ He I Lines, Phys. Rev. A 2, 1258.

1584. T. A. Dillon, E. W. Sm1th, J. Cooper, \& M. Mizushima, Semiclassical Treatment of Strong Collisions in Pressure Broadening, Phys. Rev. A 2, 1839.

1585. G. G. Dolgov-Savel'ev \& V. I. Sekerin, H1gh-Speed Measurement of Spectral Line W1dths and Shifts w1th the Fabry-Perot Interferometer, Instrum. Exp. Tech. (USSR) No. I, 209.

1586. C. M. Dutta, N. C. Dutta, \& T. P. Das, Many-Body Approach to the Hyperfine Pressure Shift in Optical-Pumping Experiments, Phys. Rev. A 2,30 .

1587. A. Eberhagen \& R. Wunderl1ch, Profile Measurements of Pressure Broadened He IILines, Z. Phys. 232, 1.

1588. J. Fiutak \& E. Czuchaj, The Classical Path Approximation in the Theory of Line Broadening by Fore1gn Gases, Acta Phys. Pol. A $37,85$.

1589. J. D. E. Fortna, R. C. Elton, \& H. R. Griem, Measurement of the Electron-Impact Broadening of Ionized N1trogen and Carbon Resonance Lines in a High-Pressure Electr1c Shock Tube, Phys. Rev. A 2, 1150.

1590. W. Fullerton \& C. Cowley, An Extension of the Theory of Line Broadening by Neutral Atoms to H1gher-order Terms in the Interaction Potent1al, Astrophys. J. $162,327$.

1591. Yu. I. Galushkin, Electrodynamic Line Broadening Together with the L1near Stark Effect, Sov. Astron. - AJ 14, 301.

1592. J. R. Gre1g, H. R. Griem, L. A. Jones, \& T. Oda, Observation of a Plasma Polar1zation Shift for the Resonance Line of Ionized Helium, Phys. Re\%. Lett. 24 , 3.

1593. J. R. Gre1g \& L. A. Jones, Stark Broadening of Two Neutral Helium Lines in Plasmas, Phys. Rev. A I, 1261 . 
1594. H. R. Griem, Dynamical Corrections to Holtsmark's Theory of Spectral Line Broadening from Linear Stark Effects, Comments At. Mol. Phys. $2,19$.

1595. H. R. Griem, Cross Sections for the Electron Impact Broadening of the $2 \mathrm{P}$ Levels of Hydrogen and Ionized Helium, Comments At. Mol. Bys. $\underline{2}, 53$.

1596. H. R. Griem, How Accurate are $H_{B}$ Stark Profiles?, Comments At. Mol. Phys. $2,103$.

1597. H. R. Griem, Collective Effects on the Profiles of Spectral Lines Broadened by Electrons and Ions in a Plasma, Comments At. Mol. Phys. 1, 145.

1598. T. Hänsch \& P. Toschek, Theory of a Three-Level Gas Laser Amplifier, Z. Phys. $\underline{236}, 213$.

1599. Y. Hamada, The Optical Measurement of the Fluctuation Level in a Turbulent Plasma, J. Phys. Soc. Jap. 29, 463.

1600. J. Hardorp \& M. Scholz, The Atmospheres of Tau Scorpil (BO V) and Lambda Leporis (B0.5 IV), Astrophys. J., Suppl. Ser. 19, No. 173, 193.

1601. F. Hartmann \& F. Hartmann-Boutron, Shift and Broadening of the ${ }^{87}$ Rb $0-0$ Line Due to Collisions with Krypton Buffer-Gas Atoms, Phys. Rev. A 2, 1885.

1602. L. Herman \& G. Coulaud, Shift and Broadening of Neutral Atomic Lines by Collision with Foreign Gas Atoms, J. Quant. Spectrosc. Radiat. Transfer 10, 571. (Fr.)

1603. R. A. Hill \& P. Kepple, Stark-Profile Calculations for the First Four Hydrogen Balmer Lines, Sandia Laboratories Report \#SC-M-70-584.

1604. W. R. Hindmarsh, A. N. Du Plessis, \& J. M. Farr, Determination of Dispersion Forces from the Collision Broadening of Spectral Lines, J. Phys. B $\underline{3}$, L5.

1605. TJ. Hollander, B. J. Jansen, J. J. Plaat, \& C. Th. J. Alkemade, Zeeman Scanning of Alkaline-Earth Absorption Line Profiles in Flames at Atmospheric Pressure, J. Quant. Spectrosc. Radiat. Transfer 10, 1301.

1606. N. W. Jalufka \& J. P. Craig, Stark Broadening of Singly Ionized Nitrogen Lines, Phys. Rev. A $\underline{1}, 221$.

1607. A. F. Jones \& D. L. Misell, The Problem of Error in Deconvolution, J. Phys. A $\underline{3}$, 462 .

1608. J. F. Kielkopf, J.F. Davis, \& J. A. Gwinn, Profiles of Foreipn-Gas-Broadened Atomic Lines and Satellite Bands, J. Chem. Phys. 53, 2605. 
1609. D. M. Kim, M. O. Scully, \& W. E. Lamb, Jr., Quantum Theory of an Optical Maser. V. Atomic Motion and Reco1l, Phys. Rev. A $\underline{2}, 2534$.

1610. S. Klarsfeld, On Stark Broadening Functions for Nonhydrogenic Ions, Phys. Lett. A 33,437 .

1611. S. Klarsfeld, Exact Calculation of Electron-Broadening Shift Functions, Phys. Lett. A $\underline{32}, 26$.

1612. E. V. Kondrat'eva,Stark Sh1ft in the Wavelengths of the Spectral Lines of Si I, $\mathrm{Ge} I, \mathrm{Sn} I$, and $\mathrm{Pb} I$ in a Spark Discharge, Opt. Spectrosc. (USSR) $28,449$.

1613. E. V. Kondrat'eva \& L. I. Fomichenko, Stark Shift of Spectral Lines of Al I, Ga I, In I, Tl I, Sb I, BI I, Te I in a Spark Discharge, Opt. Spectrosc. (USSR) 29, 434.

1614. N. Konjevic, Lj. Cirkovic, \& J. Labat, Laser Interferometric Measurements of Electron Density in a Shock Wave Plasma, Fizika 2, 121.

1615. N. Konjevic, J. Labat, Lj. Cirkovic, \& J. Puric, Measurement of the Stark Broadening Parameters of Some Singly Ionized Argon Lines, Z. Phys. 235, 35.

1616. N. Konjevic, V. Mitrovic, Lj. Cirkovic, \& J. Labat, Measurement of the Stark Broadening Parameters of Several Sinf,ly Ionized Nitrogen Lines, Fizika 2, 129.

1617. N. Konjevic, M. Platisa, \& J. Labat, Experimental Study of the Stark Broadening of Neutral Chlorine Lines, Phys, Lett. A $32,420$.

1618. N. Konjevic, J. Puric, Lj. Cirkovic, \& J. Labat, Measurements of the Stark Broadening Parameters of Several S1 II Lines, J. Phys. B $\underline{3}, 999$.

1619. N. Konjevic, D. Radivojevic, Lj. Cirkovic, \& J. Labat, Investigation of the Stark Broadening of Several Cl II Lines, J. Phys. B $\underline{3}, 1742$.

1620. M. Korten \& H. F. Berg, Stark-Effect Calculations in the Second Lyman-Series of Ionized Helium, Z. Phys. 239, 322.

1621. H. J. Kusch \& H. P. Pritschow, Broadening and Shift of Calcium Lines by Microfields, Astron. Astrophys. 4, 31. (Ger.)

1622. J. Laurent \& S. Weniger, Study of Absorption Line Shapes of Some Multiplets of Neutral Atomic Nickel in the Near Ultraviolet, J. Quant. Spectrosc. Radiat. Transfer 10, 315. (Fr.)

1623. V. Lawetz \& D. A. Hutchinson, Hameka Theory of Linewidths, J. Chem. Phys. $\underline{52}, 4160$.

1624. A. V. Lazarev, Effect of Doppler Broadening on the Line Shape of Spontaneous Radiation, Opt. Spectrosc. (USSR) 28,572 . 
1625. M. A. Levine \& C. C. Gallagher, Stark Broadening for Turbulence Studies in a Confined Plasma, Phys. Lett. A $\underline{32}, 14$.

1626. W. D. Lyon \& C. A. Mead, Emission versus Absorption in Resonance Pressure Broadening, Phys. Rev. A 1, 659 .

1627. M. Malinovsky \& S. Sahal, Semi-Classical Calculation of the Sh1ft of Neutral Atomic Lines by Electronic Collisions. Adlabatic Limit., C. R. H. Acad. Sc1., Ser. B 270, 1409. (Fr.)

1628. J. T. Manassah \& H. M. Foley, Resonance Broadening Using Green Functions, Phys. Lett. A $31,265$.

1629. V. S. Mechev \& L. E. Eroshenko, Determination of the Temperature of an Arc Discharge Plasma in Argon, Avtomaticheskaya Svarka 23, 1. (Russ.)

1630. J. Meyer \& R. J. Beck, Measurement of the Broadening of S1licon Lines by Electrons and Hydrogen Atoms, Astron. Astrophys. $8,93$.

1631. J. Meyer, J. C. Burnett, \& B. Stansfield, Investigation of Pressure Broadening of a Neon Line using a Zeeman Scanning Technique, J. Quant. Spectrosc. Radiat. Transfer 10, 799 .

1632. D. Mihalas \& L. H. Auer, Non-LTE Model Atmospheres. V. Multi-Line HydrogenHellum Models for 0 and Early B Stars, Astrophys. J. $160,1161$.

1633. M. H. Miller \& R. D. Bengtson, Measured Stark Widths and Sh1fts for Neutral Atomic Lines, Phys. Rev. A $1,983$.

1634. A. A. Misyunas; A. D. Valuzh1s, \& N. A. Stul'pinene, The Influence of Temperature and Pressure of Xe on the Collision Effects of the Resonance Line of $\mathrm{Cd}^{114} \lambda$ 3261 \&, L1tov. F1z. Sb. 10, 953. (Russ.)

1635. G. A. Moo-Young, J. R. Greig, \& H. R. Griem, Measurement of the Stark Broadening of the Resonance Lines of Neutral Argon and Neon, Phys. Rev. A $2,1617$.

1636. Nguyen-Hoe \& M. Caby, An Approximation for the Treatment of Near Collisions in the Stark Broadening of Hydrogen Lines, C. R. H. Acad. Sc1., Ser. B $270,1657$. (Fr.)

1637. J. Norris \& B. Baschek, Neutral-Helium Line Strengths. I. Line Profiles for a Grid of Approximate Line-Blanketed Model Atmospheres, Astrophys. J. Suppl. Ser. 19, No. 176,305 . 
1638. H. Nubbemeyer, D. Stuck, \& B. Wende, Stark-Broadening of Neon I-Transitions w1th Weak Electrical Field Dependence $\left(2 p^{5} 3 s-2 p^{5} 30\right)$, Z. Phys. 234, 29. (Ger.)

1639. P. E. Oettinger, Radiation-Induced Line Broadening of the Principal Serles of Sodium, J. Quant. Spectrosc. Radiat. Transfer 10, 127.

1640. T. Ya. Popova, A. K. Popov, S. G. Rautian, \& A. A. Feskt1stov, Resonant Radiative Processes, Sov. Phys. - JETP $30,243$.

1641. J. G. Powles \& B. Carazza, A 'Non-Classical' Information Theory of Spectral Line Shape, J. Phys. A $\underline{3}, 335$.

1642. L. P. Presnyakov, Broadening of H1ghly Exc1ted Atomic Levels in an Atmosphere of Alkal1-Metal Atoms, Phys. Rev. A 2, 1720.

1643. J. Puric, J. Labat, Lj..Cirkovic, \& N. Konfevic, Experimental Study of Stark Broadening of Neutral Helium Line 5876 in a Plasma, Fizika $\underline{2}, 67$.

1644. J. L. Queffelec \& M. Girault, Experimental Determination, as a Function of Temperature, of the Half-Width and Shift of the 4300 Emission Line of an Argon Plasma at Atmospher1c Pressure, C. R. H. Acad. Sc1., Ser. B $270,471$. (Fr.)

1645. S. Ray, G. Das, P. Maldonado, \& A. C. Wahl, Theoretical Evaluation of the Fractional Hyperfine Pressure Shift of Paramagnetic Atoms in a Noble Gas, Phys. Rev. A 2 , 2196.

1646. D. E. Roberts, Semi-Classical Calculations of the Collisional Broadening of Ion Lines, Astron. Astrophys. 6,1 .

1647. E. Roueff, A Theoretical Model for the Interaction between Exc1ted and Ground State Atoms. Application to Pressure Broadening, Astron. Astrophys. I, 4.

1648. M. Sass1, L. Herman, \& G. Coulaud, Relative Intensities and Relative Shifts of the $2 \mathrm{P}-4 \mathrm{~F}$ and $2 \mathrm{P}-4 \mathrm{D} \mathrm{LI}$ I Lines as a Function of Electron Concentration, Phys. Lett. A $\underline{32}, 549$.

1649. M. Sass1, L. Herman, \& G. Coulaud, Shift of the Lines of the Cs I Atom due to the Simultaneous Action of an Electric Field and a Constant Magnetic Field, C. R. H. Acad. Sc1., Ser. B 270,884 . (Fr.)

1650. B. Sayer, M. Sass1, \& J. C. Jeannet, Determination of the Electron Densities in an Ionized Cesium Vapor from Stark Linewidths, C. R. H. Acad. Sc1., Ser. B 271, 839. (Fr.) 
1651. F. R. Scott, R. V. Neldigh, J.R. McNally, Jr., \& W. S. Cooper, III, Use of Optical Spectra to Measure Large Electric Flelds in a Hot-Ion Plasma, J. Appl. Phys. 41, 5327 .

1652. M. O. Scully, D. M. K1m, \& W. E. Lamb, Jr., Quantum Theory of an Opt1cal Maser. IV. Generalization to Include Finite Temperature and Cavity Detuning, Phys. Rev. A 2 , 2529.

1653. M. J. Seaton, Committee 3: Collision Cross Sections and Line Broadening I. Line Broadening, "Transactions of the International Astronomical Union," Vol. XIV A, 128.

1654. H. L. Shipman \& S. E. Strom, Lines of Neutral Helium in 0- and B-Type Stars, Astrophys. J. 159, 183.

1655. V. V. Skidan \& E. Ya. Shrelder, Resonance Broadening of the $L_{\alpha}$ Line of Hydrogen, Opt. Spectrosc. (USSR) 28, 340 .

1656. S. Stenholm, Pressure Effects in a High-Intensity Gas Laser, Phys, Rev. A $2,2089$.

1657. J. Szudy, Satellite Band Accompanying the Hg-Resonance Line Broadened by He, Acta Phys. Pol. A $\underline{38}, 779$.

1658. M. Takeo, Theoretical Calculation of Pressure-Broadened Atomic Line Profiles, Phys. Rev. A 1 , 1143.

1659. D. K. L. Tan \& S. Y. Ch'en, Pressure Effects of Forelgn Gases on the Absorption Lines of Cesium. VII. The Shift of High-Member Lines by Various Rare Gases, Phys. Rev. A 2,1124 .

1660. E. S. Trekhov, A. F. Fomenko, \& Yu. M. Khoshev, The Temperature Profile of the Plasma Column of an Induction Discharge in Argon at Atmospheric Préssure, High Temp. (USSR) $\underline{8}, 685$.

1661. A. Tsuj1 \& H. Narum1, Polarization Shifts in Plasma, Progr. Theor. Phys. $44,1424$.

1662. A. Tsuj1 \& H. Narum1, Theory of Electron Impact Broadening in Plasma, Progr. Theor. Phys. $\underline{4}, 1557$.

1663. Yu. A. Vdovin, N. A. Dobrodeev, V. M. Dubovik, \& V. K. Matskevich, Collisions with Resonance Transfer of Excltation in Alkal1 Metal Vapors and for Transitions with $2 \leftrightarrow 1,1 \leftrightarrow 1$ Moments, "Voprosy Teor11 Atomnykh Stolknoven11," S.S.S.R., 50-64 (Ed. Yu. A. Vdovin, Atom1zdat, Moscow). (Russ.) 
1664. Yu. A. Vdovin, V. M. Galitski1, \& V. V. Yakimets, Atomic Collisions and Optical Phenomena, "Voprosy Teorli Atomnykh Stolknovenil," S.S.S.R., 3-38 (Ed. Yu. A. Vdovin, Atomizdat, Moscow). (Russ.)

1665. C. R. Vidal, J. Cooper, \& E. W. Smith, Hydrogen Stark Broadening Calculations with the Unified Classical Path Theory, J. Quant. Spectrosc. Radiat. Transfer 10, 1011; Nat. Bur. Stand. (U.S.), Monogr. 116.

1666. D. Voslamber, A Non-Markovian Impact Theory Comprehending Partially Overlapping Lines, J. Quant. Spectrosc. Radiat. Transfer 10, 939.

1667. R. E. Weiss, R. H. Lambert, \& L. C. Balling, Temperature Dependence of Hyperfine Pressure Shifts. II. Nitrogen in Helium, Neon, and Molecular Nitrogen, Phys. Rev. A $\underline{2}, 1745$.

1668. R. J. Weymann, Electron-Scattering Line Profiles in Nuclei of Seyfert Galaxies, Astrophys. J. 160,31 .

1669. J. J. Wright, L. C. Balling, \& R. H. Lambert, Temperature Dependence of Hyperfine Pressure Shifts. I. Deuterium in Helium from -135 to $400^{\circ} \mathrm{C}$, Phys. Rev. A I, 1018.

1670. B. Ya'akobi \& S. Goldsmith, Plasma Polarization Shift of Extreme Ultra-Violet Spark Lines, Phys. Lett. A $\underline{31}, 408$.

1671. S. P. Zagorodnikov, G. E. Smolkin, E. A. Stripanova, \& G. V. Sholin, Determination of the Turbulence Level in a Collisionless Magnetosonic Shock Wave by Measuring the Stark Broadening of the Balmer $\mathrm{H}_{B}$ Line, JETP Lett. 11, 323.

1672. G. V. Zelenin, A. A. Kutsyn, M. E. Maznichenko, O. S. Pavlichenko, \& V. A. Suprunenko, Observation of Plasma Satellites Near Forbldden Lines of He I in a Turbulently Heated Plasma, Sov. Phys. - JETP 31, 1009.

1971

1692. G. S. Agarwal, Master-Equation Approach to Spontaneous Emission. III. Many-Body Aspects of Emission from Two-Level Atoms and the Effect of Inhomogeneous Broadening, Phys. Rev. A $4,1791$.

1693. V. A. Alekseev, A. V. Vinogradov, \& I. I. Sobel'man, Macroscopic Approach to Effects of Radiative Interaction of Atoms and Molecules, Sov. Phys. - Usp. 13, 576.

1694. V. A. Alekseev \& E. A. Yukov, Broadening of Spectral Lines of Nonhydrogenic Ions, "Physies of Atomic Collisions," 토, 75-79 (Ed. D. V. Skobeltsyn, Consultants Bureau, New York). 
1695. K. S. Anderson, On the Interpretation of the $H_{\alpha}$ Profile of the Seyfert Galaxy NGC 5548, Astrophys. J. 169, 449; Astrophys J. 172, 785.

1696. E. A. Asmaryan \& Yu. L. Klimontovich, Spectral Line Broadening by Electrons in Nonequilibrium Partly Ionized Plasma, Opt. Spectrosc. (USSR) 31, 14.

1697. M. E. Bacon, Classical-Path Calculation of the Impact-Broadening Operator for the Stark Broadening of $\mathrm{H}_{\alpha}$, Phys. Rev. A $\underline{3}, 825$.

1698. L. M. Bal1 \& R. B. Higgins, On Radiative Decay of an Atom with Two Close-Lying Excited States, Phys. Lett. A $\underline{35}, 95$.

1699. K. S. Barnes, Quantum Mechanical Calculations of the Electron Impact Broadening of Isolated Ion Lines, J. Phys. B $\underline{4}, 1377$.

1700. K. Behringer, High Accuracy Measurements of the Spectrum of a Hydrogen Plasma, Z. Phys. 246, 333. (Ger.)

1701. G. Bekefi, E. V. George, \& P. A. Politzer, Stark Profiles of Forbidden and Allowed Transitions in a Dense, Laser-Produced Helium Plasma, MIT Research Laboratory of Electronics, Quarterly Progress Report No. 102, 67.

1702. G. Bekefi, E. V. George, \& B. Ya'akobi, Stark Profiles of the He I 4471 \& Line and of Its Two Forbidden Components, Measured in a Laser-Produced Plasma, MIT Research Laboratory of Electronics, Quarterly Progress Report No. 103, 86.

1703. Y. Ben-Aryeh \& A. Sorgen, Self-Broadening of Molecular Spectral Lines. I. General Theory, Phys. Rev. A $\underline{4}, 2170$.

1704. A. Ben-Reuven, Resonance Broadening of Spectral Lines, Phys. Rev. A 4 , 2115.

1705. N. Ben-Yosef \& A. G. Rubin, Forbidden Optical Transitions Stimulated by Plasma Turbulence in Helium, J. Quant. Spectrosc. Radiat. Transfer $11,1$.

1706. S. M. Benett \& H. R. Griem, Calculated Stark Broadening Parameters for Isolated Spectral Lines from the Atoms Helium Through Calcium and Cesium, University of Maryland Technical Report No. 71-097.

1707. P. R. Berman \& W. E. Lamb, Jr., Theory of Collision Effects on Line Shapes Using a Quantum-Mechanical Description of the Atomic Center-of-Mass Motion--Application to Lasers. II. The Pseudoclassical Collision Model and Steady-State Laser Intensities, Phys. Rev. A 4 , 319.

1708. J.W. Birkeland, M. E. Bacon, \& W. G. Braun, Profiles of the He I 4471.5- and 4922-A Lines in a dc Arc, Phys. Rev. A $\underline{3}, 354$. 
1709. C. Bottcher, Unified Classical Path Theories of Pressure Broadening, J. Phys. B 4, L99.

1710. R. G. Breene, Jr., Density Dependence in Resonance Broadening, Nuovo Cimento B 4, 1 .

1711. A. Brissaud \& U. Frisch, Theory of Stark Broadening--II Exact Line Profile with Model Microfield, J. Quant. Spectrosc. Radiat. Transfer 11, 1767.

1712. M. Brocklehurst \& S. Leeman, The Pressure Broadening of Radio Recombination Lines, Astrophys. Lett. $9,35$.

1713. M. Brocklehurst \& M. J. Seaton, The Profiles of Radio Recombination Lines, Astrophys. Lett. 9 , 139 .

1714. C. F. Bruce \& P. Hannaford, On the Widths of Atomic Resonance Lines from HollowCathode Lamps, Spectrochim. Acta, Part B 26, 207.

1715. K. A. Brueckner, Collision Broadening by Neutral Hydrogen, Astrophys. J. $169,621$.

1716. B. R. Bulos \& W. Happer, Nuclear-Spin Inertia and Pressure Broadening, of ${ }^{2} \mathrm{P}_{1 / 2}$ Hanle-Effect Signals, Phys. Rev. A 4 , 849.

1717. B. R. Bulos, A. Marshall, \& Wapper, Light Shifts Due to Real Transitions in Optically Pumped Alkali Atoms, Phys. Rev. A $\underline{4}, 51$.

1718. D. D. Burgess, An Explanation of the Apparent Non-Observation of 'Near' Plasma Satellite Emission Lines in Highly Turbulent Plasmas, J. Phys. B 4 , L7.

1719. D. D. Burgess \& C. J. Cairns, Experimental Studies of Helium Line Broadening in a Plasma: II. Low Electron Densities (Lines with Forbidden Components), J. Phys. B 4,1364 .

1720. D. D. Burgess \& N. J. Peacock, Reduced Limits on the Magnitude of Possible Polarization Shifts, J. Phys. B $\underline{4}$, L94.

1721. M. Caby \& Nguyen-Hoe, Thermal Average of the Evolution Operator Involved in the Calculation of the Electronic Broadening of the Ly- $\alpha$ Line of Hydrogen, C. R. H. Acad. Sci., Ser. B 272, 1410. (Fr.)

1722. P. W. Chan, Evidence of Density Inhomogeneity Broadeninf of Plasma Satellites from Light Scattering, Phys. Fluids 14, 2787.

1723. W. R. Chappell, J. Cooper, E. W. Smith, \& T. Dillon, A Kinetic Theory of Spectral Line Shapes, J. Statist. Phys. 3 , 401. 
1724. S. Y. Ch'en \& R. O. Garrett, Pressure Effects of Cs Lines Due to a M1xture of Two Rare Gases, Phys. Rev. A 4, 412.

1725. S. Y. Ch'en \& A. T. Lonseth, Pressure Effects of Rare Gases on the Absorption Line $\mathrm{Ca}$ 4227. I. The Effects of Argon and Helium, Phys. Rev. A $3,946$.

1726. R. Cheng, B. W1lliams, \& M. Cooper, The Treatment of Errors in the Deconvolution of Line Profile Measurements, Ph11. Mag. 23, 115.

1727. E. Churchwell, Observational Evidence for Stark Broadening In Radio Recombination Lines, Astron. Astrophys. 15, 90.

1728. J. Cooper, S. Klarsfeld, \& G. K. Oertel, Class1cal Path Broadening Functions for a Debye-Shielded Interaction, JILA Report No. 107.

1729. J. Cooper, E. W. Smith, \& W. R. Chappell, An Adiabatic Treatment of Ion Dynamics for Forbidden Line Profiles, Phys. Lett. A $34,363$.

1730. C. R. Cowley, An Approximate Stark Broadening Formula for Use in Spectrum Synthesis, Observatory 91, 139.

1731. E. Czuchaj \& J. Fiutak, The Binary Collision Approximation in the Theory of Line Broadening by Forelgn Gases, Acta Phys. Pol. A $40,165$.

1732. G. J. Dalenoort, The Holtsmark-Cont1nuum Model for the Stat1st1cal Descript1on of a Plasma, Z. Phys. 248, 22.

1733. J. Davis \& S. Morin, Relevant Atomic Parameters for Doubly-Ionized Aluminum, J. Quant. Spectrosc. Rad1at. Transfer 11, 495.

1734. J. Davis \& S. Morin, Electron Impact Broadening of Na I, Mult1plet 9, Spectral Lines, J. Quant. Spectrosc. Rad1at. Transfer 11, 129.

1735. V. A. Davydk1n, B. A. Zon, N. L. Manakov, \& L. P. Rapoport, Quadrat1c Stark Effect on Atoms, Sov. Phys, - JETP 33, 70.

1736. C. Deutsch, H. W. Drawin, \& L. Herman, Stark and Zeeman Effects on NeutralHelium Lines, Phys. Rev, A $\underline{3}, 1879$.

1737. J.W. Dufty, Ion Motion in Plasma Line Broadening, Phys. Rev. A 2 , 534.

1738. J. H. Eberly, Inhomogeneous Broadening in the Theory of Superrad1ant Emiss1on, Acta Phys. Pol. A $39,633$.

1739. J. H. Eberly, Beats and Inhomogeneous Broadening in Superradiant Fluorescence, Lett. Nuovo Cimento $1,182$. 
1740. G. H. Ecker \& K. G. Fischer, Individual and Collective Aspects of the Microfield Distribution, Z. Naturforsch. A $26,1360$.

1741. V. V. Eliseev \& G. V. Sholin, Satellites of the Cesium Absorption Lines in an Intrinsic Gas, Opt. Spectrosc. (USSR) 30, 222.

1742. E. S. Ensberg \& C. L. Morgan, Pressure Shifts of Hyperfine Frequencies in OneElectron Atoms, Nat. Bur. Stand. (U.S.), Spec. Publ. 343, 321.

1743. J. C. Evans \& G. Elste, Line Broadening in Y Equule1, Astron. Astrophys. $12,428$.

1744. R. J. Exton, W1dths of Opt1cally Th1ck Lines, J. Quant. Spectrosc. Rad1at. Transfer 11, 1377 .

1745. H. Falk, H. Becker-Ross, \& H. Schiller, On the Contribution of Radiative Diffusion on the Fine Profile of Resonance Lines, Ann. Phys. (Leipzig) 26, 166. (Ger.)

1746. J. M. Farr \& W. R. H1ndmarsh, Collision Broadening in the Strontium Resonance Line, $\lambda 4607 \AA$, J. Phys, B $\underline{4}, 568$.

1747. R. Frledberg, S. R. Hartmann, \& J. T. Manassah, Frequency Sh1fts in Resonant Systems, Phys. Lett. A $\underline{35}, 161$.

1748. U. Frisch \& A. Brissaud, On the Validity of the Unifled Classical Path Treatment of Stark Broadening, J. Phys. B 4,1230 .

1749. U. Frisch \& A. Brissaud, Theory of Stark Broadening--I Soluble Scalar Model as a Test, J. Quant. Spectrosc. Rad1at. Transfer 11, 1753.

1750. W. Fullerton \& C. R. Cowley, Calculations of Van der Waals Broadening for Lines of Astrophys1cal Interest, Astrophys. J. 165, 643.

1751. C. C. Gallagher \& M. A. Levine, Observation of $H_{B}$ Satelites in the Presence of Turbulent Electric Flelds, Phys. Rev. Lett. 27, 1693.

1752. J. I. Gersten, Asymptotic Line Shape in Collision-Induced Light Scattering, Phys. Rev. A $\underline{4}, 98$.

1753. J. T. Godfrey, C. R. Vidal, E. W. Smith, \& J. Cooper, Effect of Time Ordering in the Unifled Theory, Phys. Rev. A 3 , 1543; Nat. Bur. Stand. (U.S.), Monogr. 121.

1754. H. R. Grlem, Effects of Resonances on the Electron Impact Broadening of Ion Lines, Comments At. Mol. Phys. 2, 147 . 
1755. H. R. Griem, On Stark Profiles of Forbidden Components, Comments At. Mol. Phys. $\underline{2}, 206$.

1756. H. R. Griem, D1fferent Absorption and Emission Line Shapes for Stark-Broadened Resonance Lines in Helium Plasmas, Comments At. Mol. Phys. $\underline{3}, 1$.

1757. T. J. Hammond \& C. F. Gallo, Effects of Argon Atoms on the Self-Absorpt1on and the Intensity of $\mathrm{Hg}$ 2537-A Radiation in Hg+Ar Discharges, Appl. Opt. 10, 58.

1758. J. S. Hildum \& J. Cooper, Stark Broadening of Calc1um Ion Resonance Lines, Phys. Lett. A $\underline{36}, 153$.

1759. R. A. H1ll, J. B. Gerardo, \& P. C. Kepple, Stark Broadening of $H_{B}, H_{\gamma}$, and $\mathrm{H}_{\delta}$ : A Comparison of Theory and Exper1ment, Phys. Rev. A $\underline{3}, 855$.

1760. H. Holweger; Damping and Solar Abundance of Sodlum from Na I Fraunhofer Lines, Astron. Astrophys. 10, 128 .

1761. H. Holweger, The Broadening by Neutral Hydrogen in the Solar Atmosphere, Comments to the Note by Roueff and Van Regemorter (1971), Astron. Astrophys. 12, 319.

1762. R. S. Howard \& C. H. Dugan, Pressure Broadening of 0 I $\lambda 5577$ by Argon, Chem. Phys. Lett. $8,433$.

1763. D. Ikenberry \& T. P. Das, Hyperfine Pressure Shift for Interacting Atoms: P1tfalls of a Var1at1onal Procedure, Phys. Rev, Lett. 27, 79.

1764. M. Iwao \& K. JayaRam, Theoret1cal Est1mation of the Spectral Line Broadening Constants of Copper I, Aeta Phys. Pol. A $\underline{40}, 527$.

1765. H. C. Jacobson, Intermolecular Forces from Atomic Line-Shape Exper1ments, Phys. Rev. A ㄴ, 1368 .

1766. H. C. Jacobson, Moment Analys1s of Atomic Spectral Lines, Phys, Rev. A $4,1363$.

1767. J. E. Jenkins \& D. D. Burgess, Experimental Studies of Helium Line Broadening in a Plasma: I. High Electron Dens1ties, J. Phys. B 4, 1353.

1768. L. A. Jones, J. R. Gre1g, T. Oda, \& H. R. Griem, Stark-Profile Measurements for the First Four na Lines of Ionized Helium, Phys. Rev. A $\underline{4}, 833$.

1769. P. Kepple, Stark Profile Calculations for Ionized Helium Lines, University of Maryland Technical Report No. 72-018.

1770. Yu. L. Klimontovich, Problems of Stat1stical Theory of Interaction of Atoms with Radiation, Sov. Phys. - Usp. 13, 480. 
1771. G. A. Kobzev, Calculating the Collision Broadening of Ionic Lines, Opt. Spectrosc. (USSR) $\underline{30}, 106$.

1772. N. Konjevic \& M. Platisa, On the Application of Griem's Semiempirical Formula for the Computation of Stark Widths of Isolated Ion Lines in Plasmas, "ThIrd Conference on Atomic Spectroscopy," No. 56 (University of Reading, Reading, England).

1773. N. Konjev1c, M. Plat1sa, \& J. Purlc, Electron Impact Broadening of Ionized Chlorine Lines, J. Phys. B $\underline{4}, 1541$.

1774. W. C. Kreye, Interferometric Studies of Wide-Lorentzlan-Width Ar II and Ne II Spectral Lines Exc1ted in a Hollow-Cathode D1scharge, J. Opt. Soc. Amer. 61, 833.

1775. S. I. Krylova, L. A. Lulzova, V. A. Solyan1kova, \& A. D. Khakhaev, Constant Stark and Van der Waals Interactions for Exc1ted States of Ar and Ne, Zh. Prikl. Spektrosk. 14, 919. (Russ.)

1776. D. Kunik \& U. Kaldor, Hyperfine Pressure Shift of Hydrogen in Helium, J. Chem. Phys. 55, 4127 .

1777. H. J. Kusch, On the Broadening of He I Lines and the $H_{B}$ LIne by Stark Effects from Microflelds, Z. Naturforsch. A 26, 1970. (Ger.)

1778. H. J. Kusch, W. Lochte-Holtgreven, \& P. Massmann, Pressure Broadening of N1ckel Lines by Argon, Ann. Phys. (Lelpz1g) 26, 267. (Ger.)

1779. A. L. Kuzemsky \& K. Walasek, On the Calculation of the Natural Width of the Spectral Lines of the Atom by the Methods of Nonequilibrium Statistical Mechanics, Lett. Nuovo Cimento $2,953$.

1780. B. Landheer \& A. V. Durrant, Calculation of Spectral Line Profiles for Combined Doppler and Lorentz Broadening, J. Phys. B $\underline{4}$, L36.

1781. D. S. Leckrone, The He I Line Profiles in Normal B Type Spectra, Astron. Astrophys. 11, 387 .

1782. R. Lee, The Unifled Theorles of Line Broadening, J. Phys. B 4, 1640.

1783. E. L. Lew1s, L. F. McNamara, \& H. H. Michels, Broadening of the Sodium D Lines by Atomic Hydrogen. An Analysis in Terms of the NaH Molecular Potentials, Phys. Rev. A $\underline{3}, 1939$.

1784. E. L. Lew1s, M. M. Rebbeck, \& J. M. Vaughan, Resonance Broadening in the Spectrum of Potassium, J. Phys. B 느, 741 .

1785. M. A. Mazing \& P. D. Serapinas, Broadening and Shift of H1ghly Exc1ted Levels of Potassium and Cesium Atoms, Sov. Phys. - JETP $\underline{33}, 294$. 
1786. G. A. Mikhnenko, E. D. Protsenko, E. A. Sedo1, \& M. P. Sorok1n, Experimental Study of the Collision Broadening of the $0.63 \mu$ Line of a He-Ne Laser, Opt. Spectrosc. (USSR) 30,65 .

1787. M. H. Miller, R. A. Ro1g, \& G. A. Moo-Young, Experimental Widths and Shifts for 3s-3p Neon Lines, Phys. Rev. A $\underline{4}, 971$.

1788. M. Mizushima, Velocity Distribution Effect in Pressure Broadened Spectral Lines, J. Quant. Spectrosc. Radiat. Transfer 11, 471.

1789. M. I. Molchanov, The Effect of Collisions on the Broadening of the Ne Lines $\lambda=0.63 \mu, \mathrm{Zh}$. Prikl. Spektrosk. 14, 65. (Russ.)

1790. J. J. Monaghan, A Note on the Volgt Function, Mon. Not1c. Roy. Astron. Soc. 152, 509.

1791. R. H. Nelson \& A. J. Barnard, Profiles of He I 4471 and 4922 A in a Pulsed Arc, J. Quant. Spectrosc. Radiat. Transfer 11, 161.

1792. J. Norris, Neutral-Hellum Line Strengths. IV. Fourteen "Normal" Stars of Population I, Astrophys. J., Suppl. Ser. 23, No. 197, 193.

1793. H. Nowotny, Diagram Summation for Resonance Broadening Calculations, Phys. Lett. A $\underline{36}, 481$.

1794. K. Okazak1, K. Ando, K. Mor1, \& K. Okamoto, A Mult1channel System for Determinat1on of Time Varying Spectral Line Profiles, Jap. J. Appl. Phys. 10, 886.

1795. B. J. O'Mara \& R. W. Simpson, Comments on the Broadening of He I Lines with Forbidden Components, Astron. Astrophys. $\underline{15}, 334$.

1796. B. E. J. Pagel, Importance of Spectral Line Shapes in Astrophysics, J. Phys. B 4. 279 .

1797. D. Park, The Classical Theory of Pressure Broadening, Amer. J. Phys. $\underline{39}, 682$.

1798. A. Pedlar \& R. D. Davies, Stark Broadening in High Quantum Number Recombination Lines of Hydrogen, Nature - Phys. Sc1. 231, 49.

1799. H. Pfennig, On the Stark Broadening of Ly - $\alpha$ by Strong Electron Collisions, Phys. Lett. A $\underline{34}, 292$.

1800. H. Pfennig, On Stark Broadening of the Hydrogen Line Ly- $\alpha$ by Strong Electron Col11sions, Z. Naturforsch. A 26, 1071. (Ger.)

1801. M. Plat1sa \& J. Pur1c, Analysis of Instrumental Profile of Axicon -- Scanned Fabry-Perot "Spectrometer, Flzika $\underline{3}, 175$. 
1802. M. Plat1sa, J. Pur1c, N. Konjev1c, \& J. Labat, Measurement of Electron-Impact Broadening of Ionlzed Beryllium and Barlum Lines in an Electric Shock Tube Plasma, Astron. Astrophys. 15, 325.

1803. A. G. Pokrovsk11 \& M. Ya. Rozinsk11, Study of the Poss1b1l1t1es of Determining the Instrument Function of IR Spectrometers from Absorption Spectra, Opt. Spectrosc. (USSR) 31, 247 .

1804. J. Pur1c, N. Konjev1c, M. Plat1sa, \& J. Labat, Stark Sh1fts of Cl I and Cl II Lines, Phys. Lett. A $37,425$.

1805. J. Pur1c, M. Plat1sa, \& N. Konjev1c, Stark Broadening of Singly Ion1zed Stront1um and Calcium Lines, Z. Phys. 247, 216.

1806. J. L. Queffelec \& M. Girault, Study of the Profiles of Emission Lines of a Stab1l1zed Plasma Arc of Cylindrical Symmetry, Rev. Phys. Appl. 6, 401. (Fr.)

1807. J. J. Quemener, C. Paquet, \& P. Marmet, Natural Line Shapes Resolved in the Ionization Y1eld of $\mathrm{He}^{+}$Below the $\mathrm{n}=2$ Threshold, Phys. Rev. A $4,494$.

1808. J.-Y. Ronc1n, Relat1onsh1p Between Matr1x Shifts and Pressure Effects on Spectral LInes, J. Quant. Spectrosc. Radlat. Transfer 11, 1151.

1809. F. Rostas \& J. L. Lema1re, Low Pressure Measurement of the Broadening and Sh1ft of the Caesium $4555 \AA$ and $4593 \AA$ Lines by Hellum and Argon, J. Phys. B $\underline{4}, 555$.

1810. F. Rostas, J. L. Lema1re, \& P. Felenbok, Dual-Channel Multiplex System for Prec1se Measurement of Displacement and Shape of Spectral Lines, Appl. Opt. 10, 801 .

1811. L. J. Roszman, The Effects of Ion Motion on Spectral Line Broadening in Plasmas, Thes1s, Un1versity of Florida.

1812. E. Roueff \& H. Van Regemorter, The Broadening by Neutral Hydrogen in the Solar Atmosphere, Astron. Astrophys. 12, 317 .

1813. A. Royer, Semiclassical and Classical Spectrum in the Adlabat1c Theory of Pressure Broadening, Phys. Rev. A $\underline{4}, 499$.

1814. A. Royer, Expansion of the Spectrum in Powers of the Density in the Adlabat1c Theory of Pressure Broaden1ng, Phys, Rev. A 3 , 2044.

1815. S. Sahal-Brechot \& E. Segre, Sem1-Class1cal Calculations of Electron and Ion Collisional Broadening of the Strongest U.V. Ion1c Lines of Astrophysical Interest, Astron. Astrophys. 13, 161; "H1ghl1ghts of Astronomy," 566-574 (Ed. De Jager, I.A.U.). 
1816. F. Schuller, On the j-Dependence of Collision-Induced Shift and Broadentng of Atomic Fine Structure Components, J. Quant. Spectrosc. Radiat. Transfer $11,1725$.

1817. M. Semel \& I. Soru-Escaut, on the Broadening of the Balmer Lines during a Flare, Astron. Astrophys. 12, 340. (Fr。)

1818. G. V. Sholin, Stark Broadening of the Hydropen Spectral Lines in a Turbulent Plasma, Sov. Phys. - Dokl. 15, 1040.

1819. G. V. Sholin, V. S. Lisitsa, \& V. I. Kogan, Amplitude Modulation and NonAdiabaticity in the Stark Broadening of Hydrogen Lines in a Plasma, Sov. Phys. JETP 32,758 .

1820. E. W. Smith, J. Cooper, W. R. Chapnell, \& T. Dillon, An Imbact Theory for Doppler and Pressure Broadening--I. General Theory, J. Quant. Spectrosc. Radiat. Transfer 11, 1547 .

1821. E. W. Smith, J. Cooper, W. R. Chappell, \& T. Dillon, An Impact Theory for Doppler and Pressure Broadening--II. Atomic and Molecular Systems, J. Quant. Spectrosc. Radiat. Transfer 11, 1567 .

1822. M. A. J. Snijders \& A. B. Underhill, Evidence Concerning the Complexity of the Line Forming; Problem in He I, Mon. Not1c. Roy. Astron. Soc. 151, 215.

1823. A. Sorgen \& Y. Ben-Aryeh, Self-Broadening of Molecular Spectral Lines. II. Classical-Path Approximation, Phys. Rev. A 4 , 2178.

1824. D. N. Stacey \& J. Cooper, Non-Adiabatic Effects in van der Waals Broadening, J. Quant. Spectrosc. Radiat. Transfer 11, 1271.

1825. J. Szudy, On the Correlation Form of the Jablonsk1 Pressure Broadening Theory, Bull. Acad. Pol. Sci., Ser. Sci., Math., Astron., Phys. 19, 153.

1826. J. Szudy, The Franck-Condon Princinle and the Broadening of Isolated Spectral Lines in Plasmas, Acta Phys. Pol. A $40,361$.

1827. D. K. L. Tan, Pressure Shifts of Cs Absorntion Lines Due to Binary Mixtures of Rare Gases, Phys. Lett. A $34,263$.

1828. V. M. Tatarenkov \& A. N. Titov, Effect of Neon-Neon Collisions on the Characteristics of the $3 \mathrm{~s}_{2}-3 \mathrm{p}_{4}$ Laser Transition of the $\mathrm{Ne}^{20}$ Atom, Opt. Spectrosc. (USSR) 30,434 .

1829. A. Tip \& F. R. McCourt, Kinetic Theory of Pressure Broadening, Physica (Utrecht) 52, 109 . 
1830. S. D. Tvorogov \& V. V. Fomin, Theory of Spectral Line Contours in the Far Wings, Opt. Spectrose. (USSR) $30,228$.

1831. C. J. Ultee, Line Broadening Cross Sections of Fluorine and Iodine Atom ESR Lines, J. Chem. Phys. 54, 5437.

1832. C. R. Vidal, J. Cooper, \& E. W. Smith, Unifled Theory Calculations of Stark Broadened Hydrogen Lines Including Lower State Interactions, J. Quant. Spectrosc. Rad1at. Transfer 11, 263; Nat. Bur. Stand. (U.S.), Monogr. 120.

1833. W. L. Wlese \& D. E. Kelleher, On the Cause of the Redshifts in White-Dwarf Spectra, Astrophys. J. 166 , L59.

1834. S. P. Zagorodnikov, G. E. Smolkin, E. A. Striganova, \& G. V. Sholin, Method of Measurement of Nonequilibrium Electric Flelds in a Turbulent Plasma from Stark Broadening of the Spectral Lines of Hydrogen, Sov. Phys. - Dokl. 15, 1122.

1835. L. P. Zakatov, A. G. Plakhov, V. V. Shapkin, \& G. V. Sholin, Measurement of the No1se Level of Langmuir Oscillations in a Beam-Plasma System Based on Stark Broadening of the Spectral Lines of Hydrogen, Sov. Phys. - Dokl. 16, 451.

1836. E. K. Zavolsk11, Yu. G. Kalinin, V. A. Skoryupin, V. V. Shapkin, \& G. V. Sholin, Observation of Asymmetry of the Distribution of Turbulent Electric Fields in a Direct Discharge Plasma by Means of the Polarization in the Stark Proflle of the $\mathrm{H}_{\alpha}$ Line, JETP Lett. 13,12 .

1837. E. K. Zavolski1, Yu. G. Kalinin, V. A. Skoryupin, V. V. Shapkin, \& G. V. Sholin, Measurement of Electric Fields in a Turbulent Plasma by the Stark Broadening of the Spectral Lines in Hydrogen, Sov. Phys. - Dokl. 15, 823.

1838. G. I. Zav'yalov, A. Yu. Zav'yalova, \& N. A. Prilezhaeva, Investigation of the Asymmetry of the Resonance Lines of Mercury $\lambda=2537 \AA$, Izv. Vyssh. Ucheb. Zaved., F1z. No. 8, 139. (Russ.)

1858. A. K. Atakan \& H. C. Jacobson, Comparison of Experimental and Theoretical Pressure-Broadened Atomic Line Shapes, J. Quint. Spectrosc. Radiat. Transfer $12,289$.

1859. J. M. Bassalo \& M. Cattani, Broadening and Shift of Atomic Lines Produced by Fast Electron Collisions, Can. J. Phys. 므, 151.

1860. P. Bogen, Pressure Broadening of Multiply Ionized Carbon Lines, Z. Naturforsch. A 27,210 . 
1861. M. Borenstein \& W. E. Lamb, Jr., Effect of Veloc1ty-Changing Collisions on the Output of a Gas Laser, Phys. Rev. A $\underline{5}, 1311$.

1862. M. Cattan1, On the Calculation of the Pressure Line Shape in the Impact ApproxImation, Phys. Lett. A $\underline{38}, 147$.

1863. C. Cohen-Tannoudj1, Light Shifts and Multiple Quantum Transitions, "Physics of the One- and Two-Electron Atoms," 326-340 (Ed. F. Bopp \& H. Kleinpoppen, NorthHolland Publishing Co., Amsterdam).

1864. J. Comer \& F. H. Read, A Simple Method of Obtaining Resonance Energies from Broadened Profiles in Scattering Experiments, J. Phys. E $\underline{5}, 211$.

1865. B. M. Dodsworth, J. C. Gay, \& A. Omont, Self-Broadening of the Level Crossing Curves observed in Backscattering (The $6{ }^{3} \mathrm{P}_{1}$ Level of Mercury), J. Phys. (Paris) 33, 65. (Fr.)

1866. J. M. Evans, Jr. \& J. Cooper, Determination of Van der Waals Broadening at Temperatures of Astrophysical Interest, J. Quant. Spectrosc. Radiat. Transfer 12 , 259.

1867. M. Fabry \& J. R. Cussenot, Spectroscopic Measurements of Parameters in a LowDensity Alkal1-Metal Plasma, J. Appl. Phys. 43, 357.

1868. B. J. Feldman \& M. S. Feld, Laser-Induced Line-Narrowing Effects in Coupled Doppler Broadened Transitions. II. Standing-Wave Features, Phys. Rev. A $\underline{5}, 899$.

1869. W. W. Hicks, R. A. Hess, \& W. S. Cooper, Combined Zeeman and High-Frequency Stark Effects, with Applications to Neutral-Helium Lines Useful in Plasma Diagnostics, Phys. Rev. A $\underline{5}, 490$.

1870. H. C. Jacobson, Computation of Pressure Effects of Inert-Gas Mixtures on Atomic Line Shapes, Phys. Rev. A $\underline{5}, 989$.

1871. W. W. Jones, Measurement and Calculation of the Stark Broadening Parameters of Singly Ionized Calclum and Magnesium, University of Maryland Technical Report No. $72-051$.

1872. J. F. Klelkopf, Forces Between Excited Alkall Atoms and Noble Gases, Phys. Rev. A 5.484 .

1873. R. W. Lee, Ion Dynamic Correction to Forbidden Line Profiles, J. Phys. B $\underline{5}, L 23$.

1874. V. S. Lisitsa \& G. V. Sholin, Exact Solution of the Problem of the Broadening of the Hydrogen Spectral Lines in the One-Electron Theory, Sov. Phys. - JETP $34,484$. 
1875. K. Niemax, Satellites of Cs I Lines, Phys. Lett. A $38,141$.

1876. J. T. O'Brien \& C. F. Hooper, Jr., Low-Frequency Electric Microfleld Distributions In a Plasma Containing Multiply Charged Ions, Phys. Rev. A $5,867$.

1877. G. Peach, The Broadening of Radio Recombination Lines by Electron Collisions, Astrophys. Lett. 10, 129.

1878. E. Peytremann, Theoretical Effect of Varlous Broadening Parameters on Ultraviolet Line Profiles, Astron. Astrophys. 17, 76.

1879. J. Purlc \& N. Konjevic, Stark Shifts of Some Isolated Spectral Lines of Singly Ionized Earth Alkaline Metals, Z. Phys. 249, 440.

1880. G. P. Reck \& R. J. Hood, Binary Collision Broadening: Approximate Methods, J. Chem. Phys. 56, 1230 .

1881. E. Roueff, Broaden1ng of Alkal1 Lines by Atomlc Hydrogen, Phys, Lett. A $38,8$.

1882. M. Sass1, Determination of the Electronic Density of an Ionized Plasma Bepinning with the Distance Between the Peaks of the "Allowed" Line of L1 I $\left(2^{2} \mathrm{P}-4^{2} \mathrm{D}\right)$ (or

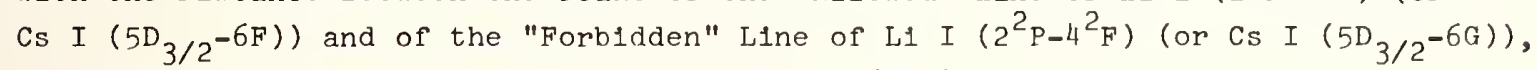
J. Quant. Spectrosc. Radiat. Transfer 12, 75. (Fr.)

1883. M. Sassi \& G. Coulaud, Calculated Ionic Profiles in the Refion of the Forbidden Component Cs I $(6 \mathrm{G}-5 \mathrm{D})$, J. Phys. B $\underline{5}, \mathrm{~L} 35$.

1884. E. W. Smith, J. Cooper, \& C. R. Vidal, Comments on the Validity of the Unifled Classical Path Theory of Stark Broadening, J. Phys. B $\underline{5}$, L33.

1885. M. L. Strekalov \& A. I. Burshte1n, Collapse of Shock-Broadened Mult1plets, Sov. Phys. - JETP $\underline{34}, 53$.

1886. R. C. Sze, E. T. Antropov, \& W. R. Bennett, Jr., Lorentz W1dth Measurements on the Argon Ion Laser Transitions, Appl. Opt. 11, 197.

1887. R. C. Sze \& W. R. Bennett, Jr., Spontaneous-Em1ssion Profiles of Argon-Ion Laser Transitions, Phys. Rev. A $\underline{5}, 837$.

1888. G. Yamamoto \& T. Aok1, Line Broadening Theory of Asymmetric-Top Molecule, J. Quant. Spectrosc. Radiat. Transfer 12, 227.

1889. E. A. Yukov, Stark Broadening of S1 II and S1 III Lines, Sov. Astron. - AJ 15, 867. 


\section{LIST OF AUTHORS}

\begin{tabular}{|c|c|c|c|}
\hline Author & Ref. No.* & Author & Ref. No.* \\
\hline Agв rwa 1, G. S. & 1692 & Armstrong, B. H. & 886,1138 \\
\hline Agnew, L. & $796,821,1038$ & Arnold, J. 0 . & 1378 \\
\hline Alekseev, V. A. & $\begin{array}{l}1039,1136,1247 \\
1548,1693,1694\end{array}$ & Arnous, E. & 403,421 \\
\hline $\begin{array}{l}\text { Alexander, M. H. } \\
\text { Ali, A. W. }\end{array}$ & $\begin{array}{l}1377 \\
761,961\end{array}$ & $\begin{array}{l}\text { Asagoe, } \mathrm{K} . \\
\text { Asmaryan, E. A. }\end{array}$ & $\begin{array}{l}92,122 \\
1696\end{array}$ \\
\hline Alkemade, C. Th.J. & $.1011,1148,1605$ & Assous, $\mathrm{R}$. & $1248,1249,1550$ \\
\hline Allen, C. W. & 145,822 & $\begin{array}{l}\text { Atwood, M. R. } \\
\text { Auer, L. H. }\end{array}$ & $\begin{array}{l}702 \\
1632\end{array}$ \\
\hline Allen, L. C. & 885 & Aulehla, E. & \\
\hline Allen, R. H. & 1411 & Aurela, A. M. & 1551 \\
\hline Aller, L. H. & 499 & Avila, C. & 1104,1105 \\
\hline $\begin{array}{l}\text { Alpiner, B. P. } \\
\text { Alyamovskii, V. N. }\end{array}$ & $\begin{array}{l}764 \\
.591,642,756\end{array}$ & Avrett, E. H. & 962 \\
\hline Ama ldi, E. & 180,181 & Babcock, H. D. & 106 \\
\hline $\begin{array}{l}\text { Anderson, K. S. } \\
\text { Anderson, L. W. }\end{array}$ & $\begin{array}{l}1695 \\
592,643,696,1002\end{array}$ & Bacon, M. E. & $\begin{array}{l}1250,1379,1380, \\
1381,1552,1697, \\
1708\end{array}$ \\
\hline Anderson, P. W. & $350,402,443,495$ & Baird, J. C., Jr. & $592,643,696$ \\
\hline Ando, $K$ & 1137,1794 & Bali, L. M. & 1698 \\
\hline Andreeva, T. L. & 974 & Ballik, E. A. & $\begin{array}{l}223,220 \\
1040\end{array}$ \\
\hline Antonov, A. S. & 1549 & Balling, L. C. & $1522,1667,1669$ \\
\hline $\begin{array}{l}\text { Aoki, T. } \\
\text { Arditi, M. }\end{array}$ & $\begin{array}{l}1526,1888 \\
556,697\end{array}$ & Baranger, M. & $\begin{array}{l}558,559,560,593 \\
668,698,757,770\end{array}$ \\
\hline
\end{tabular}

* The numbers refer to paper identification numbers of Part 3. 


\begin{tabular}{|c|c|c|c|}
\hline Author & Ref. No.* & Author & Ref. No.* \\
\hline Baravian, G. & 1382 & Ben-Reuven, A. & $963,1041,1042$ \\
\hline Bardocz, A. & 758 & & 1704 \\
\hline Barger, R. L. & 1139 & Ben-Yosef, N. & 1705 \\
\hline Barnard, A. J. & $\begin{array}{l}1251,1383,1384 \\
1553,1791\end{array}$ & Benattar, $R$. & 1382 \\
\hline Barnes, K. S. & 1554,1699 & Bender, P. L. & $\begin{array}{l}561,562,699,889 \\
1387\end{array}$ \\
\hline Barnes, S. W. & 192 & Benedict, W. S. & 760 \\
\hline Barte 1s, H. & $\begin{array}{l}351,352,366,422 \\
517,759\end{array}$ & Benett, S. M. & 1706 \\
\hline Baschek, B. & 1320,1637 & Bengtson, R. D. & $\begin{array}{l}1253,1388,1560 \\
1561,1633\end{array}$ \\
\hline Batarchukova, N.R. & 496 & Bennett, R. B. & 497,646 \\
\hline Bayer-Helms, F. & $823,824,825,826$ & Bennett, $W_{.} R_{\bullet}, J r$. & $1141,1886,1887$ \\
\hline Bazhov, A. S. & 1555 & Berg, H. F. & $\begin{array}{l}761,1043,1142, \\
1143,1620\end{array}$ \\
\hline Beaty, E. C. & 561,562 & & \\
\hline Beck, R. J. & 1630 & Bergeon, $\mathrm{R}$. & $\begin{array}{l}404,444,468,503 \\
563\end{array}$ \\
\hline Becker-Ross, H. & 1745 & Bergstedt, $\mathrm{K}$. & 700 \\
\hline Beckner, E. H. & 913 & Berman, P. R. & $1389,1562,1707$ \\
\hline Bederson, B. & 1556 & Bernstein, M. J. & 975 \\
\hline Behmenburg, W. & $887,888,1252$ & Berreman, D. W. & 1254 \\
\hline Behringer, $\mathrm{K}$. & 1700 & Besombes, F. & 1390 \\
\hline Bekefi, G. & $1525,1701,1702$ & Beuche1t, $R$. & 517 \\
\hline Bekenstein, J. D. & 1557 & Bezzerides, B. & $\begin{array}{l}1144,1145,1391 \\
1392\end{array}$ \\
\hline Bely, 0 & 1385,1558 & Bhat ta charyya, D.K. & 315 \\
\hline $\begin{array}{l}\text { Belyaev, M. P. } \\
\text { Ben-Aryeh, Y. }\end{array}$ & $\begin{array}{l}1357 \\
1703,1823\end{array}$ & $\begin{array}{l}\text { Biberman, L. M. } \\
\text { Bieneiwski, T. M. }\end{array}$ & $\begin{array}{l}367 \\
890\end{array}$ \\
\hline
\end{tabular}

*The numbers refer to paper identification numbers of Part 3. 


\begin{tabular}{|c|c|c|c|}
\hline Author & Ref. No.* & Author & Ref. No.* \\
\hline Billings, D. E. & 891 & Braun, W. G. & 1393,1708 \\
\hline Biondi, M. A. & 969 & Brechot, S. & $\begin{array}{l}828,893,894,1149, \\
1150,1151,1169\end{array}$ \\
\hline Birke land, J. W. & $1146,1393,1708$ & & $\begin{array}{l}1255,1330,1501, \\
1502,1573,1627\end{array}$ \\
\hline Birnbaum, G. & 1044,1147 & & 1815 \\
\hline Blandin, J. & $1157,1255,1261$ & Breene, R. G., Jr. & $\begin{array}{l}519,701,895,1152, \\
1256,1257,1565\end{array}$ \\
\hline Blitzer, L. & 469 & & $1566,1567,1710^{\circ}$ \\
\hline Bloom, A. L. & $644,1045,1046$ & Breit, G. & 594 \\
\hline Bloom, S. & 423,478 & Bretagne, J. & 1382 \\
\hline Bober, L. & 1394,1446 & Bridges, J. M. & 1047,1153 \\
\hline Böhm, K. H. & 645 & Brissaud, A. & $1711,1748,1749$ \\
\hline Bötticher, W. & 827,1179 & Brochard, J. & 1162,1568 \\
\hline Bogen, P. & $518,1563,1860$ & Brocklehurst, M. & 1712,1713 \\
\hline Boggs, J. E. & 1204 & Brout, R. & 520 \\
\hline Boldt, G. & 892,964 & Brown, R. A. & 1258 \\
\hline Bolwijn, P. T. & 1148 & Broyles, A. A. & $471,521,564$ \\
\hline Bonczyk, P.A. & 1409 & Bruce, C. F. & 1714 \\
\hline Bondarev, A. F. & 762 & Brueckner, K. A. & 1715 \\
\hline Borenstein, $M_{\text {. }}$ & 1286,1861 & Buckmaster, H. A. & 1396 \\
\hline Born, M. & 159 & Budini, $\mathrm{P}$. & 260 \\
\hline Bottcher, C. & 1395,1709 & Bueren, H. G. van & 1048 \\
\hline Bouchiat, C. C. & 1564 & Bues, I. & 1397 \\
\hline Bouchiat, M. A. & 1564 & Bulos, B. R. & 1716,1717 \\
\hline Bracewe $11, R . N$. & 470 & Burge:, $\mathrm{H} . \mathrm{C}$. & $93,107,146,160$ \\
\hline Brandt, A. F. & 186 & & \\
\hline
\end{tabular}

*The numbers refer to paper identification numbers of Part 3. 


\begin{tabular}{|c|c|c|c|}
\hline Author & Ref. No.* & Author & Ref. No.* \\
\hline Burgess, D. D. & $\begin{array}{l}965,1154,1259, \\
1569,1570,1571, \\
1572,1718,1719, \\
1720,1767\end{array}$ & $\begin{array}{l}\text { Chang, C. S. } \\
\text { Chapelle, J. }\end{array}$ & $\begin{array}{l}353 \\
1157,1255,1261, \\
1573\end{array}$ \\
\hline Burkhardt, G. & 275 & Chappe11, W. R. & $\begin{array}{l}1400,1574,1723, \\
1729,1820,1821\end{array}$ \\
\hline $\begin{array}{l}\text { Burnett, J. C. } \\
\text { Burshtein, A. I. }\end{array}$ & $\begin{array}{l}1631 \\
966,1049,1050 \\
1051,1155,1260 \\
1885\end{array}$ & $\begin{array}{l}\text { Chebotaev, V. P. } \\
\text { Chen, C. L. }\end{array}$ & $\begin{array}{l}1141,1305 \\
1262\end{array}$ \\
\hline $\begin{array}{l}\text { Cabannes, F. } \\
\text { Caby, M. } \\
\text { Cairns, C. J. }\end{array}$ & $\begin{array}{l}1157,1261 \\
1636,1721 \\
1571,1719\end{array}$ & $\mathrm{Ch}^{\prime}$ en, S. Y. & $\begin{array}{l}235,236,247,248, \\
276,277,278,308, \\
341,353,405,424, \\
455,472,497,522, \\
523,533,646,647, \\
702,703,704,898, \\
939,1062,1158, \\
1173,1401,1402, \\
1403,1440,1450, \\
1451,1452,1575, \\
1659,1724,1725\end{array}$ \\
\hline Carazza, B. & 1641 & Cheng, $R$. & 1726 \\
\hline Carr, J. B. & 644 & Chi, A. R. & 561,562 \\
\hline Carrington, C. G. & 1398 & Chiarella, C. & 1053 \\
\hline Carver, T. R. & 556,697 & Choong, S. P. & 206 \\
\hline Casimir, H. & 161 & Choudhury, M. H. & 1404 \\
\hline Castex, M..C. & 1174,1399 & Chow, K. $-W_{\bullet}$ & 1510 \\
\hline Castle, B. & 539 & Chowdhury, S. S. & 1405 \\
\hline Cayless, M. A. & 1052 & Chudzynski, S. & 968 \\
\hline Cayre 1, R。 & 445 & Churchwe11, E. & 1727 \\
\hline $\begin{array}{l}\text { Chaika, M. P. } \\
\text { Chan, P. W. }\end{array}$ & $\begin{array}{r}1273 \\
.1722\end{array}$ & Cirkovic, Lj. & $\begin{array}{l}1464,1614,1615, \\
1616,1618,1619, \\
1643\end{array}$ \\
\hline Chandra sekharan, V. & 703 & & \\
\hline
\end{tabular}




\section{Author}

\section{Ref. No.*}

Cittert, P.H. van

Clark, K. C.

982

Clarke, G.A.

763

Clayton, E. D.

405

Cohen, V. W.

1387

Connor, T. R.

969

Cook, D. W.

1406

Cooper, C. D.

Cooper, J .

Cooper, M.

Cooper, W. S.

Cordover, R. H.

Corney, A.

Coulaud, G.

Cowley, C.

Craggs, J. D .

Craig, J.P. 892
1869 1409

1398,1410 $1602,1648,1649$, 1883

$332,383,798$

\section{5}

$929,965,1054$, $1055,1159,1160$, $1381,1383,1384$, $1400,1407,1408$, $1486,1508,1511$, $1512,1513,1515$, $1518,1553,1574$, $1576,1584,1665$, $1723,1728,1729$, $1753,1758,1820$, $1821,1824,1832$, 1866,1884

1726

$1411,1590,1730$, 1750

1606
Author

Ref. No.*

Curnutte, B.

797

Curtis, W.

534

Curzon, F. L.

1327

Czucha j, E.

$1412,1588,1731$

Dahmen, M.

1263

Dalenoort, G. J .

$1056,1161,1413$, $1414,1578,1579$, 1732

Da 1garno, A.

1503

Da 1ton, M. L., Jr. 970

Damaschini, $R$.

1162

Danilova, V. I.

333

Das, G.

1580,1645

Das, T. P.

$1477,1493,1494$, $1495,1586,1763$

Davies, J. T.

829

Davies, R. D.

1798

Davis, J .

$1163,1164,1214$, $1264,1265,1328$, $1581,1733,1734$

Davis, J.F. 1608

Davis, W. D. 1388

Davison, W. D. 1415

Davydkin, V. A.

1735

*The numbers refer to paper identification numbers of Part 3. 


\begin{tabular}{|c|c|c|c|}
\hline Author & Ref. No.* & Author & Ref. No.* \\
\hline Day, R. A. & $\begin{array}{l}971,972,1416, \\
1582\end{array}$ & Drobyshevskii,E.M. & 900 \\
\hline Debye, $\mathrm{P}$. & 46 & Dronov, A. P. & 705 \\
\hline De Croutte, E. & 837,838 & Dubovik, V. M. & 1663 \\
\hline deHaas, N. & 1521 & Dubrovskii, G. B. & 496 \\
\hline Desilva, A. W. & 1467 & Dudkin, V. A. & 974 \\
\hline Deutsch, C. & $\begin{array}{l}1073,1266,1267, \\
1417,1418,1419, \\
1420,1421,1583, \\
1736\end{array}$ & $\begin{array}{l}\text { Duffieux, P. M. } \\
\text { Dufty, J. W. } \\
\text { Dugan, C. H. }\end{array}$ & $\begin{array}{l}648 \\
1424,1737 \\
1762\end{array}$ \\
\hline DeWitt, $\mathrm{H}$. & 927 & Dumont, S. & 1058 \\
\hline Di Giacomo, A. & $899,973,1057$ & Du Plessis, A. N. & 1604 \\
\hline Dicke, R. H. & 425,446 & Durham, J. & 1105 \\
\hline Dickerman, P. J. & 566,764 & Durrant, A. V. & 1780 \\
\hline Dillon, T. A. & $\begin{array}{l}1584,1723,1820, \\
1821\end{array}$ & Dutta, C. M. & 1586 \\
\hline Dinke lacker, 0 . & 61 & Dutta, N. C. & 1586 \\
\hline Dobrodeev, N. A. & 1663 & Dyne, R. J. & 1425 \\
\hline Dodsworth, B. M. & & & \\
\hline $\begin{array}{l}\text { Dolgov-Save 1'ev, } \\
\text { G. G. }\end{array}$ & 1585 & $\begin{array}{l}\text { Eberhagen, } A . \\
\text { Eberly, } J: H .\end{array}$ & $\begin{array}{l}975,1587 \\
1738,1739\end{array}$ \\
\hline $\begin{array}{l}\text { Donohue, R. J. } \\
\text { Douglas, A. V. }\end{array}$ & $\begin{array}{l}1306 \\
261\end{array}$ & Ecker, G. & $\begin{array}{l}524,525,526 \\
1426,1427,1740\end{array}$ \\
\hline Doyle, R. 0 . & 1503 & Eckerle, K. L. & 1215 \\
\hline Draegert, D. A. & 1268 & Edels, H. & 383 \\
\hline Drawin, H. W. & $\begin{array}{l}928,1073,1091, \\
1165,1205,1266, \\
1267,1419,1420, \\
1421,1423,1736\end{array}$ & $\begin{array}{l}\text { Edmonds, F. N., Jr. } \\
\text { Edwards, D. F. }\end{array}$ & $\begin{array}{l}473,498,1059, \\
1166,1269 \\
1250,1379,1380, \\
1552,\end{array}$ \\
\hline
\end{tabular}

*The numbers refer to paper identification numbers of Part 3 . 


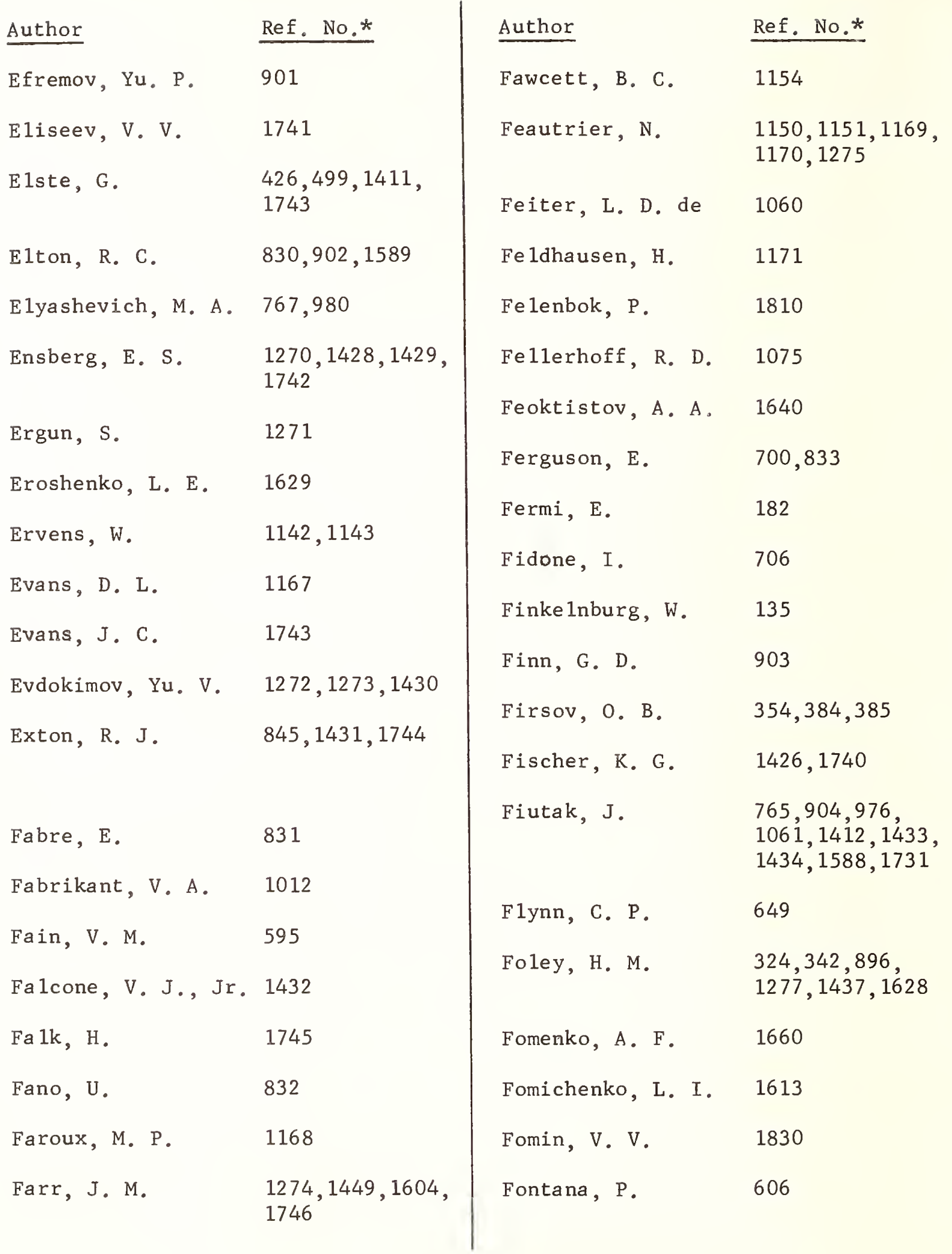

*The numbers refer to paper identification numbers of Part 3. 


\section{Author}

Foote, P. D.

Fortna, J. D. E. 1435,1589

Foster, J. S.

$95,96,261$

Fountain, C. W.

898

Fowler, R. G.

500

Fox, R. L.

1436

Fraenke 1, B. S.

1276

Franz, F.A.

834

Frenke1, J .

113,124

Friedberg, R.

1747

Frisch, U.

$1711,1748,1749$

Fröhlich, H. 325

Füchtbauer, Chr.

$36,54,61,84$,
$162,163,183$,
$184,185,186$,
$200,201,202$,
$243,262,263$,
279,280

Fullerton, W.

1590,1750

Furch, B.

1142,1143

Fursov, V. S.
$213,219,264$, 270
Author

Ref. No.*

Galitskii, V. M.

1221,1664

Ga1lagher, C. C. 1625,1751

Ga11o, C. F.

1172,1757

Ga 1t, J. A.

527,528

Galushkin, Yu. I. 1591

Garrett, R. 0 .

$1062,1158,1173$, 1575,1724

Garrison, R. L. 1319,1482

Gaviola, E.

114

Gentry, R。

618

George, E. V.

Gerardo, J. B.

Gericke, W. E.

Gersten, J. I.

Gerthsen, $P$.

Gervat, A.

Gieske, H. A.

Gilbert, D. E.

Gileva, M. V.

Gill, T. P.

Ginsburg, V. L.

Girault, M.

Gladney, H. M.

Glarum, S. H.
1701,1702

$1063,1181,1759$

708

$1277,1437,1752$

447

1438

1439

1402,1440

1357

977

288

1644,1806

885

885

*The numbers refer to paper identification numbers of Part 3. 


\section{Author}

Godart, J . L.

1382

Godfrey, J. T .

1753

Göhring, R.

1278

Gössler, F.

$162,163,185$,

187,200

Gold, L.

650

Goldenbaum, G. C.

1467

Goldfarb, V. M.

905

Goldsmith, S.

1276,1670

Gompertz, G.

1441

Gonchukov, S. A.

1279,1442

Gora, E.

214

Gorbacheva, N. S.

835

Gorodnichyus, G. A. 709

Gorodnichyute, M.G. 709

Granier, J .

$836,837,838$, $978,979,1064$ $1065,1066,1067$, 1174,1390

Granier, $R$.

$710,836,837$, $838,978,979$, $1064,1065,1066$, $1067,1174,1390$, 1399,1443

Grechikhin, L. I. $766,767,839$, 906,980

Gregory, C.

297
Author

Ref. No.*

Greig, J . R.

$929,1280,1388$ $1592,1593,1635$, 1768

Gridneva, S. M.

1068

Griem, H. R.

$448,572,596$, $651,652,653$, $711,761,768$, $769,770,771$, $772,902,907$, $908,961,972$, $981,1069,1070$, $1175,1176,1177$, $1280,1281,1282$, $1283,1296,1301$, $1439,1444,1445$, $1467,1558,1589$, $1592,1594,1595$, $1596,1597,1635$, $1706,1754,1755$, 1756,1768

Griffith, R.

1446

Gri11et, L.

227

Grindlay, J . E. 1572

Groot, W. de 203

Gross, E. P. 474

Grudanov, V. S. 1357

Grycuk, T. $\quad 909,968,1447$

Gubin, M. A. 1284

Gurevich, I. M. 367

Guthrie, D. V. 21

Gwinn, J . A . $569,1285,1297$, 1608

*The numbers refer to paper identification numbers of Part 3 . 


\begin{tabular}{|c|c|c|c|}
\hline Author & Ref. No.* & Author & Ref. No.* \\
\hline Gyorffy, B. L. & 1286 & Hashimoto, S. & 1090 \\
\hline & & Hearn, A. G. & 840,911 \\
\hline Haag, $T$. & 1397 & Heesen, W. von & 263 \\
\hline Hänsch, $\mathrm{T}$. & $1287,1448,1598$ & Heimann, G. & 243 \\
\hline Häusler, G. & $262,279,280$ & Heit ler, W. & 421,449 \\
\hline Haken, $\mathrm{H}$. & 1071 & Henke 1, W. D. & 450 \\
\hline Hallin, R. & 1072 & Henning, $\mathrm{H}$. & 1165,1423 \\
\hline Hama da, H. & 136,164 & Hepner, G. & $475,529,712$ \\
\hline Hamada, Y. & 1599 & Herman, L. & $\begin{array}{l}411,530,557,831, \\
928,982,1073 .\end{array}$ \\
\hline Hammond, G. L. & 773,781 & & $1091,1165,1205$ \\
\hline Hammond, T. J. & 1757 & & $\begin{array}{l}1420,1421,1423, \\
1602,1648,1649\end{array}$ \\
\hline Hanna ford, P. & 1714 & & 1736 \\
\hline Hanot, $M$. & 97 & Herman, $\mathrm{R}$. & $\begin{array}{l}485,507,530, \\
713,760\end{array}$ \\
\hline Hansen, C. F. & 910 & & \\
\hline Hantzsche, E. & 774 & Hermansdorfer, H. & 975 \\
\hline & $\begin{array}{l}1178,1307,1716 \\
1717\end{array}$ & $\begin{array}{l}\text { Hernandez, G. } \\
\text { Hessberg, H. }\end{array}$ & $\begin{array}{l}1074 \\
1179\end{array}$ \\
\hline Hardorp, J. & 1600 & Hettner, G. & 597,598 \\
\hline Harrison, G. R. & 74 & Hey, P. & 714 \\
\hline Harrison, J. A. & 798 & Heyde, R. von der & 1288 \\
\hline Hartmann, F. & 1601 & Hicks, W. W. & 1577,1869 \\
\hline Hartmann, S. R. & 1747 & Hiei, E. & 617 \\
\hline Hartmann-Boutron, F. & 1601 & Higgins, R. B. & 1698 \\
\hline
\end{tabular}

*The numbers refer to paper identification numbers of Part 3. 


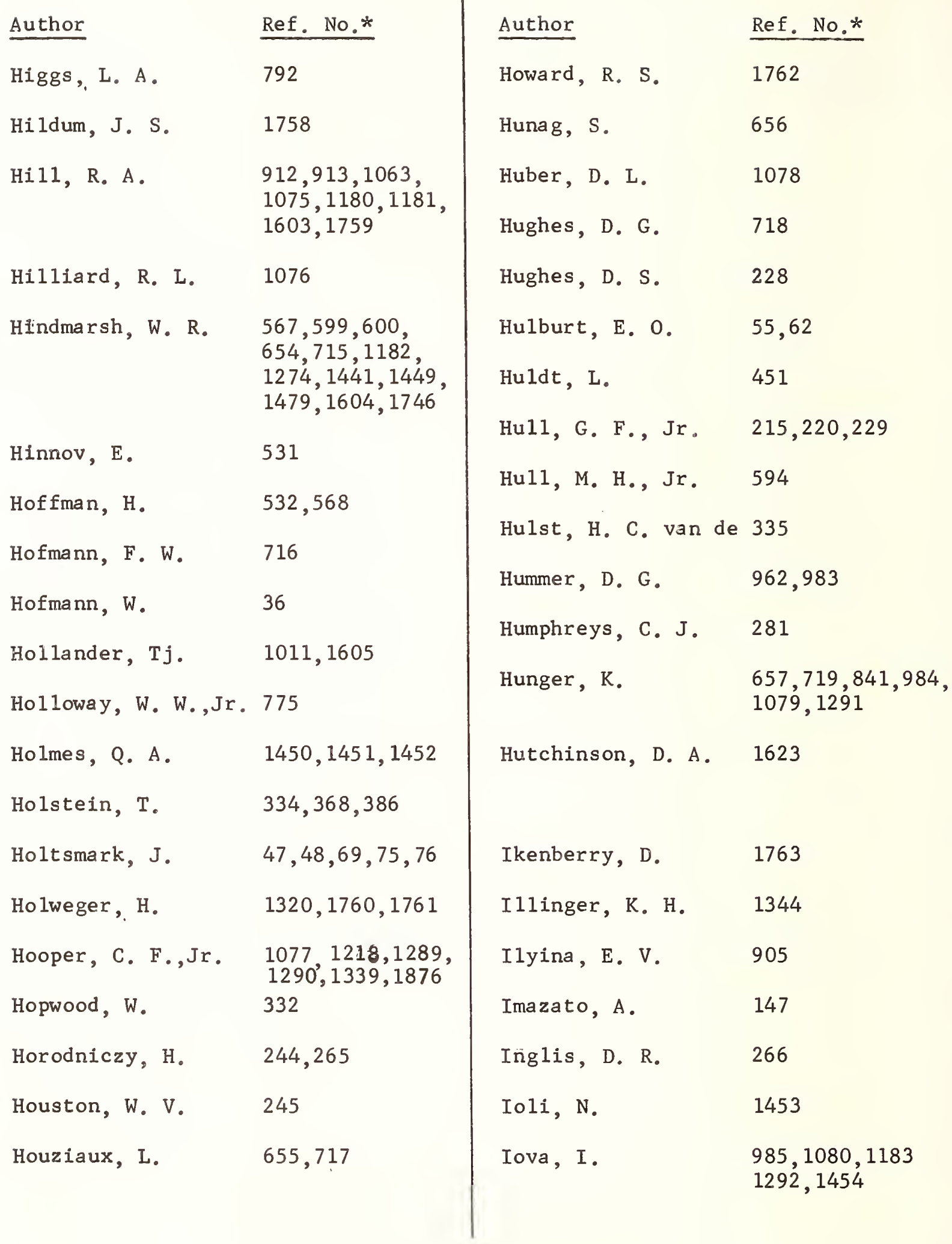

*The numbers refer to paper identification numbers of Part 3. 
Author

Ishimura, $\mathrm{T}$.

Ivashevskii, S. N. 901

Iwao, M.

Jablonski, A.

Jackson, C. V.

Jackson, J.L.

Jacobson, H. C.

Jäger, H.

Jager, C. de

Jalufka, N. W.

James, H. G.

Jansen, B. J.

Javan, A.

Jaya Ram, K.

Jeannet, J.C.

Jefferies, J. T.

Jefimenko, 0 .

Jencke1, L.

Jenkins, J.E.
1184

1764

Ref. No.*

1764

$137,230,244,246$, $265,267,282,316$, $343,842,986,1293$, 1455

216

658

$1436,1765,1766$,
1858,1870 1456

$406,659,843$

1081,1606

1251

1605

1108

1764

1650

660,1294

$497,522,533,534$, $569,844,845,914$, 987,988

\section{9}

1767

$\begin{array}{ll}\text { Author } & \frac{\text { Ref.No.* }}{\text { Jensen, H. }} \\ \text { Jensen, V. O. } & 1652 \\ \text { Johannesson, J. } & 190 \\ \text { Johnson, M. } & 476 \\ \text { Johnson, W. B. } & 1514 \\ \text { Jones, A. F. } & 1185,1607 \\ \text { Jones, L. A. } & 1592,1593,1768 \\ \text { Joos, G. } & 54,61,369 \\ \text { Jügens, G. } & 407 \\ \text { Jugaku, J. } & 499,601 \\ \text { Jung, M. } & 846\end{array}$

Kaldor, U.

1776

Kalinin, Yu. G. 1836, 1837

Kaliteyevskii, N. I.1273

Ka lman, G.

732

Kaplan, S. A.

1457

Kapuscinska, M. I. 674

Karamcheti, $\mathrm{K}$.

1299

Kasabov, G. A.

1068

Kastha, G. S.

355,427

Kastler, A.

847

Kavanagh, R. W.

430

*The numbers refer to paper identification numbers of Part 3. 


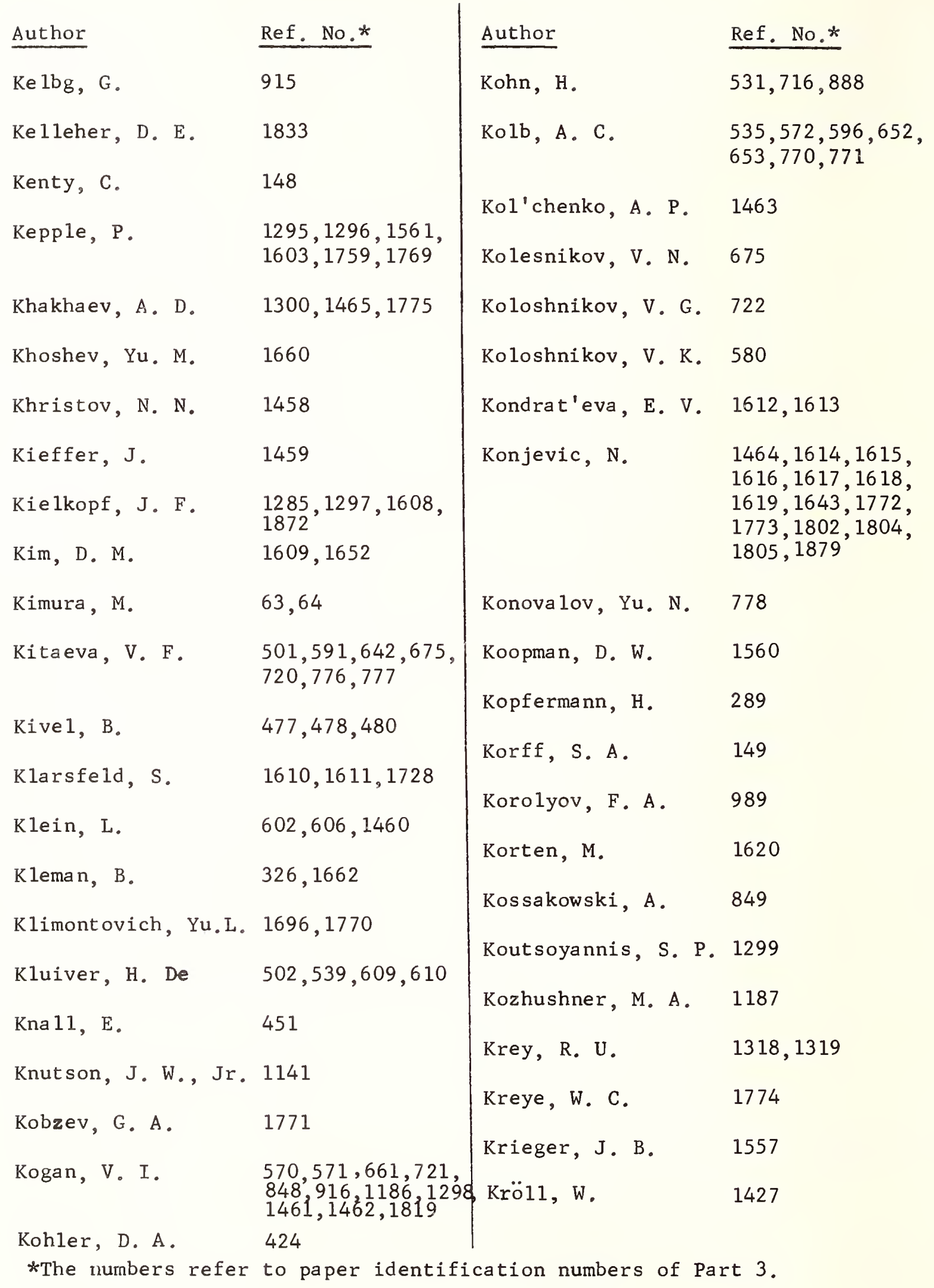


Author

Krogdah $1, \mathrm{M} . \mathrm{K}$.

Krylova, S. I.

Kubiak, M.

Kubo, R.

Kudrin, L. P.

Kuhn, H. G.

Kulp, M.

Kundt, H. E.

Kunik, D.

Kunze, H. J .

Kunze, P.

Kurochka, L. N.

Kusch, H. J.

Kushnikov, Yu. A. 344

Kutsyn, A. A.

1672

Kuzemsky, A. I.

Kwiatkowski, S.

Labat, J .

$1464,1614,1615$, $1616,1617,1618$, $1619,1643,1802$, 1804

$1300,1465,1775$

909

452

$850,851,852$, 853,917 $233,918,990$, 1188,1466

150,166

187

1776

$1301,1445,1467$

138

$1189,1302,1303$, 1468

$573,1171,1190$, $1191,1192,1193$, $1263,1288,1621$, 1777,1778

1779

849,919
Author

$188,189,231,232$,

*The numbers refer to paper identification numbers of Part 3 .
Ref. No.*

$723,779,991$ 1194

La los, G. T.

780,781

Lamb, W. E., Jr.

$1286,1389,1562$, $1609,1652,1707$,

Lambert, R. H.

$782,789,854$, $1522,1667,1669$

Lambropoulos, P.

1195

Landheer, B.

1780

Lang, $\mathrm{K}$.

$387,408,428,536$

La pworth, K. C. 724

Larenz, R. W.

$657,719,783,841$, $984,1079,1291$

Lau, E.

190

Laurent, J . $\quad 1469,1622$

Lawetz, V.

1623

Lazarev, A. V. 1624

Leckrone, D. S. 1781

Lee, R.

1782,1873

Lee, Y. C.

1470

Leeman, S.

1712

Legowski, S.

725

Lemaire, J . L. 1809, 1810

Lennuier, $\mathrm{R}$.

$723,967,991$, 1156,1194

Lenz, W.

167,168 


\section{Author}

Levine, M. A.

Lewis, E. L.

Lewis, $M$.

Leycuras, Y.

Lichtenstein, M.

Lifshitz, E. V.

Lightman, A.

Lim, C. P.

Lin, D. L。

Lincke, $\mathrm{R}$ 。

Lindholm, E.

Lisitsa, V. S.

Lisitsyn, V.N.

Lloyd, P.E.

Lochte-Holtgreven, W. 479, 1778

London, F.

Lonseth, A. T.

Looi, E. C.

Lorentz, H. A.

Lortet, M. C.

Louboutin, R.

Louër, D.
228

189

1725

1158,1173

11

1474

Ref. No.*

1625,1751

$990,1188,1196$ $1403,1471,1472$, 1783,1784

$537,574,607,726$

$855,856,1083$, 1084

565

1304,1473

1140

1280

1470

761,920

$290,326,327,1662$

$1186,1461,1819$,

1305

1476

1475,1476
Author

Ref. No.*

Lüscher, $\mathrm{E}$.

775,834

Luizova, L. A.

$1300,1465,1775$

Luk'yanov, S. Yu

575

Lyle, G. C.

1378

Lyon, W. D.

1626

Lyons, J. D.

1477,1495

MacDona,1d, D.K.C. 718

Machekute, R.

1483

Magidson, V. V. 778

Maisse 1, L. I. 603

Ma jkowski, R. F. 1306

Makarov, A.P. $\quad 1478$

Ma ldonado, P. 1645

Malinovsky, M.

1627

Malyshev, V. I. 974

Manakov, N. L. $\quad 1735$

Manassah, J. T. 1628,1747

Mande1'sht'am, S.L. $370,538,580,604$, $605,608,722,784$, 857

Marasanov, Yu.P. 722

*The numbers refer to paper identification numbers of Part 3. 


\section{Author}

Margenau, H.
Ref. No.*

$151,169,170,171$, $172,174,204,217$, $234,356,388,423$, $478,480,481,482$, $537,574,602,606$, $607,662,663,713$, 733

Marinkovic, M. D. 921

Marmet, $P$.

1807

Marsha11, A.

1717

Maschke, E. K.

1085

Massmann, $P$.

1778

Mathur, B. S.

1307

Matskevich, V. K. 1663

Matsuo, S.

727

May, A. D.

1406

Mazing, M. A.

$538,580,604,605$, $608,722,785,786$, $857,921,922,1086$, 1136,1785

1672

1479

1094

1829

897

McDermott, M. N.

429

McDona 1d, J . K.

992

McLean, E. A.

173
Author $\quad$ Ref. No.*

McNa 11y, J . R., Jr. 1651

McNamara, L. F. 1783

Mead, C. A. 664, 1003, 1308, 1626

Mechev, V. S. 1629

Meier, H. 84

Meinhold, G. $\quad 1191$

Menon, T. K. $\quad 1480$

Mensing, L. $\quad 77,126$

Messerschmidt, D. 1197

Meunier, J . $\quad 1321$

Mewe, R.

Meyer, J. $\quad 924,1630,1631$

Meyerott, R. $\quad 481,482$

Mezhericher, E. M. 392

Michels, A. $\quad 502,539,609,610$

Míchels, H. H. 1783

Miche1son, A. A. 6

Middelkoop, D. 609

Mies, F. H. 1309

Mihalas, D. 993,1632

Mikhnenko, G. A. $1279,1442,1481$, 1786

Miller, M. H. $\quad 1310,1388,1560$, 1633,1787

*The numbers refer to paper identification numbers of Part 3. 


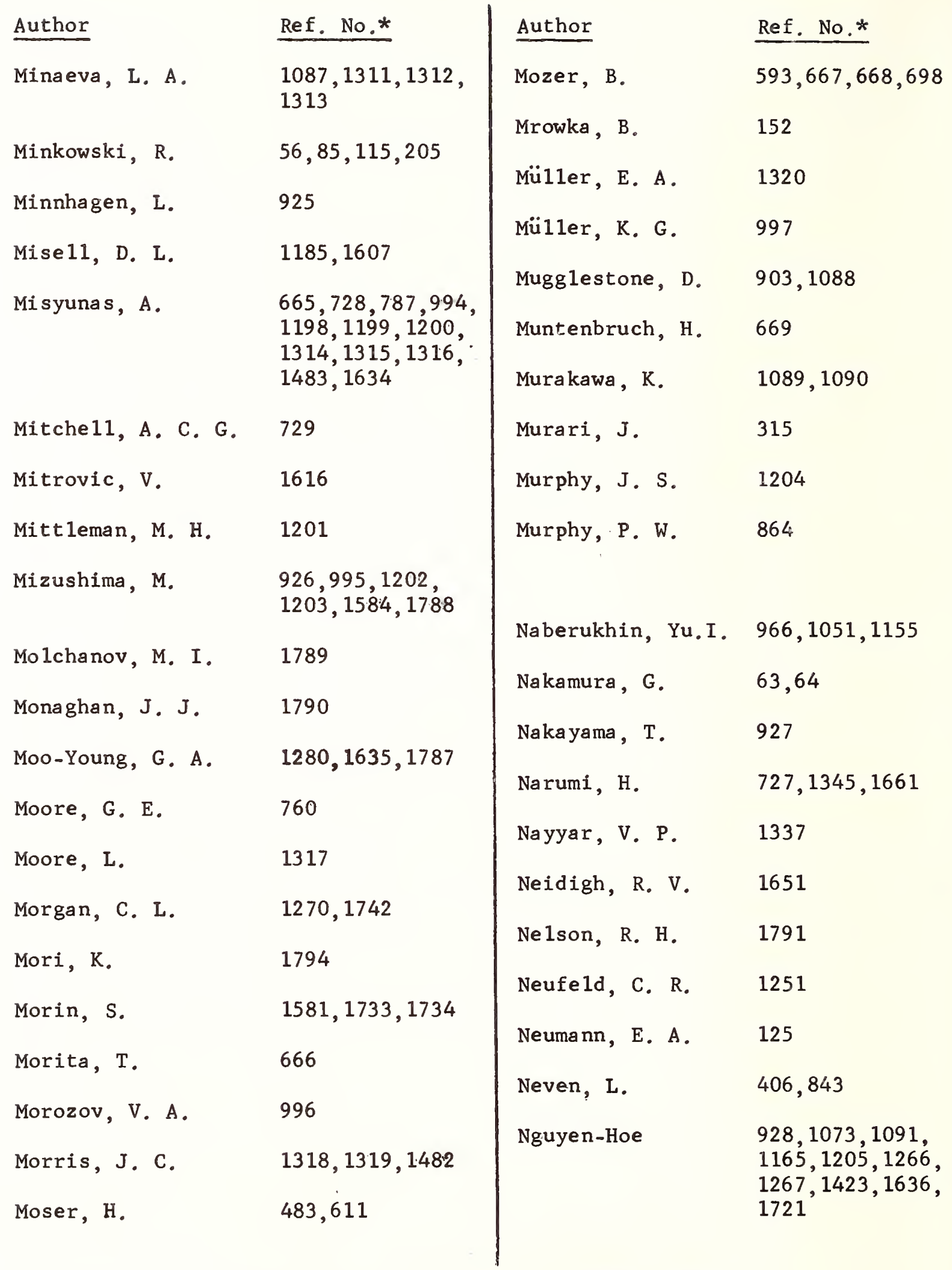

*The numbers refer to paper identification numbers of Part 3. 


\section{Author}

Nicolet, W. E.

Ref. No.*

1225

Niemax, K.

1875

Nieuwenhuijzen, H. 1048

Norkunas, V.

1199,1483

Norris, J.

1637,1792

Noskov, M. M.

543

Novick, R.

Nowotny, $\mathrm{H}$.

1793

Nubbemeyer, $\mathrm{H}$.

$1484,1485,1638$

Ny, T. Z .

$206,235,236,247$, 248

Obsersche lp, E. $\quad 1192,1193$

o'Brien, J. T.

1876

Obukhov-Denisov,V.V.776

Oda, T.

1592,1768

Odintsov, V. I.

989

Oerte1, G.

$770,1081,1160$, $1206,1408,1576$, 1728

Oettinger, P. E. 1486,1639

ofelt, G. S.

1081

Ohno, A.

Okamoto, $\mathrm{K}$.

Okazaki, K.

730

1794

1794

Oksengorn, B.
Author

Ref. No.*

o'Mara, B. J.

1088,1795

Omont, A.

Orthmann, W.

Oss, J. P.

Oxenius, J.

$1092,1321,1422$, 1865

$78,98,99$

1393

998

Page 1, B. E. J. 1796

Pa lmer, U.

1576

Palumbo, G.

1280

Pancharatnam, S. 1093

Pannekoek, A.

249

Pao, C. S.

278

Paquet, $\mathrm{C}$.

1807

Paquette, D. R. 799,865

Pargamanik, L. E. 788,858

Park, D.

1797

Parker, W. J.

472

Parsons, M. L. 1094

Paterson, M. S. 371

Pavlichenko, o. S. 1672

Pavlov, M.

1322

Peach, G.

1554,1877

Peacock, N. J.

$929,1154,1720$

*The numbers refer to paper identification numbers of Part 3. 


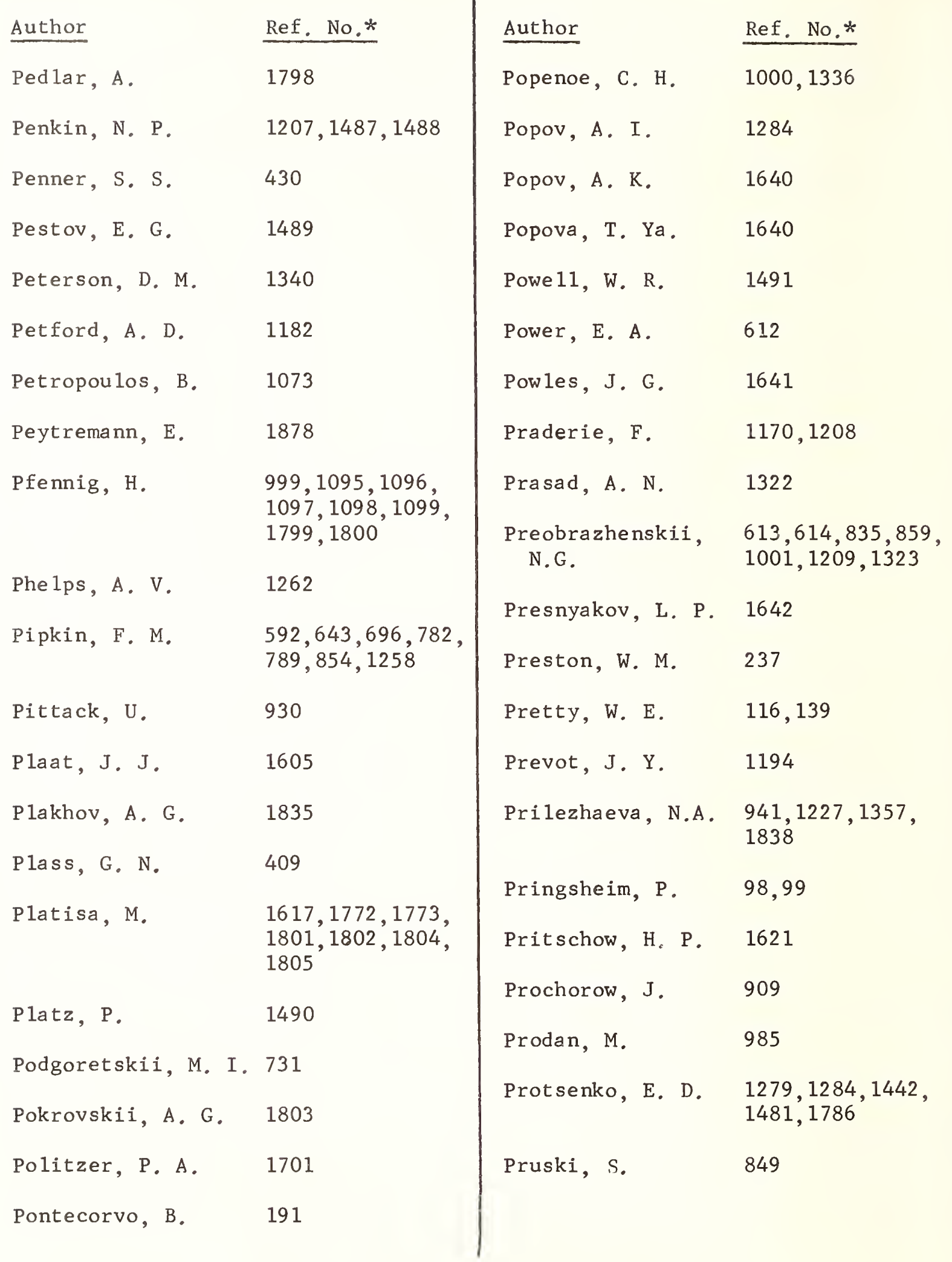

*The numbers refer to paper identification numbers of Part 3. 


\section{Author}

Puric, J .

Putlitz, G. Zu

1428,1429

Pyatigorskii, G. M. 858

$\begin{array}{ll}\text { Queffelec, J. I. } & 1644,1806 \\ \text { Quemener, J. J. } & 1807\end{array}$

Radivojevic, D.

1619

Ramberg, E.

192

Ramsden, S. A.

992

Ramsey, A. T.

1002

Rand, S.

1492

Rao, B. K.

1493

Rapoport, L. P.

1735

Rautian, S. G.

Ravodina, 0. V.

Ray, S.

$1477,1494,1495$, 1580,1645

Rayleigh, Lord

Read, F. H.

1,41

1864

Rebane, V. N.

1496

Rebbeck, M. M.
Author

Ref. No.*

Reck, G. P.

$1003,1497,1880$

Reesinck, J. J. M. 335

Regemorter, H. Van $577,615,828,860$, $893,894,931,932$, $1004,1151,1169$, $1170,1498,1499$, 1812

Reiche1, A.

933,1053

Reimers, H. J. 201

Reinheimer, J . $\quad 934$

Reinsberg, C. $\quad 207,238,250$

Richter, J.

1397

Richtmyer, F. K. 192

Ritchie, R. H. 1101

Ritter, M.

49

Robert, D.

995

Roberts, D. E.

$1102,1164,1212$, $1213,1214,1264$, $1265,1324,1325$, $1326,1327,1328$, 1646

Roberts, J. R.

1215

Robin, J .

$389,390,391,453$, $503,504,540,616$, 622,791

Robin, Si.

$505,541,542,578$

Robin, St .

$372,389,390,391$, $404,410,505,541$, $542,578,936$

*The numbers refer to paper identification numbers of Part 3. 


\begin{tabular}{|c|c|c|c|}
\hline Author & Ref. No.* & Author & Ref. No.* \\
\hline Robin-Kandare, S. & 791 & Rupin, J.M. & 936 \\
\hline Robinson, L. B. & 670 & Rusanov, V. D. & 1549 \\
\hline Roder, 0. & 827,935 & & \\
\hline Rodin, G. M. & 392 & Sadjian, H. & 733 \\
\hline Rogaczewski, J. & 674 & $\begin{array}{l}\text { Saha1, S. (a 1so } \\
\text { Saha 1-Brechot, S.) }\end{array}$ & $\begin{array}{l}828,893,894 \\
1149,1150,1151\end{array}$ \\
\hline Roig, R. A. & 1787 & & $\begin{array}{l}1169,1255,1330 \\
1501,1502,1573\end{array}$ \\
\hline Rollett, J.S. & 792 & & 1627,1815 \\
\hline Romand, J . & $372,1174,1399$ & Sa loman, E. B. & 1178 \\
\hline Rompe, $\mathrm{R}$. & 251,291 & Sando, $\mathrm{K}$. & 1503 \\
\hline Ron, A. & 732 & Sarma, M. B. K. & 734 \\
\hline Ronc in, J.-Y. & 1808 & Sassi, M. & $\begin{array}{l}1648,1649,1650 \\
1882,1883\end{array}$ \\
\hline Roos, 0. von & 793 & Saur, A. & 369 \\
\hline $\begin{array}{l}\text { Ross, D. W. } \\
\text { Rossi }\end{array}$ & $\begin{array}{l}1103 \\
26\end{array}$ & Sayer, B. & 1650 \\
\hline Rossignol-Guzzi,D. & 1438 & Schiller, H. & 1745 \\
\hline Rostas, F. & 1809,1810 & Sch lüter, $\mathrm{H}$. & $\begin{array}{l}700,833,1104 \\
1105,1166,1331 \\
1504\end{array}$ \\
\hline Roszman, L. J. & 1811 & Scholz, M. & 1197,1600 \\
\hline Roueff, $\mathrm{E}$. & $\begin{array}{l}1474,1499,1647 \\
1812,1881\end{array}$ & & \\
\hline Royer, A. & $1500,1813,1814$ & Schütz-Mensing, L. & 77,126 \\
\hline $\begin{array}{l}\text { Rozinskii, M. Ya. } \\
\text { Rubin, A. G. }\end{array}$ & $\begin{array}{l}1803 \\
1705\end{array}$ & Schu11er, F. & $\begin{array}{l}671,672,710,794, \\
1505,1506,1507 \\
1816\end{array}$ \\
\hline Rühmkorf, H. A. & 252 & Schulz, G. & 1216,1332 \\
\hline Ruland, W. & 1005,1329 & Schulz, H. & 611 \\
\hline
\end{tabular}

*The numbers refer to paper identification numbers of Part 3. 


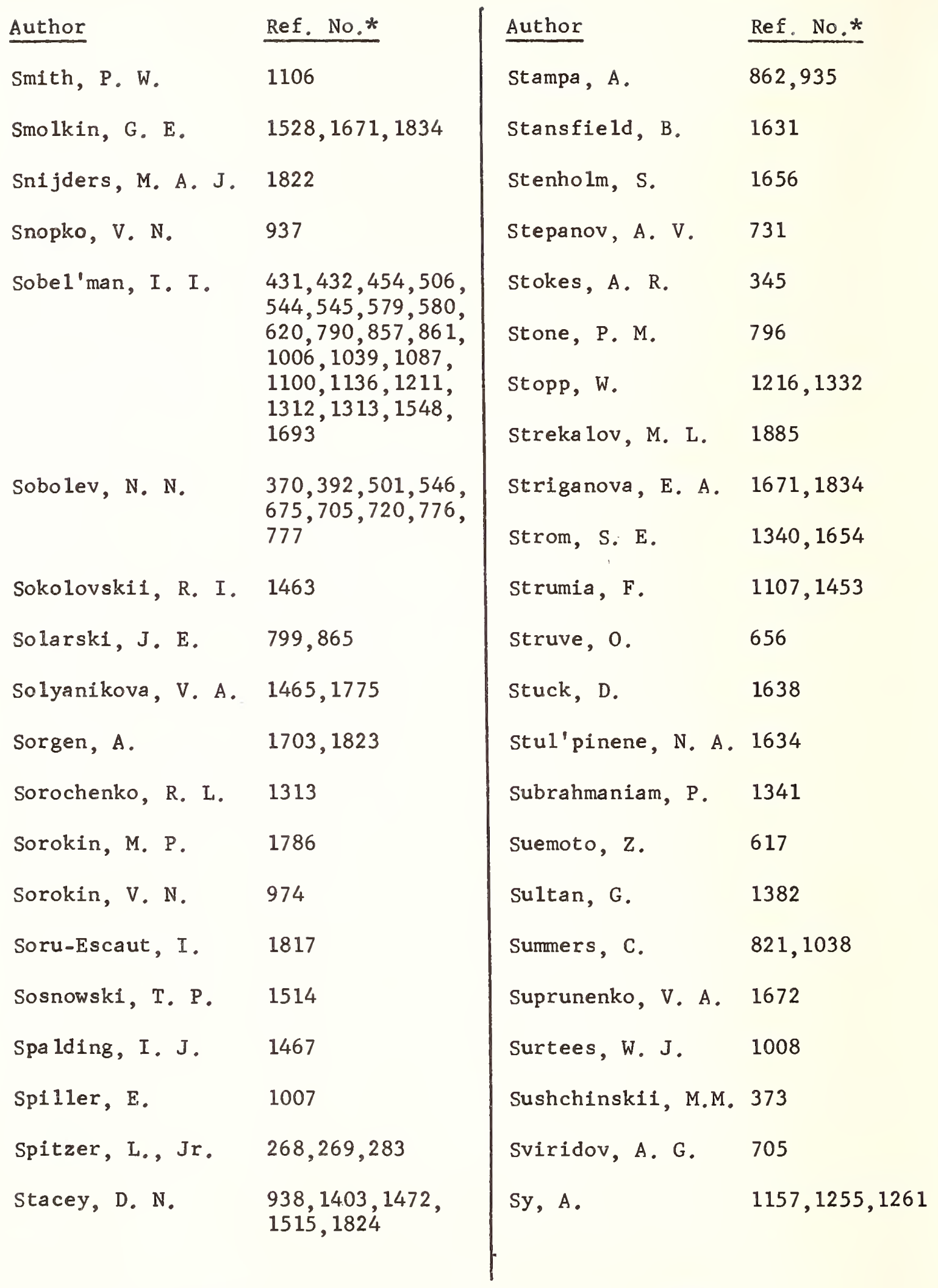

*The numbers refer to paper identification numbers of Part 3. 
Sze, R. C.

Szöke, A.

Szudy, J.

Takamine, $\mathrm{T}$.

Takebe, H.

Takeo, M.

Tako, T.

Talman, J. D.

Tan, D. K. L.

Tanaka, M.

Tang, H.

Tankin, R. S.

Tannich, J. D.

Tarasov, Yu. A.

Tatarenkov, V. M.

Teller, E.

Ten Seldam, C. A. 610

Terpugova, N. S.

Theimer, 0 .

Thomas, K. A.

Thomas, P. M.
1001

$532,568,618$

Ref. No.*

1886,1887

1108

$1109,1110,1220$, $1342,1516,1517$, $1657,1825,1826$

86

1003

$455,523,647,939$, $1450,1451,1452$, 1658

735

495

$1402,1659,1827$

1526

1307

$1167,1394,1446$

1561

917

1828

266

600,715

1285
Author

Tietz, T.

Ref. No.*

863

Timsit, R. S.

1406

Tip, A.

1829

Titov, A. N.

1828

Titov, A. V.

1549

Tittel, H.

1419

Titte1, K.

1009

Tomiser, J.

$433,456,457,458$

Toschek, P.

$1287,1448,1598$

Traving, G.

$676,1010,1197$, 1343

Trefftz, E. $999,1097,1098$, 1099

Trekhov, E. S. 1660

Trigt, C. van $\quad 1011$

Trindle, C. $0 . \quad 1344$

Troinikov, A. I. 1442,1480

Trumpy, B.

$76,79,87,101$

Tsao, C. J.

797

Tsuji, A.

1345,1661

Tsytovich, V. N. 1457

Turnbul1, R.

173

Tvorogov, S. D. 1830

Tyunina, E. S. 906

*The numbers refer to paper identification numbers of Part 3. 


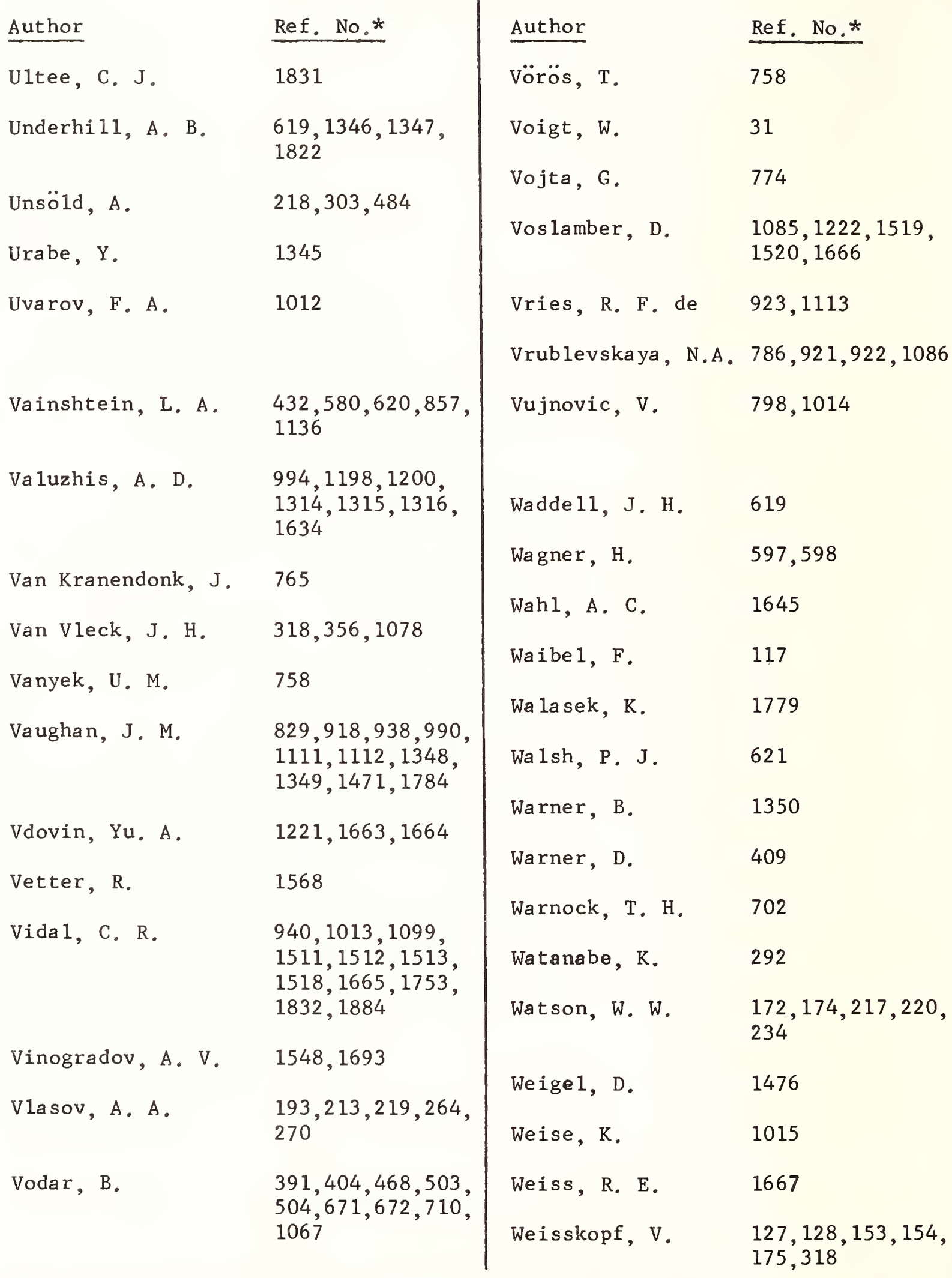

*The numbers refer to paper identification numbers of Part 3. 


\section{Author}

We itkamp, C.

Weize1, W.

We1ls, D. C., III

Welsh, H. L.

Wende, $B$.

Weniger, C.

Weniger, S.

Westenberg, A. A.

Weymann, R. J.

1668

White, A. D.

1224

White, H. E.

194

Whiting, E. E.

1351,1378

Wiese, W. L.

$795,799,864,865$, $1016,1047,1153$, 1833

127,128

$984,1079,1352$

Wilke, $\mathrm{K}$.

1560

Wilkerson, T. D.

1726

Williams, B.

1268

Williams, D.

988

Williams, G. M.

1225

Wilson, K. H.

704

Wilson, R. A., Jr. 704

Wimme 1, H. K.
Author

Ref. No.*

Winefordner, J . D. 1094

Wobig, K. H.

827

Wood, R. W. 16,21

Wright, D, L.

1045,1046

Wright, J. J.

1522,1669

Wu, T. Y .

319

Wulff, H.

581,700

Wunderlich, R.

1587

Ya'akobi, B.

$1114,1353,1354$, $1523,1524,1525$, 1670,1702

Yakimets, V. V. 1226,1664

Yamamoto, G.

1526,1888

Yamamoto, M.

1090,1115

Yaris, R.

1527

Yasuda, K.

1116

Young, C.

1017,1018

Yuasa, T.

195,208

Yukov, E. A.

$1247,1694,1889$

Zagorodnikov, S.P. $1528,1671,1834$

Zaidi, H. R.

1355,1356

Zakatov, L. P.

1835

Zavoiskii, E. K. 1836, 1837

*The numbers refer to paper identification numbers of part 3 . 


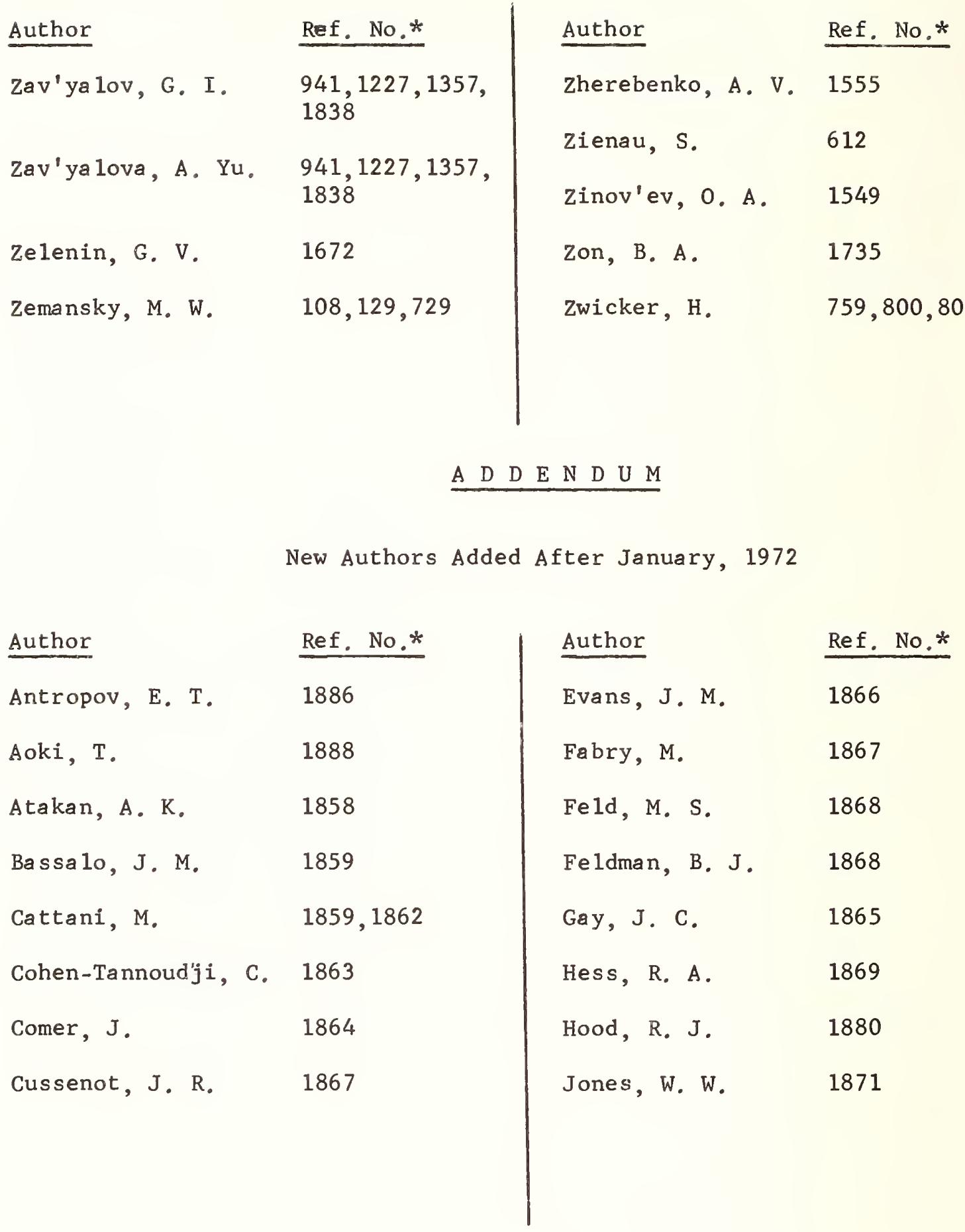

*The numbers refer to paper identification numbers of Part 3. 


2. Gov't Accession
No.

No.

Bibliography on Atomic Line Shapes and Shifts (1889 Through March 1972)

7. AUTHOR(S)

J. R. Fuhr, W. L. Wiese, and L. J. Roszman

9. PERF ORMING ORGANIZATION NAME AND ADDRESS

NATIONAL BUREAU OF STANDARDS DEPARTMENT OF COMMERCE

WASHINGTON, D.C. 20234

12. Sponsoring Organization Name and Address Supported in part by the Advanced Research Projects Agency of the Department of Defense under the Strategic Technology Office

5. Publication Date

September 1972

6. Performing Organization Code

8. Performing Organization

10. Project/Task/Work Unit No.

2320170

11. Contract/Grant No.

13. Type of Report \& Period Covered

(1889 through March 1972)

14. Sponsoring Agency Code

5. SUPPLEMENTARY NOTES

16. ABSTRACT (A 200-word or less factual summary of most significant information. If document includes a significant bibliography or literature survey, mention it here.)

This is the first general, annotated bibliography on atomic line shapes and shifts. It covers exhaustively the atomic spectral line broadening literature in about 1400 separate references extending from 1889 through March 1972. The bibliography contains four major parts: (1) All general interest papers are catalogued according to the broadening mechanisms (and, further, according to special topics under several of the mechanisms), and as to whether the work is a general theory, a general review, a table of profiles or parameters, a comment on existing work, a study of general experimental measurement techniques, or an experimental effort of general importance. Also included are selected papers on important applications of line broadening and on miscellaneous topics relating to atomic spectral line shapes and shifts. (2) In Part 2, all papers containing numerical data are ordered as to element, ionization stage, broadening mechanism (in the case of foreign gas broadening the perturbing species are 1 isted), and it is indicated whether the data are experimentally or theoretically derived. While in the two preceding parts of the bibliography the references are listed for brevity by identification numbers only, in Part 3 all references are listed completely by journal, authors, and title and are arranged chronologically and alphabetically within each year according to the principal authors. (4) A final section contains a 1 ist of all authors and their papers.

17. KEY WORDS (Alphabetical order, separated by semicolons) Atomic; instrumental broadening; line shapes; 1ine shifts; pressure broadening; resonance broadening; Stark broadening; Van der Waals broadening.

18. AVAILABILITY STATEMENT

X] UNLIMIT ED.

FOR OFFICIAL DISTRIBUTION. DO NOT RELEASE TO NTIS.

\begin{tabular}{|l|c|}
\hline $\begin{array}{l}\text { 19. SECURITY CLASS } \\
\text { (THIS REPORT) }\end{array}$ & $\begin{array}{c}\text { 21. NO. OF PAGES } \\
165\end{array}$ \\
UNCL ASSIFIED & 22. Price \\
\hline $\begin{array}{l}\text { 20. SECURITY CLASS } \\
\text { (THIS PAGE) }\end{array}$ & $\mathbf{8 1 . 7 5}$ \\
UNCL ASSIFIED & \\
\hline
\end{tabular}





\section{NBS TECHNICAL PUBLICATIONS}

\section{PERIODICALS}

JOURNAL OF RESEARCH reports National Bureau of Standards research and development in physics, mathematics, and chemistry. Comprehensive scientific papers give complete details of the work, including laboratory data, experimental procedures, and theoretical and mathematical analyses. Illustrated with photographs, drawings, and charts. Includes listings of other NBS papers as issued.

Published in two sections, available separately:

\section{- Physics and Chemistry}

Papers of interest primarily to scientists working in these fields. This section covers a broad range of physical and chemical research, with major emphasis on standards of physical measurement, fundamental constants, and properties of matter. Issued six times a year. Annual subscription: Domestic, $\$ 9.50 ; \$ 2.25$ additional for foreign mailing.

\section{- Mathematical Sciences}

Studies and compilations designed mainly for the mathematician and theoretical physicist. Topics in mathematical statistics, theory of experiment design, numerical analysis, theoretical physics and chemistry, logical design and programming of computers and computer systems. Short numerical tables. Issued quarterly. Annual subscription: Domestic, \$5.00; $\$ 1.25$ additional for foreign mailing.

\section{TECHNICAL NEWS BULLETIN}

The best single source of information concerning the Bureau's measurement, research, developmental, cooperative, and publication activities, this monthly publication is designed for the industry-oriented individual whose daily work involves intimate contact with science and technology-for engineers, chemists, physicists, research managers, product-development managers, and company executives. Includes listing of all NBS papers as issued. Annual subscription: Domestic, $\$ 3.00 ; \$ 1.00$ additional for foreign mailing.

\section{Bibliographic Subscription Services}

The following current-awareness and literaturesurvey bibliographies are issued periodically by the Bureau: Cryogenic Data Center Current Awareness Service (weekly), Liquefied Natural Gas (quarterly), Superconducting Devices and Materials (quarterly), and Electromagnetic Metrology Current Awareness Service (monthly). Available only from NBS Boulder Laboratories. Ordering and cost information may be obtained from the Program Information Office, National Bureau of Standards, Boulder, Colorado 80302 .

\section{NONPERIODICALS}

Applied Mathematics Series. Mathematical tables, manuals, and studies.

Building Science Series. Research results, test methods, and performance criteria of building materials, components, systems, and structures.

Handbooks. Recommended codes of engineering and industrial practice (including safety codes) developed in cooperation with interested industries, professional organizations, and regulatory bodies.

Special Publications. Proceedings of NBS conferences, bibliographies, annual reports, wall charts, pamphlets, etc.

Monographs. Major contributions to the technical literature on various subjects related to the Bureau's scientific and technical activities.

National Standard Reference Data Series. NSRDS provides quantitative data on the physical and chemical properties of materials, compiled from the world's literature and critically evaluated.

Product Standards. Provide requirements for sizes, types, quality, and methods for testing various industrial products. These standards are developed cooperatively with interested Government and industry groups and provide the basis for common understanding of product characteristics for both buyers and sellers. Their use is voluntary.

Technical Notes. This series consists of communications and reports (covering both other-agency and NBS-sponsored work) of limited or transitory interest.

Federal Information Processing Standards Publications. This series is the official publication within the Federal Government for information on standards adopted and promulgated under the Public Law 89-306, and Bureau of the Budget Circular A-86 entitled, Standardization of Data Elements and Codes in Data Systems.

Consumer Information Series. Practical information, based on NBS research and experience, covering areas of interest to the consumer. Easily understandable language and illustrations provide useful background knowledge for shopping in today's technological marketplace.

\section{CATALOGS OF NBS PUBLICATIONS}

NBS Special Publication 305, Publications of the NBS. 1966-1967. When ordering, include Catalog No. G13.10:305. Price $\$ 2.00 ; 50$ cents additional for foreign mailing.

NBS Special Publication 305, Supplement 1, Publications of the NBS, 1968-1969. When ordering, include Catalog No. C13.10:305/Suppl. 1. Price $\$ 4.50 ; \$ 1.25$ additional for foreign mailing.

NBS Special Publication 305, Supplement 2, Publications of the NBS, 1970. When ordering, include Catalog No. C13.10:305/Suppl. 2. Price $\$ 3.25$; 85 cents additional for foreign mailing.

Order NBS publications (except Bibliographic Subscription Services)

from: Superintendent of Documents, Government Printing Office, Washington, D.G. 20402. 
U.S. DEPARTMENT OF COMMERCE National Bureau of Standards Washington, D.C. 20234

OFFICIAL BUSINESS

POSTAGE AND FEES PAID U.S. DEPARTMENT OF COMMERCE 215

Penalty for Private Use, $\$ 300$ 